ORNL/TM-13351

OAK RIDGE

NATIONAL

LABORATORY

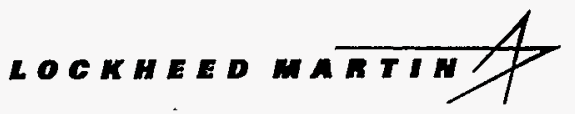

\section{Statistical Description of Liquid Low-Level Waste System Transuranic Wastes at Oak Ridge National Laboratory, Oak Ridge, Tennessee}

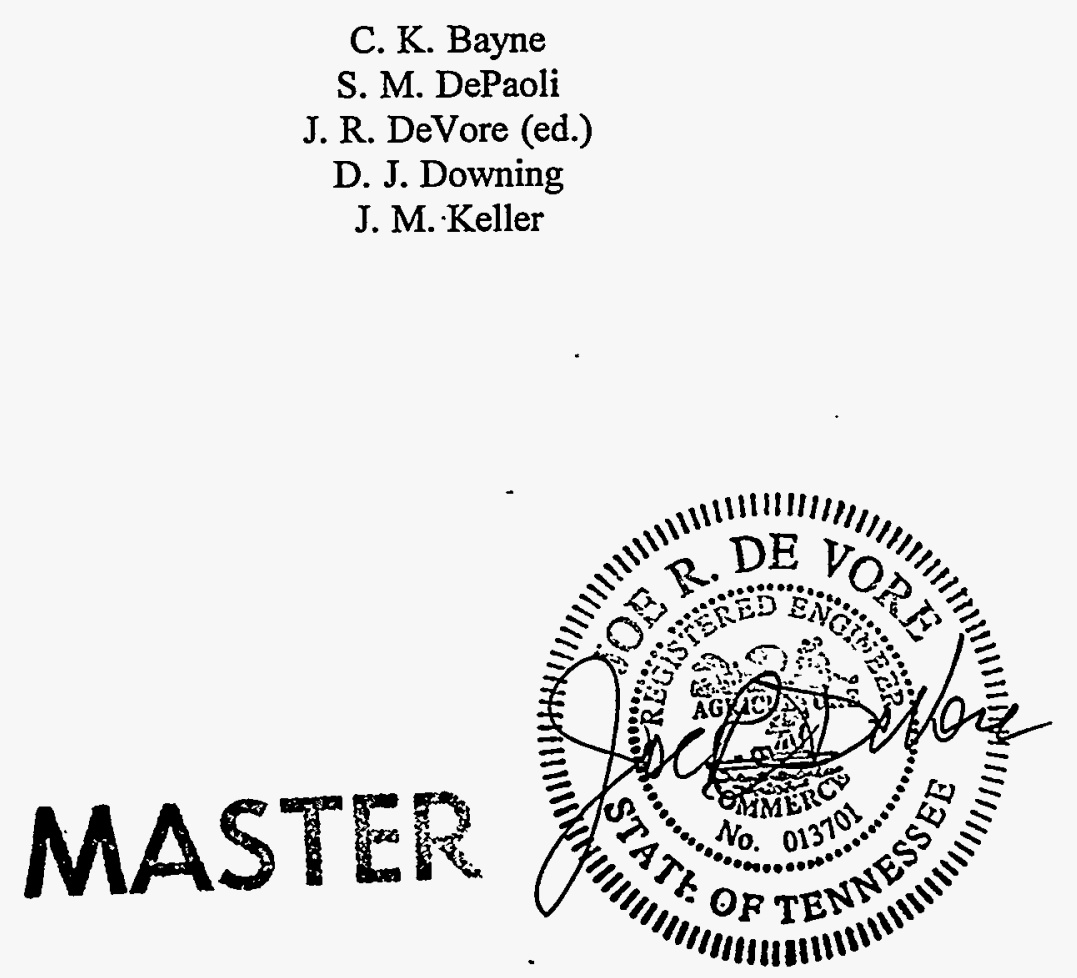

This document has been approved by the ORNL Technical Information Office
for release to the public. Date: $12 / 12 / 96$
MANAGED AND OPERATED BY LOCKHEED MARTH ENERGY RESEARCH CORPORATION FOR THE UNTED STATES DEPARTHENT OF ENERGY 


\section{STATISTICAL DESCRIPTION OF LIQUID \\ LOW-LEVEL WASTE SYSTEM \\ TRANSURANIC WASTES \\ AT OAK RIDGE NATIONAL LABORATORY, OAK RIDGE, TENNESSEE}
C. K. Bayne
S. M. DePaoli
J. R. DeVore (ed.)
D. J. Downing
J. M. Keller

Date Published-December 1996

\section{Prepared for}

\section{U.S. Department of Energy}

Waste Management Technology Division

under budget and reporting number EW 3120043

Prepared by

OAK RIDGE NATIONAL LABORATORY

Oak Ridge, Tennessee 37831 operated by

Lockheed Martin Energy Systems, Inc. for the

U.S. DEPARTMENT OF ENERGY under contract No. DE-AC05-84OR21400 


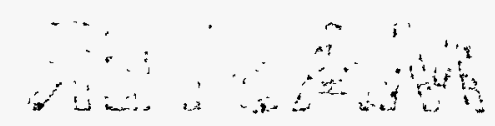




\section{DISCLAMIER}

Portions of this document may be illegible in electronic image products. Images are produced from the best available original document. 


\section{CONTENTS}

FIGURES $\ldots \ldots \ldots \ldots \ldots \ldots \ldots \ldots \ldots \ldots \ldots \ldots \ldots \ldots \ldots$

TABLES $\ldots \ldots \ldots \ldots \ldots \ldots \ldots \ldots \ldots \ldots \ldots \ldots \ldots \ldots \ldots \ldots$ vii

ABBREVIATIONS $\ldots \ldots \ldots \ldots \ldots \ldots \ldots \ldots \ldots \ldots \ldots \ldots \ldots \ldots \ldots$

EXECUTIVE SUMMARY $\ldots \ldots \ldots \ldots \ldots \ldots \ldots \ldots \ldots \ldots \ldots \ldots \ldots \ldots$

1. INTRODUCTION $\ldots \ldots \ldots \ldots \ldots \ldots \ldots \ldots \ldots \ldots \ldots \ldots \ldots \ldots \ldots \ldots \ldots$

2. THE LLLW SYSTEM AT ORNL $\ldots \ldots \ldots \ldots \ldots \ldots \ldots \ldots \ldots \ldots \ldots \ldots \ldots$

2.1 GUNITE AND ASSOCIATED TANKS (GAAT) . . . . . . . . . . 2-1

2.2 OLD HYDROFRACTURE FACILITY (OHF) . . . . . . . . . . . . . $2-3$

2.3 BETHEL VALLEY EVAPORATOR SERVICE TANKS (BVEST) $\ldots \ldots \ldots \ldots \quad 2-6$

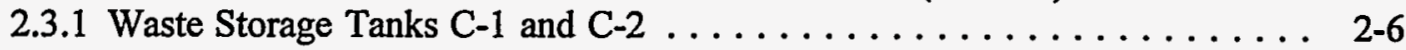

2.3.2 Waste Evaporator System . . . . . . . . . . . . . . . . 2-8

2.4 MELTON VALLEY STORAGE TANKS (MVST) $\ldots \ldots \ldots \ldots \ldots \ldots \ldots \ldots$

2.5 ANTICIPATED CHANGES TO ORNL LLLW $\ldots \ldots \ldots \ldots \ldots \ldots \ldots \ldots \ldots$

2.5 .1 MVST-CIP . . . . . . . . . . . . . . . . . . . $2-11$

2.5.2 Cesium Removal . . . . . . . . . . . . . . . . 2-11

2.5.3 Additional Evaporation . . . . . . . . . . . . . . . . 2-11

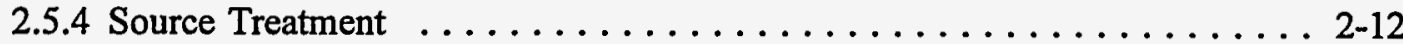

3. DISCUSSION OF DATA FROM PREVIOUS SAMPLING CAMPAIGNS $\ldots \ldots \ldots$.

3.1 PREVIOUS REPORTS, SAMPLING METHODS, AND LIMITATIONS . . . . . 3-1

3.1.1 Peretz Report (ORNL/TM-10218, 1986) . . . . . . . . . . . . . . . . 3-1

3.1.2 Autrey Reports (ORNL/ER-13, 1990 and ORNL/ER-19, 1992) . . . . . . . 3-3

3.1.3 Sears Report (ORNL/TM-11652, 1990) . . . . . . . . . . . . . . . . 3-3

3.1.4 GAAT Reports (ORNL/ER/Sub/87-99053/74, 1995

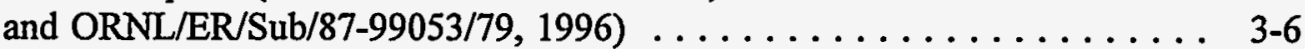

3.1.5 1996 OHF Report and Recent MVST and BVEST Data .......... 3-8

3.2 PREVIOUS REPORTS, ANALYTICAL METHODS, AND LIMITATIONS . . . 3-8

3.2.1 Peretz Report (ORNL/TM-10218, 1986) . . . . . . . . . . . . . . . . . 3-9

3.2.2 Autrey Reports (ORNL/ER-13, 1990 and ORNL/ER-19, 1992) . . . . . . 3-9

3.2.3 Sears Report (ORNL/TM-11652, 1990) . . . . . . . . . . . . . 3-11

3.2.4 GAAT Data (ORNL/ER/Sub/87-99053/74, 1995

and ORNL/ER/Sub/87-99053/79, 1996) . . . . . . . . . . . . 3-13

3.2.5 OHF Data (1996) . . . . . . . . . . . . . . . . . . 3-17

3.2.6 Recent Data for MVST and BVEST (ORNL/TM-13234, 1996

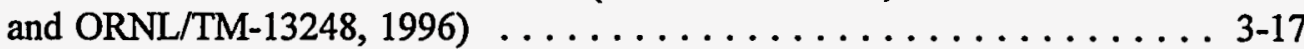

3.2.7 Summary of Data Limitations and Data Qualifications . . . . . . . . . 3-18

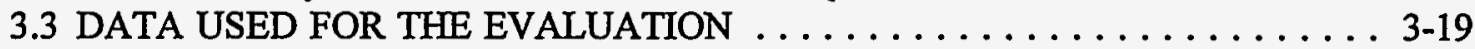

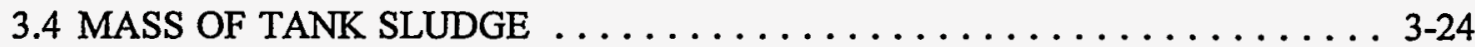

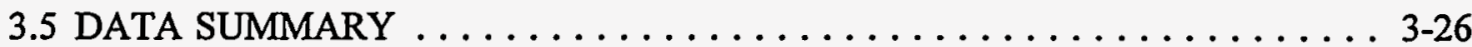


4. ESTIMATING PROPERTY BOUNDS . . . . . . . . . . . . . . 4-1 4.1 ASSUMPTIONS FOR STATISTICALLY CORRECT

CHARACTERIZATION . . . . . . . . . . . . . . . . . . 4-1

4.2 AN OVERVIEW OF STATISTICAL INTERVALS $\ldots \ldots \ldots \ldots \ldots \ldots \ldots \ldots .44$

4.3 DEFINITIONS AND EXAMPLES $\ldots \ldots \ldots \ldots \ldots \ldots \ldots \ldots \ldots \ldots . \ldots \ldots$. 4.3

4.3.1 Confidence Interval for the Population Mean $\ldots \ldots \ldots \ldots \ldots \ldots \ldots \ldots . . \ldots 4-5$

4.3.2 Confidence Interval for the Probability of Being

less than a Specified Value . . . . . . . . . . . . . . . 4-6

4.3.3 Tolerance Intervals to Contain a Specified Population Proportion . . . . . . 4-6

4.3.4 One-sided and Two-sided Prediction Bounds to Contain All of M Future

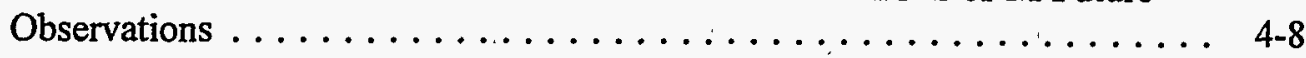

4.3.5 Log Transformations . . . . . . . . . . . . . . . . . . . 4-9

4.4 PREDICTION INTERVALS WHEN THE DATA IS EXPONENTIALLY

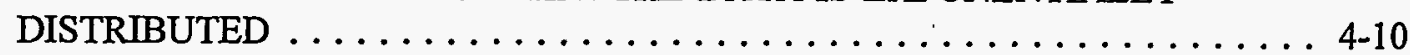

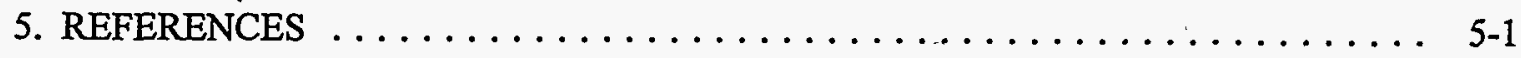

APPENDIX A. A HISTORY OF TANK WASTE AT ORNL . . . . . . . . A-1

APPENDIX B. TANK SAMPLING DATA ................ B-1 


\section{FIGURES}

2.1 Diagram of ORNL Tank Farm System . . . . . . . . . . . . . 2-2

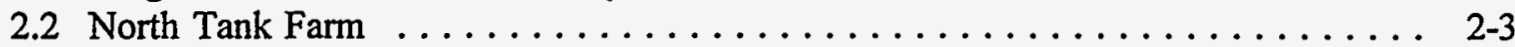

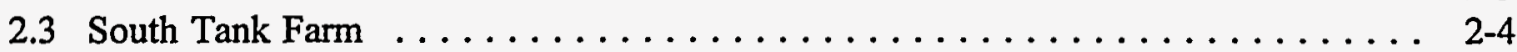

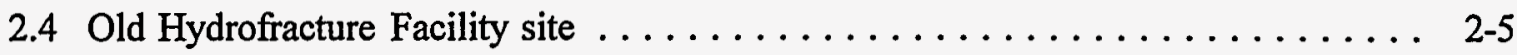

2.5 Layout of BVEST and Evaporator Facility . . . . . . . . . . . . . . 2-7

2.6 Melton Valley Storage Tanks . . . . . . . . . . . . . . . . . . 2-9

3.1 Soft sludge sampler . . . . . . . . . . . . . . . . . . . . . $3-5$

3.2 Frequency of measurements for the physical variables $\ldots \ldots \ldots \ldots \ldots \ldots \ldots$. $\ldots \ldots$

3.3 Frequency of measurements for the chemical measurements . . . . . . . . . 3-24

3.4 Frequency of measurements for the radiological measurements . . . . . . . . . 3-24

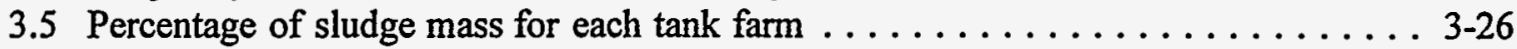





\section{TABLES}

3.1 Summary of ORNL LLLW system tank sampling campaigns . . . . . . . . . . 3-1

3.2 Categorization of waste by similar chemical properties . . . . . . . . . . 3-9

3.3 Summary of data limitations and additional needs $\ldots \ldots \ldots \ldots \ldots \ldots . . \ldots .19$

3.4 Sludge data obtained from referenced reports that was restricted

from statistical analysis . . . . . . . . . . . . . . . . . . 3-20

3.5 Number of measurements on sludge samples from 1985 to $1996 \ldots \ldots$. . . . . 3-22

3.6 Average number of variables measures on sludge samples for each year . . . . 3-23

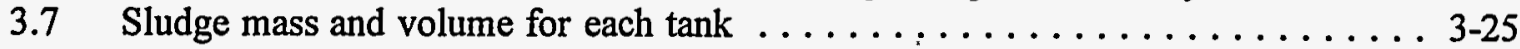

3.8 Sludge mass and volume for each tank farm $\ldots \ldots \ldots \ldots \ldots \ldots \ldots \ldots \ldots . \ldots \ldots$

3.9 Definition of summary statistics . . . . . . . . . . . . . . . . 3-27

3.10 Summary statistics for physical measurements on sludge samples . . . . . . . 3-28

3.11 Summary statistics for chemical measurements $(\mathrm{mg} / \mathrm{kg})$ on sludge samples . . . . 3-31

3.12 Summary statistics for radiological measurements $(\mathrm{Bq} / \mathrm{g})$ on sludge samples . . . 3-39

3.13 Weighted summary statistics for physical measurements on sludge samples . . . . 3-47

3.14 Weighted summary statistics for chemical measurements on sludge samples . . . . 3-49

3.15 Weighted summary statistics for radiological measurements on sludge samples . . 3-54

4.1 Selected percentiles of the student's $t$-distribution . . . . . . . . . . . 4-14

4.2 The factor $\mathrm{g}_{(0.95, \mathrm{p}, \mathrm{n})}$ for calculating two-sided $95 \%$ tolerance intervals and the factor $\mathrm{r}_{(0.95, \mathrm{~m}, \mathrm{n})}$ for calculating two-sided $95 \%$ prediction intervals

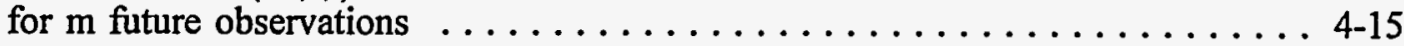

4.3 The factor $\mathrm{g}_{(0.95, \mathrm{p}, \mathrm{n})}$ for calculating two-sided $99 \%$ tolerance intervals, and the factor $\mathrm{r}_{(0.95, \mathrm{p}, \mathrm{n})}$ for calculating two-sided $99 \%$ prediction intervals

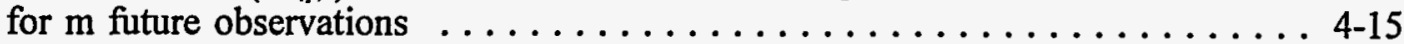

4.4 Factors $g_{(1-\alpha, p, n)}^{\prime}$ for calculating normal distribution one-sided $100(1-\alpha) \%$

tolerance bounds . . . . . . . . . . . . . . . . . . . . 4-16

4.5 Factors $r_{(1-\alpha, m, n)}^{\prime}$ for calculating normal distribution one-sided $100(1-\alpha) \%$ prediction bounds for $\mathrm{m}$ future observations using the results of a previous sample of $n$ observations . . . . . . . . . . . . . . . . 4-17

4.6 Factors $B(.95 ; m, n)$ for calculating exponential distribution two-sided $95 \%$ prediction intervals for $m$ future observations using the results of a previous sample of $\mathrm{n}$ observations $\ldots \ldots \ldots \ldots \ldots \ldots \ldots \ldots \ldots \ldots$ 4-18

B.1 Physical variable measurements on sludge samples from 1985 to $1996 \ldots \ldots$. . . B-5

B.2 Chemical variable measurements $(\mathrm{mg} / \mathrm{kg}$ ) on sludge samples from 1985 to 1996 . B-7

B.3 Radiological variable measurements $(\mathrm{bq} / \mathrm{g})$ on sludge samples

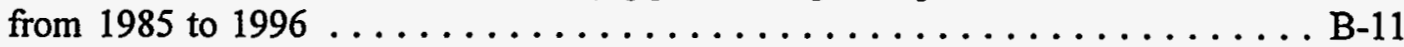

B.4 Physical variable measurements on liquid samples from 1985 to $1986 \ldots \ldots$. . . B-19

B.5 Chemical variable measurements (mg/kg) on liquid samples from 1985 to $1996 \ldots$ B-21

B.6 Radiological variable measurements $(\mathrm{bq} / \mathrm{g}$ ) on liquid samples

from 1985 to $1996 \ldots \ldots \ldots \ldots \ldots \ldots$. . . . . . . . . . . . . . . . . B-29

B.7 Sludge organic concentrations $(\mu \mathrm{g} / \mathrm{kg})$ reported in Sears' report . . . . . . . . . B B-37

B.8 Sludge organic concentrations $(\mu \mathrm{g} / \mathrm{kg})$ reported in Autrey's report . . . . . . . B-38

B.9 Sludge Arochlor concentrations $(\mu \mathrm{g} / \mathrm{kg})$ reported for GAAT tanks . . . . . . . . . B B-39

B.10 Sludge organic concentrations $(\mathrm{mg} / \mathrm{kg})$ reported in GAAT Phase 2 report

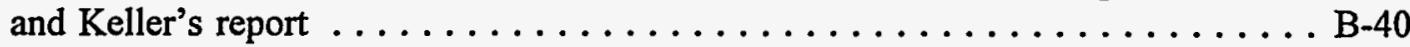


B.11 Sludge semi-volatile organic concentrations $(\mathrm{mg} / \mathrm{kg})$ reported in GAAT

Phase 2 report and Keller's report . . . . . . . . . . . . . . . B-41

B.12 Tenatively identified volatile and semi-volatile concentrations $(\mathrm{mg} / \mathrm{kg})$ reported in

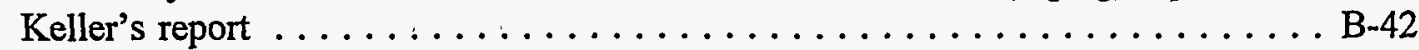

B.13 Liquid organic concentrations $(\mu \mathrm{g} / \mathrm{l})$ reported in Sears' report $\ldots \ldots \ldots \ldots \ldots$ B-43

B.14 Liquid organic concentrations $(\mu \mathrm{g} / \mathrm{l})$ measured by direct aqueous injection gas chromatograph reported in Autrey's report .................. B-43

B.15 Liquid organic concentrations $(\mu \mathrm{g} / \mathrm{l})$ measured by gas chromatographlmass spectrometry reported in Autrey's report . . . . . . . . . . . . . B-45

B.16 Liquid semi-volatile organic concentrations ( $\mu \mathrm{g} / \mathrm{l})$ reported in Autrey's report . . B-47

B.17 Liquid organic concentrations $(\mathrm{mg} / \mathrm{l})$ reported in GAAT Phase 2 report and Keller's report $\ldots \ldots \ldots \ldots \ldots \ldots \ldots \ldots \ldots \ldots \ldots \ldots \ldots \ldots$

1 


\section{ABBREVIATIONS}

\begin{tabular}{|c|c|}
\hline AA & atomic absorption \\
\hline ALARA & as low as reasonably achievable \\
\hline ASME & American Society of Mechanical Engineers \\
\hline ASTM & American Society for Testing Materials \\
\hline BVEST & Bethel Valley Evaporator Service Tank \\
\hline CFR & Code of Federal Regulations \\
\hline DAIGC & direct aqueous injection gas chromatography \\
\hline DOE & U.S. Department of Energy \\
\hline DSOL & dissolved solids \\
\hline EASC & Emergency Avoidance Solidification Campaign \\
\hline EPA & U.S. Environmental Protection Agency \\
\hline FFA & Federal Facility Agreement \\
\hline FY & fiscal year \\
\hline GAAT & Gunite and Associated Tanks \\
\hline GC/MS & gas chromatography/mass spectrometry \\
\hline GFAA & graphic furnace atomic absorption \\
\hline IC & Ion chromatography \\
\hline ICAR & inorganic carbon \\
\hline ICP-AES & Inductively Coupled Plasma Atomic Emission Spectroscopy \\
\hline ITE & in-tank evaporation \\
\hline LLLW & liquid low-level waste \\
\hline LLW & low-level waste \\
\hline LWSP & Liquid Waste Solidification Project \\
\hline MVST & Melton Valley Storage Tanks \\
\hline MVST-CIP & MVST Capacity Increase Tanks \\
\hline NHVOA & nonhalogenated volatile organic analysis \\
\hline NTF & North Tank Farm \\
\hline $\mathrm{OHF}$ & Old Hydrofracture Facility \\
\hline ORNL & Oak Ridge National Laboratory \\
\hline OTE & Out of Tank Evaporation \\
\hline RCRA & Resource Conservation and Recovery Act \\
\hline REDC & Radiochemical Engineering Development Center \\
\hline RFP & Request for Proposal \\
\hline RMAL & Radioactive Materials Analytical Laboratory \\
\hline SSMS & spark source mass spectrometry \\
\hline SSOL & suspended solids \\
\hline STF & South Tank Farm \\
\hline SVOA & Semivolatile Organic Compound Analysis \\
\hline SVOC & semivolatile organic compound \\
\hline TCAR & total carbon \\
\hline TCS & tank characterization system \\
\hline TIMS & thermal ionization mass spectrometry \\
\hline TOC & total organic carbon \\
\hline TRU & transuranic \\
\hline TSOL & total solids \\
\hline
\end{tabular}


TWCP

VOA

WAC

WAG

WIPP
Transuranic Waste Characterization Program

volatile organics analysis

waste acceptance criteria

Waste Area Grouping

Waste Isolation Pilot Plant 


\section{EXECUTIVE SUMMARY}

The U.S. Department of Energy (DOE) has presented plans for processing transuranic low-level liquid wastes located at Oak Ridge National Laboratory (ORNL). The Tennessee Department of Health and Environment has mandated that the processing of these wastes must begin by the year 2002 and that the goal should be permanent disposal at a site located off the Oak Ridge Reservation. To meet this schedule, DOE will solicit bids from various private sector companies for the construction of a processing facility to be operated by the private sector on a contract basis. This report will support the Request for Proposal process by giving potential vendors information about the wastes contained in the ORNL tank farm system. The report consolidates all current data about the properties and the waste composition and presents methods to calculate the error bounds of the data in the best technically defensible manner possible.

Liquid low-level wastes (LLLW) have been generated since ORNL began operations. Before 1984 the waste was discharged to settling basins for dilution, disposed of in seepage pits after decay, or disposed of on-site by the hydrofracture process. From 1984 to the present time, these wastes have been concentrated and stored in the Bethel Valley Evaporator Service Tanks (BVESTs) and Melton Valley Storage Tanks (MVSTs). When storage space in the tanks becomes limited, the liquid portion has been solidified into concrete monoliths. The ORNL LLLW tank system is described in Chap. 2. An operating history of tank waste at ORNL, including Gunite and Associated Tanks (GAAT) operations, Old Hydrofracture Facility (OHF) operations, GAAT sluicing operations, Building 2531 evaporator operations, evaporation operations at the MVST facility, and waste composition changes as a result of evaporation, is given in Appendix A.

Future changes to ORNL LLLW are certain given the many different programs already in progress and planned to deal with ORNL's liquid waste problems. Legacy wastes will be handled by consolidation of all sludges into MVSTs before solidification by the private sector vendor. Generation of wastes by ongoing programs at ORNL will add newly generated waste, which must also be treated, to the system. These wastes could be different than the wastes being generated today. To assure that adequate storage capacity is always available, close management of the waste movements will be required. How and in what sequence these occur will greatly influence the composition of the wastes the private sector will see. The order in which the sludges are transferred and the degree of mixing performed could be handled in several different ways. The schedule for these operations as well as the order of the operations will be developed over a period of time and cannot be discerned at the present time.

Sludges from GAAT, OHF, and BVEST will be consolidated in MVSTs whereas supernates (containing no sludges) will be consolidated in the new MVST-Capacity Increase Tanks.

Demonstration of cesium removal activities will continue in fiscal year 1997 for removal of cesium from up to 25,000 gallons of MVST supernate. Future supernate cesium removal may also occur. Additional evaporation will be initiated in the future to further reduce the volumes of supernates to gain storage space within the tanks for additional storage of newly generated wastes. A combination of the Out of Tank Evaporator and the Building 2518 
evaporator facilities will be used for this. The expected supernate $\mathrm{NaNO}_{3}$ concentration should be $\sim 8 M$ when this is complete. The Radiochemical Engineering Development Center (REDC) is presently the largest contributor of radionuclides to the ORNL waste stream. REDC is supposed to start treating their waste to remove ${ }^{137} \mathrm{Cs}$ and reduce the transuranic content to nontransuranic in the 1998-99 time frame.

The ORNL tank system has been sampled on numerous occasions. The results of the previous sampling campaigns are summarized in this report. A general principle to use is that the later data is generally more accurate because the analytical laboratory had more practice at doing the analysis as.well as better equipment. The BVEST and MVST systems are part of the active waste systems, and the composition of the wastes reported for them have changed during since the sampling occurred. This is particularly true for the supernates, which are transferred and treated on a regular basis.

The analytical methodology and data limitations for radioactive waste tank samples collected from 1985 to present are also summarized. The full scope of analytical data discussed in this summary was not taken as part of a comprehensive characterization of the LLLW system. The waste tank data collection represents many different projects with different needs, analytical requirements, and data quality objectives: In addition, the list of analytical measurements and the quality level varied between projects. The most critical data limitation associated the characterization of underground storage tanks is the limited access to the tank contents, which restricts the options available for statistical sampling. Both vertical segregation in the sludge (layering) and concentration gradients were observed in the liquid phase. For the MVST, BVEST, and OHF tanks, the sludge has only been sampled in a single location. Many GAAT had sludge samples taken at three different locations and large differences in concentration were observed for most species measured.

For the reasons discussed previously, the data used in the evaluation required close screening to ensure that the statistical analysis used the best data possible. Some sludge measurements were excluded from the analysis for various reasons as was all supernate data (because it is expected to be significantly different by the time the private sector vendor begins processing the sludge). Measurements from the various reports have been standardized so their units are consistent throughout this report. Six statistics were calculated to summarize the sludge measurements: the number of measurements, mean, standard deviation, minimum, maximum, and relative error (standard deviation/mean $\times 100 \%$ ). These data are included for all included measurements in tabular form.

A correct and valid analysis of data for the purpose of making statistical inference, such as creating confidence intervals or bounds on some parameter, requires certain assumptions. Three major assumptions allow correct results to follow from an analysis: (1) the assumption of a specified population, (2) the assumption of a random sample, and (3) the assumption that the sampled population is the target population. The first assumes that the data come from a specific and well-defined population. In our setting, the population consists of the possible set of analytes. The fact that we do not analyze for all possible analytes means that we do not have a complete description of the population of interest and may be missing important analytes that may have important interaction effects with analytes that are measured. This interaction could have serious implications when trying to determine bounds on a given analyte. The second assumption is that the sample taken is random. In our situation this is 
violated in several respects. The most obvious and serious violation is that the samples selected came from one position in the tank because the tank only has one opening from which to sample. The requirement of a random sample is critical in that the statistical intervals reflect only the variability introduced by the sampling process and do not take into account any biases that might be introduced by nonrandom samples. In addition, the core type samples taken showed definite layers of material, which was composited and analyzed. This results in no estimate of the variability of the analyte in a given tank and yields a mean concentration. This nonrandomness can lead to heavily biased observations, the results of which are not amenable to adjustment. Finally, the methods used assume that the population of interest is the same as that sampled. Because the population of interest is the MVSTs after transfer from the other tanks, we simply are not sampling the population of interest.

Methods of calculating the following intervals are given with examples on how to use them: Confidence interval for the population mean, confidence interval for the probability of being greater than a specified value, tolerance intervals to contain a population proportion, and prediction bounds to contain all of $\mathrm{m}$ future observations. These intervals are appropriate under the given assumptions. In addition to the given assumptions, we must also assume for the four intervals that the sample was drawn from a normally distributed population. Intervals for the probability of being greater than a specified value, tolerance intervals, and prediction bounds can be calculated if the underlying distribution is assumed to be lognormal. Prediction intervals for the case when the underlying distribution is exponential can also be calculated. The users of the report can calculate their own confidence intervals with these formulas based on the appropriate assumptions. 


\section{INTRODUCTION}

The U.S. Department of Energy (DOE) has presented plans for processing liquid lowlevel wastes (LLLW) located at Oak Ridge National Laboratory (ORNL) in the LLLW tank system. These wastes are among the most hazardous on the Oak Ridge Reservation and exhibit both Resource Conservation and Recovery Act (RCRA) toxic and radiological hazards. The Tennessee Department of Health and Environment has mandated that the processing of these wastes must begin by the year 2002 and that the goal should be' permanent disposal at a site located off the Oak Ridge Reservation. To meet this schedule, DOE will solicit bids from various private sector companies for the construction of a processing facility on land located near the ORNL Melton Valley Storage Tanks (MVSTs) to be operated by the private sector on a contract basis.

Four tank farms (a total of 26 tanks) contain these wastes: the Gunite and Associated Tanks (GAAT), the Old Hydrofracture Facility (OHF) tanks, the Bethel Valley Evaporator Service Tanks (BVESTs) and MVST. The present plans are to transfer the wastes now in the GAAT, OHF tanks, and BVEST as well as newly generated wastes to the eight MVSTs for storage before treatment by a private sector waste processor. Presently, it has not been determined which MVST will be the destination for waste in any individual BVEST, GAAT, or OHF tank, nor has it been determined which MVST will have waste removed or modified to make room for the transferred wastes.

This report will support of the Request for Proposal (RFP) process and will give potential vendors information about the wastes contained in the ORNL tank farm system. The report consolidates current data about the properties and composition of these wastes and presents methods to calculate the error bounds of the data in the best technically defensible manner possible. The report includes information for only the tank waste that is to be included in the RFP. 


\section{THE LLLW SYSTEM AT ORNL}

LLLW wastes have been generated at ORNL since operations began. Before 1966, the waste was discharged to settling basins for dilution or disposed of in seepage pits after decay. From 1966 to 1984, much of this waste was disposed of on-site by the hydrofracture process.

The OHF tanks and MVSTs described herein are actually service tanks for the two hydrofracture facilities. From 1984 to present, these wastes have been concentrated and stored in BVESTs and MVSTs. When storage space in the tanks becomes limited, the liquid portion has been solidified into concrete monoliths. The ORNL LLLW tank system is illustrated in Fig. 2.1 ${ }^{1}$. The following is a description of the ORNL LLLW tank system. An operating history of tank waste at ORNL, including GAAT operations, OHF operations, GAAT sluicing operations, Building 2531 evaporator operations, evaporation operations at the MVST facility, and waste composition changes as a result of evaporation, is given in Appendix A.

\subsection{GUNITE AND ASSOCIATED TANKS (GAAT)}

GAAT $^{2}$ include eight tanks in the North Tank Farm, six tanks in the South Tank Farm, and tanks W-11 and TH-4. The latter two tanks will not be discussed because they will not be included in the RFP. In addition, only tanks W-3 and W-4 in the North Tank Farm are part of the RFP; therefore the other six will not be discussed. The North Tank Farm and South Tank Farm are in the approximate center of ORNL (on both sides of Central Avenue). Central Avenue is the main east-west thoroughfare for ORNL. The North Tank Farm, shown in Fig. 2.2, is a $45.7-\mathrm{m} \times 54.9-\mathrm{m}(150-\mathrm{ft} \times 180-\mathrm{ft})$ lot near the intersection of Third Street and Central Avenue. It is bordered on the north by the Surface Science Laboratory (Building 3137), on the east by a lot where the Solid State Research Facility will be constructed, on the south by Central Avenue, and on the west by Third Street.

The South Tank Farm is located across Central Avenue, south of the North Tank Farm (Fig. 2.3). It is bordered on the north by Central Avenue, on the east by Fourth Street, on the south by the Metal Recovery Facility (Building 3505), and on the west by Third Street. Tank W-11 is southeast of the South Tank Farm.

The two RFP tanks in the North Tank Farm (W-3 and W-4) are constructed of gunite (sprayed cement slurry). Tanks W-3 and W-4, which have capacities of 160,860 L (42,500 gal) each, are in the southeastern part of the farm. Each tank has an array of inlet and outlet lines that lead to valve boxes where waste transfers are controlled. Each tank also has an associated dry well that drains the immediate area around a tank which is intended to control potential leaks.

The South Tank Farm contains six gunite tanks (W-5 through W-10). Tanks W-5 through $\mathrm{W}-10$ are $643,450-\mathrm{L}(170,000$-gal) tanks arranged in two rows of three with a $18.3-\mathrm{m}(60-\mathrm{ft})$ center-to-center distance. The domed waste storage tanks are $15.2 \mathrm{~m}(50 \mathrm{ft})$ in diameter with a vertical height of $5.5 \mathrm{~m}(18 \mathrm{ft})$ at the center and $4.6 \mathrm{~m}(15 \mathrm{ft})$ at the walls. Each tank has an associated dry well and an array of pipes and valve boxes. 


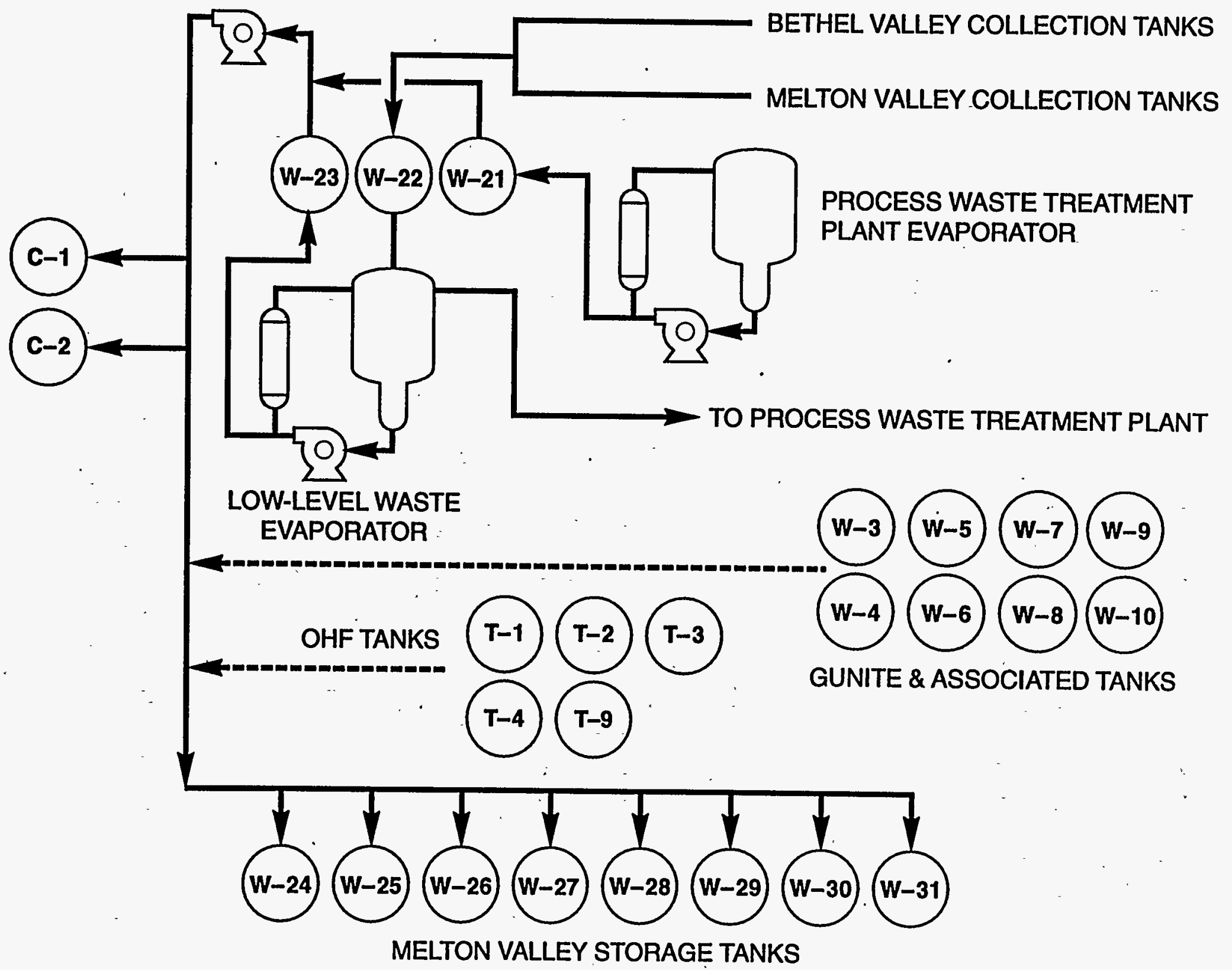

Fig. 2.1. Diagram of ORNL Tank Farm System. 


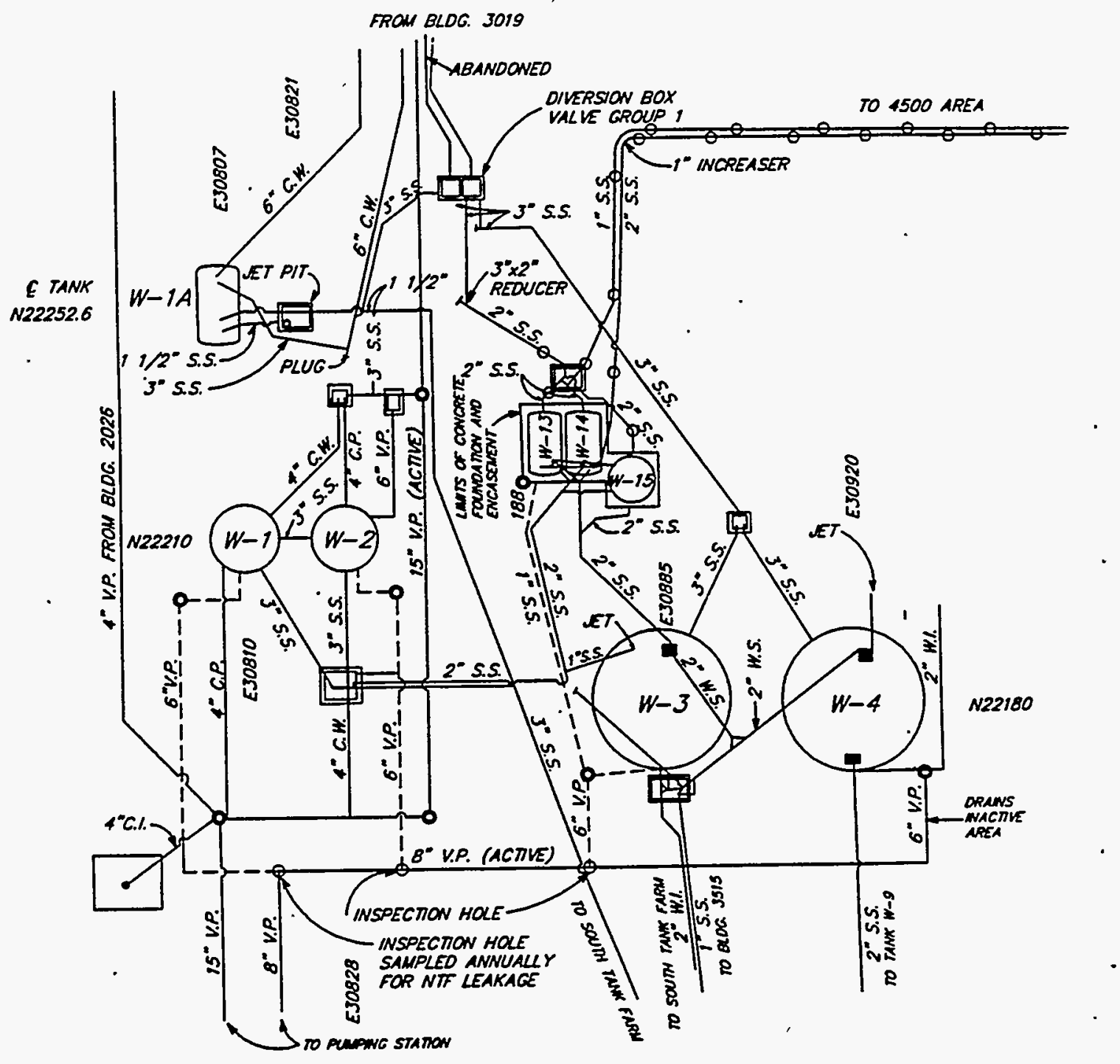

Fig. 2.2. North Tank Farm.

\subsection{OLD HYDROFRACTURE FACILITY(OHF)}

The OHF Facility ${ }^{3,4}$ was built in 1963 and operated from 1964 until it was shut down in 1980. The purpose of this facility was to dispose of liquid waste by the hydrofracture process, which consisted of mixing the waste with grout and injecting the mixture into a shale formation located $\sim 305 \mathrm{~m}(1000 \mathrm{ft})$ below ground surface. In 1966, after test injections in $1964-65$, the facility became operational for the routine disposal of concentrated intermediate-level waste solutions. Improvements and modifications were made to the process and the facility throughout this series of injections, which ended in 1979. The hydrofracture process was operated as a large-scale batch process. However, each injection was a continuous operation. Each injection disposed of an annual accumulation of waste solution of about $378,500 \mathrm{~L}(100,000 \mathrm{gal})$. During an. injection, waste solution was pumped to the mixer and 
mixed with a stream of dry solids. The resulting grout was pumped down the injection well and out into the shale formation at an injection pressure of about $3000 \mathrm{psi}$.

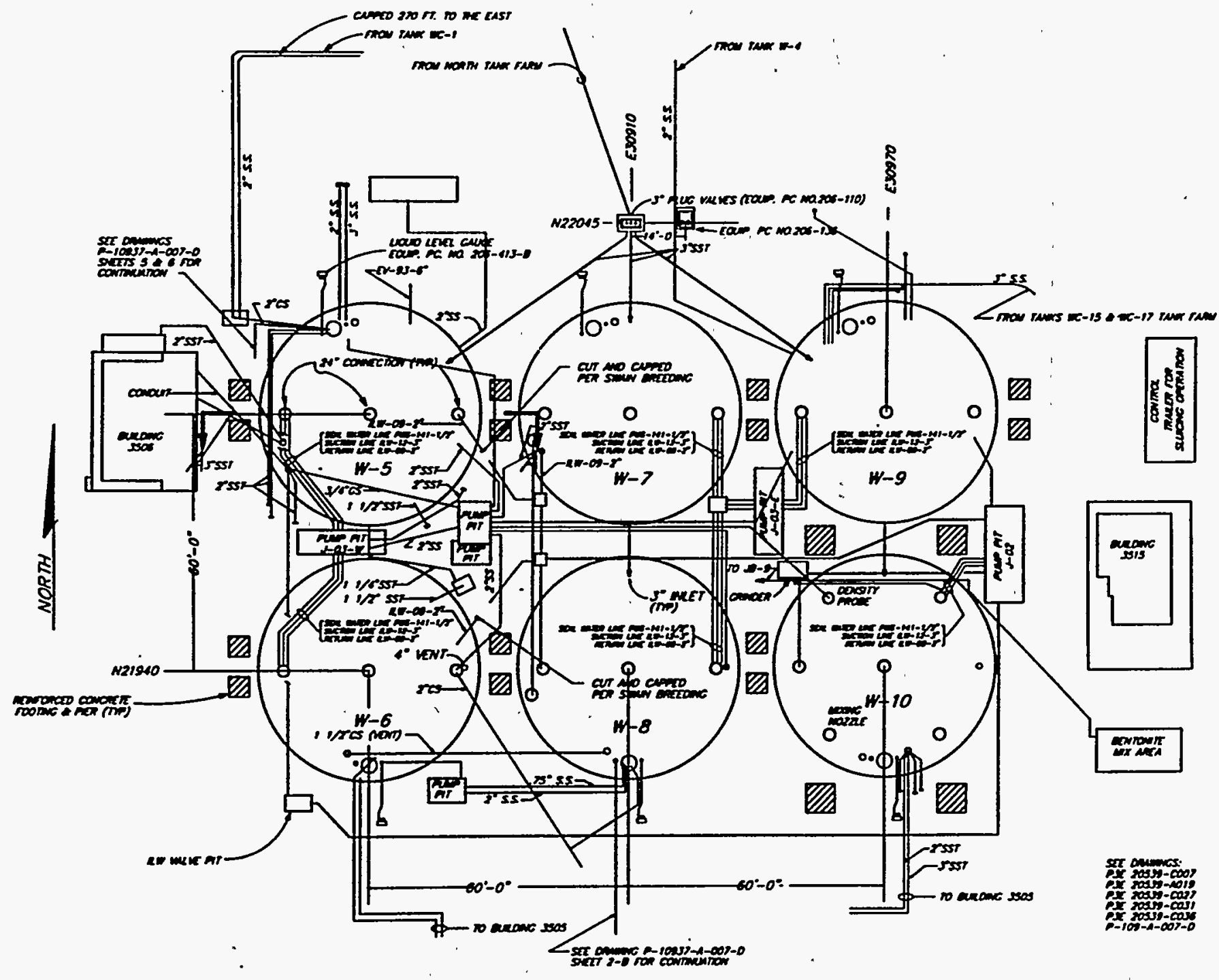

Fig. 2.3. South Tank Farm.

The OHF Facility is located in Melton Valley, approximately $1.1 \mathrm{mi}$ south of the ORNL main plant area within the secured area of Waste Area Grouping (WAG) 5. Figure 2.4 shows the site layout and all pertinent structures. The OHF underground waste storage tanks are buried less than $110 \mathrm{yd}$ west of Building 7852 and approximately 131 yd east of White Oak Creek. 


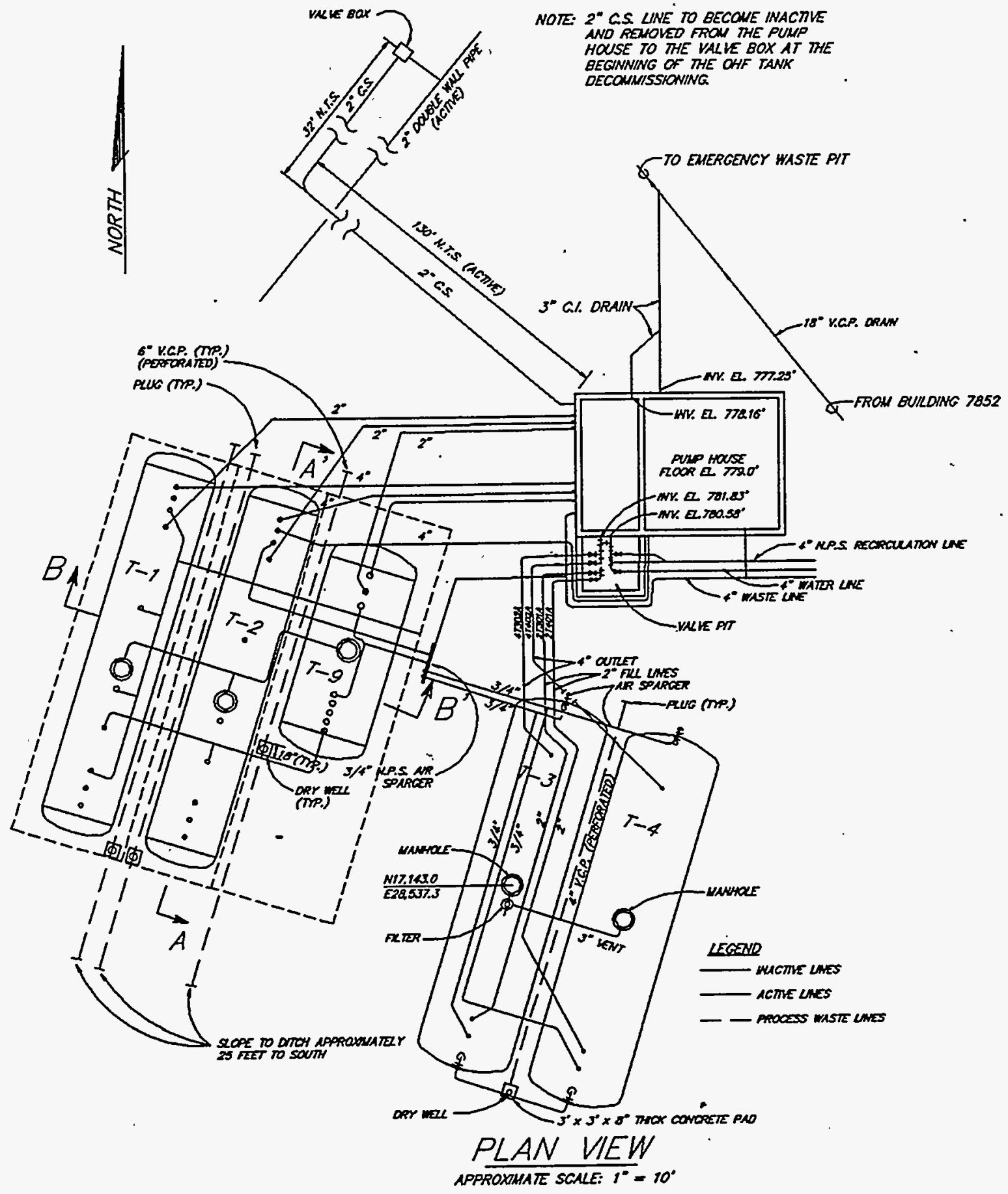

Fig. 2.4,Old Hydrofracture Facility site.

Five underground storage tanks ranging in size from 13,000 to 25,000 gal capacity are located at the OHF Facility (T-1, T-2, T-3, T-4, and T-9). The five tanks are buried beneath relatively shallow earth backfill near Building 7852. The tanks were installed in two phases, 
with tanks T- I, T-2, and T-9 being installed initially and tanks T-3 and T-4 installed later. Tanks T-1, T-2, and T-9 were surplus carbon steel tanks from the Oak Ridge Y- 12 Plant and were installed circa 1963 at the OHF site to store LLLW. These tanks were refitted to include additional internals for mixing and sludge retrieval. In 1966, two additional storage tanks (T-3 and $\mathrm{T}-4$ ) were added to the system. They were surplus rubber-lined carbon steel tanks and were installed in a pit next to the existing three tanks.

Tanks T-1 and T-2 are $8 \mathrm{ft}$ in diameter and $44 . \mathrm{I} \mathrm{ft}$ long with nominal capacities of 15,000 gal. Nominal wall thickness is 1 in. (Weeren 1995). Tank T-9 is $10 \mathrm{ft}$ in diameter and $23.8 \mathrm{ft}$ long with a nominal capacity of 13,000 gal. The internal piping is similar to that of T-1 and T-2 except that only: two airlift pumps were installed. Tanks T-3 and T-4 are 10.5 $\mathrm{ft}$ in diameter and $42.1 \mathrm{ft}$ long. Each of these tanks has 5/8-in.-thick walls with a nominal capacity of 25,000 gal. Each has a rubber lining on the inside. Fittings of each tank include an 18-in. (nominal) manway in the middle of each tank, which contains a pneumatic level indicator (Fig. 2.4), three airlift pumps, a 2-in. inlet near one end of the tank, and a 4-in. suction line near the same end. The suction line extends to near the bottom of the tank.

\subsection{BETHEL VALLEY EVAPORATOR SERVICE TANKS (BVEST)}

The three Evaporator Service Tanks ${ }^{1}$ (W-21, W-22, and W-23) are essentially identical in construction. Each of the 12' diameter, 61'-4 3/8" long all-welded vessels is fabricated of $1 / 2^{\prime \prime}$ thick American Society of Mechanical Engineers (ASME) SA-240, type 304L stainless steel in accordance with ASME Code Section VIII. The tanks operate at atmospheric pressure or slightly less $\left(-1^{\prime \prime} \mathrm{wg}\right)$, but are designed for $15 \mathrm{psig}$ and $150^{\circ} \mathrm{F}$; the test pressure is 22.5 psig. A diagram of the Evaporator Service Tank is shown in Fig. 2.5.

Two of the tanks, W-21 and W-22, are located in a single reinforced concrete vault 31' wide, $65^{\prime}-4^{\prime \prime}$ long, by $16^{\prime}-2^{\prime \prime}$ high; the floor elevation is $779^{\prime}-10^{\prime \prime}$. These tanks receive the raw low-level waste (LLW) by gravity from the Waste Collection Header. Tank W-23 is located in a separate vault $19^{\prime}$ wide, $65^{\prime}-4^{\prime \prime}$ long, by $16^{\prime}-8^{\prime \prime}$ high; the floor elevation is $788^{\prime}-6^{\prime \prime}$. Tank W-23 is used to receive the concentrated waste from the evaporators; however, the three tanks are interconnected by piping, which is so arranged that their contents may be interchanged.

The tanks and vaults are designed in accordance with the philosophy for containment of radioactive liquids and provide double containment. The reinforced concrete walls of the vaults vary in thickness from 2' to $3^{\prime}$ and both vaults are located below grade level. The concrete roof slabs are 3' thick and are provided with removable stepped plugs to permit access to the vault. The vault floors and the walls to a height of 7'-2" are lined with 16 gauge, type 304L stainless steel sheet. Sumps and sump pumps are provided in each vault to permit leakage to be retumed to the Service Tanks. The entire installation is constructed in accordance with the Uniform Building Code, 1970, for Seismic Zone 2.

\subsubsection{Waste Storage Tanks $\mathrm{C}-1$ and $\mathrm{C}-2^{1}$}

It was originally estimated that the six gunite storage tanks, which contain no special provisions for cooling, could handle a maximum heat load of about $17,000 \mathrm{BTU} / \mathrm{h}(5 \mathrm{KW})$. Thus, the radionuclid concentration in the LLLW had to be restricted to 5-10 Ci/gal, which corresponds to a heat generation rate of about $0.1 \mathrm{BTU} / \mathrm{gal}$. It was anticipated that some processes at ORNL could produce liquid waste with a considerably higher concentration than 


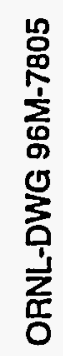
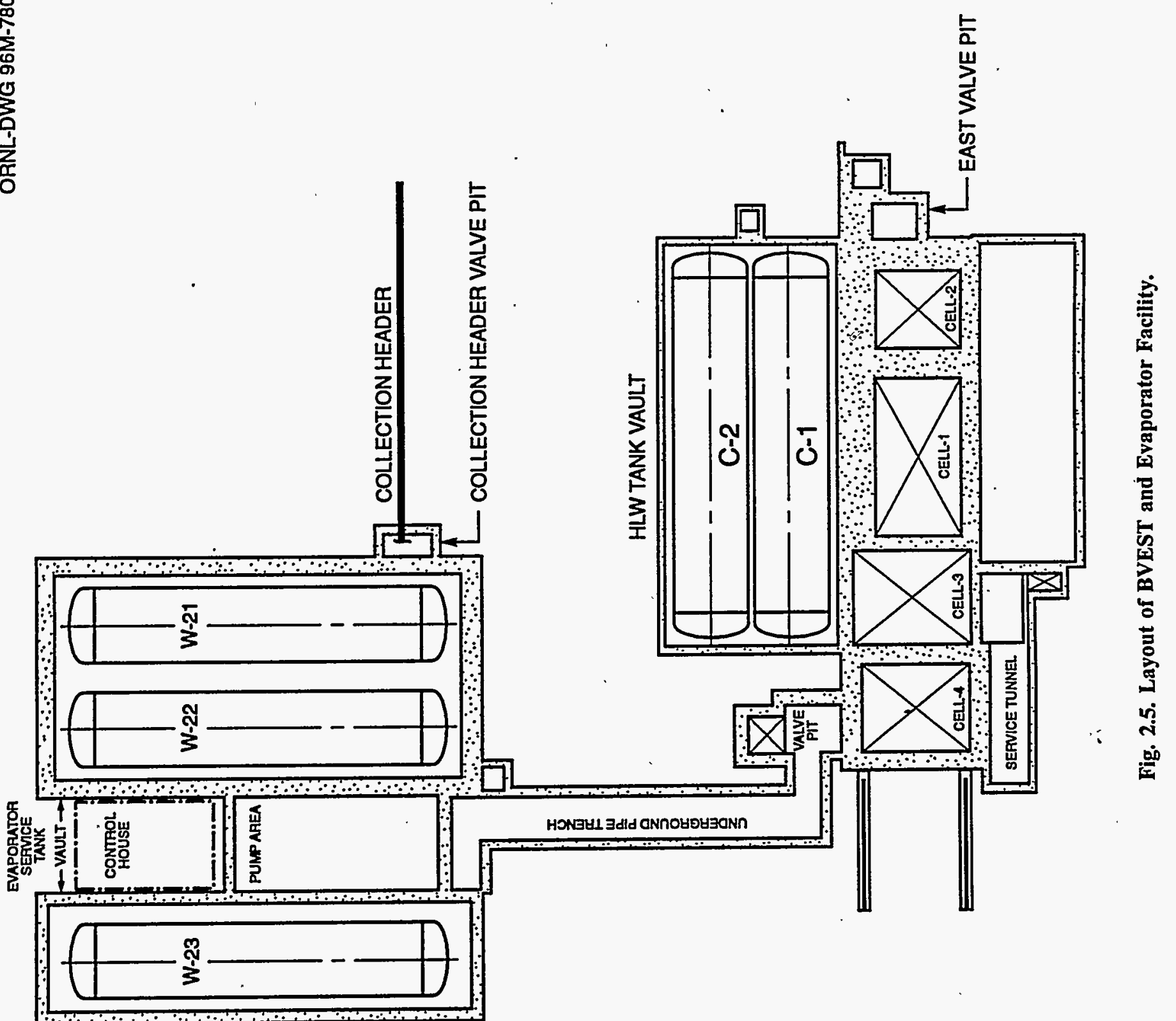
this and, thus, a substantially higher heat generation rate. Consequently, in 1964 two internally and externally cooled 50,000-gal tanks were installed to handle this liquid waste. These tanks are located in an underground, reinforced-concrete vault located adjacent to and directly north of the Evaporator Building (2531) (Fig. 2.5).

The two storage tanks are of all-welded construction, fabricated of American Society for Testing Materials (ASTM) A240-6IT Type 304L stainless steel 1/2" thick. The 61' long by 12' diameter horizontal tanks were designed to meet the requirements of ASME Code Section VIII. The design pressure is $30 \mathrm{psig}$ at a temperature of $200^{\circ} \mathrm{F}$. The tanks were hydrostatic tested at 50 psig. The tanks are capable of storing acidic wastes with activities up to 2,800 $\mathrm{Ci} / g a l$, which will generate about $32 \mathrm{BTU} / \mathrm{h}$ gallon, if produced from 6 months' cooled high-burnup uranium. However, the tanks were never used for materials of this concentration.

In recent years Tanks $\mathrm{C}-1$ and $\mathrm{C}-2$ have received waste from Tank W-23 for storage and are considered a part of the BVEST tank farm.

\subsubsection{Waste Evaporator System ${ }^{1}$}

Dilute LLLW from the liquid collection system is fed to the evaporators for concentration. Two 600-gallon-per-hour evaporators are available to concentrate the LLLW; both are housed in Building 2531. One evaporator is served by a 4400 gal feed tank (A-1). The other evaporator is fed directly from one of the evaporator service tanks (W-21 or W-22). Aside from this the operations are identical. These facilities are shown in Fig. 2.5.

The evaporator installations each consist of an evaporator vessel in which the volume reduction takes place, a vapor filter, a water cooled condenser, and a condensate catch tank. With the exception of the condensers, the equipment in both systems is identical; however, the inspection, testing, and quality assurance requirements for the new modifications are more rigorous than those applied to the earlier installation.

The evaporators may be operated singly or concurrently and are arranged so that cross connections between the two facilities allow maximum flexibility. Evaporator concentrate is stored in Tank W-23 before transfer to MVST.

Because the cessation of waste disposal operations brought about by the shutdown on New Hydrofracture, Tanks W-21 and W-23 have been used to store evaporator concentrate. Tank W-22 is presently used as the evaporator feed tank; Tanks W-21, W-23, C-1, and C-2 are being used for concentrate storage.

\subsection{MELTON VALLEY STORAGE TANKS (MVST) ${ }^{1}$}

Storage capacity for the concentrated LLW is provided by $8,50,000$ gal storage tanks installed in 2 underground vaults located adjacent to the new hydrofracture site in Melton Valley. These tanks were originally used to store concentrated waste before injection into the shale formations below the adjacent New Hydrofracture Facility. Because hydrofracture is no longer an approved method for waste disposal, these tanks are the final storage point of LLLW at ORNL. A diagram of these tanks is shown in Fig. 2.6. 
PLAN VIEW OF TANK VAULTS SHOWING ACCESS PORT LOCATIONS

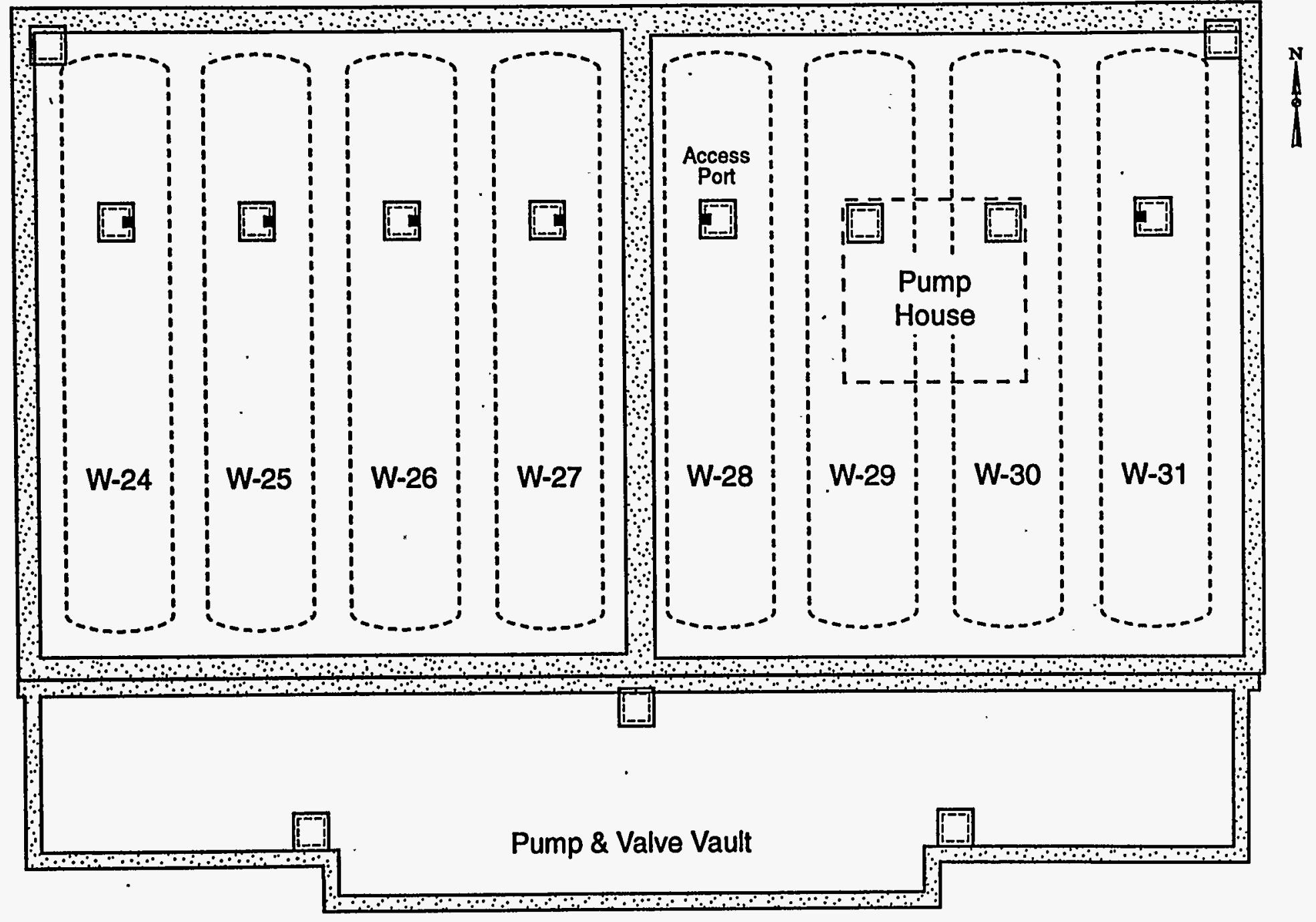

Fig. 2.6. Melton Valley Storage Tanks. 
The eight tanks (W-24 through W-31) and their reinforced concrete vaults are designed in accordance with current philosophy for containment safeguards for radioactive liquids; the vaults provide secondary containment. The $1 / 2^{\prime \prime}$ thick, $61^{\prime} 47 / 8^{\prime \prime}$ long, $12^{\prime}$ diameter all-welded horizontal vessels are fabricated of ASME SA 240 Type 304L stainless steel. They are virtually identical to the evaporator service tanks W-21, W-22, and W-23. Although they operate at atmospheric pressure they are designed for $15 \mathrm{psig}$ at $150^{\circ} \mathrm{F}$ and are hydrostatic tested to 22.5 psig. The applicable codes and standards may be found in reference 4 of Sect. 2 .

Four tanks are located in each of two identical, reinforced-concrete underground vaults. Each vault is $67^{\prime}$ long by $64^{\prime}$ wide and $19^{\prime}$ high. The vaults have reinforced concrete walls $2^{\prime}$ $6^{\prime \prime}$ to $5^{\prime}$ thick and are covered with $3^{\prime}$ concrete ceilings. They are lined to a height of $7^{\prime} 2^{\prime \prime}$ with 16-gauge stainless steel sheet to prevent leakage. Each vault is provided with a $3^{\prime}$ square $1 \mathrm{ft}$. deep sump to collect leakage. The vaults are served by a $22^{\prime}$ ' wide by $130^{\prime}, 6^{\prime}-8^{\prime \prime}$ high pipe tunnel located below grade immediately south of the vaults. This tunnel, which contains piping and pumping equipment, is also lined to a height of 3' with 16-gauge stainless steel.

The storage tanks are equipped with liquid level indicators, temperature and specific gravity measuring devices, air spargers, and sampling devices. Readouts are available in the local Control House. Liquid level alarms warn of potential overfilling. A nonspecific alarm, which indicates the existence of an abnormal condition, is telemetered to the Waste Operations Control Center (Bldg. 3105). In addition, the tanks are interconnected to minimize the probability of overfilling.

\subsection{ANTICIPATED CHANGES TO ORNL LLLW}

Anticipated changes to ORNL LLLW are certain given the many different programs that are already in progress or are planned to deal with ORNL's liquid waste problems. Legacy wastes will be handled with consolidation of all sludges in MVSTs before solidification by a private sector vendor. Present generation of wastes by ongoing programs at ORNL will add newly generated waste to the system, which must also be treated. These wastes could be different than the wastes being generated today. To assure that adequate storage capacity is always available, close management of the waste movements will be required. Sludges from GAAT, OHF, and BVEST will be consolidated in MVSTs whereas supernatants (containing no sludges) will be consolidated in the new MVST Capacity Increase Tanks (MVST-CIP) discussed herein.

The OHF tanks will be sluiced with water and the contents pumped to an existing LLLW valve box located northwest of Building 7852, tying into the main transfer line to the MVST facility. The BVEST sludges will be suspended in LLLW concentrate either by a fluidic based or more conventional mixer pump-sluicer system and pumped to the MVSTs. GAAT sludge will be resuspended in water with a series of sluicer/confined sluicer and remote robotic techniques and transferred to MVSTs.

How and in what sequence these occur will greatly influence the composition of the wastes that the waste processer will see. The order in which the sludges will be transferred and the degree of mixing could occur in a number of different ways. The schedule for these operations as well as the order of the operations will be developed over a period of time and cannot be discerned at present. In addition to the mixing of the sludges, other programs are in 
place to deal with different aspects of LLLW. Sections 2.5.1 through 2.5.4 briefly describe these programs (some of these programs are contingent upon funding).

\subsubsection{MVST-CIP}

The Federal Facilities Agreement (FFA) requires the transfer of wastes from noncompliant tanks. The existing MVSTs are at or very near their capacity because of delays in the concentrated LLLW processing facility. Therefore, to fully comply with the FFA to keep the LLLW collection and transfer system operational, return to more conservative OSR limits, contain water used for the sludge transfers, and support other environmental restoration programs, additional storage capacity was required.

The most cost-effective method of providing this capacity was determined to be the construction of 6,100,000 gal cylindrical tanks adjacent to the existing MVST facility. The new facility has the capability to transfer liquids and readily pumpable sludges to the existing MVST facility, to receive liquids and readily pumpable sludges from the existing MVST facility and Bethel Valley Evaporator Facility, and to transfer liquids to the Bethel Valley Evaporator Facility for treatment. In addition, a line to the existing Liquid Waste Solidification Project (LWSP) facility will be provided; these tanks are presently under construction and are scheduled for comissioning in July 1998. At this time, all supernatant will be removed from MVSTs and transferred here, and sludges contained in the OHF tanks, GAAT, and BVEST will be moved into MVSTs and turned over to the waste processer for treatment.

\subsubsection{Cesium Removal ${ }^{6}$}

The cesium concentration of MVST supernatant will continue to increase to much greater levels than those encountered previously. This will continue until the Radiochemical Engineering Development Center (REDC) implements source treatment activities in 1998. Cesium removal will be required for future LWSP campaigns to reduce radiation exposure and shielding and shipping costs for transport of the solidified supernatant to the Nevada Test Site.

Demonstration operations activities will be continued to evaluate the ability to process radioactive waste through the use of mobile, modular systems (compact processing units or CPUs) available for deployment near the site on an "as needed" basis. Operability of a full-scale treatment system for an extended duration is required before routine deployment.

In fiscal year (FY) 1996, the demonstration system was fabricated, cold testing was performed with the selected ion exchanger, the demonstration system was installed, and hot operations initiated. In FY 1997, operation of the system will be continued for removal of cesium from, up to 25,000 gal of MVST supernatant. WMRAD anticipates future use of the system (subject to available funding) to remove cesium from MVST supernatant to reduce the radiation exposure and costs associated with processing of the supernatant into a grouted waste form.

\subsubsection{Additional Evaporation}

Additional evaporation will be initiated in the future to further reduce the volumes of supernatants to gain storage space within the tanks for additional storage of newly generated wastes. Evaporation will also be used to remove the water used to transport sludges from the 
GAAT and OHF facilities in addition to using settling and pump-back of sluicing liquids. A combination of Out of Tank Evaporation (OTE, Appendix A) and the Building 2518 evaporator facilities will be used for this. Future In-Tank Evaporation (Appendix A) is not presently planned because OTE is faster and more efficient. The best present estimate is to evaporate the supernatants and sluice waters in MVST, BVEST, OHF, and GAAT almost to the point of saturation as the legacy waste is consolidated in MVST and MVST-CIP. The expected supernatant $\mathrm{NaNO}_{3}$ concentration should be approximately $8 M$ when this is complete.

\subsubsection{Source Treatment}

Currently, REDC is the largest contributor of radionuclides to the ORNL waste stream. They produce approximately 15,000 gal of dilute LLLW per year, containing approximately $10,000 \mathrm{Ci}$ of radionuclides. ORNL's dilute generation, including REDC's contribution, is about $590,000 \mathrm{gal} /$ year of dilute LLLW containing about $15,000 \mathrm{Ci}$ of radionuclides. REDC waste is expected to start pretreating their LLLW to remove ${ }^{137} \mathrm{Cs}$ and other fission products and reduce the transuranic (TRU) content to non-TRU. The pretreatment will consist of an ion exchange system, evaporator, and pot dryer, which will produce a very small volume of concentrated ${ }^{137} \mathrm{Cs}$, other fission products, and TRU as a solid waste, but will remove $>99 \%$ of the activity now entering the LLLW system. 


\section{DISCUSSION OF DATA FROM PREVIOUS SAMPLING CAMPAIGNS}

The ORNL tank system has been sampled on numerous occasions for different reasons. This section summarizes results of the previous sampling campaigns, as compiled from the referenced reports. For more detailed information the reader is referred to the individual campaign reports. A general principle to use here is that the later data is generally more accurate, mostly because the analytical laboratory had more practice at doing the analyses as well as better equipment. The BVEST and MVST systems are part of the active waste systems, and the composition of the wastes reported for them have changed since the sampling occurred. This is particularly true for the supernatants, which are transferred and treated on a regular basis. Table 3.1 below summarizes the reports, sampling dates, and tanks sampled.

Table 3.1 Summary of ORNL LLLW system tank sampling campaigns

\begin{tabular}{lllc}
\hline \multicolumn{1}{c}{ Report number } & \multicolumn{1}{c}{ Sampling dates } & \multicolumn{1}{c}{ Tanks sampled } & Reference \\
\hline ORNL/TM-10218 & July 1985 & W-24 to W-28 & 7 \\
& November 1985 & W-24 to W-31 & \\
ORNL/ER-13 & July 1988 & T-1, T-2, T-3, T-4, T-9, W-3, & 8 \\
& & W-4, W-5, W-6, W-7, W-8, & \\
& & W-9, W-10 & 10 \\
ORNL/TM-11652 & December 1989 & W-24 to W-28, W-31 & 10 \\
& January 1990 & W-21, W-23 & 11 \\
ORNL/ER/Sub/87- & November 1994 & W-3, W-4, W-5, W-6, & 12 \\
99053/74 & W-7, W-8, W-9, W-10 & 13 \\
ORNL/ER/Sub/87- & August 1995 & W-3, W-4, W-5, W-6, & 14 \\
L9053/79 & & W-7, W-8, W-9, W-10 & \\
ORNL/TM-13248 & March 1996 & T-1, T-2, T-3, T-4, T-9 & 15 \\
\hline
\end{tabular}

\subsection{PREVIOUS REPORTS, SAMPLING METHODS, AND LIMUTATIONS}

\subsubsection{Peretz Report (ORNL/TM-10218, 1986)}

The samples analyzed and reported in the Peretz report ${ }^{7}$ were not taken as part of a planned comprehensive characterization of the LLW system. Rather, the samples were collected at different times to answer specific questions. Thus, procedures and responsible personnel were different for various samplings. In nearly all cases, the Waste Management Section of the ORNL Operations Division was responsible for actually collecting the samples. Because of the radioactivity of the samples, they were submitted to the Radioactive Materials Analytical Laboratory (Bldg. 2026). From this laboratory, samples were distributed to other groups in the Analytical Chemistry Division. Request numbers were originally assigned to the samples at Building 2026, and in some cases, these numbers carried onto analyses performed at other locations. The major laboratory groups involved in the analyses are the Radioactive 
Materials Analytical Laboratory, the Transuranium Analytical Laboratory, the Chemical and Physical Analysis Laboratory, the Mass Spectrometry Laboratory, and the Organic Analysis Laboratory.

\subsubsection{Melton Valley Storage Tanks}

Data on the contents of MVSTs were generated from two sampling campaigns in July and November 1985. During the July sampling, liquid samples were taken through a single nozzle penetration (designated the "G3" nozzle) in five of the 50,000 gal tanks. Samples were collected by inserting a hose from the suction side of a sampling pump into the tanks through a shield plug above the nozzle. Samples were drawn from near the top, the middle, and the bottom of the liquid layer in each tank. A sample of liquid was also taken from the sludge region at the bottom of each tank. Whatever solids were drawn up with the liquid became part of the sample. Tanks W-24 through W-28 were only sampled in the July sampling phase.

The second sampling phase was conducted in November 1985. All eight tanks were sampled through the same nozzle penetration. A liquid sample and a solids sample were taken from each tank. The liquid sample was collected by suspending an open sample bottle into the middle of the liquid phase. Although stated as a mid-tank sample, the bottles were filled immediately upon entering the liquid contents and were then mixed somewhat at the middle level. Solid samples were taken by pushing a hollow rod into the sludge phase until the bottom of the tank was reached. Cores of sludge were then removed from the rod. Because the sludge in Tank W-31 was particularly hard, extra force was required to reach the tank bottom. External circulation of the tanks, a standard practice at the time the samples were taken, was stopped to allow the liquid and sludge phases to more fully separate for the November sampling. Aeration was continued, however, to maintain mixing in the liquid phase.

Physical observations were recorded during the second sampling. Concerns focused on the quantity and physical characteristics of the sludge layer. An estimate of the depth of sludge. present in each tank was made by noting at what point the sampling rod seemed to encounter the sludge phase. The depth estimates obtained in this manner were rough (plus or minus six inches), and led to approximate estimates of the volume of sludge present in each tank.

\subsubsection{Evaporator Service Tanks}

Tanks W-21, W-22, and W-23 were sampled in November 1985, after the second sampling at MVST. Sludge samples were taken from all three of these tanks, and a liquid sample was taken from Tank W-23. Procedures were similar to those used at MVST. Cores were taken from the sludge near the tank centers, and a bottle was suspended into Tank W-23 for the liquid sample. No access points exist on tanks C-1 and C-2, so these tanks were not sampled.

\subsubsection{Gunite storage tanks}

Sampling of the Gunite tanks was always difficult because only one penetration was available, and the solids were stratified into different layers characteristic of wastes generated by ORNL in different years. The data available on the sludge removed from GAAT appears in the operations reports that document sampling and other activities conducted during each sluicing campaign. A summary of these sludge removal and injection activities is given in Appendix A of reference 11. Samples taken from MVST before each injection are also given. 
The sampling technique was not detailed but could be presumed to be as described above for MVST.

Data in the Peretz report probably do not well represent the residual contents now present in GAAT. This residual material was found to be too hard to be sluiced and removed and includes minor heels of suspended sludge, which could not be pumped out. Hard residual sludge is probably highly inhomogeneous. One of the more intriguing observations of this residual material is the presence of well-shaped octahedral crystals, as large as 6 in. on a side. Some of these crystals were removed and found to be formed primarily of sodium phosphate. Any definitive characterization of this residual material would be extremely difficult.

Qualitative descriptions of the sampled material are listed in Appendix B.

\subsubsection{Autrey Reports (ORNL/ER-13, 1990 and ORNL/ER-19, 1992)}

The Autrey reports ${ }^{8,9}$ present the results of a 2-year effort to sample and analyze the contents of 30 inactive radioactive waste storage tanks, including GAAT. This section describes the sample collection activities associated with the eight GAAT tanks that will be contributing sludges to MVST. The primary purpose for sampling the inactive waste tanks was to determine whether these tanks contain hazardous wastes as defined by RCRA regulations (40 CFR Pt. 261, Subparts C and D). In addition, the tank contents needed to be characterized sufficiently to select viable treatment strategies and meet final waste-form criteria.

From the outset of this project, it was realized that sample analyses would provide only a relative quantification of the tank liquid and sludge contents and were not meant to be statistically defensible according to U.S. Environmental Protection Agency (EPA) SW-846 protocol. Because of the physical design of most of the tanks, sample collection could take place only from within a very limited area inside the tank. Sample quantities were also limited to minimize radiation exposure to the field personnel collecting the samples. The tank liquids were expected to be fairly homogeneous given the length of time for the solids to settle.

Most liquid samples were collected with a small vacuum pump, as described in Sect. 3.1.3. Although this procedure could volatilize the lighter organics in the liquid, this approach minimized radiation exposure to personnel and was quite simple to operate. Liquid samples were usually collected near the top at the midpoint and at the bottom of the tank. Otherwise, samples were collected from the top and bottom of the tank.

Liquid/sludge interfaces in the tanks were found by using a Markland Model 10 sludge gun. Because earlier reports indicated that both soft and hard sludges could be found, two different sludge collectors were prepared. These collectors were updated versions of the collectors used for the Sears study. Attempts to collect sludge were made first with the soft-sludge collector. Hard sludges were encountered in only 4 of the 12 concrete tanks sampled.

\subsubsection{Sears Report (ORNL/TM-11652, 1990) ${ }^{10}$}

This section describes the sample collection techniques used to collect data for the Sears report. Detailed, task-specific procedures are given in Appendixes $\mathrm{E}$ and $\mathrm{F}$ of ref. 10; these include general sampling procedures, instructions for the different types of samplers, precleaning and decontamination of equipment, sample custody, and field log records. 
Sampling was conducted for six MVST (tanks W-24 through W-28 and tank W-31) and two of concentrate storage tanks (tanks W-21 and W-23) at the evaporator complex in Bethel Valley. Samples were drawn through the penetration (the "G3" nozzle) used to house the liquid level instrumentation.This access is a 3-in.-diam. pipe that penetrates the tank from the vault roof. Samples were collected at MVST from September to December 1989, and from tanks W-21 and W-23 at the evaporator service facility in January 1990.

Liquid samples were taken at three levels: one-third, one-half, and two-thirds depth of the aqueous supernatant. The air-liquid and the liquid-sludge interfaces were located through the use of the Markland Model 10 sludge gun, thus establishing the depth of the supernatant liquid in the tank. The air-liquid interface was checked for the presence of any immiscible (e.g., organic) layer; no immiscible or stratified liquid layers were detected in the tanks with the Markland instrument. Samples representative of a vertical "core" of sludge were collected to pick up layering in the waste. Because only sludge directly under the access port can be sampled, the samples may not be representative of other locations in the tank and should be considered merely an indicator of the tank contents. Samples of the aqueous supernatants in tanks W-29 and W-30 were collected by using the pump module (Isolock) sampler. There is no access to sample the sludge in these tanks. No waste additions or transfers took place at MVST while sampling was in progress. The air spargers for MVST had been off since before the 1988 Emergency Avoidance Solidification Campaign, except when tanks W-25 and W-26 were sparged for about $24 \mathrm{~h}$ to mix the liquid contents after the August 1989. waste transfers.

Samples of the supernatant liquid were collected from tanks W-21, W-23 to W-28, and W-31 by using a vacuum pump sampling system. Samples were taken as described previously, except in Tank W-21, where the liquid layer was only 8-in. deep and only one sample was taken. The sample was pulled by vacuum from the specified level in the tank through Teflon tubing into the sample jar. The depth of the liquid phase and sampling locations were determined from the Markland measurements. Teflon tubing was cut to length, premeasured, and marked with tape to indicate when the end of the tubing had been lowered below the access pipe flange to the appropriate level in the tank liquid. A stainless steel weight was attached to the lower end to keep the tubing vertical. The upper end of the tubing was plugged while the tubing was lowered to restrict entry of liquid until the desired depth was reached. After the sample was taken, the liquid remaining in the tubing was drained back into the tank, and the tubing was removed. New tubing was used at each sampling location to avoid cross contamination of the samples.

The air-liquid interface was checked for the possible presence of an organic layer floating on the aqueous supernatant. The bottom-opening soft sludge sampler (Fig. 3.1) was used to collect a column of liquid at the interface. The location of this interface was determined with the Markland detector during the presampling survey. Before sampling, the appropriate length was measured on the handle of the sampling device, and the handle was marked with tape to show how deep to lower the sampler into the tank. The sample was pulled and examined visually in the field for the possible presence of immiscible liquid layers. Samples from the air-liquid interface were drawn from the following tanks: W-21, W-23 through W-28, and W-31. Tanks W-29 and W-30 were not sampled because the "G3" nozzle in these tanks is being used to support supernatant solidification activities, and the equipment could not be readily removed for sampling. The interface was clear in all the samples with no immiscible phases. No organic layer was observed in any of these tanks. The interface sample was returned to the tank, and the sampler was then used to collect a soft sludge sample. 


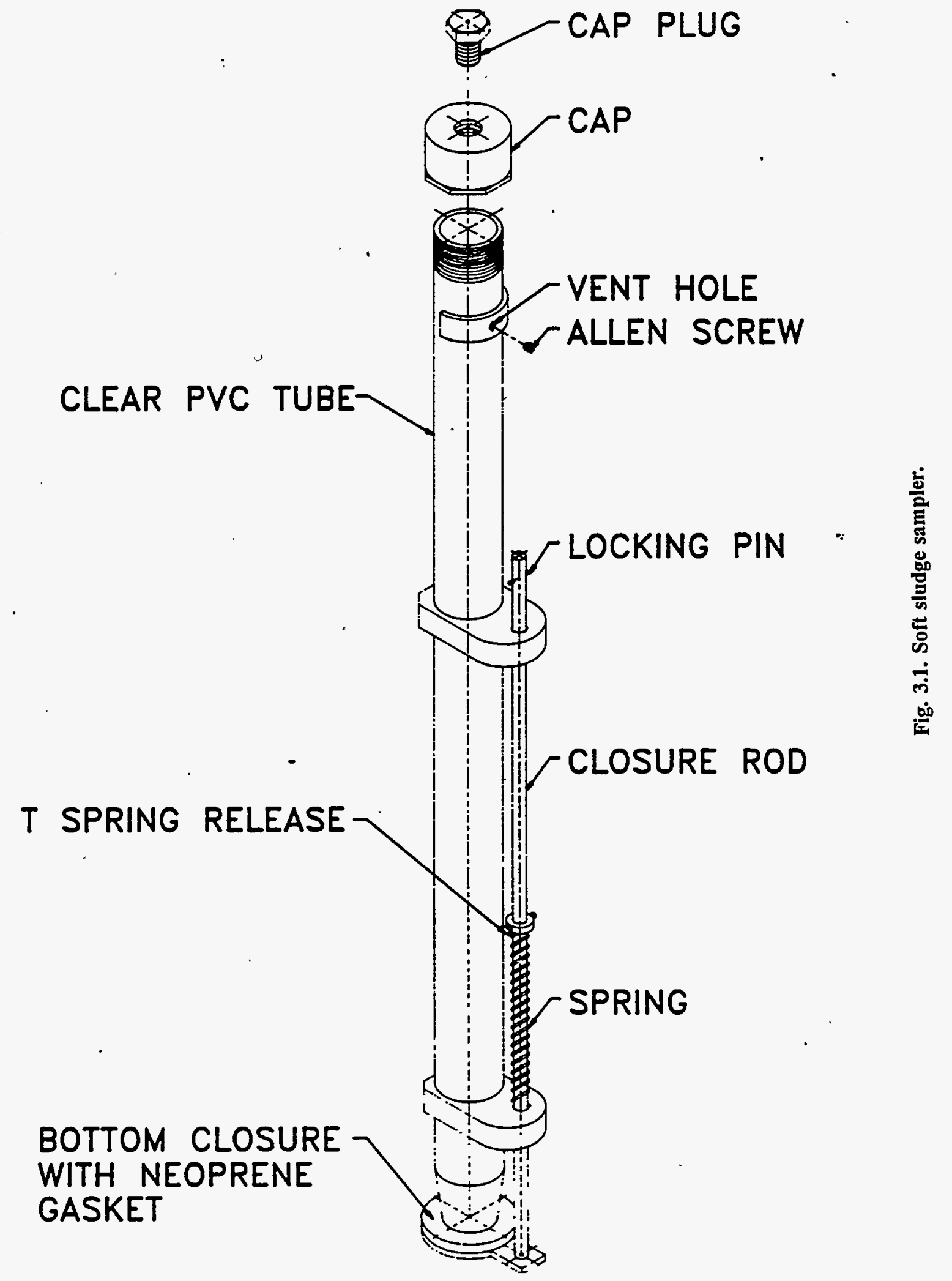


A bottom-opening, soft sludge sampler was used to collect a core of sludge up to 20-in. deep. The device consists of a detachable handle assembly and a hollow probe of clear polyvinylchloride (PVC) pipe with a bottom closure that can be controlled from above. The sludge was usually more than 20 -in. deep in the tanks. Samples were collected at successively lower layers to obtain a vertical profile. Because the sample collector is a clear material, visual measurements of sludge depth can be made and other properties observed. This examination was performed in a hot cell at the High Radiation Level Analytical Laboratory. If this sample could not be obtained with the soft-sludge sampler, a "hard" sludge sampler was used.

The earlier work by Peretz et al. ${ }^{7}$ indicated the presence of a hard crusty layer in Tank W-27 that might require cutting blades to take a sample. A commercial hard sludge sampler with an auger-type bit was used for this layer. This sampler consists of a stainless steel pipe (barrel) about 1.4-in. in diameter by 10-in.-long, sharpened blades at the bottom, a gate valve to hold the sample in place, a vented cap, and handle sections. A cross handle was used to apply a turning pressure to cut the sludge. Two tanks, W-27 and W-31, contained layers of "hard" sludge.

The locations (depths) for collecting the sludge samples were developed from the Markland data on the location of the liquid sludge interface and from the available information on the distance from the access point to the bottom of the tank. Specific depths were defined for collecting the upper samples. Before sampling, the appropriate lengths were measured on the handle and marked with tape to show when the sampler had been lowered to the specified depth in the tank. The bottom sample was collected by pushing the sampler to the bottom of the tank. The depth to the tank bottom was recorded on the log sheet. In sampling lower layers, the sampler was closed until the bottom tip of the sampler was approximately 1 in. above the lowest point previously sampled. The sampler was then opened, lowered to the specified depth, and the sludge sample collected.

Qualitative descriptions of the sampled material are listed in Appendix B.

\subsubsection{GAAT Reports (ORNL/ER/Sub/87-99053/74, 1995 and ORNL/ER/Sub/87-99053/79, 1996)}

The characterization of the heel of material left in the gunite tanks was a well organized, extensively managed effort ${ }^{11,12}$. The August-November 1994 sampling and analysis (Phase I) of 12 underground radioactive waste tanks is documented in ref. 12. The sampling plan for the 1995 characterization of the eight GAAT tanks is documented in ORNL Inactive Waste Tanks Sampling and Analysis Plan, ORNL/RAP/LTR-88/24, April 1988. The sampling plan was amended by "Addendum 1: ORNL Inactive Tanks Sampling and Analysis Plan" in August 1994 (Phase I) and again by "Addendum 1, Revision 2: ORNL Inactive Tanks Sampling and Analysis Plan," DOE/OR/02-1354/D2, February 1995 (Phase II). Field team instructions are found in ORNL Remedial Investigation/Feasibility Study Project Field Work Guides 01-WG-20, Field Work Guide for Sampling of Gunite and Associated Tanks and 01-WG-21, Field Work Guide for Tank Characterization System Operations at ORNL. The field efforts were conducted under the programmatic and procedural umbrella of the ORNL Remedial Investigation/Feasibility Study Program.

Tanks sampled during the Phase I campaign were W-1, W-2, W-3, and W-4 in the North Tank Farm (NTF); W-5, W-6, W-7, W-8, W-9, W-10, and W-11 in the South Tank Farm (STF); and TH-4. Both liquid and sludge (when present) samples were collected. Preliminary 
analysis results were reported in December 1994. The campaign was intended to provide data for criticality safety, engineering design, and waste management as they apply to the GAAT treatability study and remediation.

Phase I samples were collected through existing tank risers. By using a peristaltic pump, two liquid samples were taken from tanks containing $6 \mathrm{ft}$ or more of liquid-one at $1 / 4$ and one at $3 / 4$ of the total depth. Otherwise, tanks were sampled at the middle of the liquid depth. Initially, 250-mL samples were taken, but because low activity in the liquids resulted in high detection limits, the sample volume was changed to $500 \mathrm{~mL}$.

Phase I sludge samples were collected in a 1-in.-diam. tube lowered vertically into the sludge. Clear Lexan tubes were used for soft sludges so that any layering could be observed. Stainless steel tubes with a honed edge were driven by hand into the sludge bed in an attempt to collect any hardpan sludge on the tank floor. Before each sample was taken, the depth of the liquid and sludge was measured by using the top-of-riser elevation as a reference. The liquid level was measured by a standard water level meter designed for use in wells. The sludge was measured by a sludge probe based on a photoelectric eye. The water-level meter is very accurate, but the sludge probe is less so. On the basis of some trial-and-error and duplicate measurements, the sludge probe was discovered to be accurate to approximately \pm 1 in.

Eight tanks (W-3 and W-4 in NTF and W-5 through W-10 in STF) were sampled again (Phase II) from May through August 1995. Analyses of the samples began immediately upon receipt, and data validation and data base preparation were completed in December 1995.

Access to the tanks was again through existing risers. Two methods were used to collect information inside the tanks: pole samplers, as in Phase I, and a newly developed tank characterization system (TCS). TCS was developed because the tube sampler could only collect samples directly beneath existing tank risers. TCS is a floating system that uses the existing water in a tank as a platform and support for instruments and samplers. A floating boom is fed into the tank through the riser, and its position within the tank is controlled by rotation and insertion/withdrawal. An instrument or sampler is mounted at the end of the boom. TCS is an inexpensive system assembled from off-the-shelf components that allows access to all parts of a tank. The major components of TCS are the boom system (support structure and floating boom) video camera and lights, sludge grab sampler, wall chip sampler, and sonar depth finder. The boom system consists of a plastic chain with added flotation and a lazy-susan support structure that rests on top of the tank riser. Positioning of the TCS boom is recorded in polar coordinates: distance and angle. Mock-up testing showed positioning to be repeatable within a few inches.

The video camera was intended for above- and below-water inspections of tank contents; however, underwater inspections were not successful because of unexpected optical properties of the wastewater (the camera could not focus, although it worked well in a swimming pool and a mock-up tank).

The sludge grab sampler was used to retrieve samples from the tanks. The sampler is a clamshell device that is lowered from the TCS boom (by a motorized reel) to the bottom of the tank. The sampler is then closed by a hydraulic actuator and retrieved. Because it is lowered from a floating system, the clamshell must be lightweight. Though the hydraulic 
actuator is quite strong, the clamshell does not have enough weight to sink into denser sludges. This is likely to bias the samples somewhat toward lighter materials in the tanks.

The sonar depth finder consisted of a commercially available depth finder mounted on the floating boom. By varying the sensitivity of the system, the operator can discriminate between the 'sludge surface and the bottom of the tank. High sensitivity settings return the sludge surface position, and low sensitivity settings return the denser concrete bottom.

TCS was used to characterize tanks W-3, W-4, W-5, W-6, W-8, W-9, and W-10. Tank W-7 contained almost no standing water; therefore, sludge samples were collected in 1 -in.-diam tubes lowered vertically into the sludge directly beneath the risers. Clear plastic tubes were used for soft sludges so that any layering could be observed. Stainless steel tubes with honed edges were hand-driven into the sludge bed to collect hardpan sludge that may rest on the tank floor. Four samples were collected from Tank W-7: two in Lexan tubes and two in steel tubes.

Sludge mapping was used for more accurate calculation of the quantities of material present. The maps were created from data collected by TCS. Testing at the GAAT test tank at the New Hydrofracture Facility showed the measurements to be accurate to $+0.1 \mathrm{ft}$, which was confirmed by duplicate field measurements and by an optical sludge probe directly below the tank risers. Sludge maps were generated by using "Surfer for Windows" software. Questionable sonar measurement points (where the field team noted objects or strange sonar signal characteristics) were removed from the database before plotting. The readings are based on operator interpretation because density variations in both the sludge and the "bottom" can cause variation in the results, particularly if the bottom of a tank is covered with hard sludge or sand and gravel. Detailed maps are shown in Appendix B of ref. 12. Appendix B presents a summary of qualitative field observations.

\subsubsection{OHF Report and Recent MVST and BVEST Data}

Tank sampling methods used for the 1996 sampling $^{13}$ of the OHF tanks were identical to those used for the Sears study, as were tank sampling methods used for the 1996 sampling ${ }^{14,15}$ of BVEST and MVST. Qualitative descriptions of the samples are found in Appendix B.

\subsection{PREVIOUS REPORTS, ANALYTICAL METHODS, AND LIMITATIONS}

This section summarizes the analytical methodology and data limitations for radioactive waste tank samples collected from 1985 to present. The full scope of analytical data discussed in this summary was not taken as part of a comprehensive characterization of the LLLW system. The waste tank data collection represents many different projects with different needs, analytical requirements, and data quality objectives. In addition, the list of analytical measurements and the quality level varied between projects. The scope of this data review includes MVST, the BVEST, the OHF tanks in WAG.5, and the inactive GAAT located in NTF and STF. On the basis of major chemical characteristics, these waste tanks can be grouped into three categories. The characteristics of these four groups of radioactive waste are listed in Table 3.2 . 
Table 3.2. Categorization of waste by similar chemical properties

\begin{tabular}{|c|c|c|}
\hline Category & Tanks $^{a}$ & Chemical characteristics \\
\hline Group 1 & $\begin{array}{l}B V E S T+M V S T \\
\mathrm{~W}-21, \mathrm{~W}-22, \mathrm{~W}-23, \mathrm{~W}-24, \mathrm{~W}-25, \\
\mathrm{~W}-26, \mathrm{~W}-27, \mathrm{~W}-28, \text { and } \mathrm{W}-31\end{array}$ & $\begin{array}{l}\text { High Na or K nitrate content } \\
\text { Moderate levels of depleted uranium } \\
\text { Sludge both RCRA and TRU }\end{array}$ \\
\hline Group 2 & $\begin{array}{l}G A A T \\
W-3, W-4, W-5, W-6, W-7, W-8, W-9 \text {, } \\
\text { and W-10 }\end{array}$ & $\begin{array}{l}\text { Water washed } \\
\text { Low Na and } \mathrm{K} \text { nitrate content } \\
\text { Moderate levels of normal uranium } \\
\text { Sludge both RCRA and TRU. }\end{array}$ \\
\hline Group 3 & $\begin{array}{l}\text { OHF } \\
\mathrm{T}-1, \mathrm{~T}-2, \mathrm{~T}-3, \mathrm{~T}-4, \mathrm{~T}-9\end{array}$ & $\begin{array}{l}\text { Low } \mathrm{Na} \text { and } \mathrm{K} \text { nitrate content } \\
\text { Elevated nitrite and tributyl phosphate content } \\
\text { Moderate levels of enriched uranium } \\
\text { High thorium content } \\
\text { High radioactive Sr content } \\
\text { Sludge both RCRA and TRU }\end{array}$ \\
\hline
\end{tabular}

Tanks $\mathrm{C}-1$ and $\mathrm{C}-2$ are not on this list because there is no access for sampling. These tanks have never been sampled. Tanks W-29 and W-30 were not sampled because access to the sample ports are blocked with pipelines to the LWSP solidification equipment.

\subsubsection{Peretz Report (ORNL/TM-10218, 1986)}

The earliest data considered for this summary are those in the the Peretz ${ }^{7}$ et. al report, which discusses data collected in from 1985 to 1986 . The Peretz report is a good source for radiochemical and physical data for the MVST and BVEST systems, but the inorganic data have limited value because large sample dilutions were required before measurements on analytical instruments not designed for radioactive work. Inorganic data was not provided for sludge samples. Some elemental data were measured by spark source mass spectrometry (SSMS) provided for liquid samples from MVST and a few small waste collection tanks. Measurements by SSMS are semi-quantitative at best, with typical error ranges of $300-500 \%$. The only organic data provided were for the LLW Collection System (WC-10, WC-13, WC-14, 2026, 3019, REDC, Oak Ridge Reservation, and High Flux Isotope Reactor), which includes small tanks located at several ORNL facilities. The Peretz report is the only reliable source of radiochemical data for tanks W-29 and W-30 sludge inventory.

\subsubsection{Autrey Reports (ORNL/ER-13, 1990 and ORNL/ER-19, 1992)}

The Autrey ${ }^{8,9}$ et. al reports discuss the first systematic ORNL effort to determine the EPA hazard classifications for the radioactive supernatant liquids and sludge contained in the inactive waste tanks. The two reports on this project involved the inspection, sampling, and analysis of 30 out of 33 radioactive waste tanks located throughout the ORNL complex. The scope of this project included the GAAT and OHF tanks listed in Table 3.1 plus several miscellaneous inactive tanks. The primary goal of this project was to identify inorganic and organic waste classifications for each tank by RCRA regulations (40 CFR Pt. 261, Subparts C and D). Limited funding was available for the additional radiochemical, process metal, and physical measurements, which explains the short list of metals (uranium and silicon) outside the regulatory envelope and the cursory summary provided for the anion data. The radiochemical data consisted of gross alpha/beta measurements, gamma spectrometry for the 
major emitters, total radioactive strontium $\left({ }^{89} \mathrm{Sr}+{ }^{90} \mathrm{Sr}\right)$, and an inexpensive identification of alpha emitters by alpha spectrometry with no prior chemical separations or sample clean-up. Strontium- 89 is analyzed for but is not normally found because it has decayed. There was no funding for analyzing the uranium or plutonium isotopics by mass spectrometry to address criticality concerns.

The data collected for the Autrey report was one of the early attempts to apply the EPA SW-846 $6^{16}$ analytical methodology for inorganic and organic measurements to radioactive samples. The application of SW-846 to radioactive samples was a considerable learning experience for the laboratory, and the techniques and data quality have improved significantly since these data were collected. Some of the problems with the application of regulatory methods to radioactive samples included addressing as low as reasonably achievable (ALARA) concerns (both dose and contamination control), meeting holding times with the additional sample handling requirements, and the chemical complexity of the samples, which resulted in interference problems not addressed by the regulatory methods. Also, expectations for quality control acceptance criteria for matrix spike recoveries and duplicate reproducibility were unrealistic. The performance of these quality control measurements were degraded because of the complex chemical matrix effects and the sample handling constraints required because of the radioactivity.

The metal data for the Autrey report was significantly better than previous projects because new analytical instrumentation designed for containment of radioactivity was installed in the laboratory for this project. The new instrumentation included an inductively coupled plasma-atomic emission spectrometer (ICP-AES) and a graphite furnace atomic absorption (GFAA) system with a mercury cold vapor attachment. Both of these instruments were configured in radiochemical hoods with filtered ventilation for contamination control and personnel safety. The anion data for this project have limited value because an ion chromatograph for radioactive samples was not available and large dilutions were required before analysis of the samples in a conventional laboratory not designed to handle radioactive materials. The analytical error for these inorganic measurements are within the range of current performance standards of approximately $\pm 10 \%$, but the data user should be aware that the ICP-AES measurement errors increase significantly for the Autrey data if high concentrations of iron or uranium were present.

No analytical instruments were in place for organic analysis on radioactive samples during the time period of the Autrey project, but the lack of this equipment had little impact on the data quality for some of the organic measurements. The sample preparation methods for the volatile organic analysis (VOA) and the semivolatile organic analysis (SVOA) involves extraction into organic solvents. The extractions separate most of the radioactivity from the organic compounds of interest allowing measurements by gas chromatography/mass spectrometry (GC/MS), performed in a "cold" laboratory. The luxury of removing the radioactivity was not available for the category of water soluble organic compounds measured by nonhalogenated volatile organic analysis (NHVOA) methods such as direct aqueous injection gas chromatography (DAIGC). DAIGC measurements for this project required large dilutions to reduce the radioactivity before measurements. PCB measurements were not performed for the Autrey project.

The quality of the radiochemical data for the Autrey reports was sufficient for waste classification, but the data user needs to realize that the activities reported for the actinide elements are based on gross screening measurements by alpha spectrometry with no sample 
preparation to improve the alpha spectra. There was insufficient funding for radiochemical separations to reduce the dissolved solids and spectral interferences for alpha spectrometry. Radiochemical separations were performed for the tritium, ${ }^{14} \mathrm{C}$, and total radioactive strontium measurements because there were no less-expensive alternatives. The gross alpha activities reported for the Autrey project may be biased low if the sample matrix had high dissolved solids present. The radionuclides measured by gamma spectrometry-which mostly consists of the $\mathrm{Cs}, \mathrm{Co}$, and $\mathrm{Eu}$ isotopes-meet current quality standards with a typical error range of $\pm 10 \%$.

Based on recent data, two obvious typographical errors occurred in the data tables from the first Autrey report. The first error is in Table 4.4 of ref. 8, for sample T3/S4 involving the sludge density, which was reported as $1.930 \mathrm{~g} / \mathrm{mL}$ but should have been $1.390 \mathrm{~g} / \mathrm{mL}$. The second error also involved transposing results between two data fields and effects the activities reported for ${ }^{252} \mathrm{Cf}$ and ${ }^{244} \mathrm{Cm}$ for sample T2/S40 in Table 4.6 of ref. 8. Based on recent data and the pattern observed for the other OHF sludge samples reported in ref. 8, the ${ }^{252} \mathrm{Cf}$ activity is $<200 \mathrm{~Bq} / \mathrm{g}$ and the ${ }^{244} \mathrm{Cm}$ activity is $1.8 \mathrm{e}+05 \mathrm{~Bq} / \mathrm{g}$. Based on data collected since 1985 , there has never been any ${ }^{252} \mathrm{Cf}$ activity identified in the LLLW processing systems including GAAT, OHF tanks, MVST, and BVEST.

\subsubsection{Sears Report (ORNL/TM-11652, 1990)}

The purpose of the Sears ${ }^{10}$ study was to determine the characteristics of the supernatant and sludge contained in the active LLLW system, which includes both the MVST and BVEST systems as listed in Table 3.1. The objective of the Sears study was to provide waste characterization data to satisfy the following needs:

- determination of TRU classification,

- determination of RCRA classification,

- $\quad$ support the LWSP, and

- support research and development activities for waste management alternatives.

Samples of the supernatant liquid and sludge were collected from MVST and two of the BVEST (W-21 and W-23). These samples were analyzed for major chemical constituents, radionuclides, RCRA metals, total organic carbon, and physical properties. The project also included a scoping survey for VOA and SVOA constituents in liquid and sludge from tanks W-24, W-25, and W-31. To support the liquid waste solidification project, the liquid from two of MVST (W-29 and W-30) were also characterized for the organic compounds.

The quality of the analytical data for the metal and organic measurements on the MVST and BVEST samples is comparable to the data set for the Autrey report, and the discussions on the analytical error also apply to the Sears data set. Overall data quality improved some because the laboratory staff gained experience by working on the Autrey project. A significant difference observed with the MVST and BVEST samples was a much higher sodium and potassium nitrate content in both the supernatant liquid and sludge. This high nitrate salt content did cause measurement problems with the GFAA and ICP-AES methods. The alkali-nitrate matrix was very corrosive to the graphite furnaces used for GFAA measurements and very few samples $(<10)$ could be processed without replacing the furnace tube. The supernatant liquids had a high dissolved solids content and required a large dilution before measurement by ICP-AES to avoid problems with the sample introduction system into the 
plasma. The list of metals determined was extended to include nine more common metals of interest to the developmental staff working on waste management options.

The level of chloride present in the MVST and BVEST liquid and sludge samples were sufficient to cause the loss of silver as insoluble silver chloride, which resulted in low spike recoveries for silver. No attempt was made to improve the silver spike recoveries because most of the samples exceeded the regulatory limits for several other RCRA metals. Also, the method for improving silver recovery uses high levels of chloride, which is very corrosive to stainless steel. Stainless steel is used extensively in radiochemical laboratories for laboratory bench tops, hoods, and glove boxes.

The soluble silicon listed for the liquid samples in the Sears report have limited value because the samples were acidified before measurement, which results in the loss of insoluble forms of silicon. Total silicon in the sludge was not measured for this project. The quality of the remaining metal data in the Sears report is sufficient to meet most waste management decisions.

The measurement of inorganic anions in the supernatant liquid samples required large dilutions to handle the high nitrate levels, and only the chloride and nitrate results are acceptable. Anion data were not provided for the sludge samples in the Sears report.

The quality of the radiochemical data in the Sears report is sufficient for most waste classification requirements with the exception of the ${ }^{235} \mathrm{U}$ activities reported for the sludge samples. Waste management requested that the ${ }^{235} \mathrm{U}$ activity be reported after the project was completed and the report was in preparation. Funding was not available to re-analyze the samples for ${ }^{235} \mathrm{U}$, and the laboratory was requested to provide estimates based on existing gamma spectrometry data. Because of the sample dilutions used to optimize the counting for the major gamma emitters, the detection limits for ${ }^{235} \mathrm{U}$ were so high that the calculated activity limit gave a result that was physically impossible. The ${ }^{235} \mathrm{U}$ data was listed in the report as less than values with unit of activity, and it was not apparent, unless the activities were converted to mass, that the results were implying a ${ }^{235} \mathrm{U}$ mass that exceeded $100 \%$ of the sample weight. Therefore, the ${ }^{235} \mathrm{U}$ data in the Sears report should not be used.

There may be a low bias for the gross beta data because of the loss of radioactive cesium as a volatile chloride salt when the counting plates were prepared for counting on a gas-flow proportional counter. Current studies indicate that some of the cesium chloride is lost at temperatures in excess of $400^{\circ} \mathrm{C}$, which is typical when preparing counting plates. For the last several years, the Radioactive Materials Analytical Laboratory (RMAL) has used liquid scintillation counting for all gross beta measurements to avoid this problem. The cesium activities determined by gamma spectrometry are not effected by this temperature problem because the sample preparation does not use high temperatures.

The alpha activity data show some improvement for the Sears report when compared with earlier data because the high dissolved solids content was reduced with a ferric hydroxide precipitation to separate the actinides from the high sodium/potassium nitrate. This technique is discussed in the Sears report along with some performance data for the technique. In general, most of the radiochemical measurements have an analytical error in the range of $\pm 10 \%$.

The quality of the organic data for the Sears report is similar to previous organic data provided for waste tanks, and the discussions for the Autrey organic data applies to the Sears 
data. The VOA and SVOA compounds were extracted into organic solvents, and the extractions with low levels of radioactivity were transported to conventional laboratories for GC/MS measurements. The water soluble organics were determined by DAIGC after a large dilution to reduce the radioactivity. PCB measurements were not performed for the Sears project.

\subsubsection{GAAT Data (ORNL/ER/Sub/87-99053/74, 1995 and ORNL/ER/Sub/87-99053/79, 1996)}

Twelve GAAT underground radioactive waste tanks were sampled and characterized from August to November 1994. Both liquid and sludge (when present) were collected from tanks W-01, W-02, W-03, and W-04 in NTF; tanks W-05, W-06, W-07, W-08, W-09, W-10, and W-11 in STF; and tank TH-4, located east of STF. A summary ${ }^{11}$ of the Phase I GAAT data was published in June 1995. Then 8 of the 12 GAAT tanks (W-03 through W-10) were resampled for sludge in different locations during the summer of 1995 to determine the degree of heterogeneity for the selected waste tanks. A summary ${ }^{12}$ of the Phase II GAAT data was published in February 1996. An evaluation ${ }^{17}$ of the Phase I and II data was published in March 1996. The Phase I and II GAAT projects generated the most extensive collection of analytical data for ORNL waste tanks available at the time the project was completed. The quality assurance level for this data set is sufficient to meet current waste acceptance criteria (WAC) and regulatory requirements for most waste storage sites. The transuranic sludge from the Phase II samples (tanks W-06 through W-10) was characterized under a DOE/CAO approved quality assurance project plan for Waste Isolation Pilot Plant (WIPP) characterization, which should classify the data as acceptable knowledge for the WIPP WAC. The sludge collected in Phase II provides the only set of ORNL tank data available to evaluate the horizontal distribution of chemical and radiochemical species throughout the tanks.

Most of the analytical methodology for the GAAT projects employed the current RMAL analytical protocols for characterization of liquid and sludge from ORNL waste tanks. All samples were digested with microwave techniques before analysis. The liquids were either filtered to remove suspended particles through Whatman 20 micron ashless filter paper or clarified by centrifugation. Forty milliliters of the clarified sample was then transferred to a Teflon $^{\mathrm{TM}}$ microwave vessel, and $5 \mathrm{~mL}$ of concentrated nitric acid (15.8M) was added for the digestion. The digestion followed the SW-846 Method 3015, Microwave Assisted Digestion of Aqueous Samples and Extracts. Sludge samples were prepared by weighing about $0.5 \mathrm{~g}$ (wet weight) of sample into a Teflon microwave vessel and by adding $10 \mathrm{~mL}$ of concentrated nitric acid. After digestion any remaining residue (mostly insoluble silicates) was removed by centrifugation. The sludge digestion followed SW-846 Method 3051, Microwave Assisted Digestion of Sediments, Sludges, Soils, and Oils. The digested samples were then distributed for metal and radiochemical analysis. Studies have been performed to verify that these digestion techniques are sufficient to give the total content for all analytes except silver and silicon. The silicon content was not requested for this project; silver data is discussed in this section.

A total of 26 metals were determined by either ICP-AES or GFAA, including 9 RCRA metals and 17 metals of interest for process development, waste treatment options, and criticality safety. Mercury was determined by cold vapor atomic absorption; arsenic, lead, selenium, and thallium were determined by GFAA; all remaining metals were determined by ICP-AES. 
All of the metals measurements followed protocols established in SW-846 methods, which included the following protocols:

- Method 6010A: Inductively Coupled Plasma - Atomic Emission Spectroscopy;

- $\quad$ Method 6020: Inductively Coupled Plasma-Mass Spectrometry;

- Method 7000A: Atomic Absorption Methods,

7060A: Arsenic (AA, Furnace Technique),

7421: Lead (AA, Furnace Technique),

7740: Selenium (AA, Furnace Technique), and

7841: Thallium (AA, Furnace Technique);

- Method 7470A: Mercury in Liquid Waste (Manual Cold Vapor Method); and

- Method 7471A: Mercury in Solid or Semisolid Waste (Manual Cold Vapor Method).

The sample preparation method listed in Method 7471A was replaced with Method 3051 to improve contamination control and improve the recovery of mercury from sludge samples. A collaborative study ${ }^{18}$ involving ORNL, RMAL, and Argonne National Laboratory was perfomed to demonstrate equivalency with the SW-846 method. EPA requested that the results of this study be included in the next update of SW-846.

Sludge samples that contained high levels of uranium $(>1000 \mathrm{mg} / \mathrm{L})$ resulted in excessive spectral interferences in the measurement of several metals (aluminum, antimony, beryllium, copper, magnesium, silver, and vanadium). The uranium was removed by techniques ${ }^{19}$ developed by RMAL using extraction chromatography, specifically the use of a commercially available EIChrom TRU-Spec ${ }^{\mathrm{TM}}$ resin developed by Argonne National Laboratory. The sludge digest was passed through a TRU-Spec column followed by a $4 M$ nitric acid wash. All actinides, including the uranium, were removed from the sample solution. The acid solution from the initial loading plus the acid wash was combined, diluted to a known volume, and analyzed by ICP-AES.

The silver data for the GAAT project has limited value as a result of poor spike recoveries, which resulted from the precipitation of silver chloride. No attempt was made to improve the silver recovery for the reasons discussed previously. The soluble silicon in the supernatant liquid samples and the total silicon in the sludge samples were not determined for the GAAT project. All metal, anion, and radiochemical data for the sludge samples were * reported on a wet weight basis. The water content for each sludge sample was reported so the data can be converted to a dry weight result if needed.

The uranium and plutonium isotopics were determined after radiochemical separation by thermal ionization mass spectrometry,(TIMS). The uranium and plutonium isotopic ratios, along with the total uranium and thorium by ICP-AES, are needed for the evaluation of criticality safety. For liquid samples with a high $\mathrm{pH}$, only the uranium isotopic ratios were measured by TIMS; the plutonium concentration in basic samples were too low for TIMS measurements and a conservative lower boundary for the isotopic dilution of the fissile plutonium was estimated from the radiochemical data. The isotopic ratios for both the uranium and plutonium in the sludge samples were measured by TIMS. The mass spectrometry data for uranium and plutonium was used to calculate the activity for all the uranium and plutonium isotopes observed. For long lived radionuclides, the mass spectrometry measurements are more accurate and sensitive than conventional counting techniques. 
The inorganic anions in the supernatant liquid samples were measured directly by ion chromatography (IC) after a dilution with water. The sludge samples were prepared by weighing $1 \mathrm{~g}$ of wet sludge into $10 \mathrm{~mL}$ of water which was agitated for $10 \mathrm{~min}$. The slurry was centrifuged, and the supernatant was analyzed for water soluble anions. The IC measurements followed SW-846 Method 9056, Determination of Inorganic Anions by Ion Chromatography. The insoluble anions in the sludge were not determined for the GAAT projects. Mthods used on more recent samples can be used to determine the total halides, total phosphorous, and total sulfur to estimate the corresponding insoluble anions present in the sludge samples. The insoluble carbonate (mostly calcium carbonate) can be estimated from the total inorganic carbon measured after combustion in a carbon analyzer.

The major metal content, along with the anion data, can be used as a quality check by calculating the mass and charge balance for each sample. All of the liquid and sludge samples analyzed for the GAAT projects yielded good agreement for both mass and charge balance. The mass and charge balance results are excellent considering the assumptions required about the chemical form and oxidation states present in the samples.

The sludge in the GAAT tanks had been extensively washed with water during sluicing operations before sampling. This water wash removed most of the water soluble salts (mostly sodium/potassium nitrate), which significantly lowered the dissolved solids content in the liquid samples and decreased the salt content of the sludge samples. Because of the lower salt content in the samples, special sample preparation for alpha measurements was not necessary. The gross alpha measurements were taken by gas-flow proportional counting with the voltage plateau lowered below the level where beta particles would be counted to ensure minimum interference. The gross beta measurements were performed by liquid scintillation counting to avoid the loss of radioactive cesium observed when high temperatures are used preparing counting plates. The analytical errors for the alpha activity measurements were in the range of $\pm 8-10 \%$. The gross beta activity reported is actually a total activity that included the summation of counts from the beta particles, alpha particles, and the conversion electrons. For most samples, the beta counts dominate the total activity. The analytical errors for the total activity measurements were in the range of $\pm 8-10 \%$.

The gamma emitters were determined by gamma spectrometry with a n-type high-purity germanium detector that had a nominal efficiency of $25 \%$ relative to the standard sodium iodide detector. All positively identified gamma-emitting radionuclides were reported along with less than values for ${ }^{60} \mathrm{Co},{ }^{152} \mathrm{Eu},{ }^{154} \mathrm{Eu}$, and ${ }^{155} \mathrm{Eu}$, which are routinely observed in ORNL waste. The analytical error for the gamma emitting radionuclides was in the range of $\pm 10-12 \%$.

Determination of total radioactive strontium $\left({ }^{89} \mathrm{Sr}+{ }^{90} \mathrm{Sr}\right)$ requires a chemical separation to remove the ${ }^{90} \mathrm{Y}$ in secular equilibrium with the ${ }^{90} \mathrm{Sr}$. Because of the absence of other short-lived radionuclides in the waste, no attempt was made to determine the ${ }^{89} \mathrm{Sr}$ $\left(\mathrm{t}_{1 / 2}=50.5\right.$ days), and the total radioactive strontium was reported as ${ }^{90} \mathrm{Sr}$ activity in the GAAT data reports. The analytical error for the total radioactive strontium was in the range of $\pm 10-15 \%$.

For ORNL waste, Plutonium alpha activity is the primary driver for determination of the TRU waste classification based on the $100 \mathrm{nCi} / \mathrm{g}(3700 \mathrm{~Bq} / \mathrm{g})$ requirement. To ensure an accurate measurement of plutonium, the plutonium was chemically separated from all other radioactivity before measurement. After the plutonium separation, the relative isotopic 
distribution was determined by both alpha spectrometry and TIMS. The measurement by alpha spectrometry only provides acceptable data for the ${ }^{238} \mathrm{Pu}$ and the sum of the ${ }^{239} \mathrm{Pu}$ and ${ }^{240} \mathrm{Pu}$. The ${ }^{239} \mathrm{Pu}$ and ${ }^{240} \mathrm{Pu}$ peaks cannot be resolved because of a similar alpha energy $(5.50 \mathrm{MeV})$. The TIMS measurements give an accurate result for all the plutonium isotopes, including ${ }^{241} \mathrm{Pu}$, which is a pure beta emitter. The activity for each plutonium isotope can be calculated from the relative atom percent for each isotope and the total plutonium alpha activity. The analytical error for the plutonium activities were in the range of $\pm 5-8 \%$. The ${ }^{241} \mathrm{Am}$ activity can be estimated by subtracting the ${ }^{238} \mathrm{Pu}$ activity, measured after the plutonium separation, from the $5.15 \mathrm{MeV}$ alpha peak $\left({ }^{238} \mathrm{Pu}+{ }^{241} \mathrm{Am}\right)$ measured by alpha spectrometry on the gross alpha counting plate. The ${ }^{241} \mathrm{Am}$ has a $59 \mathrm{KeV}$ gamma ray, but the high background below $100 \mathrm{KeV}$ with a n-type germanium detector introduces a large error for the ${ }^{241} \mathrm{Am}$ gamma peak area. Also, none of commercially available gamma peak processing software tested to date performs well measuring the peak area for high count rate samples in the energy region of $59 \mathrm{KeV}$.

The sludge samples were analyzed for PCBs during Phase I of the project. The samples were prepared by SW-846 Method 3550A, Ultrasonic Extraction, and Method 3665, Sulfuric Acid/Permanganate Cleanup. The samples were then measured by SW-846 Method 8081, Organochlorine Pesticides and PCBs as Aroclors by Gas Chromatography: Capillary Column Technique. Only Tank W-10 exceeded the internal Lockheed Martin Energy Systems, Inc., limit of $2 \mathrm{ppm}$ with a total PCB content of $3.4 \mathrm{ppm}$ (Aroclor $1254+1260$ ). None of the liquid-phase samples were analyzed for PCBs because of the low solubility of PCBs in water.

In Phase II, sludge samples were taken from two different locations in each tank sampled. The sludge sample from tanks W-06 through W-10, which are all transuranic waste, were characterized for VOA, NHVOA, and SVOA by protocols established in SW-846 methods, which included the following protocols:

- Method 8260A: Volatile Organic Compounds by Gas Chromatography/Mass . Spectrometry (GC/MS): Capillary Column Technique.

- Method 8270B: Semivolatile Organic Compounds by Gas Chromatography/Mass Spectrometry (GC/MS): Capillary Column Technique. Sample preparation by Method 3550A: Ultrasonic Extraction.

- Method 8015A: Nonhalogenated Volatile Organics by Gas Chromatography.

The organic measurements were done on two samples collected from different locations in each of the tanks except Tank W-7. Tank W-7 had the organic measurements done on three locations along a vertical core of the sludge.

The organic analytical methods used for the GAAT sludge samples were the same as those used for the DOE/CAO Transuranic Waste Characterization Program (TWCP) and, as stated before, were based on SW-846 methods adapted for radioactive samples. These methods were qualified by the method performance demonstration requirements of the TWCP Quality Assurance Program Plan, Revision B. Blanks, matrix spikes, and matrix spike duplicates were prepared and run with the samples. The VOA and SVOA measurements included surrogate standards. 


\subsubsection{OHF Data (1996)}

The OHF tanks consist of five tanks located in WAG 5 and include T1 through T4 and T9. OHF supernatant liquid samples were collected in January 1996; sludge samples were collected in February-March 1996. The OHF data are summarized in a letter report ${ }^{13}$. The gamma radiation dose rate from the OHF sludge samples were comparable to the MVST or BVEST sludge samples. However, the beta radiation dose from the OHF sludge was an order of magnitude worse than any other ORNL sludge samples processed by the RMAL staff. This additional beta dose was caused by the higher levels of ${ }^{90} \mathrm{Sr}$ present in the OHF sludge. High levels of RCRA metals $(\mathrm{Cr}, \mathrm{Hg}$, and $\mathrm{Pb}$ ) were observed in all the $\mathrm{OHF}$ sludge samples, and all the sludge samples were determined to be transuranic based on plutonium content. Elevated levels of ${ }^{233} \mathrm{U}$ was observed in the OHF sludge samples, and the sum of the ${ }^{233} U$ and ${ }^{235} \mathrm{U}$ exceeded the administrative criticality control limits for waste. This will complicate any transfer of this material to other waste tanks until this concern is addressed. A significant difference occurred in the uranium isotopic ratios for the OHF supernatant liquid samples and the OHF tank sludge samples. This difference may indicate that the OHF sludge samples do not represent the overall sludge content for each tank or could indicate that the liquid is not in equilibrium with all of the sludge.

Most of the discussions concerning the GAAT data also apply to the OHF tank data with the exception of the silver and silicon results. The sample preparation for both the liquid and sludge samples were taken through a nitric-hydrochloric acid digestion to ensure acceptable spike recovery for the silver. The liquid samples were diluted with water and maintained basic for measurement of the soluble silicon. The sludge samples were digested in the nitric-hydrofluoric acid to ensure acceptable measurement of the total silicon present. The quality assurance level for the OHF data set was similar to the GAAT project and is sufficient to meet the waste acceptance criteria and regulatory requirements for most waste storage and disposal sites. All five of the sludge samples from the OHF tanks were characterized under a DOE/CAO approved quality assurance project plann for WIPP characterization, which classifies the data as acceptable knowledge for the WIPP WAC.

\subsubsection{Recent Data for MVST and BVEST (ORNL/TM-13234, 1996 and ORNL/TM-13248, 1996)}

Analytical data for samples collected from several of the active waste tanks from November 1993 through February 1996 are summarized in two ORNL reports. The supernatant liquids from MVST tanks and sludge from W-21, W-23, and W-25 were characterized by RMAL, and the results are presented and discussed in a recent ORNL report $^{14}$. The supernatant and sludge from BVEST Tank W-22 was sampled in the fall of 1994 and characterized by RMAL; the data are documented in a recent Sears ${ }^{15}$ report. The samples analyzed and reported in these reports were not taken as part of a planned comprehensive characterization of the LLLW system. The samples were collected at different times with different analytical requirements. Therefore, the set of measured parameters may vary some from tank to tank. The level of quality assurance approximates that required for regulatory measurements with the understanding that sample size requirements are reduced and modifications to reduce sample handling are required for radiation dose considerations (ALARA). Also, some procedure modifications are required to handle matrix interference problems. Deviations from procedures or other sample problems are documented in the data files located in RMAL. The regulatory holding time requirements for mercury and organic analyses complied with the SW-846 requirements. 
Previous analytical work on the MVST and BVEST liquid and sludge samples did not specifically address criticality concerns. There was limited radiochemical data on ${ }^{233} \mathrm{U},{ }^{235} \mathrm{U}$ and ${ }^{239} \mathrm{Pu}$; the data reported was taken from gross screening measurements. The past data for fissile actinides in these waste tanks had relatively large analytical errors and should be used with caution. The new analytical data for fissile isotopes in this report are based on more precise and accurate techniques. The uranium and plutonium were each chemically separated from the waste matrix and isotopic ratios were determined by thermal ionization mass spectrometry. The mass spectrometry data gives detailed and accurate information on the major fissile isotopes present. However, these isotopic ratio measurements for the sludge do not represent the average isotopic ratios for all the sludge present in each tank. The isotopic data for each liquid sample should be more representative of the overall supernatant present than comparable measurements for the sludge. On the basis of physical observations, the tank sludge tends to be segregated into vertical layers, which indicates minimal mixing of the sludge material as it was added to the tank. Because of limited access to the tanks, no analytical data are available to evaluate segregation horizontally across the tank.

This recent data for MVST and BVEST samples provides the first accurate data for uranium and plutonium isotopic ratios in the active LLLW system and was needed to address criticality safety questions for the these waste tanks. All the uranium isotopic ratios determined for MVST and BVEST samples indicate the fissile isotopes of uranium ${ }^{233} \mathrm{U}$ and ${ }^{235} \mathrm{U}$ ) have been highly diluted with ${ }^{238} \mathrm{U}$. Some of the first radiochemical data for ${ }^{29} \mathrm{Tc}^{237} \mathrm{~Np}$, and ${ }^{241} \mathrm{Pu}$ activities in the active LLLW system are provided in these recent data summaries. Although, we are confident that greater than $99 \%$ of the radioactivity has been accounted for in these waste samples, there remains some interest in the measurement of radionuclides for nickel $\left({ }^{59} \mathrm{Ni}\right.$ and $\left.{ }^{63} \mathrm{Ni}\right)$ and samarium $\left({ }^{51} \mathrm{Sm}\right)$. These additional radionuclides need to be considered for future waste characterization projects.

The quality assurance level for the MVST and BVEST samples was similar to the OHF project and is sufficient to meet the waste acceptance criteria and regulatory requirements for most waste storage and disposal sites. The transuranic sludge from the W-21, W-22, W-23 BVEST tanks was characterized under a DOE/CAO approved quality assurance project plan for WIPP characterization, which classifies the data as acceptable knowledge for the WIPP WAC.

\subsubsection{Summary of Data Limitations and Data Qualifications}

Table 3.3 summarizes some of the data limitations and other qualifications associated with the data available for the waste tanks listed. The most critical data limitation associated the characterization of underground storage tanks is the limited access to the tank contents, which restricts the options available for statistical sampling. Both vertical segregation in the sludge (layering) and concentration gradients have been observed in the liquid phase. For the MVST, BVEST, and OHF tanks the sludge has only been sampled in a single location. Many of the GAAT tanks had sludge samples taken at three different locations, and large differences in concentration were observed for most species measured. 
Table 3.3 Summary of data limitations and additional needs

\begin{tabular}{|c|c|c|}
\hline Category & Tanks $^{a}$ & Data limitations/qualifications \\
\hline Group 1 & $\begin{array}{l}\text { BVEST }+ \text { MVST } \\
\mathrm{W}-21, \mathrm{~W}-22, \mathrm{~W}-23, \mathrm{~W}-24, \mathrm{~W}-25 \\
\mathrm{~W}-26, \mathrm{~W}-27, \mathrm{~W}-28, \text { and } \mathrm{W}-31\end{array}$ & $\begin{array}{l}\text { Nonstatistical sampling } \\
\text { Semiquantitative alpha data } \\
\text { Heterogenous waste } \\
\text { Incomplete U isotopics } \\
\text { Incomplete Pu isotopics } \\
\text { No data for tanks C1 and C2 } \\
\text { Lack for data for W-29 sludge } \\
\text { Lack of data for W-30 sludge } \\
\text { Limited PCB data } \\
\text { Sludge both RCRA and TRU } \\
\text { No water soluble chelator data }\end{array}$ \\
\hline Group 2 & $\begin{array}{l}\text { GAAT } \\
\mathrm{W}-1, \mathrm{~W}-2, \mathrm{~W}-3, \mathrm{~W}-4, \mathrm{~W}-5, \mathrm{~W}-6, \\
\mathrm{~W}-7, \mathrm{~W}-8, \mathrm{~W}-9, \text { and } \mathrm{W}-10\end{array}$ & $\begin{array}{l}\text { Multiple samples/locations } \\
\text { Criticality concerns addressed } \\
\text { Heterogenous waste } \\
\text { No water soluble chelator data }\end{array}$ \\
\hline Group 3 & $\begin{array}{l}\text { OHF } \\
\mathrm{T}-1, \mathrm{~T}-2, \mathrm{~T}-3, \mathrm{~T}-4, \mathrm{~T}-9\end{array}$ & $\begin{array}{l}\text { Non-statistical sampling } \\
\text { One set of } U \text { and } \mathrm{Pu} \text { isotopics } \\
\text { Elevated }{ }^{233} \mathrm{U} \text { content } \\
\text { Criticality concerns not } \\
\text { addressed } \\
\text { Heterogenous waste } \\
\text { Sludge both RCRA and TRU } \\
\text { No water soluble chelator data }\end{array}$ \\
\hline
\end{tabular}

Tanks C-1 and C-2 are not on this list because there is no access for sampling.
These tanks have never been sampled. Tanks W-29 and W-30 were not sampled
because access to the sample ports are blocked with pipelines to the LWSP
equipment. Depleted uranium is to be added to the wastes in the OHF tanks to achieve
compliance with administrative guidelines.

\subsection{DATA USED FOR THE EVALUATION}

For reasons discussed previously, the data used for the evaluation required close screening so that the statistical analysis used the best possible data available. Some sludge measurements taken several years ago were excluded from the analysis for various reasons described in Table 3.4. The supernate data were not included because the supernate content is expected to be different by the time the private sector vendor begins processing the sludge. The raw data used in this statistical analysis are reproduced in Appendix B. Measurements were standardized from the various reports so that their units were consistent throught this report. Table 3.4 lists the various referenced reports that contained the original data and the data from those reports that were restricted from this analysis. 
Table 3.4 Sludge data obtained from referenced reports that was restricted from statistical analysis

\begin{tabular}{ll}
\hline \multicolumn{1}{c}{ Report } & \multicolumn{1}{c}{ Data changes } \\
\hline Peretz et. al & $\begin{array}{l}\text { A. Cation/anion data not used } \\
\text { (ORNL/TM-10218) 1986 the Peretz report } \\
\end{array}$ \\
& $\begin{array}{l}\text { B. Samples labeled as "sludge" } \\
\text { samples in Peretz report not used } \\
\text { (only used samples labeled as }\end{array}$ \\
For more details see "solid") \\
Sect. 3.1.1 of this report
\end{tabular}

Autrey et. al

(ORNL/ER-13) 1990

Sears et. al

(ORNL/TM-11652) 1990

Bechtel

(ORNL/ER/Sub/87-

99053/74) 1995

Bechtel

(ORNL/ER/Sub/87 -

99053/79) 1996.
A. Density of 1.93 for Tank T-3 sludge in Autrey report was changed to 1.39

B. ${ }^{252} \mathrm{Cf}$ and $\mathrm{d}^{244} \mathrm{Cm}$ values for sludge sample from Tank T-2 were reversed in Autrey report C. ${ }^{228} \mathrm{Th},{ }^{232} \mathrm{Th}$, and ${ }^{233} \mathrm{U}$ analyses given in the Autrey report were removed from this data set

D. Anion analyses for sludges in the Autrey report were not used

A. ${ }^{235} U$ analyses reported given in the Sears report were removed from this data set

B. Used Transuranium Analytical Laboratory data over Inorganic and Physical Analysis Group data where duplicate analyses were given

No changes to data set

No changes to data set.
A. Analyses not deemed reliable

B. In the Peretz report, the "sludge" samples were taken as liquid samples in the sludge region of the tanks. All other sampling of sludges in the tanks (other analyses and reports) has been a core sample of the sludge itșelf, and was referred to as a "solid" sample in the Peretz report

A. The value given in the report is believed to be wrong. This change is consistent with more recent sampling of this tank

B. Values for ${ }^{252} \mathrm{Cf}$ and ${ }^{244} \mathrm{Cm}$ appeared to be reversed in the Autrey document. These values were switched and are thus consistent with more recent sampling of this tank and other OHF tank samples

C. These analyses were removed from this data set because they were deemed unreliable. The gamma spectra were misinterpreted D. The measurement of the anions is thought to be to be inaccurate due to excessive dilution of samples

A. The ${ }^{233} \mathrm{U}$ values were calculated, not measured, and the calculated values were determined to be inaccurate

B. Per advice of J. M. Keller. Transuranium Analytical Laboratory data deemed more reliable 
Table 3.4 (continued)

\begin{tabular}{|c|c|c|}
\hline Report & Data changes & Reason \\
\hline $\begin{array}{l}\text { Keller et. al } \\
\text { (ORNL/TM-13248) } 1996\end{array}$ & $\begin{array}{l}\text { A. Data for Tank W-25 sludge } \\
\text { from the Keller report was not } \\
\text { used in this data set } \\
\text { B. Excluded the data for sludge } \\
\text { samples treated with } \mathrm{HCl} \text {, with } \\
\text { the exception of the } \mathrm{Ag}, \mathrm{Sb} \text {, and } \\
\mathrm{P} \text { analyses } \\
\mathrm{C} \text {. Only anion analyses from the } \\
\text { water prepared sludge samples in } \\
\text { the Keller report were used in } \\
\text { this data set }\end{array}$ & $\begin{array}{l}\text { A. The sludge samples had been stored and } \\
\text { treated differently than other sludge samples. } \\
\text { In addition, the analyses were run with } \\
\text { different digestions than other analyses for } \\
\text { sludges } \\
\text { B. Analyses of } \mathrm{Ag} \text { and Sb are typically done } \\
\text { with an } \mathrm{HNO}_{3} / \mathrm{HCl} \text { digestion. P was } \\
\text { determined this way also } \\
\text { C. Other analyses (other than anions) are not } \\
\text { accurate with a water dissolution only }\end{array}$ \\
\hline $\begin{array}{l}\text { Sears, M. B. } \\
\text { (ORNL/TM-13234) } 1996\end{array}$ & No changes to data set & \\
\hline $\begin{array}{l}\text { Francis et. al } \\
\text { (Draft) } 1996\end{array}$ & No changes to data set & \\
\hline
\end{tabular}

The physical, chemical, and radiological measurements that ORNL has made on tank sludge range in time from 1985 to 1996. The type of measurements as well as the number vary from tank to tank as well as from year to year. Table 3.5 lists the number of measurements made for each variable for the sludge matrix.

Table 3.6 shows the average number of physical, chemical, and radiological variables for each tank farm. The number of variables are averaged over the variables measured on the different tanks in each tank farm. We see that there was no year in which all the variables were measured.

Figures 3.2, 3.3, and 3.4 illustrate the frequency of variables measured for the physical, chemical, and radiological measurements, respectively. These figures show which variables have the predominate measurement in the data set. 
$3-22$

Table 3.5 Number of measurements on sludge samples from 1985 to 1996

\begin{tabular}{|c|c|c|c|c|c|}
\hline $\begin{array}{l}\text { Physical } \\
\text { variables }\end{array}$ & $\begin{array}{c}\text { No. of } \\
\text { measurements }\end{array}$ & $\begin{array}{c}\text { Chemical } \\
\text { variables } \\
(\mathrm{mg} / \mathrm{kg})\end{array}$ & $\begin{array}{c}\text { No. of } \\
\text { measurements }\end{array}$ & $\begin{array}{l}\text { Radiological } \\
\text { variables } \\
\text { (bq/g) }\end{array}$ & $\begin{array}{c}\text { No. of } \\
\text { measurements }\end{array}$ \\
\hline Density $(\mathrm{g} / \mathrm{ml})$ & 42 & $\mathrm{Ag}$ & 65 & $\mathrm{H}_{2} \mathrm{O}$ Fraction & 37 \\
\hline $\mathrm{H}_{2} \mathrm{O}$ Fraction & 37 & $\mathrm{Al}$ & 49 & Gross Alpha & 87 \\
\hline $\mathrm{pH}$ & 13 & As & 62 & Gross Beta & 87 \\
\hline TSOL (mg/g) & 35 & $\mathrm{~B}$ & 48 & Am241 & 40 \\
\hline DSOL (mg/g) & 1 & $\mathrm{Ba}$ & 65 & Au198 & 8 \\
\hline SSOL (mg/g) & 1 & $\mathrm{Be}$ & 65 & $\mathrm{C} 14$ & 15 \\
\hline $\mathrm{TOC}(\mathrm{mg} / \mathrm{kg})$ & 61 & $\mathrm{Ca}$ & 49 & Cf 252 & 17 \\
\hline ICAR (mg/kg) & 45 & $\mathrm{Cd}$ & 65 & Ce144 & 10 \\
\hline \multirow[t]{2}{*}{ TCAR $(\mathrm{mg} / \mathrm{kg})$} & 45 & Co & 39 & $\mathrm{Cm} 243$ & 10 \\
\hline & & $\mathrm{Cr}$ & 65 & $\mathrm{Cm} 244$ & 71 \\
\hline TSOL $=$ Total & & Cs & 7 & $\mathrm{Co} 60$ & 74 \\
\hline Solids & & $\mathrm{Cu}$ & 39 & Cs134 & 36 \\
\hline $\mathrm{DSOL}=$ & & $\mathrm{Fe}$ & 49 & Cs137 & 76 \\
\hline Dissolved Solids & & $\mathrm{Hg}$ & 65 & Eu152 & 66 \\
\hline SSOL $=$ & & $\mathrm{K}$ & 49 . & Eu154 & 68 \\
\hline Suspended & & $\mathrm{Mg}$ & 49 & Eu155 & 62 \\
\hline Solids & & $\mathrm{Mn}$ & 65 & H3 & 16 \\
\hline $\mathrm{TOC}=$ Total & & $\mathrm{Na}$ & 49 & $\mathrm{Nb} 95$ & 12 \\
\hline Organic Carbon & & $\mathrm{Ni}$ & 65 & Np237 & 7 \\
\hline $\mathrm{ICAR}=$ & & $\mathrm{P}$ & 7 & ${ }^{238} \mathrm{Pu} /{ }^{41} \mathrm{Am}$ & 42 \\
\hline Inorganic Carbon & & $\mathrm{Pb}$ & 65 & ${ }^{239} \mathrm{Pu} /{ }^{240} \mathrm{Pu}$ & 60 \\
\hline TCAR $=$ Total & & $\mathrm{Sb}$ & 39 & Pu238. & 63 \\
\hline \multirow[t]{16}{*}{ Carbon } & & $\mathrm{Se}$ & 62 & Pu239 & 44 \\
\hline & & $\mathrm{Si}$ & 12 & Pu240 & 28 \\
\hline & & $\mathrm{Sr}$ & 48 & $\mathrm{Pu} 241$ & 28 \\
\hline & & Th & 49 & $\mathrm{Pu} 242$ & 30 \\
\hline & & $\mathrm{Tl}$ & 62 & Pu244 & 26 \\
\hline & & $\mathrm{U}$ & 65 & Ru106 & 10 \\
\hline & & V & 39 & Sr90 & 76 \\
\hline & & $\mathrm{Zn}$ & 39 & Тс99 & 8 \\
\hline & & Bromides & 35 & Th232 & 39 \\
\hline & & Chlorides & 35 & $\mathrm{U} 233$ & 64 \\
\hline & & Fluorides & 35 & U234 & 35 \\
\hline & & Nitrates & 35 & $\mathrm{U} 235$ & 28 \\
\hline & & Nitrites & 5 & U236 & 28 \\
\hline & & Phosphates & 35 & U238 & 40 \\
\hline & & Sulfates & 35 & ${ }^{233} \mathrm{U} /{ }^{234} \mathrm{U}$ & 4 \\
\hline & & Cyanide & 1 & Zr95 & 1 \\
\hline
\end{tabular}


$3-23$

Table 3.6 Average number of variables measured on sludge samples for each year

\begin{tabular}{|c|c|c|c|c|c|c|c|}
\hline \multirow{2}{*}{$\begin{array}{c}\text { Measurement } \\
\text { variable } \\
\text { (number) }\end{array}$} & \multirow{2}{*}{$\begin{array}{l}\text { Tank } \\
\text { farm }\end{array}$} & \multicolumn{6}{|c|}{ Sample year } \\
\hline & & 1985 & 1989 & 1990 & 1994 & 1995 & 1996 \\
\hline \multirow{4}{*}{$\begin{array}{l}\text { Physical } \\
\text { (9) }\end{array}$} & GAAT & & 2.0 & & 5.3 & 4.6 & \\
\hline & BVEST & & & 5.0 & 8.0 & & 5.0 \\
\hline & MVST & 0.4 & 4.9 & & & & \\
\hline & OHF & & 2.4 & & & & 6.0 \\
\hline \multirow{4}{*}{$\begin{array}{c}\text { Chemical } \\
\text { (38) }\end{array}$} & GAAT & & 13.0 & & 32.8 & 32.0 & \\
\hline & BVEST & & & 22.0 & 27.0 & & 12.0 \\
\hline & MVST & & 22.0 & & & & \\
\hline & $\mathrm{OHF}$ & & 13.0 & & & & 37.0 \\
\hline \multirow{4}{*}{$\begin{array}{c}\text { Radiological } \\
\text { (38) }\end{array}$} & GAAT & & 13.0 & & 23.2 & 19.3 & \\
\hline & BVEST & 8.8 & & 19.0 & 26.0 & & 26.0 \\
\hline & MVST & 7.9 & 19.0 & & & & \\
\hline & OHF & & 14.0 & & & & 26.8 \\
\hline
\end{tabular}

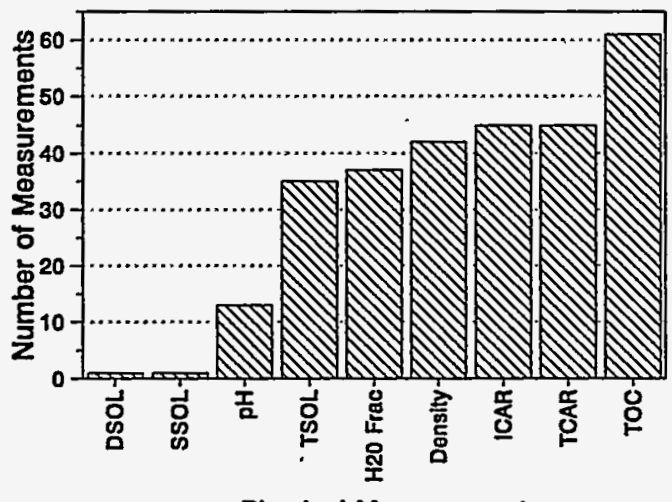

Physical Measurements

Fig. 3.2. Frequency of measurements for the physical variables. 


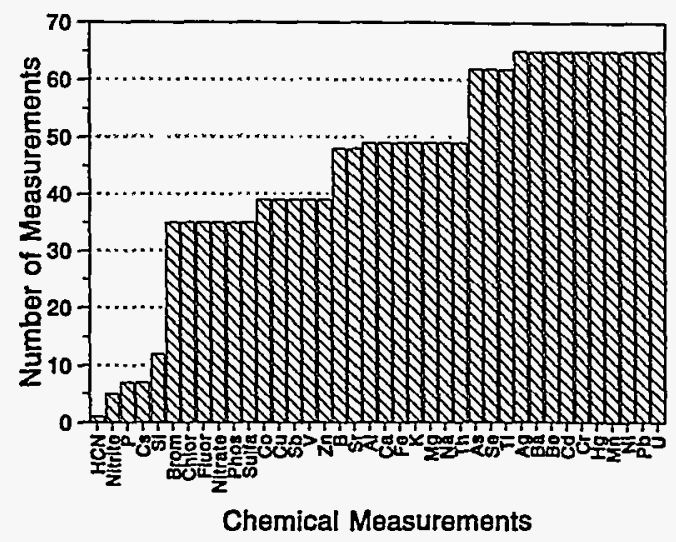

Fig. 3.3 Frequency of measurements for the chemical measurements.

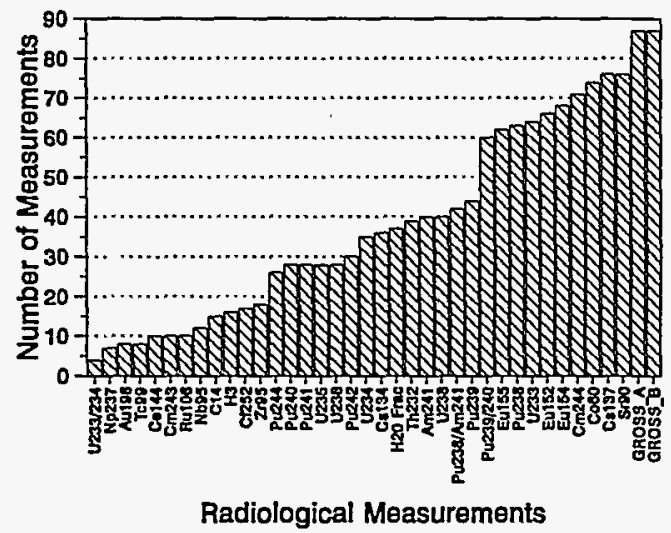

Fig. 3.4. Frequency of measurements for the radiological measurements.

\subsection{MASS OF TANK SLUDGE}

ORNL has determined the mass and volume of the sludges in the 26 tanks considered in this report. Table 3.7 shows the sludge masses and volumes in terms of kilograms (mass) and gallons (volume). This table also reports the fraction of the total mass 1,011,143 kilograms and the fraction of the total volume 199,700 gallons.

Table 3.8 summarizes the sludge mass and volume by tank farm. The tank farm mass fractions are used to calculate weighted means and weighted standard deviations for the summary statistics. Figure 3.5 illustrates the percentage of the total mass for each tank farm. 
Table 3.7 Sludge mass and volume for each tank

\begin{tabular}{|c|c|c|c|c|c|}
\hline Rank & Tank & $\begin{array}{l}\text { Sludge mass } \\
(\mathrm{kg})\end{array}$ & $\begin{array}{c}\text { Fraction of } \\
\text { total mass } \\
(1,011,143 \mathrm{~kg})\end{array}$ & $\begin{array}{l}\text { Sludge volume } \\
\text { (gallons) }\end{array}$ & $\begin{array}{l}\text { Fraction of } \\
\text { total volume } \\
(199,700 \text { gal })\end{array}$ \\
\hline 1 & T-9 & 2195 & 0.00217 & 500 & 0.00250 \\
\hline 2 & W-3 & 3206 & 0.00317 & 700 & 0.00351 \\
\hline 3 & $T-1$ & 4027 & 0.00398 & 800 & 0.00401 \\
\hline 4 & $\mathrm{~W}-4$ & 6359 & 0.00629 & 1400 & 0.00701 \\
\hline 5 & $T-4$ & 6465 & 0.00639 & 1400 & 0.00701 \\
\hline 6 & $T-2$ & 6544 & 0.00647 & 1300 & 0.00651 \\
\hline 7 & C-1 & 7949 & 0.00786 & 1500 & 0.00751 \\
\hline 8 & $C-2$ & 7949 & 0.00786 & 1500 & 0.00751 \\
\hline 9 & $T-3$ & 10413 & 0.01030 & 2100 & 0.01052 \\
\hline 10 & W-9 & 13282 & 0.01314 & 2900 & 0.01452 \\
\hline 11 & W-5 & 15500 & 0.01533 & 3500 & 0.01753 \\
\hline 12 & $W-22$ & 30113 & 0.02978 & 6800 & 0.03405 \\
\hline 13 & W-6 & 34129 & 0.03375 & 7100 & 0.03555 \\
\hline 14 & W-28 & 40605 & .0 .04016 & 7200 & 0.03605 \\
\hline 15 & $W-10$ & 42241 & 0.04178 & 9300 & 0.04657 \\
\hline 16 & W-31 & 42922 & 0.04245 & 9000 & 0.04507 \\
\hline 17 & W-7 & 45477 & 0.04498 & 8900 & 0.04457 \\
\hline 18 & W-8 & 46056 & 0.04555 & 10400 & 0.05208 \\
\hline 19 & $W-24$ & 56275 & 0.05565 & 11800 & 0.05909 \\
\hline 20 & W-29 & 56624 & 0.05600 & 11000 & 0.05508 \\
\hline 21 & $W-30$ & 56624 & 0.05600 & 11000 & 0.05508 \\
\hline 22 & $\mathrm{~W}-21$ & 58997 & 0.05835 & 10900 & 0.05458 \\
\hline 23 & W-23 & 90628 & 0.08963 & 16400 & 0.08212 \\
\hline 24 & $W-25$ & 103921 & 0.10278 & 20800 & 0.10416 \\
\hline 25 & W-27 & 104315 & 0.10317 & 21200 & 0.10616 \\
\hline 26 & W-26 & 118327 & 0.11703 & 20300 & 0.10165 \\
\hline
\end{tabular}


Table 3.8 Sludge mass and volume for each tank farm

\begin{tabular}{cccc}
\hline $\begin{array}{c}\text { Tank farm } \\
\text { (No. of tanks) }\end{array}$ & Tanks & $\begin{array}{c}\text { Sludge mass } \\
(\mathbf{k g})\end{array}$ & $\begin{array}{c}\text { Fraction of } \\
\text { total mass } \\
(\mathbf{1 , 0 1 1 , 1 4 3 ~ k g )}\end{array}$ \\
\hline OHF (5) & T-1,T-2,T-3,T-4,T-9 & 29,644 & 0.029317 \\
BVEST (5) & $\begin{array}{c}\text { C-1,C-2,W-21, } \\
\text { W-22,W-23 }\end{array}$ & 195,636 & 0.193480 \\
& W-3,W-4,W-5,W-6, & 206,250 & 0.203977 \\
GAAT (8) & W-7,W-8,W-9,W-10 &. & 0.573226 \\
& $\begin{array}{l}\text { W-24,W-25,W-26,W-27, } \\
\text { MVST (8) }\end{array}$ & 579,613 & \\
\hline
\end{tabular}

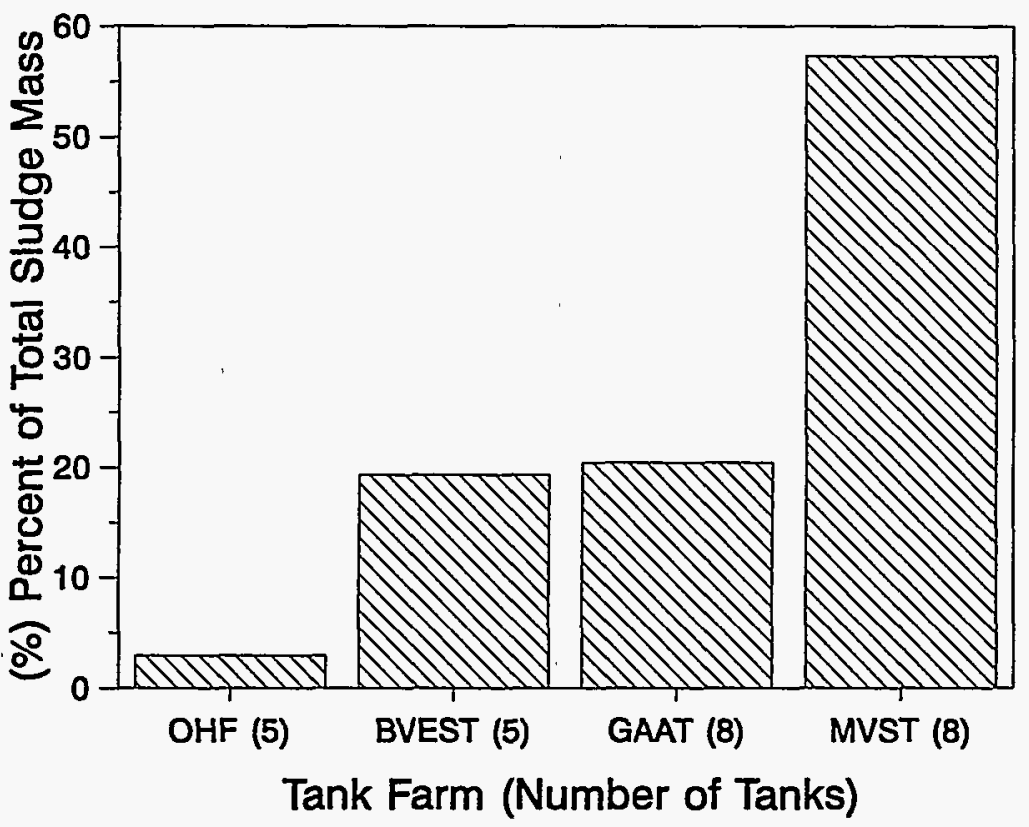

Fig. 3.5. Percentage of sludge mass for each tank farm.

\subsection{DATA SUMMARY}

Six statistics were calculated to summarize the sludge measurements [i.e., number of measurements, mean, standard deviation, minimum measurement value, maximum measurement value, and the \%relative error $=100 \% \times($ standard deviation $) /$ mean $]$. These statistics are defined in Table 3.9 below. Tables 3.10 to 3.12 list the summary statistics for all tank measurements for the physical, chemical, and radiological measurements, respectively. These tables included unweighted summary statistics for all tanks, weighted summary statistics for all tanks, and unweighted summary statistics for each tank farm. The weighted summary statistics are based on the mass fraction of the four tank farms (see Table 3.8). 


\section{3-27}

The detection limit values were used in the summary statistics for measurements reported as less than the detection limit value. This procedure may cause positive biases (i.e., larger than the true value) for the summary statistics. However, this procedure was believed to be the most conservative approach for the data user. Measurements that are reported as zero are also included in the database. These measurements indicated that no response was detected for the measured variable. A zero response for a variable is different from not measuring a variable on a sample.

Table 3.9 Definition of summary statistics

\begin{tabular}{|c|c|c|}
\hline Statistic & Formula & Description \\
\hline $\begin{array}{c}\text { Number of } \\
\text { Measurements }\end{array}$ & $\mathbf{N}$ & $\begin{array}{l}\text { Number of measurements } \\
\text { for a set of samples. }\end{array}$ \\
\hline Mean & $\bar{X}=\frac{1}{N} \sum_{j=1}^{N} x_{j}$ & $\begin{array}{l}\text { Average of } N \text { measurements } \\
\text { represented by the symbols } \\
\qquad X_{1}, X_{2}, \ldots, X_{N}\end{array}$ \\
\hline Weighted Mean & $\overline{X_{W}}=\sum_{j=1}^{N} w_{j} X_{j}$ & $\begin{array}{l}\text { Weighted average of } \mathrm{N} \\
\text { measurements. The weights are } \\
\text { represented by } \\
\mathrm{W}_{1}, \mathrm{~W}_{2}, \ldots, \mathrm{W}_{\mathrm{N}} .\end{array}$ \\
\hline Std Dev & $S=\sqrt{\frac{1}{N-1} \sum_{j=1}^{N}\left(x_{j}-\bar{X}\right)^{2}}$ & $\begin{array}{l}\text { Standard deviation of } \mathrm{N} \\
\text { measurements. An estimate of } \\
\text { precision. }\end{array}$ \\
\hline Weighted Std Dev & $S_{W}=\sqrt{\frac{1}{N-1} \sum_{j=1}^{N} W_{j}\left(X_{j}-\overline{X_{W}}\right)}$ & $\begin{array}{l}\text { Weighted standard deviation of } \mathrm{N} \\
\text { measurements. A weighted estimate } \\
\text { of precision. The weights are } \\
\text { represented by } \\
\mathrm{W}_{1}, \mathrm{~W}_{2}, \ldots, \mathrm{W}_{\mathrm{N}} .\end{array}$ \\
\hline Minimum & Minimum & Smallest value of $\mathrm{N}$ measurements. \\
\hline Maximum & Maximum & Largest value of $\mathrm{N}$ measurements. \\
\hline Percent Relative Error & $\%$ R.E. $=100 \% \times \frac{S t d \text { Dev }}{\text { Mean }}$ & $\begin{array}{l}\text { Standard deviation divided by the } \\
\text { mean and expressed as a } \\
\text { percentage. An estimate of } \\
\text { standardized precision. }\end{array}$ \\
\hline
\end{tabular}


Table 3.10 Summary statistics for physical measurements on sludge samples

\begin{tabular}{|c|c|c|c|c|c|c|}
\hline Variable & $\mathbf{N}$ & Mean & Std. Dev. & Minimum & Maximum & \%R.E. \\
\hline \multicolumn{7}{|c|}{ Unweighted statistics over all tanks } \\
\hline $\begin{array}{l}\text { Density } \\
(\mathrm{g} / \mathrm{mL})\end{array}$ & 42 & 1.28 & 0.13 & 1.07 & 1.57 & 10.03 \\
\hline $\mathrm{H}_{2} \mathrm{O}$ fraction & 37 & 0.71 & 0.11 & 0.42 & 0.89 & 15.37 \\
\hline $\mathrm{pH}$ & 13 & 10.21 & 0.69 & 9.10 & 11.50 & 6.80 \\
\hline $\begin{array}{l}\text { TSOL } \\
(\mathrm{mg} / \mathrm{g})\end{array}$ & 35 & 467.71 & 184.38 & 253.00 & 964.00 & 39.42 \\
\hline $\begin{array}{l}\mathrm{DSOL} \\
(\mathrm{mg} / \mathrm{g})\end{array}$ & 1 & 25.50 & . & 25.50 & 25.50 & - \\
\hline SSOL (mg/g) & 1 & 242.00 & - & 242.00 & 242.00 & - \\
\hline $\begin{array}{c}\text { TOC } \\
(\mathrm{mg} / \mathrm{kg})\end{array}$ & 61 & $\begin{array}{c}5499.33 \\
.\end{array}$ & 5541.09 & 100.00 & 28000.00 & 100.76 \\
\hline $\begin{array}{c}\mathrm{ICAR} \\
(\mathrm{mg} / \mathrm{kg})\end{array}$ & 45 & 7047.56 & 7042.96 & 1110.00 & 32000.00 & 99.93 \\
\hline $\begin{array}{c}\text { TCAR } \\
(\mathrm{mg} / \mathrm{kg})\end{array}$ & 45 & 10903.33 & 8696.27 & 1820.00 & 32500.00 & 79.76 \\
\hline \multicolumn{7}{|c|}{ Weighted statistics over all tanks } \\
\hline $\begin{array}{l}\text { Density } \\
(\mathrm{g} / \mathrm{mL})\end{array}$ & 42 & 1.30 & 0.06 & 1.07 & 1.57 & 4.95 \\
\hline $\mathrm{H}_{2} \mathrm{O}$ fraction & 37 & 0.71 & 0.05 & 0.42 & 0.89 & 6.68 \\
\hline $\mathrm{pH}$ & 13 & 10.27 & 0.22 & 9.10 & 11.50 & 2.18 \\
\hline $\begin{array}{l}\text { TSOL } \\
(\mathrm{mg} / \mathrm{g})\end{array}$ & 35 & 473.52 & 94.30 & 253.00 & 964.00 & 19.92 \\
\hline $\begin{array}{l}\text { DSOL } \\
(\mathrm{mg} / \mathrm{g})\end{array}$ & 1 & 25.50 & - & 25.50 & 25.50 & . \\
\hline $\mathrm{SSOL}(\mathrm{mg} / \mathrm{g})$ & 1 & 242.00 & · & 242.00 & 242.00 & - \\
\hline $\begin{array}{c}\text { TOC } \\
(\mathrm{mg} / \mathrm{kg})\end{array}$ & 61 & 4528.39 & 2024.75 & 100.00 & 28000.00 & 44.71 \\
\hline $\begin{array}{c}\mathrm{ICAR} \\
(\mathrm{mg} / \mathrm{kg})\end{array}$ & 45 & 6994.18 & 3444.79 & 1110.00 & 32000.00 & 49.25 \\
\hline $\begin{array}{l}\text { TCAR } \\
(\mathrm{mg} / \mathrm{kg})\end{array}$ & 45 & 10599.41 & 4306.73 & 1820.00 & 32500.00 & 40.63 \\
\hline
\end{tabular}


Table 3.10 (continued)

\begin{tabular}{|c|c|c|c|c|c|c|}
\hline Variable & $\mathbf{N}$ & Mean & Std. Dev. & Minimum & Maximum & \%R.E. \\
\hline \multicolumn{7}{|c|}{$\begin{array}{l}\text { Unweighted statistics over OHF Tank Farm } \\
\quad \text { (mass fraction }=0.029317)\end{array}$} \\
\hline $\begin{array}{l}\text { Density } \\
(\mathrm{g} / \mathrm{mL})\end{array}$ & 7 & 1.28 & 0.08 & 1.16 & 1.39 & 6.36 \\
\hline $\mathrm{H}_{2} \mathrm{O}$ fraction & 5 & 0.67 & 0.05 & 0.60 & 0.72 & 7.79 \\
\hline $\mathrm{pH}$ & 5 & 10.08 & 0.89 & 9.30 & 11.50 & 8.86 \\
\hline $\begin{array}{l}\mathrm{TSOL} \\
(\mathrm{mg} / \mathrm{g})\end{array}$ & 5 & 441.00 & 271.55 & 253.00 & 921.00 & 61.58 \\
\hline $\begin{array}{l}\mathrm{DSOL} \\
(\mathrm{mg} / \mathrm{g})\end{array}$ & 0 & . & . & . & . & . \\
\hline SSOL (mg/g) & 0 & . & - & . & . & . \\
\hline $\begin{array}{c}\mathrm{TOC} \\
(\mathrm{mg} / \mathrm{kg})\end{array}$ & 10 & 9898.00 & 8239.91 & 100.00 & 28000.00 & 83.25 \\
\hline $\begin{array}{c}\mathrm{ICAR} \\
(\mathrm{mg} / \mathrm{kg})\end{array}$ & 5 & 11620.00 & 4667.12 & 5200.00 & 16000.00 & 40.16 \\
\hline $\begin{array}{c}\text { TCAR } \\
(\mathrm{mg} / \mathrm{kg})\end{array}$ & 5 & 17800.00 & 6379.66 & 13000.00 & 29000.00 & 35.84 \\
\hline \multicolumn{7}{|c|}{$\begin{array}{l}\text { Unweighted statistics over BVEST Tank Farm } \\
\quad \text { (mass fraction }=0.193480)\end{array}$} \\
\hline $\begin{array}{l}\text { Density } \\
(\mathrm{g} / \mathrm{mL})\end{array}$ & 5 & 1.37 & 0.12 & 1.17 & 1.46 & 8.81 \\
\hline $\mathrm{H}_{2} \mathrm{O}$ fraction & 3 & 0.55 & 0.17 & 0.42 & 0.74 & 29.84 \\
\hline $\mathrm{pH}$ & 0 & - & . & - & - & . \\
\hline $\begin{array}{l}\mathrm{TSOL} \\
(\mathrm{mg} / \mathrm{g})\end{array}$ & 3 & 441.00 & 150.73 & 268.00 & 544.00 & 34.18 \\
\hline $\begin{array}{l}\mathrm{DSOL} \\
(\mathrm{mg} / \mathrm{g})\end{array}$ & 1 & 25.50 & . & 25.50 & 25.50 & - \\
\hline SSOL (mg/g) & 1 & 242.00 & . & 242.00 & 242.00 & . \\
\hline $\begin{array}{c}\mathrm{TOC} \\
(\mathrm{mg} / \mathrm{kg})\end{array}$ & 5 & 6580.00 & 9095.50 & 100.00 & 22100.00 & 138.23 \\
\hline $\begin{array}{c}\mathrm{ICAR} \\
(\mathrm{mg} / \mathrm{kg})\end{array}$ & 5 & 20100.00 & 9588.01 & 10400.00 & 32000.00 & 47.70 \\
\hline $\begin{array}{c}\text { TCAR } \\
(\mathrm{mg} / \mathrm{kg})\end{array}$ & 5 & 26640.00 & 6141.91 & 18500.00 & 32500.00 & 23.06 \\
\hline
\end{tabular}


Table 3.10 (continued)

\begin{tabular}{|c|c|c|c|c|c|c|}
\hline Variable & $\mathbf{N}$ & Mean & Std. Dev. & Minimum & Maximum & \%R.E. \\
\hline \multicolumn{7}{|c|}{$\begin{array}{l}\text { Unweighted statistics over GAAT Tank Farm } \\
\text { (mass fraction }=0.203977 \text { ) }\end{array}$} \\
\hline $\begin{array}{l}\text { Density } \\
(\mathrm{g} / \mathrm{mL})\end{array}$ & 23 & 1.24 & 0.13 & 1.07 & 1.57 & 10.82 \\
\hline $\mathrm{H}_{2} \mathrm{O}$ fraction & 29 & 0.73 & 0.10 & 0.58 & 0.89 & 13.32 \\
\hline $\mathrm{pH}$ & 8 & 10.29 & 0.59 & 9.10 & 11.10 & 5.77 \\
\hline $\begin{array}{l}\text { TSOL } \\
(\mathrm{mg} / \mathrm{g})\end{array}$ & 11 & 475.73 & 220.21 & 300.00 & 944.00 & 46.29 \\
\hline $\begin{array}{l}\mathrm{DSOL} \\
(\mathrm{mg} / \mathrm{g})\end{array}$ & 0 & . & . & . & . & . \\
\hline SSOL $(\mathrm{mg} / \mathrm{g})$ & 0 & . & . & . & . & . \\
\hline $\begin{array}{c}\mathrm{TOC} \\
(\mathrm{mg} / \mathrm{kg})\end{array}$ & 38 & 4588.92 & 4013.78 & 200.00 & 14600.00 & 87.47 \\
\hline $\begin{array}{c}\mathrm{ICAR} \\
(\mathrm{mg} / \mathrm{kg})\end{array}$ & 27 & 3374.44 & 1678.64 & 1110.00 & 7900.00 & 49.75 \\
\hline $\begin{array}{c}\text { TCAR } \\
(\mathrm{mg} / \mathrm{kg})\end{array}$ & 27 & 6366.67 & 3814.22 & 1900.00 & 16600.00 & 59.91 \\
\hline \multicolumn{7}{|c|}{$\begin{array}{l}\text { Unweighted statistics over MVST Tank Farm } \\
\text { (mass fraction }=0.573226 \text { ) }\end{array}$} \\
\hline $\begin{array}{l}\text { Density } \\
(\mathrm{g} / \mathrm{mL})\end{array}$ & 7 & 1.35 & 0.12 & 1.26 & 1.54 & 8.61 \\
\hline $\mathrm{H}_{2} \mathrm{O}$ fraction & 0 & . & . & . & . & . \\
\hline $\mathrm{pH}$ & 0 & . & . & . & . & . \\
\hline $\begin{array}{l}\text { TSOL } \\
(\mathrm{mg} / \mathrm{g})\end{array}$ & 16 & 475.56 & 146.76 & .342 .00 & 964.00 & 30.86 \\
\hline $\begin{array}{l}\mathrm{DSOL} \\
(\mathrm{mg} / \mathrm{g})\end{array}$ & 0 & . & . & . & . & . \\
\hline SSOL $(\mathrm{mg} / \mathrm{g})$ & 0 & . & . & . & . & . \\
\hline $\begin{array}{c}\text { TOC } \\
(\mathrm{mg} / \mathrm{kg})\end{array}$ & 8 & 3650.00 & 2562.99 & 410.00 & 8530.00 & 70.22 \\
\hline $\begin{array}{c}\mathrm{ICAR} \\
(\mathrm{mg} / \mathrm{kg})\end{array}$ & 8 & 8428.75 & 6745.66 & 1410.00 & 21900.00 & 80.03 \\
\hline $\begin{array}{c}\mathrm{TCAR} \\
(\mathrm{mg} / \mathrm{kg})\end{array}$ & 8 & 12068.75 & 9203.75 & 1820.00 & 30400.00 & 76.26 \\
\hline
\end{tabular}


3-31

Table 3.11 Summary statistics for chemical measurements $(\dot{\mathrm{mg}} / \mathrm{kg})$ on sludge samples

\begin{tabular}{|c|c|c|c|c|c|c|}
\hline Variable & $\mathbf{N}$ & Mean & Std. Dev. & Minimum & Maximum & \%R.E. \\
\hline \multicolumn{7}{|c|}{ Unweighted statistics over all tanks } \\
\hline $\mathrm{Ag}$ & 65 & 6.17 & 9.39 & 0.01 & 50.00 & 152.13 \\
\hline Al & 49 & 9898.58 & 10774.17 & 17.50 & 51100.00 & 108.85 \\
\hline As & 62 & 9.02 & 16.35 & 0.47 & 69.00 & 181.23 \\
\hline B & 48 & 16.74 & 19.19 & 1.20 & 104.00 & 114.67 \\
\hline $\mathrm{Ba}$ & 65 & 95.31 & 169.88 & 2.94 & 1300.00 & 178.25 \\
\hline $\mathrm{Be}$ & 65 & 3.25 & 7.27 & 0.00 & 45.40 & 223.80 \\
\hline $\mathrm{Ca}$ & 49 & 20193.10 & 20680.91 & 301.00 & 83900.00 & 102.42 \\
\hline $\mathrm{Cd}$ & 65 & 8.29 & 9.01 & 0.52 & 42.00 & 108.66 \\
\hline $\mathrm{Co}$ & 39 & 4.22 & 4.27 & 1.30 & 24.20 & 101.33 \\
\hline $\mathrm{Cr}$ & 65 & $365.48^{\circ}$ & 488.75 & 10.00 & 2400.00 & 133.73 \\
\hline Cs & 7 & 6.00 & 7.48 & 1.43 & 22.50 & 124.69 \\
\hline $\mathrm{Cu}$ & 39 & 64.22 & 50.13 & 6.03 & 293.00 & 78.06 \\
\hline $\mathrm{Fe}$ & 49 & 5273.37 & 5682.57 & 195.00 & 20300.00 & 107.76 \\
\hline $\mathrm{Hg}$ & 65 & 81.35 & 101.54 & 0.82 & 585.00 & 124.83 \\
\hline $\mathrm{K}$ & 49 & 537.8 .35 & 5370.36 & 219.00 & 25200.00 & 99.85 \\
\hline $\mathrm{Mg}$ & 49 & 3300.41 & 4250.37 & 47.80 & 16000.00 & 128.78 \\
\hline $\mathrm{Mn}$ & 65 & 135.58 & 238.40 & 0.00 & 1510.00 & 175.85 \\
\hline $\mathrm{Na}$ & 49 & 35105.71 & 24397.88 & 4040.00 & 82000.00 & 69.50 \\
\hline $\mathrm{Ni}$ & 65 & 86.53 & 89.69 & 4.60 & 452.00 & 103.65 \\
\hline $\mathbf{P}$ & 7 & 10452.86 & 3582.83 & 6940.00 & 16000.00 & 34.28 \\
\hline $\mathrm{Pb}$ & 65. & 519.12 & 962.93 & 5.00 & 7320.00 & 185.49 \\
\hline $\mathrm{Sb}$ & 39 & 26.35 & 15.40 & 9.70 & 56.00 & 58.45 \\
\hline $\mathrm{Se}$ & 62 & 9.01 & 17.86 & 0.30 & 86.00 & 198.13 \\
\hline $\mathrm{Si}$ & 12 & 4932.08 & 8843.15 & 159.00 & 32500.00 & 179.30 \\
\hline $\mathrm{Sr}$ & 48 & 133.17 & 230.70 & 2.43 & 992.00 & 173.24 \\
\hline Th & 49 & 13541.87 & 26848.72 & 94.60 & 124000.00 & 198.26 \\
\hline $\mathrm{Tl}$ & 62 & 9.68 & 13.75 & 0.30 & 75.20 & 142.13 \\
\hline $\mathrm{U}$ & 65 & 51050.97 & 75087.89 & 451.00 & 330000.00 & 147.08 \\
\hline
\end{tabular}


Table 3.11 (continued)

\begin{tabular}{|c|c|c|c|c|c|c|}
\hline Variable & $\mathbf{N}$ & Mean & Std. Dev. & Minimum & Maximum & \%R.E. \\
\hline V & 39 & 3.33 & 2.01 & 0.38 & 7.80 & 60.39 \\
\hline $\mathrm{Zn}$ & 39 & 141.53 & 251.69 & 1.50 & 1100.00 & 177.84 \\
\hline Bromides & 35 & 448.00 & 993.89 & 4.63 & 3280.00 & 221.85 \\
\hline Chlorides & 35 & 558.02 & 966.72 & 5.00 & 3760.00 & 173.24 \\
\hline Fluorides & 35 & 1252.46 & 2181.11 & 17.50 & 11900.00 & 174.15 \\
\hline Nitrates & 35 & 17650.81 & 35312.63 & 10.00 & .166000 .00 & 200.06 \\
\hline Nitrites & 5 & 1510.80 & 1823.68 & 219.00 & 4670.00 & 120.71 \\
\hline Phosphates & 35 & 2396.49 & 2227.68 & 18.50 & 7900.00 & 92.96 \\
\hline Sulfates & 35 & 3498.94 & 3189.21 & 250.00 & 9400.00 & 91.15 \\
\hline Cyanide & 1 & 5.40 & . & 5.40 & 5.40 & . \\
\hline \multicolumn{7}{|c|}{ Weighted statistics over all tanks } \\
\hline Ag & 65 & 7.88 & 4.53 & 0.01 & 50.00 & 57.52 \\
\hline $\mathrm{Al}$ & 49 & 8012.46 & 4695.30 & 17.50 & 51100.00 & 58.60 \\
\hline As & 62 & 17.18 & 10.21 & 0.47 & 69.00 & 59.42 \\
\hline B & 48 & 12.51 & 8.14 & 1.20 & 104.00 & 65.07 \\
\hline $\mathrm{Ba}$ & 65 & 93.65 & 77.30 & 2.94 & 1300.00 & 82.54 \\
\hline $\mathrm{Be}$ & 65 & 1.83 & .1 .97 & 0.00 & 45.40 & 107.45 \\
\hline $\mathrm{Ca}$ & 49 & 24100.46 & 10981.66 & 301.00 & 83900.00 & 45.57 \\
\hline $\mathrm{Cd}$ & 65 & 9.20 & 5.00 & 0.52 & 42.00 & 54.41 \\
\hline Co & 39 & 3.64 & 1.69 & 1.30 & 24.20 & 46.37 \\
\hline $\mathrm{Cr}$ & 65 & 337.40 & 225.02 & 10.00 & $\cdot 2400.00$ & 66.69 \\
\hline Cs & 7 & 3.96 & 1.37 & 1.43 & 22.50 & 34.53 \\
\hline $\mathrm{Cu}$ & 39 & 53.51 & 13.46 & 6.03 & 293.00 & 25.15 \\
\hline Fe & 49 & 4319.89 & 2581.07 & 195.00 & 20300.00 & 59.75 \\
\hline $\mathrm{Hg}$ & 65 & 65.61 & 37.14 & 0.82 & 585.00 & 56.60 \\
\hline $\mathrm{K}$ & 49 & 6381.12 & 2546.91 & 219.00 & 25200.00 & 39.91 \\
\hline $\mathrm{Mg}$ & 49 & 4052.20 & 2271.74 & 47.80 & 16000.00 & 56.06 \\
\hline $\mathrm{Mn}$ & 65 & 104.16 & 106.43 & 0.00 & 1510.00 & 102.18 \\
\hline $\mathrm{Na}$ & 49 & 43892.46 & 11856.67 & 4040.00 & 82000.00 & 27.01 \\
\hline
\end{tabular}


Table 3.11 (continued)

\begin{tabular}{|c|c|c|c|c|c|c|}
\hline Variable & $\mathbf{N}$ & Mean & Std. Dev. & Minimum & Maximum & \%R.E. \\
\hline $\mathrm{Ni}$ & 65 & 63.42 & 27.04 & 4.60 & 452.00 & 42.63 \\
\hline $\mathbf{P}$ & 7 & 13158.71 & 925.01 & 6940.00 & 16000.00 & 7.03 \\
\hline $\mathrm{Pb}$ & 65 & 462.24 & 438.00 & 5.00 & 7320.00 & 94.76 \\
\hline $\mathrm{Sb}$ & 39 & 27.30 & 6.79 & 9.70 & 56.00 & 24.87 \\
\hline $\mathrm{Se}$ & 62 & 18.73 & 11.63 & 0.30 & 86.00 & 62.12 \\
\hline $\mathrm{Si}$ & 12 & 2272.82 & 1675.01 & 159.00 & 32500.00 & 73.70 \\
\hline $\mathrm{Sr}$ & 48 & 88.75 & 52.81 & 2.43 & 992.00 & 59.50 \\
\hline Th & 49 & 5867.64 & 5178.35 & 94.60 & 124000.00 & 88.25 \\
\hline $\mathrm{Tl}$ & 62 & 12.05 & 6.15 & 0.30 & 75.20 & 51.03 \\
\hline $\mathbf{U}$ & 65 & 48161.88 & 34238.16 & 451.00 & 330000.00 & 71.09 \\
\hline V & 39 & 2.88 & 0.68 & 0.38 & 7.80 & 23.69 \\
\hline $\mathrm{Zn}$ & 39 & 133.22 & 110.87 & 1.50 & 1100.00 & 83.23 \\
\hline Brọmides & 35 & 506.63 & 443.14 & 4.63 & 3280.00 & 87.47 \\
\hline Chlorides & 35 & 470.71 & 364.37 & 5.00 & 3760.00 & 77.41 \\
\hline Fluorides & 35 & 1401.09 & 968.46 & 17.50 & 11900.00 & 69.12 \\
\hline Nitrates & 35 & 19501.12 & 15375.54 & 10.00 & 166000.00 & 78.84 \\
\hline Nitrites & 5 & 1510.80 & 312.25 & 219.00 & 4670.00 & 20.67 \\
\hline Phosphates & 35 & 2722.96 & 925.10 & 18.50 & 7900.00 & 33.97 \\
\hline Sulfates & 35 & 3816.91 & 1373.99 & 250.00 & 9400.00 & 36.00 \\
\hline Cyanide & 1 & 5.40 & . & 5.40 & 5.40 & . \\
\hline \multicolumn{7}{|c|}{$\begin{array}{l}\text { Unweighted statistics over OHF Tank Farm } \\
\text { (mass fraction }=0.029317)\end{array}$} \\
\hline $\mathrm{Ag}$ & 10 & 1.24 & 0.83 & 0.15 & 2.90 & 66.88 \\
\hline $\mathrm{Al}$ & 5 & 20304.00 & 9980.74 & 9320.00 & 34500.00 & 49.16 \\
\hline As & 10 & 1.83 & 0.97 & 1.00 & 4.00 & 53.05 \\
\hline B & 5 & 42.14 & 6.52 & 31.80 & 49.70 & 15.47 \\
\hline $\mathrm{Ba}$ & 10 & 64.36 & 26.87 & 26.50 & 115.00 & 41.75 \\
\hline $\mathrm{Be}$ & 10 & 9.49 & 15.46 & 0.00 & 45.40 & 162.90 \\
\hline $\mathrm{Ca}$ & 5 & 31160.00 & 7068.45 & 20600.00 & 37900.00 & 22.68 \\
\hline
\end{tabular}


Table 3.11 (continued)

\begin{tabular}{|c|c|c|c|c|c|c|}
\hline Variable & $\mathbf{N}$ & Mean & Std. Dev. & Minimum & Maximum & \%R.E. \\
\hline $\mathrm{Cd}$ & 10 & 11.21 & 3.21 & 6.60 & 16.40 & 28.67 \\
\hline Co & 5 & 8.90 & 4.06 & 4.24 & 14.20 & 45.62 \\
\hline $\mathrm{Cr}$ & 10 & 106.63 & 65.91 & 10.00 & 241.00 & 61.81 \\
\hline Cs & 5 & 7.32 & 8.73 & 1.43 & 22.50 & 119.25 \\
\hline $\mathrm{Cu}$ & 5 & 151.26 & 85.86 & 64.30 & 293.00 & 56.76 \\
\hline $\mathrm{Fe}$ & 5 & 7704.00 & 6021.41 & 3.150 .00 & 17900.00 & 78.16 \\
\hline $\mathrm{Hg}$ & 10 & 121.58 & 176.88 & 1.80 & 585.00 & 145.49 \\
\hline $\mathrm{K}$ & 5 & 2600.80 & $\cdot 2031.82$ & 974.00 & 6140.00 & 78.12 \\
\hline $\mathrm{Mg}$ & 5 & 3414.00 & 1214.59 & 1730.00 & 5140.00 & 35.58 \\
\hline $\mathrm{Mn}$ & 10 & 166.20 & 186.71 & 0.00 & 472.00 & 112.34 \\
\hline $\mathrm{Nà}$ & 5 & 8388.00 & 5967.04 & 4040.00 & 18800.00 & 71.14 \\
\hline $\mathrm{Ni}$ & 10 & 204.10 & 145.98 & 50.00 & 452.00 & 71.52 \\
\hline$P$ & 5 & 8694.00 & 2249.31 & 6940.00 & 12600.00 & 25.87 \\
\hline $\mathrm{Pb}$ & 10 & 513.00 & 183.77 & 229.00 & 860.00 & 35.82 \\
\hline $\mathrm{Sb}$ & 5 & 18.00 & 1.41 & 17.00 & 20.00 & 7.86 \\
\hline $\mathrm{Se}$ & 10 & 1.35 & 0.40 & 0.74 & 2.00 & 29.49 \\
\hline Si & 5 & 9734.00 & 12731.00 & 3640.00 & 32500.00 & 130.79 \\
\hline $\mathrm{Sr}$ & 5 & 692.40 & 352.65 & 282.00 & 992.00 & 50.93 \\
\hline Th & 5 & 88620.00 & 24615.58 & 56800.00 & 124000.00 & 27.78 \\
\hline $\mathrm{Tl}$ & 10 & 1.25 & 0.42 & 0.60 & 2.00 & 33.44 \\
\hline $\mathrm{U}$ & 10 & 3245.00 & 2066.09 & 1000.00 & 7870.00 & 63.67 \\
\hline $\mathrm{V}$ & 5 & 7.04 & 0.50 & 6.60 & 7.80 & 7.14 \\
\hline $\mathrm{Zn}$ & .5 & 179.40 & 35.18 & 149.00 & 236.00 & 19.61 \\
\hline Bromides & 5 & 32.77 & 27.89 & 4.63 & 70.00 & 85.11 \\
\hline Chlorides & 5 & 1144.20 & 1486.96 & 247.00 & 3760.00 & 129.96 \\
\hline Fluorides & 5 & 215.60 & 55.86 & 140.00 & 272.00 & 25.91 \\
\hline Nitrates & 5 & 1333.90 & 1738.22 & 27.90 & 4250.00 & 130.31 \\
\hline Nitrites & 5 & 1510.80 & 1823.68 & 219.00 & 4670.00 & 120.71 \\
\hline Phosphates & 5 & 114.66 & 87.42 & 18.50 & 195.00 & 76.24 \\
\hline
\end{tabular}


Table 3.11 (continued)

\begin{tabular}{|c|c|c|c|c|c|c|}
\hline Variable & $\mathbf{N}$ & Mean & Std. Dev. & Minimum & Maximum & \%R.E. \\
\hline Sulfates & 5 & 1170.20 & 1048.85 & 339.00 & 2960.00 & 89.63 \\
\hline Cyanide & 0 & · & : & & $\cdot$ & $\cdot$ \\
\hline \multicolumn{7}{|c|}{$\begin{array}{l}\text { Unweighted statistics over BVEST Tank Farm } \\
\qquad \text { (mass fraction }=0.193480 \text { ) }\end{array}$} \\
\hline $\mathrm{Ag}$ & 5 & 17.33 & 21.27 & 2.03 & 50.00 & 122.74 \\
\hline $\mathrm{Al}$ & 5 & 1776.40 & 840.66 & 852.00 & 2800.00 & 47.32 \\
\hline As & 5 & 21.24 & 22.78 & 4.40 & 50.00 & 107.25 \\
\hline B & 4 & 7.38 & 2.10 & 5.03 & 10.00 & 28.48 \\
\hline $\mathrm{Ba}$ & 5 & 62.98 & 11.69 & 48.40 & 78.00 & 18.56 \\
\hline $\mathrm{Be}$ & 5 & 1.28 & 1.73 & 0.00 & 3.66 & 134.94 \\
\hline $\mathrm{Ca}$ & 5 & 54600.00 & 18658.91 & 33600.00 & 83900.00 & 34.17 \\
\hline$C d$ & 5 & 27.40 & 8.72 & 16.10 & 39.00 & 31.81 \\
\hline Co & 3 & 3.02 & 1.99 & 1.30 & 5.20 & 66.01 \\
\hline $\mathrm{Cr}$ & 5 & 179.20 & 42.01 & 146.00 & 248.00 & 23.45 \\
\hline Cs & 2 & 2.69 & 0.17 & 2.57 & 2.81 & 6.31 \\
\hline $\mathrm{Cu}$ & 3 & 49.67 & 24.11 & 33.70 & 77.40 & 48.54 \\
\hline $\mathrm{Fe}$ & 5 & 2464.00 & 896.18 & 1900.00 & 4040.00 & 36.37 \\
\hline $\mathrm{Hg}$ & 5 & 39.95 & 41.05 & 8.44 & 105.00 & 102.77 \\
\hline $\mathrm{K}$ & 5 & 13054.00 & 8602.88 & 3270.00 & 25200.00 & 65.90 \\
\hline $\mathrm{Mg}$ & 5 & 10470.00 & 4946.89 & 3620.00 & 16000.00 & 47.25 \\
\hline $\mathrm{Mn}$ & 5 & 114.20 & 118.89 & 0.00 & 275.00 & 104.10 \\
\hline $\mathrm{Na}$ & 5 & 50860.00 & 25256.05 & 15400.00 & 82000.00 & 49.66 \\
\hline $\mathrm{Ni}$ & 5 & 84.80 & 18.32 & 69.60 & 110.00 & 21.61 \\
\hline$P$ & 2 & 14850.00 & 1626.35 & 13700.00 & 16000.00 & 10.95 \\
\hline $\mathrm{Pb}$ & 5 & 352.60 & 64.91 & 290.00 & 450.00 & 18.41 \\
\hline $\mathrm{Sb}$ & 3 & 45.67 & 17.04 & 26.00 & 56.00 & 37.31 \\
\hline Se & 5 & 15.62 & 15.75 & 4.40 & 39.00 & 100.85 \\
\hline $\mathrm{Si}$ & 3 & 2059.67 & 1682.83 & 159.00 & 3360.00 & 81.70 \\
\hline $\mathrm{Sr}$ & 4 & 265.00 & 44.16 & 200.00 & 295.00 & 16.66 \\
\hline
\end{tabular}


Table 3.11 (continued)

\begin{tabular}{|c|c|c|c|c|c|c|}
\hline Variable & $\mathbf{N}$ & Mean & Std. Dev. & Minimum & Maximum & \%R.E. \\
\hline Th & 5 & 10516.00 & 3026.17 & 7460.00 & 14000.00 & 28.78 \\
\hline $\mathrm{Tl}$ & 5 & 29.44 & 26.49 & 10.00 & 75.20 & 89.99 \\
\hline $\mathrm{U}$ & 5 & 29700.00 & 8887.91 & 17000.00 & 39700.00 & 29.93 \\
\hline V & 3 & 3.25 & 2.58 & 0.38 & 5.37 & 79.33 \\
\hline $\mathrm{Zn}$ & 3 & 951.00 & 176.55 & 756.00 & 1100.00 & 18.56 \\
\hline Bromides & 2 & 279.50 & 269.41 & 89.00 & 470.00 & 96.39 \\
\hline Chlorides & 2 & 2145.00 & 1449.57 & 1120.00 & 3170.00 & 67.58 \\
\hline Fluorides & 2 & 171.00 & 19.80 & 157.00 & 185.00 & 11.58 \\
\hline Nitrates & 2 & 146000.00 & 28284.27 & 126000.00 & 166000.00 & 19.37 \\
\hline Nitrites & 0 & • & - & . & $\cdot$ & . \\
\hline Phosphates & 2 & 205.00 & 7.07 & 200.00 & 210.00 & 3.45 \\
\hline Sulfates & 2 & 5785.00 & 3174.91 & 3540.00 & 8030.00 & 54.88 \\
\hline Cyanide & 1 & 5.40 & . & 5.40 & 5.40 & . \\
\hline \multicolumn{7}{|c|}{$\begin{array}{l}\text { Unweighted statistics over GAAT Tank Farm } \\
\text { (mass fraction }=0.203977 \text { ) }\end{array}$} \\
\hline $\mathrm{Ag}$ & 42 & 4.96 & 7.27 & 0.01 & 26.30 & 146.55 \\
\hline $\mathrm{Al}$ & 31 & 10754.79 & 11429.63 & 17.50 & 51100.00 & 106.27 \\
\hline As & 39 & 2.30 & 2.03 & 0.47 & 7.00 & 88.07 \\
\hline B & 31 & 16.32 & 20.41 & 2.50 & 104.00 & 125.07 \\
\hline $\mathrm{Ba}$ & 42 & 111.65 & 208.99 & 2.94 & 1300.00 & 187.19 \\
\hline $\mathrm{Be}$ & 42 & 2.62 & 4.16 & 0.00 & 15.60 & 159.17 \\
\hline $\mathrm{Ca}$ & 31 & 7776.19 & 8596.51 & 301.00 & 31600.00 & 110.55 \\
\hline $\mathrm{Cd}$ & 42 & 4.08 & 3.45 & 0.52 & 22.00 & 84.65 \\
\hline $\mathrm{Co}$ & 31 & 3.58 & 4.06 & 1.30 & 24.20 & 113.34 \\
\hline $\mathrm{Cr}$ & 42 & 505.17 & 560.42 & 97.00 & 2400.00 & 110.94 \\
\hline Cs & 0 & . & . & - & . & . \\
\hline $\mathrm{Cu}$ & 31 & .51 .59 & 26.70 & 6.03 & 115.00 & 51.75 \\
\hline $\mathrm{Fe}$ & 31 & 6163.39 & 6285.01 & 195.00 & 20300.00 & 101.97 \\
\hline $\mathrm{Hg}$ & 42 & 86.93 & 88.36 & 0.82 & 416.00 & 101.65 \\
\hline
\end{tabular}


Table 3.11 (continued)

\begin{tabular}{|c|c|c|c|c|c|c|}
\hline Variable & $\mathbf{N}$ & Mean & Std. Dev. & Minimum & Maximum & \%R.E. \\
\hline $\mathrm{K}$ & 31 & 3711.77 & 4076.18 & 219.00 & 13000.00 & 109.82 \\
\hline $\mathrm{Mg}$ & 31 & 1294.52 & 2297.73 & 47.80 & 11100.00 & 177.50 \\
\hline Mn & 42 & 156.65 & 274.52 & 0.00 & 1510.00 & 175.24 \\
\hline $\mathrm{Na}$ & 31 & 29610.97 & 21026.95 & 5070.00 & 68700.00 & 71.01 \\
\hline $\mathrm{Ni}$ & 42 & 66.99 & 60.11 & 4.60 & 233.00 & 89.73 \\
\hline $\mathbf{P}$ & 0 & . & . & . & . & . \\
\hline $\mathrm{Pb}$ & 42 & 594.52 & 1188.35 & 5.00 & 7320.00 & 199.88 \\
\hline $\mathrm{Sb}$ & 31 & 25.83 & 15.22 & 9.70 & 50.00 & 58.92 \\
\hline $\mathrm{Se}$ & 39 & 1.72 & 1.81 & 0.30 & 5.40 & 105.07 \\
\hline $\mathrm{Si}$ & 4 & 1084.00 & 1523.30 & 190.00 & 3360.00 & 140.53 \\
\hline $\mathrm{Sr}$ & 31 & 28.71 & 20.98 & 2.43 & 66.20 & 73.06 \\
\hline $\mathrm{Th}$ & 31 & 4267.15 & 3979.27 & 94.60 & 16400.00 & 93.25 \\
\hline $\mathrm{Tl}$ & 39 & 7.98 & 11.92 & 0.30 & 36.10 & 149.38 \\
\hline$U$ & 42 & 73116.50 & 85516.06 & 451.00 & 330000.00 & 116.96 \\
\hline $\mathrm{V}$ & 31 & 2.74 & 1.42 & 0.50 & 5.40 & 51.64 \\
\hline $\mathrm{Zn}$ & 31 & 57.09 & 69.78 & 1.50 & 362.00 & 122.23 \\
\hline Bromides & 28 & 534.18 & 1095.16 & 5.00 & 3280.00 & 205.01 \\
\hline Chlorides & 28 & 339.99 & 687.00 & 5.00 & 2840.00 & 202.07 \\
\hline Fluorides & 28 & 1514.86 & 2373.40 & 17.50 & 11900.00 & 156.67 \\
\hline Nitrates & 28 & 11396.75 & 15168.04 & 10.00 & 42000.00 & 133.09 \\
\hline Nitrites & 0 & . & . & . & . & . \\
\hline Phosphates & 28 & 2960.50 & 2144.33 & 147.00 & 7900.00 & 72.43 \\
\hline Sulfates & 28 & 3751.50 & 3288.49 & 250.00 & 9400.00 & 87.66 \\
\hline Cyanide & 0 & . & . & . & - & - \\
\hline \multicolumn{7}{|c|}{$\begin{array}{l}\text { Unweighted statistics over MVST Tank Farm } \\
\quad \text { (mass fraction }=0.573226)\end{array}$} \\
\hline $\mathrm{Ag}$ & 8 & 11.75 & 8.36 & 5.40 & 30.00 & 71.11 \\
\hline $\mathrm{Al}$ & 8 & 5153.75 & 5036.15 & 830.00 & 16000.00 & 97.72 \\
\hline As & 8 & 43.13 & 15.73 & 27.00 & 69.00 & 36.4 .8 \\
\hline
\end{tabular}


Table 3.11 (continued)

\begin{tabular}{|c|c|c|c|c|c|c|}
\hline Variable & $\mathbf{N}$ & Mean & Std. Dev. & Minimum & Maximum & \%R.E. \\
\hline B & 8 & 7.18 & 6.81 & 1.20 & 22.00 & 94.92 \\
\hline $\mathrm{Ba}$ & 8 & 68.38 & 49.83 & 17.00 & 180.00 & 72.87 \\
\hline $\mathrm{Be}$ & 8 & 0.00 & 0.00 & 0.00 & 0.00 & . \\
\hline $\mathrm{Ca}$ & 8 & 39950.00 & 18116.05 & 5600.00 & 62000.00 & 45.35 \\
\hline $\mathrm{Cd}$ & 8 & 14.79 & 13.69 & 1.50 & 42.00 & 92.58 \\
\hline $\mathrm{Co}^{-}$ & 0 & . & . & . & . & . \\
\hline $\mathrm{Cr}$ & 8 & 72.13 & 44.34 & 27.00 & 170.00 & 61.48 \\
\hline Cs & 0 & . & . & $\therefore$ & . & . \\
\hline $\mathrm{Cu}$ & 0 & . & . & . & . & . \\
\hline $\mathrm{Fe}$ & 8 & 2061.25 & 2408.82 & 420.00 & 7700.00 & 116.86 \\
\hline $\mathrm{Hg}$ & 8 & 27.63 & 18.29 & 11.00 & 64.00 & 66.21 \\
\hline $\mathrm{K}$ & 8 & 8775.00 & 2971.17 & 6100.00 & 15000.00 & 33.86 \\
\hline $\mathrm{Mg}$ & 8 & 6521.25 & 4474.90 & 870.00 & 15000.00 & 68.62 \\
\hline Mn & 8 & 0.00 & 0.00 & 0.00 & 0.00 & . \\
\hline $\mathrm{Na}$ & 8 & 63250.00 & 8713.70 & 48000.00 & 71000.00 & 13.78 \\
\hline $\mathrm{Ni}$ & 8 & 43.25 & 24.80 & 17.00 & 92.00 & 57.34 \\
\hline$P$ & 0 & . & . & . & . & .. \\
\hline $\mathrm{Pb}$ & 8 & 235.00 & 118.92 & 120.00 & 470.00 & 50.61 \\
\hline $\mathrm{Sb}$ & 0 & . & . & . & . & . \\
\hline $\mathrm{Se}$ & 8 & 50.00 & 16.98 & 29.00 & 86.00 & 33.96 \\
\hline $\mathrm{Si}$ & 0 & . & . & . & . & . \\
\hline $\mathrm{Sr}$ & 8 & 122.50 & 42.34 & 30.00 & 170.00 & 34.57 \\
\hline Th & 8 & 4448.75 & 3929.44 & 1370.00 & 11800.00 & 88.33 \\
\hline $\mathrm{Tl}$ & 8 & 16.13 & 5.62 & 9.00 & 27.00 & 34.84 \\
\hline $\mathbf{U}$ & 8 & 8308.75 & 8098.35 & 1960.00 & 24100.00 & 97.47 \\
\hline $\mathrm{V}$ & 0 & . & . & . & . & . \\
\hline $\mathrm{Zn}$ & 0 & . & . & . & . & . \\
\hline Bromides & 0 & . & . & . & . & . \\
\hline Chlorides & 0 & . & . & . & . & . \\
\hline
\end{tabular}


Table 3.11 (continued)

\begin{tabular}{|c|c|c|c|c|c|c|}
\hline & & Mean & Std. Dev. & Minimum & Maximum & \%R.E. \\
\hline Variable & $\mathbf{N}$ & & & $\cdot$ & & . \\
\hline Fluorides & 0 & . & . & · & . & $\cdot$ \\
\hline Nitrates & 0 & $r$. & ; & . & · & $\cdot$ \\
\hline Nitrites & 0 & & 9 & - & · & $\cdot$ \\
\hline Phosphates & 0 & . & $\cdot$ & • & $\cdot$ & $\cdot$ \\
\hline Variable & $\mathbf{N}$ & & Std. Dev. & Minimum & Maximum & \%R.E. \\
\hline & & Unweight & ed statistics ov & all tanks & & \\
\hline $\mathrm{H}_{2} \mathrm{O}$ fraction & 37 & 0.71 & 0.11 & 0.42 & 0.89 & 15.37 \\
\hline Gross alpha & 87 & 92537.24 & 131079.69 & 900.00 & 650000.00 & 141.65 \\
\hline Gross beta & 87 & 8360650.57 & 12640862.86 & 70000.00 & 59000000.00 & 151.19 \\
\hline${ }^{241} \mathrm{Am}$ & 40 & 9787.75 & 9352.41 & 0.00 & 52000.00 & 95.55 \\
\hline${ }^{198} \mathrm{Au}$ & 8 & 5133.75 & 3622.21 & 1480.00 & 9990.00 & 70.56 \\
\hline${ }^{4} \mathrm{CI}$ & 15 & 494.80 & 563.00 & 17.00 & 2200.00 & 113.78 \\
\hline${ }^{252} \mathrm{Cf}$ & 17 & 126.12 & 174.52 & 2.00 & 500.00 & 138.38 \\
\hline${ }^{144} \mathrm{Ce}$ & 10 & 12880.00 & 8787.09 & 3900.00 & 28000.00 & 68.22 \\
\hline${ }^{243} \mathrm{Cm}$ & 10 & 12340.00 & 7840.24 & 3600.00 & 26000.00 & 63.54 \\
\hline${ }^{244} \mathrm{Cm}$ & 71 & 61336.63 & 102126.04 & 6.00 & 530000.00 & 166.50 \\
\hline${ }^{60} \mathrm{Co}$ & 74 & 35237.11 & 55253.91 & 12.00 & 260000.00 & 156.81 \\
\hline${ }^{134} \mathrm{Cs}$ & 36 & 3337.14 & 7769.81 & 20.00 & 46000.00 & 232.83 \\
\hline
\end{tabular}


Table 3.12 (contiqued)

\begin{tabular}{|c|c|c|c|c|c|c|c|}
\hline${ }^{152} \mathrm{Eu}$ & 66 & 130293.18 & $\begin{array}{l}1459871.60 \\
277221.69\end{array}$ & 13000.00 & 11000000.00 & 207.12 & \\
\hline${ }^{154} \mathrm{Eu}$ & 68 & 68259.07 & $1373 \mathrm{i} 3.41$ & $\begin{array}{r}90.00 \\
900\end{array}$ & 1300000.00 & 212.77 & \\
\hline${ }^{155} \mathrm{Eu}$ & 62 & 20478.87 & $35811 . k \cdot 4$ & 52.00 & 640000.00 & 201.17 & \\
\hline${ }^{3} \mathrm{H}$ & 16 & 39.35 & 47.54 & 0.00 & 2000.00 & 174.87 & \\
\hline${ }^{95} \mathrm{Nb}$ & 12 & 3517.50 & 3656.52 & $: \quad 560.00$ & 12210.00 & $103:$ & \\
\hline${ }^{237} \mathrm{~Np}$ & 7 & 10.44 & 4.48 & 6.10 & 19.00 & 42.87 & \\
\hline${ }^{238} \mathrm{Pu} /{ }^{241} \mathrm{Am}$ & 42 & $7653: 31$ & 10705.22 & 0.00 & 51300.00 & 139.88 & \\
\hline${ }^{239} \mathrm{Pu} /{ }^{240} \mathrm{Pu}$ & 60 & 5401.60 & 4965.43 & ; 210.00 & 24900.00 & 91.93 & \\
\hline${ }^{238} \mathrm{Pu}$ & 63 & 8092.32 & 10244.45 & 6.00 & 48000.00 & 126.59 & 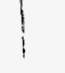 \\
\hline${ }^{239} \mathrm{Pu}$ & 44 & 3457.32 & 2801.62 & 100.00 & 11000.00 & 81.03 & \\
\hline${ }^{240} \mathrm{Pu}$ & 28 & 1735.88 & 2302.64 & 3.50 & 8800.00 & 132.65 & \\
\hline${ }^{241} \mathrm{Pu}$ & 28 & 13840.98 & 17230.17 & 0.10 & 66300.00 & 124.49 & \\
\hline${ }^{242} \mathrm{Pu}$ & 30 & 3.93 & 5.97 & 0.00 & 20.00 & 151.95 & \\
\hline${ }^{244} \mathrm{Pu}$ & 26 & 0.32 & 0.42 & 0.00 & 1.00 & 130.24 & \\
\hline${ }^{106} \mathrm{Ru}$ & 10 & 22860.00 & 17927.33 & 5700.00 & 62000.00 & 78.42 & \\
\hline${ }^{90} \mathrm{Sr}$ & 76 & 3418910.53 & 6108028.55 & 16000.00 & 32000000.00 & 178.65 & \\
\hline${ }^{99} \mathrm{Tc}$ & 8 & 202.63 & 273.81 & 13.00 & 810.00 & 135.13 & \\
\hline${ }^{232} \mathrm{Th}$ & 39 & 62.59 & 120.81 & 0.40 & 500.00 & 193.02 & \\
\hline${ }^{233} \mathrm{U}$ & 64 & 3231.99 & 4675.30 & 0.00 & 24000.00 & 144.66 & \\
\hline${ }^{234} \mathrm{U}$ & 35 & 846.37 & 908.01 & 8.80 & 2719.90 & 107.28 & \\
\hline${ }^{235} \mathrm{U}$ & 28 & 21.14 & 31.10 & 0.40 & 106.90 & 147.15 & \\
\hline${ }^{236} \mathrm{U}$ & 28 & 1.93 & 2.26 & 0.00 & 9.50 & 117.28 & \\
\hline${ }^{238} \mathrm{U}$ & 40 & 846.03 & 894.32 & 11.40 & 3000.00 & 105.71 & \\
\hline${ }^{233} \mathrm{U} /{ }^{234} \mathrm{U}$ & 4 & 1061.75 & 483.64 & 342.00 & 1365.00 & 45.55 & \\
\hline${ }^{95} \mathrm{Zr}$ & 18 & 36782.22 & 45837.85 & 1700.00 & 130000.00 & 124.62 & \\
\hline \multicolumn{8}{|c|}{ Weighted statistics over all tanks } \\
\hline $\mathrm{H}_{2} \mathrm{O}$ fraction & 37 & 0.71 & 0.05 & 0.42 & 0.89 & 6.68 & \\
\hline Gross alpha & 87 & 61104.97 & 35157.89 & 900.00 & 650000.00 & 57.54 & . \\
\hline
\end{tabular}


Table 3.12 (continued)

\begin{tabular}{|c|c|c|c|c|c|c|}
\hline Variable & $\mathbf{N}$ & Mean & Std. Dev. & Minimum & Maximum & \%R.E. \\
\hline Gross beta & 87 & 6181567.57 & 4818034.97 & 70000.00 & 59000000.00 & 77.94 \\
\hline${ }^{241} \mathrm{Am}$ & 40 & 8446.27 & 3084.74 & 0.00 & 52000.00 & 36.52 \\
\hline${ }^{198} \mathrm{Au}$ & 8 & 3732.39 & 1887.97 & 1480.00 & 9990.00 & 50.58 \\
\hline${ }^{4} \mathrm{Cl}$ & 15 & 415.05 & 209.50 & 17.00 & 2200.00 & 50.48 \\
\hline${ }^{252} \mathrm{Cf}$ & 17 & 38.27 & 34.96 & 2.00 & 500.00 & 91.36 \\
\hline${ }^{144} \mathrm{Ce}$ & 10 & 10647.08 & 4842.21 & 3900.00 & 28000.00 & 45.48 \\
\hline${ }^{243} \mathrm{Cm}$ & 10 & 10330.07 & 4285.77 & 3600.00 & 26000.00 & 41.49 \\
\hline${ }^{244} \mathrm{Cm}$ & 71 & 36370.20 & 24780.28 & 6.00 & 530000.00 & 68.13 \\
\hline${ }^{60} \mathrm{Co}$ & 74 & 33519.35 & 21958.20 & 12.00 & 260000.00 & 65.51 \\
\hline${ }^{134} \mathrm{Cs}$ & 36 & 4893.24 & 5555.53 & 20.00 & 46000.00 & 113.53 \\
\hline${ }^{137} \mathrm{Cs}$ & 76 & 577076.13 & 667622.19 & 13000.00 & 11000000.00 & 115.69 \\
\hline${ }^{152} \mathrm{Eu}$ & 66 & 131531.25 & 135123.47 & 90.00 & 1300000.00 & 102.73 \\
\hline${ }^{154} \mathrm{Eu}$ & 68 & 69723.86 & 67133.79 & 64.00 & 640000.00 & 96.29 \\
\hline${ }^{15 s} \mathrm{Eu}$ & 62 & 21166.34 & 17751.62 & 52.00 & 133000.00 & 83.87 \\
\hline${ }^{3} \mathrm{H}$ & 16 & 34.73 & 20.03 & 0.00 & 140.00 & 57.68 \\
\hline${ }^{95} \mathrm{Nb}$ & 12 & 2296.02 & 1827.92 & 560.00 & 12210.00 & 79.61 \\
\hline${ }^{237} \mathrm{~Np}$ & 7 & 7.77 & 0.99 & 6.10 & 19.00 & 12.77 \\
\hline${ }^{238} \mathrm{Pu} /{ }^{241} \mathrm{Am}$ & 42 & 7402.61 & 4870.59 & 0.00 & 51300.00 & 65.80 \\
\hline${ }^{239} \mathrm{Pu} /{ }^{240} \mathrm{Pu}$ & 60 & 4767.57 & 2277.67 & 210.00 & 24900.00 & 47.77 \\
\hline${ }^{238} \mathrm{Pu}$ & 63 & 6198.78 & 3491.46 & 6.00 & 48000.00 & 56.32 \\
\hline${ }^{239} \mathrm{Pu}$ & 44 & 3031.95 & 1188.23 & 100.00 & 11000.00 & 39.19 \\
\hline${ }^{240} \mathrm{Pu}$ & 28 & 950.28 & 541.16 & 3.50 & 8800.00 & 56.95 \\
\hline${ }^{241} \mathrm{Pu}$ & 28 & 10716.94 & 6639.40 & 0.10 & 66300.00 & 61.95 \\
\hline${ }^{242} \mathrm{Pu}$ & 30 & 2.05 & 1.53 & 0.00 & 20.00 & 74.82 \\
\hline${ }^{244} \mathrm{Pu}$ & 26 & 0.19 & 0.13 & 0.00 & 1.00 & 68.84 \\
\hline${ }^{106} \mathrm{Ru}$ & 10 & 18256.71 & 9435.32 & 5700.00 & 62000.00 & 51.68 \\
\hline${ }^{90} \mathrm{Sr}$ & 76 & 1850860.69 & 1424708.15 & 16000.00 & 32000000.00 & 76.98 \\
\hline${ }^{99} \mathrm{Tc}$ & 8 & 372.46 & 92.83 & 13.00 & 810.00 & 24.92 \\
\hline${ }^{232} \mathrm{Th}$ & 39 & 25.88 & 22.72 & 0.40 & 500.00 & 87.81 \\
\hline
\end{tabular}


Table 3.12 (continued)

\begin{tabular}{|c|c|c|c|c|c|c|}
\hline Variable & $\mathbf{N}$ & Mean & Std. Dev. & Minimum & Maximum & \%R.E. \\
\hline${ }^{233} \mathrm{U}$ & 64 & 2136.82 & 1596.40 & 0.00 & 24000.00 & 74.71 \\
\hline${ }^{234} \mathrm{U}$ & 35 & 950.46 & 390.14 & 8.80 & 2719.90 & 41.05 \\
\hline${ }^{235} \mathrm{U}$ & 28 & 24.86 & 13.48 & 0.40 & 106.90 & 54.21 \\
\hline${ }^{236} \mathrm{U}$ & 28 & 2.07 & 0.99 & 0.00 & 9.50 & 47.68 \\
\hline${ }^{238} \mathrm{U}$ & 40 & 943.56 & 383.49 & .11 .40 & 3000.00 & 40.64 \\
\hline${ }^{233} U /{ }^{334} U$ & 4 & 1061.75 & 218.43 & 342.00 & 1365.00 & 20.57 \\
\hline${ }^{95} \mathrm{Zr}$ & 18 & 26302.35 & 27804.62 & 1700.00 & 130000.00 & 105.71 \\
\hline \multicolumn{7}{|c|}{$\begin{array}{l}\text { Unweighted statistics over OHF Tank Farm } \\
\text { (mass fraction }=0.029317)\end{array}$} \\
\hline $\mathrm{H}_{2} \mathrm{O}$ fraction & 5 & 0.67 & 0.05 & 0.60 & 0.72 & 7.79 \\
\hline Gross alpha & 10 & 386000.00 & 169784.18 & 150000.00 & 650000.00 & 43.99 \\
\hline Gross beta & 10 & 35900000.00 & 14301903.53 & 16000000.00 & 59000000.00 & 39.84 \\
\hline${ }^{241} \mathrm{Am}$ & 6 & 20366.67 & 16831.12 & 8000.00 & 52000.00 & 82.64 \\
\hline${ }^{198} \mathrm{Au}$ & 0 & . & . & . & - & $\cdot$ \\
\hline${ }^{4} \mathrm{Cl}$ & 5 & 707.00 & 891.77 & 17.00 & 2200.00 & 126.14 \\
\hline${ }^{252} \mathrm{Cf}$ & 7 & 287.43 & 171.17 & 2.00 & 500.00 & 59.55 \\
\hline${ }^{144} \mathrm{Ce}$ & 0 & . & . & . & . & . \\
\hline${ }^{243} \mathrm{Cm}$ & 0 & . & . & . & . & . \\
\hline${ }^{244} \mathrm{Cm}$ & 9 & 280777.78 & 141060.07 & 97000.00 & 530000.00 & 50.24 \\
\hline${ }^{60} \mathrm{Co}$ & 10 & 104000.00 & 69124.69 & 43000.00 & 260000.00 & 66.47 \\
\hline${ }^{134} \mathrm{Cs}$ & 5 & 556.00 & 96.33 & 480.00 & 710.00 & 17.33 \\
\hline${ }^{137} \mathrm{Cs}$ & 10 & 573000.00 & 471594.22 & 250000.00 & 1600000.00 & 82.30 \\
\hline${ }^{152} \mathrm{Eu}$ & 10 & 67100.00 & 35328.46 & 35000.00 & 140000.00 & 52.65 \\
\hline${ }^{154} \mathrm{Eu}$ & 10 & 48690.00 & 30710.20 & 8900.00 & 120000.00 & 63.07 \\
\hline${ }^{155} \mathrm{Eu}$ & 8 & 7875.00 & 6700.91 & 2700.00 & 23000.00 & 85.09 \\
\hline${ }^{3} \mathrm{H}$ & 5 & 52.00 & 31.82 & 26.00 & 95.00 & 61.19 \\
\hline${ }^{95} \mathrm{Nb}$ & 0 & . & . & . & . & . \\
\hline${ }^{237} \mathrm{~Np}$ & 5 & 12.18 & 4.11 & 8,90 & 19.00 & 33.71 \\
\hline${ }^{238} \mathrm{Pu} /{ }^{41} \mathrm{Am}$ & 0 & . & . & . & . & . \\
\hline
\end{tabular}


Table 3.12 (continued)

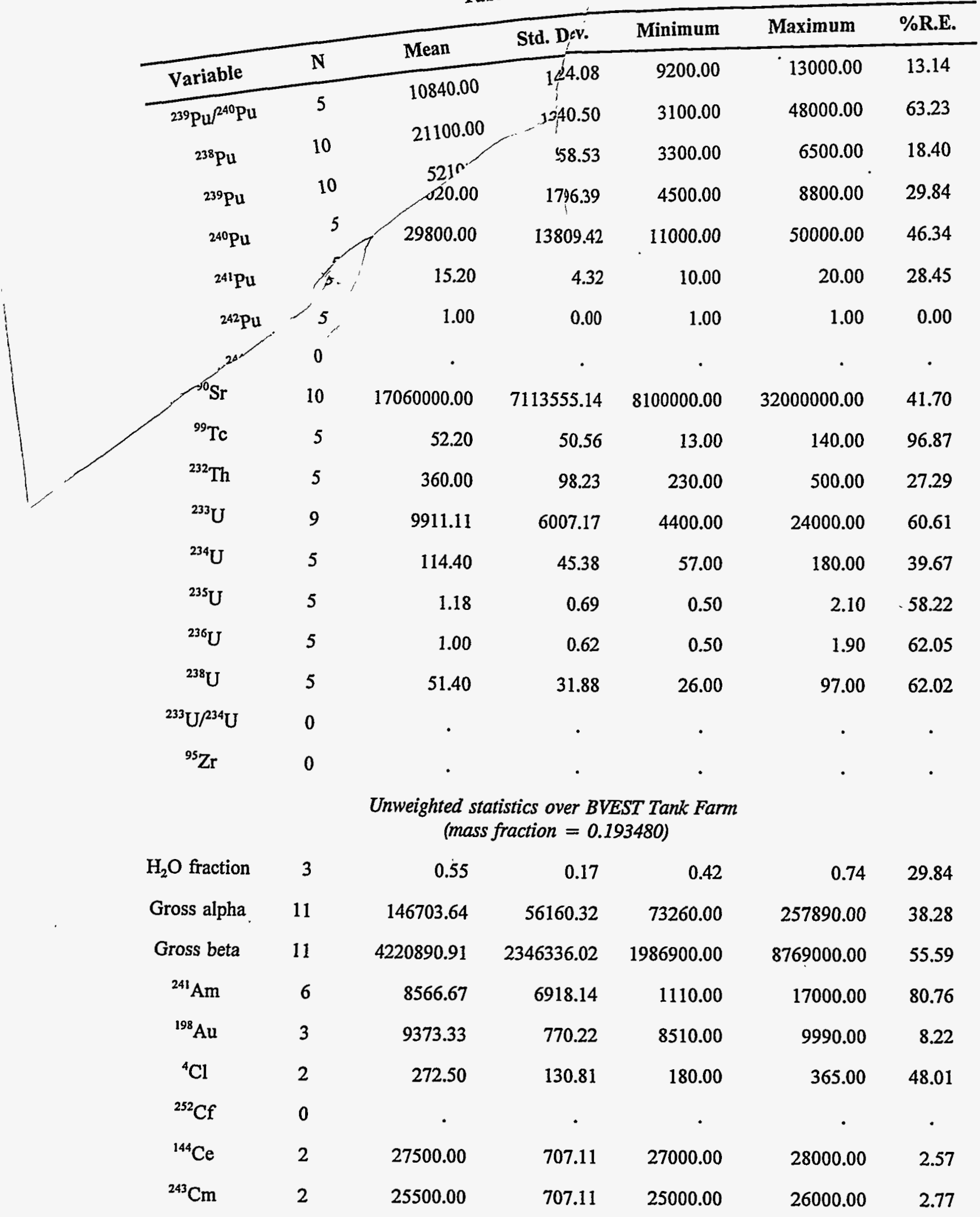


Table 3.12 (continued)

\begin{tabular}{|c|c|c|c|c|c|c|}
\hline$\frac{\text { Variable }}{244}$ & $\mathbf{N}$ & Mean & Std. Dev. & Minimum & Maximum & \%R.E. \\
\hline $\begin{array}{l}{ }^{244} \mathrm{Cm} \\
{ }^{60} \mathrm{Co}\end{array}$ & 8 & 87232.50 & 4403 & 29970.00 & 167000.00 & 56.34 \\
\hline${ }^{134} \mathrm{Cs}$ & 5 & 7378.00 & 326,63 & 27380.00 & 252000.00 & 95.79 \\
\hline${ }^{137} \mathrm{Cs}$ & 8 & 297730.00 & 12806.91 & 130000.00 & 11000.00 & 44.30 \\
\hline${ }^{152} \mathrm{Eu}$ & 8 & 742775.00 & 34406.55 & 403300.00 & 195000.00 & 43.01 \\
\hline${ }^{154} \mathrm{Eu}$ & 8 & 377396.25 & 159989.94 & 197950.00 & 400000 & 46.33 \\
\hline${ }^{155} \mathrm{Eu}$ & 8 & 100046.25 & 26505.62 & 58000.00 & 133000.00 & 29 \\
\hline${ }^{3} \mathrm{H}$ & 0 & ' & • & • & • & \\
\hline${ }^{95} \mathrm{Nb}$ & 4 & 7827.50 & 3154.63 & 4700.00 & 12210.00 & 40.30 \\
\hline${ }^{237} \mathrm{~Np}$ & 2 & 6.10 & 0.00 & 6.10 & 6.10 & 0.00 \\
\hline${ }^{238} \mathrm{Pu} /{ }^{41} \mathrm{Am}$ & 3 & 37133.33 & 12438.78 & 28000.00 & 51300.00 & 33.50 \\
\hline${ }^{239} \mathrm{Pu} /{ }^{240} \mathrm{Pu}$ & 8 & 12418.75 & 7302.58 & 4800.00 & 24900.00 & 58.80 \\
\hline${ }^{238} \mathrm{Pu}$ & 6 & 16128.33 & 8194.94 & 7200.00 & 30710.00 & 50.81 \\
\hline${ }^{239} \mathrm{Pu}$ & 3 & 3460.00 & 1015.28 & 2600.00 & 4580.00 & 29.34 \\
\hline${ }^{240} \mathrm{Pu}$ & 3 & 2836.67 & 555.91 & 2300.00 & 3410.00 & 19.60 \\
\hline${ }^{241} \mathrm{Pu}$ & 3 & 48100.00 & 15888.05 & 37000.00 & 66300.00 & 33.03 \\
\hline${ }^{242} \mathrm{Pu}$ & 3 & 2.47 & 0.64 & 2.00 & 3.20 & 26.06 \\
\hline${ }^{244} \mathrm{Pu}$ & 3 & 0.70 & 0.52 & 0.10 & 1.00 & 74.23 \\
\hline${ }^{106} \mathrm{Ru}$ & 2 & 53000.00 & 12727.92 & 44000.00 & 62000.00 & 24.01 \\
\hline${ }^{90} \mathrm{Sr}$ & 8 & 1058012.50 & 921790.65 & 377400.00 & 2726900.00 & 87.12 \\
\hline${ }^{99} \mathrm{Tc}$ & 3 & 453.33 & 326.24 & 170.00 & 810.00 & 71.96 \\
\hline${ }^{232} \mathrm{Th}$ & 3 & 34.67 & 7.23 & 30.00 & 43.00 & 20.87 \\
\hline${ }^{233} \mathrm{U}$ & 8 & 7926.94 & 5803.50 & 1850.00 & 19408.10 & 73.21 . \\
\hline${ }^{234} \mathrm{U}$ & 3 & 538.23 & 378.65 & 144.70 & 900.00 & 70.35 \\
\hline${ }^{235} \mathrm{U}$ & 3 & 5.53 & 1.10 & 4.30 & 6.40 & 19.82 \\
\hline${ }^{236} U$ & 3 & 6.53 & 2.74 & 4.10 & 9.50 & 41.93 \\
\hline${ }^{238} \mathrm{U}$ & 3 & 415.33 & 91.80 & 313.60 & 492.00 & 22.10 \\
\hline${ }^{233} U{ }^{234} U$ & 0 & . & • & . & $\cdot$ & $\cdot$ \\
\hline${ }^{95} \mathrm{Zr}$ & 5 & 83252.00 & 38975.31 & 39000.00 & 125800.00 & 46.82 \\
\hline
\end{tabular}


Table 3.12 (continued)

\begin{tabular}{|c|c|c|c|c|c|c|}
\hline Variable & $\mathbf{N}$ & Mean & Std. Dev. & Minimum & Maximum & \%R.E. \\
\hline \multicolumn{7}{|c|}{$\begin{array}{l}\text { Unweighted statistics over GAAT Tank Farm } \\
\qquad \text { (mass fraction }=0.203977)\end{array}$} \\
\hline $\mathrm{H}_{2} \mathrm{O}$ fraction & 29 & 0.73 & 0.10 & 0.58 & 0.89 & 13.32 \\
\hline Gross alpha & 42 & 25179.52 & 28326.30 & 900.00 & 110000.00 & 112.50 \\
\hline Gross beta & 42 & 3294190.48 & 3110677.98 & 70000.00 & 12000000.00 & 94.43 \\
\hline${ }^{241} \mathrm{Am}$ & 20 & 7306.50 & 6439.53 & 0.00 & 22000.00 & 88.13 \\
\hline${ }^{198} \mathrm{Au}$ & 0 & - & . & - & - & - \\
\hline${ }^{4} \mathrm{Cl}$ & 0 & $\cdot$ & $\cdot$ & - & $\cdot$ & - \\
\hline${ }^{252} \mathrm{Cf}$ & 10 & 13.20 & 14.44 & 4.00 & 50.00 & 109.36 \\
\hline${ }^{144} \mathrm{Ce}$ & 0 & . & - & - & - & - \\
\hline${ }^{243} \mathrm{Cm}$ & 0 & $\cdot$ & · & - & - & - \\
\hline${ }^{244} \mathrm{Cm}$ & 38 & 14471.34 & 18549.17 & 6.00 & 58300.00 & 128.18 \\
\hline${ }^{60} \mathrm{Co}$ & 41 & 2232.10 & 2943.14 & 12.00 & 13000.00 & 131.86 \\
\hline${ }^{134} \mathrm{Cs}$ & 18 & 1126.67 & 1093.41 & 20.00 & 3500.00 & 97.05 \\
\hline${ }^{137} \mathrm{Cs}$ & 42 & 992119.05 & 1903719.42 & 13000.00 & 11000000.00 & 191.88 \\
\hline${ }^{152} \mathrm{Eu}$ & 33 & 4054.55 & 4489.32 & 90.00 & 17000.00 & 110.72 \\
\hline${ }^{154} \mathrm{Eu}$ & 35 & 1833.91 & 2052.90 & 64.00 & 8000.00 & 111.94 \\
\hline${ }^{155} \mathrm{Eu}$ & 30 & 2549.00 & 2869.55 & 52.00 & 11000.00 & 112.58 \\
\hline${ }^{3} \mathrm{H}$ & 11 & 33.60 & 53.57 & 0.00 & 140.00 & 159.42 \\
\hline${ }^{95} \mathrm{Nb}$ & 0 & - & $\cdot$ & $\cdot$ & • & $\cdot$ \\
\hline${ }^{237} \mathrm{~Np}$ & 0 & $\cdot$ & $\cdot$ & $\cdot$ & $\cdot$ & $\cdot$ \\
\hline${ }^{238} \mathrm{Pu} /{ }^{41} \mathrm{Am}$ & 31 & 4970.94 & 6917.63 & 0.00 & 28200.00 & 139.16 \\
\hline${ }^{239} \mathrm{Pu} /{ }^{240} \mathrm{Pu}$ & 31 & 3199.29 & 2836.97 & 210.00 & 11800.00 & 88.67 \\
\hline${ }^{238} \mathrm{Pu}$ & 39 & 3748.10 & 6462.45 & 6.00 & 29000.00 & 172.42 \\
\hline${ }^{239} \mathrm{Pu}$ & 31 & 2891.68 & 3090.54 & 100.00 & 11000.00 & 106.88 \\
\hline${ }^{240} \mathrm{Pu}$ & 20 & 499.73 & 439.33 & 3.50 & 1220.00 & 87.91 \\
\hline${ }^{241} \mathrm{Pu}$ & 20 & 4712.37 & $3886: 16$ & 0.10 & 12000.00 & 82.47 \\
\hline${ }^{242} \mathrm{Pu}$ & 22 & 1.56 & 3.02 & 0.00 & 14.00 & 193.43 \\
\hline${ }^{244} \mathrm{Pu}$ & 18 & 0.07 & 0.05 & 0.00 & 0.10 & 63.82 \\
\hline
\end{tabular}


Table 3.12 (continued)

\begin{tabular}{|c|c|c|c|c|c|c|}
\hline Variable & $\mathbf{N}$ & Mean & Std. Dev. & Minimum & Maximum & \%R.E. \\
\hline${ }^{106} \mathrm{Ru}$ & 0 & . & . & . & . & . \\
\hline${ }^{90} \mathrm{Sr}$ & 42 & 1076904.76 & 1615290.40 & 16000.00 & 8600000.00 & 149.99 \\
\hline${ }^{99} \mathrm{Tc}$ & 0 & . & • & . & . & . \\
\hline${ }^{232} \mathrm{Th}$ & 31 & 17.33 & 16.16 & 0.40 & 66.60 & 93.26 \\
\hline${ }^{233} \mathrm{U}$ & 31 & 785.45 & 831.48 & 0.00 & 3100.00 & 105.86 \\
\hline${ }^{234} U$ & 27 & 1016.16 & 960.68 & 8.80 & 2719.90 & 94.54 \\
\hline - ${ }^{235} \mathrm{U}$ & 20 & 28.47 & 34.27 & 0.40 & 106.90 & 120.40 \\
\hline${ }^{236} U$ & 20 & 1.47 & 1.61 & 0.00 & 6.10 & 109.74 \\
\hline${ }^{238} \mathrm{U}$ & 32 & 1010.57 & 926.18 & 11.40 & 3000.00 & 91.65 \\
\hline${ }^{233} U{ }^{234} U$ & 4 & 1061.75 & 483.64 & 342.00 & 1365.00 & 45.55 \\
\hline${ }^{95} \mathrm{Zr}$ & 0 & . & . & . & . & . \\
\hline
\end{tabular}

Unweighted statistics over MVST Tank Farm (mass fraction $=0.573226$ )

\begin{tabular}{|c|c|c|c|c|c|c|}
\hline $\mathrm{H}_{2} \mathrm{O}$ fraction & 0. & . & & & & \\
\hline Gross alpha & 24 & 63310.83 & 46264.74 & 10730.00 & 222000.00 & 73.08 \\
\hline Gross beta & 24 & 7649616.67 & 10604502.46 & 758500.00 & 51800000.00 & 138.63 \\
\hline${ }^{241} \mathrm{Am}$ & 8 & 8972.50 & 4761.99 & 2960.00 & 17390.00 & 53.07 \\
\hline${ }^{198} \mathrm{Au}$ & 5 & 2590.00 & 1046.52 & 1480.00 & 3700.00 & 40.41 \\
\hline${ }^{4} \mathrm{Cl}$ & 8 & 417.75 & 352.12 & 76.00 & 1050.00 & 84.29 \\
\hline${ }^{252} \mathrm{Cf}$ & 0 & . & . & . & . & \\
\hline${ }^{144} \mathrm{Ce}$ & 8 & 9225.00 & 4781.74 & 3900.00 & 17000.00 & 51.83 \\
\hline${ }^{243} \mathrm{Cm}$ & 8 & 9050.00 & 4136.25 & 3600.00 & 14000.00 & 45.70 \\
\hline${ }^{244} \mathrm{Cm}$ & 16 & 40793.13 & 35331.19 & 3700.00 & 132090.00 & 86.61 \\
\hline${ }^{60} \mathrm{Co}$ & 15 & 51878.00 & 30373.67 & 8100.00 & 112110.00 & 58.55 \\
\hline${ }^{134} \mathrm{Cs}$ & 8 & 7523.38 & 15590.23 & 620.00 & 46000.00 & 207.22 \\
\hline${ }^{137} \mathrm{Cs}$ & 16 & 236666.25 & 210159.51 & 17760.00 & 684000.00 & 88.80 \\
\hline${ }^{152} \mathrm{Eu}$ & 15 & 123490.00 & 204770.58 & 3700.00 & 718000.00 & 165.82 \\
\hline${ }^{154} \mathrm{Eu}$ & 15 & 71424.00 & 104381.74 & 3700.00 & 320000.00 & 146.14 \\
\hline${ }^{155} \mathrm{Eu}$ & 16 & 20615.63 & 27318.46 & 740.00 & 97000.00 & 132.51 \\
\hline
\end{tabular}


Table 3.12 (continued)

\begin{tabular}{|c|c|c|c|c|c|c|}
\hline Variable & $\mathbf{N}$ & Mean & Std. Dev. & Minimum & Maximum & \%R.E. \\
\hline${ }^{3} \mathrm{H}$ & 0 & . & . & . & . & . \\
\hline${ }^{95} \mathrm{Nb}$ & 8 & 1362.50 & 907.10 & 560.00 & 2900.00 & 66.58 \\
\hline${ }^{237} \mathrm{~Np}$ & 0 & . & . & . & . & . \\
\hline${ }^{238} \mathrm{Pu} /{ }^{241} \mathrm{Am}$ & 8 & 6992.50 & 4137.87 & 2430.00 & 14800.00 & 59.18 \\
\hline${ }^{239} \mathrm{Pu} /{ }^{240} \mathrm{Pu}$ & 16 & 4460.50 & 2892.38 & 878.00 & 9250.00 & 64.84 \\
\hline${ }^{238} \mathrm{Pu}$ & 8 & 6983.75 & 4735.99 & 740.00 & 14430.00 & 67.81 \\
\hline${ }^{239} \mathrm{Pu}$ & 0 & . & . & . & . & . \\
\hline${ }^{240} \mathrm{Pu}$ & 0 & . & . & . & . & . \\
\hline${ }^{24 !} \mathrm{Pu}$ & 0 & . & . & . & . & . \\
\hline${ }^{242} \mathrm{Pu}$ & 0 & . & . & . & . & . \\
\hline${ }^{244} \mathrm{Pu}$ & 0 & . & . & . & . & . \\
\hline${ }^{106} \mathrm{Ru}$ & 8 & 15325.00 & 8101.63 & 5700.00 & 28000.00 & 52.87 \\
\hline${ }^{90} \mathrm{Sr}$ & 16 & 2221443.75 & 2176495.73 & 210900.00 & 7437000.00 & 97.98 \\
\hline${ }^{99} \mathrm{Tc}$ & 0 & . & . & . & . & . \\
\hline${ }^{232} \mathrm{Th}$ & 0 & . & . & . & . & . \\
\hline${ }^{233} \mathrm{U}$ & 16 & 1867.69 & 1606.63 & 444.00 & 6660.00 & 86.02 \\
\hline${ }^{234} U$ & 0 & . & . & . & . & . \\
\hline${ }^{235} \mathrm{U}$ & 0 & . & . & . & . & . \\
\hline${ }^{236} \mathrm{U}$ & 0 & . & . & . & . & . \\
\hline${ }^{238} \mathrm{U}$ & 0 & . & . & . & . & . \\
\hline${ }^{233} U /{ }^{234} U$ & 0 & . & . & . & . & . \\
\hline${ }^{95} \mathrm{Zr}$ & 13 & 18909.23 & 34991.15 & 1700.00 & 130000.00 & 185.05 \\
\hline
\end{tabular}

Table 3.13 Weighted summary statistics for physical measurements on sludge samples

\begin{tabular}{lllllll}
\hline Variable & $\cdot \mathbf{N}$ & Mean & Std. Dev. & Minimum & Maximum & \%R.E. \\
\hline
\end{tabular}

Weighted statistics by each tank's mass fraction in the OHF tank farm

$\begin{array}{crrrrrrr}\text { Density }(\mathrm{g} / \mathrm{mL}) & 7 & 1.30 & 0.04 & 1.16 & 1.39 & 2.72 \\ \mathrm{H}_{2} \mathrm{O} \text { fraction } & 5 & 0.65 & 0.02 & 0.60 & 0.72 & 3.79 \\ \mathrm{pH} & 5 & 10.42 & 0.43 & 9.30 & 11.50 & 4.13\end{array}$


Table 3.13 (continued)

\begin{tabular}{ccccccc}
\hline Variable & N & Mean & Std. Dev. & Minimum & Maximum & \%R.E. \\
\hline TSOL (mg/g) & 5 & 405.07 & 104.32 & 253.00 & 921.00 & 25.75 \\
DSOL (mg/g) & 0 &. &. &. &. &. \\
SSOL (mg/g) & 0 &. &. &. &. &. \\
TOC (mg/g) & 10 & 10233.34 & 3575.86 & 100.00 & 28000.00 & 34.94 \\
ICAR (mg/g) & 5 & 11275.07 & 1973.65 & 5200.00 & 16000.00 & 17.50 \\
TCAR (mg/g) & 5 & 18244.16 & 2903.09 & 13000.00 & 29000.00 & 15.91
\end{tabular}

Weighted statistics by each tank's mass fraction in the BVEST tank farm

\begin{tabular}{|c|c|c|c|c|c|c|}
\hline Density (g/mL) & 5 & 1.39 & 0.06 & 1.17 & 1.46 & 4.00 \\
\hline $\mathrm{H}_{2} \mathrm{O}$ fraction & 3 & 0.50 & 0.08 & 0.42 & 0.74 & 15.17 \\
\hline $\mathrm{pH}$ & 0 & . & . & . & . & . \\
\hline TSOL (mg/g) & 3 & 486.93 & 67.31 & 268.00 & 544.00 & 13.82 \\
\hline DSOL (mg/g) & 1 & 25.50 & . & 25.50 & 25.50 & . \\
\hline SSOL (mg/g) & 1 & 242.00 & . & 242.00 & 242.00 & . \\
\hline TOC (mg/kg) & 5 & 4360.38 & 3990.69 & 100.00 & 22100.00 & 91.52 \\
\hline $\operatorname{ICAR}(\mathrm{mg} / \mathrm{kg})$ & 5 & 21901.42 & 5363.75 & 10400.00 & 32000.00 & 24.49 \\
\hline TCAR (mg/kg) & 5 & 26214.45 & 3462.71 & 18500.00 & 32500.00 & 13.21 \\
\hline
\end{tabular}

Weighted statistics by each tank's mass fraction in the GAAT tank farm

$\begin{array}{crrrrrr}\text { Density (g/mL) } & 23 & 1.26 & 0.06 & 1.07 & 1.57 & 4.38 \\ \mathrm{H}_{2} \text { 0 fraction } & 29 & 0.71 & 0.03 & 0.58 & 0.89 & 4.55 \\ \mathrm{pH} & 8 & 10.20 & 0.25 & 9.10 & 11.10 & 2.48 \\ \text { TSOL (mg/g) } & 11 & 500.60 & 72.28 & 300.00 & 944.00 & 14.44 \\ \text { DSOL (mg/g) } & 0 & . & . & . & . & . \\ \text { SSOL (mg/g) } & 0 & . & . & . & . & . \\ \text { TOC (mg/kg) } & 38 & 5061.59 & 1484.73 & 200.00 & 14600.00 & 29.33 \\ \text { ICAR (mg/kg) } & 27 & 4251.67 & 548.16 & 1110.00 & 7900.00 & 12.89 \\ \text { TCAR (mg/kg) } & 27 & 7677.06 & 1434.39 & 1900.00 & 16600.00 & 18.68\end{array}$

Weighted statistics by each tank's mass fraction in the MVST tank farm

$\begin{array}{lllllll}\text { Density }(\mathrm{g} / \mathrm{mL}) & 7 & 1.36 & 0.04 & 1.26 & 1.54 & 3.26\end{array}$

$\mathrm{H}_{2} \mathrm{O}$ fraction $\quad 0$ 
Table 3.13 (continued)

\begin{tabular}{ccccccc}
\hline Variable & N & Mean & Std. Dev. & Minimum & Maximum & \%R.E. \\
\hline pH & 0 &. &. &. &. &. \\
TSOL (mg/g) & 16 & 467.53 & 42.95 & 342.00 & 964.00 & 9.19 \\
DSOL (mg/g) & 0 &. &. &. &. &. \\
SSOL (mg/g) & 0 &. &. &. &. &. \\
TOC (mg/kg) & 8 & 3720.44 & 811.29 & 410.00 & 8530.00 & 21.81 \\
ICAR (mg/kg) & 8 & 8507.72 & 2082.74 & 1410.00 & 21900.00 & 24.48 \\
TCAR (mg/kg) & 8 & 12217.10 & 2839.87 & 1820.00 & 30400.00 & 23.25 \\
\hline
\end{tabular}

Table 3.14. Weighted summary statistics for chemical measurements on sludge samples

\begin{tabular}{|c|c|c|c|c|c|c|}
\hline Variable & $\mathbf{N}$ & Mean & Std. Dev. & Minimum & Maximum & \%R.E. \\
\hline \multicolumn{7}{|c|}{ Weighted statistics (mg/kg) by each tank's mass fraction in the OHF tank farm } \\
\hline $\mathrm{Ag}$ & 10 & 1.21 & 0.38 & 0.15 & 2.90 & 31.35 \\
\hline $\mathrm{Al}$ & 5 & 17136.05 & 3463.19 & 9320.00 & 34500.00 & 20.21 \\
\hline As & 10 & 1.91 & 0.47 & 1.00 & 4.00 & 24.67 \\
\hline B & 5 & 40.72 & 3.50 & 31.80 & 49.70 & 8.60 \\
\hline $\mathrm{Ba}$ & 10 & 60.10 & 10.20 & 26.50 & 115.00 & 16.97 \\
\hline $\mathrm{Be}$ & 10 & 6.30 & 5.19 & 0.00 & 45.40 & ' 82.47 \\
\hline $\mathrm{Ca}$ & 5 & 32104.01 & 3448.25 & 20600.00 & 37900.00 & 10.74 \\
\hline $\mathrm{Cd}$ & 10 & 11.03 & 1.44 & 6.60 & 16.40 & 13.05 \\
\hline Co & 5 & 8.76 & 1.88 & 4.24 & 14.20 & 21.45 \\
\hline $\mathrm{Cr}$ & 10 & 109.42 & 29.15 & 10.00 & 241.00 & 26.64 \\
\hline Cs & 5 & 8.48 & 3.82 & 1.43 & 22.50 & 45.08 \\
\hline $\mathrm{Cu}$ & 5 & 144.16 & 42.48 & 64.30 & 293.00 & 29.47 \\
\hline $\mathrm{Fe}$ & 5 & 6593.58 & $1866.36^{\circ}$ & 3150.00 & 17900.00 & 28.31 \\
\hline $\mathrm{Hg}$ & 10 & 122.45 & 81.96 & 1.80 & 585.00 & 66.93 \\
\hline $\mathrm{K}$ & 5 & 3380.95 & 1025.98 & 974.00 & 6140.00 & 30.35 \\
\hline $\mathrm{Mg}$ & 5 & 3181.73 & 449.19 & 1730.00 & 5140.00 & 14.12 \\
\hline $\mathrm{Mn}$ & 10 & 157.58 & 81.58 & 0.00 & 472.00 & 51.77 \\
\hline $\mathrm{Na}$ & 5 & 10375.18 & 3145.80 & 4040.00 & 18800.00 & 30.32 \\
\hline
\end{tabular}


Table 3.14 (continued)

\begin{tabular}{|c|c|c|c|c|c|c|}
\hline Variable & $\mathbf{N}$ & Mean & Std. Dev. & Minimum & Maximum & \%R.E. \\
\hline $\mathrm{Ni}$ & 10 & 146.94 & 53.45 & 50.00 & 452.00 & 36.38 \\
\hline $\mathrm{P}$ & 5 & 8116.99 & 673.98 & 6940.00 & 12600.00 & 8.30 \\
\hline $\mathrm{Pb}$ & 10 & 460.82 & 86.59 & 229.00 & 860.00 & 18.79 \\
\hline $\mathrm{Sb}$ & 5 & 17.92 & 0.55 & 17.00 & 20.00 & 3.08 \\
\hline $\mathrm{Se}$ & 10 & 1.24 & 0.16 & 0.74 & 2.00 & 13.20 \\
\hline $\mathrm{Si}$ & 5 & 14099.12 & 6771.38 & 3640.00 & 32500.00 & 48.03 \\
\hline $\mathrm{Sr}$ & 5 & 586.63 & 164.30 & 282.00 & 992.00 & 28.01 \\
\hline Th & 5 & 91582.99 & 9877.01 & 56800.00 & 124000.00 & 10.78 \\
\hline $\mathrm{Tl}$ & 10 & 1.13 & 0.17 & 0.60 & 2.00 & 15.34 \\
\hline $\mathrm{U}$ & 10 & 3534.13 & 1001.20 & 1000.00 & 7870.00 & 28.33 \\
\hline V & 5 & 7.00 & 0.18 & 6.60 & 7.80 & 2.57 \\
\hline $\mathrm{Zn}$ & 5 & 180.26 & 16.29 & 149.00 & 236.00 & 9.04 \\
\hline Bromides & 5 & 31.01 & 10.32 & 4.63 & 70.00 & $33.30^{\circ}$ \\
\hline Chlorides & 5 & 812.86 & 439.89 & 247.00 & 3760.00 & 54.12 \\
\hline Fluorides & 5 & 235.31 & 20.07 & 140.00 & , 272.00 & 8.53 \\
\hline Nitrates & 5 & 1891.13 & 907.76 & 27.90 & 4250.00 & 48.00 \\
\hline Nitrites & 5 & 2187.65 & 931.45 & 219.00 & 4670.00 & 42.58 \\
\hline Phosphates & 5 & 118.65 & 36.92 & 18.50 & 195.00 & 31.12 \\
\hline Sulfates & 5 & 1555.57 & 533.21 & 339.00 & 2960.00 & 34.28 \\
\hline Cyanide & 0 & . & . & . & . & . \\
\hline
\end{tabular}

Weighted statistics ( $\mathrm{mg} / \mathrm{kg}$ ) by each tank's mass fraction in the BVEST tank farm

$\begin{array}{rrrrrrr}\mathrm{Ag} & 5 & 18.35 & 11.83 & 2.03 & 50.00 & 64.46 \\ \mathrm{Al} & 5 & 1917.03 & 508.89 & 852.00 & 2800.00 & 26.55 \\ \mathrm{As} & 5 & 23.89 & 13.70 & 4.40 & 50.00 & 57.33 \\ \mathrm{~B} & 4 & 7.41 & 1.41 & 5.03 & 10.00 & 19.09 \\ \mathrm{Ba} & 5 & 61.63 & 6.39 & 48.40 & 78.00 & 10.37 \\ \mathrm{Be} & 5 & 1.27 & 1.06 & 0.00 & 3.66 & 83.71 \\ \mathrm{Ca} & 5 & 56566.48 & 9334.11 & 33600.00 & 83900.00 & 16.50 \\ \mathrm{Cd} & 5 & 27.15 & 5.31 & 16.10 & 39.00 & 19.54\end{array}$


Table 3.14 (continued)

\begin{tabular}{|c|c|c|c|c|c|c|}
\hline Variable & $\mathbf{N}$ & Mean & Std. Dev. & Minimum & Maximum & \%R.E. \\
\hline Co & 3 & 3.48 & 1.21 & 1.30 & 5.20 & 34.86 \\
\hline $\mathrm{Cr}$ & 5 & 180.54 & 22.92 & 146.00 & 248.00 & 12.70 \\
\hline Cs & 2 & 2.72 & 0.10 & 2.57 & 2.81 & 3.78 \\
\hline $\mathrm{Cu}$ & 3 & 50.16 & 12.94 & 33.70 & 77.40 & 25.80 \\
\hline $\mathrm{Fe}$ & 5 & 2386.09 & 510.28 & 1900.00 & 4040.00 & 21.39 \\
\hline $\mathrm{Hg}$ & 5 & 29.21 & 19.01 & 8.44 & 105.00 & 65.09 \\
\hline $\mathrm{K}$ & 5 & 15553.49 & 4807.06 & 3270.00 & 25200.00 & 30.91 \\
\hline $\mathrm{Mg}$ & 5 & 11988.83 & 2563.11 & 3620.00 & 16000.00 & 21.38 \\
\hline $\mathrm{Mn}$ & 5 & 112.73 & 75.26 & 0.00 & 275.00 & 66.76 \\
\hline $\mathrm{Na}$ & 5 & 58462.33 & 13065.42 & 15400.00 & 82000.00 & 22.35 \\
\hline $\mathrm{Ni}$ & 5 & 86.98 & 11.28 & 69.60 & 110.00 & 12.96 \\
\hline$P$ & 2 & 14606.89 & 982.99 & 13700.00 & 16000.00 & 6.73 \\
\hline $\mathrm{Pb}$ & 5 & 365.60 & 40.10 & 290.00 & 450.00 & 10.97 \\
\hline Sb & 3 & 50.65 & 7.50 & 26.00 & 56.00 & 14.81 \\
\hline $\mathrm{Se}$ & 5 & 17.80 & 9.75 & 4.40 & 39.00 & 54.78 \\
\hline $\mathbf{S i}$ & 3 & 2470.75 & 734.05 & 159.00 & 3360.00 & 29.71 \\
\hline $\mathrm{Sr}$ & 4 & 268.70 & 24.90 & 200.00 & 295.00 & 9.27 \\
\hline Th & 5 & 10459.46 & 1836.37 & 7460.00 & 14000.00 & 17.56 \\
\hline $\mathrm{Tl}$ & 5 & 26.99 & 14.92 & 10.00 & $75.20^{\circ}$ & 55.28 \\
\hline $\mathrm{U}$ & 5 & 28932.06 & 5735.31 & 17000.00 & 39700.00 & 19.82 \\
\hline V & 3 & 3.50 & 1.52 & 0.38 & 5.37 & 43.27 \\
\hline $\mathrm{Zn}$ & 3 & 935.15 & 88.41 & 756.00 & 1100.00 & 9.45 \\
\hline Bromides & 2 & 319.77 & 162.83 & 89.00 & 470.00 & 50.92 \\
\hline Chlorides & 2 & 2361.69 & 876.14 & 1120.00 & 3170.00 & 37.10 \\
\hline Fluorides & 2 & 173.96 & 11.97 & 157.00 & 185.00 & 6.88 \\
\hline Nitrates & 2 & 141771.96 & 17095.42 & 126000.00 & 166000.00 & 12.06 \\
\hline Nitrites & 0 & . & . & . & - & - \\
\hline Phosphates & 2 & 203.94 & 4.27 & 200.00 & 210.00 & 2.10 \\
\hline Sulfates & 2 & 5310.40 & 1918.96 & 3540.00 & 8030.00 & 36.14 \\
\hline
\end{tabular}


Table 3.15 (continued)

\begin{tabular}{|c|c|c|c|c|c|c|}
\hline Variable & $\mathbf{N}$ & Mean & Std. Dev. & Minimum & Maximum & \%R.E. \\
\hline${ }^{234} \mathrm{U}$ & 5 & 125.06 & 17.61 & 57.00 & 180.00 & 14.08 \\
\hline${ }^{235} \mathrm{U}$ & 5 & 1.33 & 0.32 & 0.50 & 2.10 & 23.74 \\
\hline${ }^{236} \mathrm{U}$ & 5 & 1.14 & 0.27 & 0.50 & 1.90 & 24.02 \\
\hline${ }^{238} \mathrm{U}$ & 5 & 58.91 & 14.11 & 26.00 & 97.00 & 23.95 \\
\hline${ }^{233} \mathrm{U} /{ }^{234} \mathrm{U}$ & 0 & . & . & . & . & . \\
\hline${ }^{95} \mathrm{Zr}$ & 0 & . & . . & . & . & . \\
\hline \multicolumn{7}{|c|}{ Weighted statistics $(B q / g)$ by each tank's mass fraction in the BVEST tank farm } \\
\hline $\mathrm{H}_{2} \mathrm{O}$ fraction & 3 & 0.50 & 0.08 & 0.42 & 0.74 & 15.17 \\
\hline Gross alpha & 11 & 156401.96 & 34252.46 & 73260.00 & 257890.00 & 21.90 \\
\hline Gross beta & 11 & 4925721.73 & 1393002.58 & 1986900.00 & 8769000.00 & 28.28 \\
\hline${ }^{241} \mathrm{Am}$ & 6 & 8591.79 & 4064.70 & 1110.00 & 17000.00 & 47.31 \\
\hline${ }^{198} \mathrm{Au}$ & 3 & 9181.76 & 466.69 & 8510.00 & 9990.00 & 5.08 \\
\hline${ }^{4} \mathrm{Cl}$ & 2 & 292.05 & 79.07 & 180.00 & 365.00 & 27.07 \\
\hline${ }^{252} \mathrm{Cf}$ & 0 & $\because$ & . & . & . & . \\
\hline${ }^{144} \mathrm{Ce}$ & 2 & 27394.30 & 427.39 & 27000.00 & 28000.00 & 1.56 \\
\hline${ }^{243} \mathrm{Cm}$ & 2 & 25605.70 & 427.39 & 25000.00 & 26000.00 & 1.67 \\
\hline${ }^{244} \mathrm{Cm}$ & 8 & 84398.99 & 26825.16 & 29970.00 & 167000.00 & 31.78 \\
\hline${ }^{60} \mathrm{Co}$ & 8 & 106422.69 & 52165.76 & 27380.00 & 252000.00 & 49.02 \\
\hline${ }^{134} \mathrm{Cs}$ & 5 & 7208.64 & 1730.28 & $2600.00^{\circ}$ & 11000.00 & 24.00 \\
\hline${ }^{137} \mathrm{Cs}$ & 8 & 312783.07 & 74500.08 & 130000.00 & .495000 .00 & 23.82 \\
\hline${ }^{152} \mathrm{Eu}$ & 8 & 774975.69 & 192758.69 & 403300.00 & 1300000.00 & 24.87 \\
\hline${ }^{154} \mathrm{Eu}$ & 8 & 415056.76 & 91203.83 & 197950.00 & 640000.00 & 21.97 \\
\hline${ }^{155} \mathrm{Eu}$ & 8 & 106592.57 & 13352.37 & 58000.00 & 133000.00 & 12.53 \\
\hline${ }^{3} \mathrm{H}$ & 0 & . & . & . & . & . \\
\hline${ }^{95} \mathrm{Nb}$ & 4 & 7187.63 & 1387.89 & 4700.00 & 12210.00 & 19.31 \\
\hline${ }^{237} \mathrm{~Np}$ & 2 & 6.10 & 0.00 & 6.10 & 6.10 & 0.00 \\
\hline${ }^{238} \mathrm{Pu} /{ }^{241} \mathrm{Am}$ & 3 & 37715.28 & 6511.04 & 28000.00 & 51300.00 & 17.26 \\
\hline${ }^{239} \mathrm{Pu} /{ }^{240} \mathrm{Pu}$ & 8 & 13030.79 & 4258.75 & 4800.00 & 24900.00 & 32.68 \\
\hline${ }^{238} \mathrm{Pu}$. & 6 & 16025.20 & 4693.07 & 7200.00 & 30710.00 & 29.29 \\
\hline
\end{tabular}


Table 3.15 (continued)

\begin{tabular}{ccrrrrr}
\hline Variable & N & \multicolumn{1}{c}{ Mean } & Std. Dev. & Minimum & Maximum & \%R.E. \\
\hline${ }^{239} \mathrm{Pu}$ & 3 & 3128.67 & 477.09 & 2600.00 & 4580.00 & 15.25 \\
${ }^{240} \mathrm{Pu}$ & 3 & 2650.09 & 276.08 & 2300.00 & 3410.00 & 10.42 \\
${ }^{241} \mathrm{Pu}$ & 3 & 43221.83 & 7120.45 & 37000.00 & 66300.00 & 16.47 \\
${ }^{242} \mathrm{Pu}$ & 3 & 2.27 & 0.29 & 2.00 & 3.20 & 12.80 \\
${ }^{244} \mathrm{Pu}$ & 3 & 0.85 & 0.23 & 0.10 & 1.00 & 26.83 \\
${ }^{106} \mathrm{Ru}$ & 2 & 54902.62 & 7692.94 & 44000.00 & 62000.00 & 14.01 \\
${ }^{90} \mathrm{Sr}$ & 8 & 1274498.36 & 576176.29 & 377400.00 & 2726900.00 & 45.21 \\
${ }^{99} \mathrm{Tc}$ & 3 & 485.96 & 161.61 & 170.00 & 810.00 & 33.25 \\
${ }^{232} \mathrm{Th}$ & 3 & 32.68 & 3.15 & 30.00 & 43.00 & 9.64 \\
${ }^{233} \mathrm{U}$ & 8 & 9149.90 & 3520.33 & 1850.00 & 19408.10 & 38.47 \\
${ }^{234} \mathrm{U}$ & 3 & 665.14 & 187.05 & 144.70 & 900.00 & 28.12 \\
${ }^{235} \mathrm{U}$ & 3 & 5.63 & 0.64 & 4.30 & 6.40 & 11.37 \\
${ }^{236} \mathrm{U}$ & 3 & 7.45 & 1.47 & 4.10 & 9.50 & 19.71 \\
${ }^{238} \mathrm{U}$ & 3 & 424.80 & 54.12 & 313.60 & 492.00 & 12.74 \\
${ }^{233} \mathrm{U} /{ }^{234} \mathrm{U}$ & 0 &. &. &. &. &. \\
${ }^{95} \mathrm{Zr}$ & 5 & 81490.75 & 23799.88 & 39000.00 & 125800.00 & 29.21 \\
& 3 & & & & & \\
\end{tabular}

Weighted statistics (Bq/g) by each tank's mass fraction in the GAAT tank farm

$\begin{array}{crrrrrr}\mathrm{H}_{2} \mathrm{O} \text { fraction } & 29 & 0.71 & 0.03 & 0.58 & 0.89 & 4.56 \\ \text { Gross alpha } & 42 & 26765.83 & 9520.43 & 900.00 & 110000.00 & 35.57 \\ \text { Gross beta } & 42 & 4359201.43 & 1148923.61 & 70000.00 & 12000000.00 & 26.36 \\ { }^{241} \mathrm{Am} & 20 & 8806.78 & 2658.60 & 0.00 & 22000.00 & 30.19 \\ { }^{198} \mathrm{Au} & 0 & . & . & . & . & . \\ { }^{4} \mathrm{Cl} & 0 & . & . & . & . & . \\ { }^{252} \mathrm{Cf} & 10 & 16.10 & 6.20 & 4.00 & 50.00 & 38.50 \\ { }^{144} \mathrm{Ce} & 0 & . & . & . & . & . \\ { }^{243} \mathrm{Cm} & 0 & . & . & . & . & . \\ { }^{244} \mathrm{Cm} & 38 & 14847.74 & 6522.78 & 6.00 & 58300.00 & 43.93 \\ { }^{60} \mathrm{Co} & 41 & 2732.23 & 1113.34 & 12.00 & 13000.00 & 40.75 \\ { }^{134} \mathrm{Cs} & 18 & 1527.05 & 426.05 & 20.00 & 3500.00 & 27.90\end{array}$


Table 3.15 (continued)

\begin{tabular}{|c|c|c|c|c|c|c|}
\hline Variable & $\mathbf{N}$ & Mean & Std. Dev. & Minimum & Maximum & \%R.E. \\
\hline${ }^{137} \mathrm{Cs}$ & 42 & 1481629.67 & 812424.49 & 13000.00 & 11000000.00 & 54.83 \\
\hline${ }^{152} \mathrm{Eu}$ & 33 & 5318.24 & 1881.17 & 90.00 & 17000.00 & 35.37 \\
\hline${ }^{154} \mathrm{Eu}$ & 35 & 2117.40 & 780.67 & 64.00 & 8000.00 & 36.87 \\
\hline${ }^{155} \mathrm{Eu}$ & 30 & 3435.81 & 1179.67 & 52.00 & 11000.00 & 34.33 \\
\hline${ }^{3} \mathrm{H}$ & 11 & 52.26 & 21.81 & 0.00 & 140.00 & 41.72 \\
\hline${ }^{95} \mathrm{Nb}$ & 0 & . & . & . & . & . \\
\hline${ }^{237} \mathrm{~Np}$ & 0 & . & . & . & . & . \\
\hline${ }^{238} \mathrm{Pu} /{ }^{41} \mathrm{Am}$ & 31 & 5329.55 & 2385.96 & 0.00 & 28200.00 & 44.77 \\
\hline${ }^{239} \mathrm{Pu} /{ }^{240} \mathrm{Pu}$ & 31 & 2962.45 & 919.40 & 210.00 & 11800.00 & 31.04 \\
\hline${ }^{238} \mathrm{Pu}$ & 39 & 4207.84 & 2363.51 & 6.00 & 29000.00 & 56.17 \\
\hline${ }^{239} \mathrm{Pu}$ & 31 & 2884.69 & 1074.53 & 100.00 & 11000.00 & 37.25 \\
\hline${ }^{240} \mathrm{Pu}$ & 20 & 501.39 & 158.05 & 3.50 & 1220.00 & 31.52 \\
\hline${ }^{241} \mathrm{Pu}$ & 20 & 4703.98 & 1346.74 & 0.10 & 12000.00 & 28.63 \\
\hline${ }^{242} \mathrm{Pu}$ & 22 & 1.90 & 1.35 & 0.00 & 14.00 & 70.75 \\
\hline${ }^{244} \mathrm{Pu}$ & 18 & 0.07 & 0.02 & 0.00 & 0.10 & 24.65 \\
\hline${ }^{106} \mathrm{Ru}$ & 0 & . & $\because$ & . & . & . \\
\hline${ }^{90} \mathrm{Sr}$ & 42 & 1399653.26 & 679425.59 & 16000.00 & 8600000.00 & 48.54 \\
\hline${ }^{99} \mathrm{Tc}$ & 0 & . & . & . & . & . \\
\hline${ }^{232} \mathrm{Th}$ & 31 & 21.90 & 6.53 & 0.40 & 66.60 & 29.81 \\
\hline${ }^{233} U$ & 31 & 706.36 & 263.03 & 0.00 & 3100.00 & 37.24 \\
\hline${ }^{234} \mathrm{U}$ & 27 & 976.64 & 358.53 & 8.80 & 2719.90 & 36.71 \\
\hline${ }^{235} U$ & 20 & 22.24 & 10.74 & 0.40 & 106.90 & 48.28 \\
\hline${ }^{236} U$ & 20 & 1.11 & 0.48 & 0.00 & 6.10 & 42.81 \\
\hline${ }^{238} U$ & 32 & 956.50 & 321.56 & 11.40 & 3000.00 & 33.62 \\
\hline${ }^{233} U /{ }^{234} U$ & 4 & 941.40 & 199.58 & 342.00 & 1365.00 & 21.20 \\
\hline${ }^{95} \mathrm{Zr}$ & 0 & . & . & . &. & . \\
\hline
\end{tabular}

Weighted statistics (Bq/g) by each tank's mass fraction in the MVST tank farm

$\mathrm{H}_{2} \mathrm{O}$ fraction $\quad 0$

$\begin{array}{lllllll}\text { Gross alpha } & 24 & 63525.30 & 14994.04 & 10730.00 & 222000.00 & 23.60\end{array}$ 
Table 3.15 (continued)

\begin{tabular}{|c|c|c|c|c|c|c|}
\hline Variable & $\mathbf{N}$ & Mean & Std. Dev. & Minimum & Maximum & \%R.E. \\
\hline Gross beta & 24 & 8623035.41 & 4268252.48 & 758500.00 & 51800000.00 & 49.50 \\
\hline${ }^{241} \mathrm{Am}$ & 8 & 8961.73 & 1483.18 & 2960.00 & 17390.00 & 16.55 \\
\hline${ }^{198} \mathrm{Au}$ & 5 & 2746.08 & 408.00 & 1480.00 & 3700.00 & 14.86 \\
\hline${ }^{4} \mathrm{Cl}$ & 8 & 362.54 & 108.66 & 76.00 & 1050.00 & 29.97 \\
\hline${ }^{252} \mathrm{Cf}$ & 0 & . & - & . & . & . \\
\hline${ }^{144} \mathrm{Ce}$ & 8 & 8405.96 & 1551.56 & 3900.00 & 17000.00 & 18.46 \\
\hline${ }^{243} \mathrm{Cm}$ & 8 & 8726.07 & 1461.37 & 3600.00 & 14000.00 & 16.75 \\
\hline${ }^{244} \mathrm{C} \mathrm{m}$ & 16 & 39864.28 & 11560.82 & 3700.00 & 132090.00 & 29.00 \\
\hline${ }^{60} \mathrm{Co}$ & 15 & 54244.28 & 11653.02 & 8100.00 & 112110.00 & 21.48 \\
\hline${ }^{134} \mathrm{Cs}$ & 8 & 4785.35 & 4284.99 & 620.00 & 46000.00 & 89.54 \\
\hline${ }^{137} \mathrm{Cs}$ & 16 & 265307.46 & 80458.20 & 17760.00 & 684000.00 & 30.33 \\
\hline${ }^{152} \mathrm{Eu}$ & 15 & 116775.87 & 68181.33 & 3700.00 & 718000.00 & 58.39 \\
\hline${ }^{154} \mathrm{Eu}$ & 15 & 69914.70 & 38749.52 & 3700.00 & 320000.00 & 55.42 \\
\hline${ }^{155} \mathrm{Eu}$ & 16 & 19800.08 & 9370.67 & 740.00 & 97000.00 & 47.33 \\
\hline${ }^{3} \mathrm{H}$ & 0 & . & . & . & - & - \\
\hline${ }^{95} \mathrm{Nb}$ & 8 & 1354.98 & 324.35 & 560.00 & 2900.00 & 23.94 \\
\hline${ }^{237} \mathrm{~Np}$ & 0 & . & . & . & . & . \\
\hline${ }^{238} \mathrm{Pu} /{ }^{241} \mathrm{Am}$ & 8 & 7638.53 & 1573.13 & 2430.00 & 14800.00 & 20.59 \\
\hline${ }^{239} \mathrm{Pu} /{ }^{240} \mathrm{Pu}$ & 16 & 4726.84 & 1042.83 & 878.00 & 9250.00 & 22.06 \\
\hline${ }^{238} \mathrm{Pu}$ & 8 & 7179.42 & 1587.48 & 740.00 & 14430.00 & 22.11 \\
\hline${ }^{239} \mathrm{Pu}$ & 0 & . & . & : & . & - \\
\hline${ }^{240} \mathrm{Pu}$ & 0 & . & · & . & - & • \\
\hline${ }^{241} \mathrm{Pu}$ & 0 & . & - & . & . & • \\
\hline${ }^{242} \mathrm{Pu}$ & 0 & . & - & . & . & . \\
\hline${ }^{244} \mathrm{Pu}$ & 0 & . & - & . & . & . \\
\hline${ }^{106} \mathrm{Ru}$ & 8 & 14954.49 & 2901.39 & 5700.00 & 28000.00 & 19.40 \\
\hline${ }^{90} \mathrm{Sr}$ & 16 & 2188122.11 & 713319.23 & 210900.00 & 7437000.00 & 32.60 \\
\hline${ }^{99} \mathrm{Tc}$ & 0 & • & - & - & $\therefore$ & - \\
\hline${ }^{232} \mathrm{Th}$ & 0 & . & . & . & . & . \\
\hline
\end{tabular}




$$
\text { 3-60 }
$$

Table 3.15 (continued)

\begin{tabular}{ccccccc}
\hline Variable & $\mathbf{N}$ & Mean & Std. Dev. & Minimum & Maximum & \%R.E. \\
\hline${ }^{233} \mathrm{U}$ & 16 & 1999.76 & 658.43 & 444.00 & 6660.00 & 32.93 \\
${ }^{234} \mathrm{U}$ & 0 &. &. &. &. &. \\
${ }^{235} \mathrm{U}$ & 0 &. &. & $\cdot$ &. &. \\
${ }^{236} \mathrm{U}$ & 0 &. &. &. &. &. \\
${ }^{238} \mathrm{U}$ & 0 &. &. &. &. &. \\
${ }^{233} \mathrm{U} /{ }^{234} \mathrm{U}$ & 0 &. &. &. &. &. \\
${ }^{95} \mathrm{Zr}$ & 13 & 21068.79 & 15413.00 & 1700.00 & 130000.00 & 73.16 \\
\hline
\end{tabular}




\section{ESTIMATING PROPERTY BOUNDS}

\subsection{ASSUMPTIONS FOR STATISTICALLY CORRECT CHARACTERIZATION}

A correct and valid analysis of data for the purpose of making statistical inference (e.g., creating confidence intervals or bounds on some parameter) requires certain assumptions. Three major assumptions allow correct results to follow from an analysis:

1. the assumption of a specified population,

2. the assumption of a random sample, and

3. the assumption that the sampled population is the target population.

The first assumption assumes that the data come from a specific and well-defined population. This population should be stated explicitly; if not, the results are generally a precise statement about an unknown object group with vague conclusions. In our setting, the population consists of the possible set of analytes that is contained in the sludge stored in MVST. The fact that we do not analyze for all possible analytes means that we do not have a complete description of the population of interest. Thus, we may be missing important analytes that may have important interaction effects with analytes that are measured. This interaction could have serious implications when trying to determine bounds on a given analyte.

The second assumption is that the sample taken is random. The most elementary type of random sample is called a simple random sample. This means that if we take a simple random sample of $\mathbf{n}$ objects from the population that every possible sample of size $\mathbf{n}$ from the population has the same probability of being selected. In our situation, this is violated in several respects. The most obvious and serious violation is that the samples selected came from one position in the tank because there is only one opening in the tank from which to sample. The requirement of a random sample is critical in that the statistical intervals reflect only the variability introduced by the sampling process and do not take into account any biases that might be introduced by nonrandom samples. In addition, the samples that were taken were core type samples. These cores showed definite layers of material. Rather than. sampling from each layer, the layers were composited (blended) and then analyzed. This results in no estimate of the variability of the analyte in a given tank and yields a mean concentration. Because there is no way to adjust for this compositing and sampling from a single position in the tank, there is no way to adjust the statistical intervals that are calculated. This nonrandomness can lead to heavily biased observations, and the results are not amenable to adjustment. A major concern here is the lack of information on the variability of the analyte concentrations. This variability is necessary to determine the spread of the distribution, and by mixing the layers and analyzing the homogenized sample this information is lost.

Third, the methods used assume that the population of interest is the same as that which is sampled. Because the population of interest is MVST after transfer from the other tanks, we simply are not sampling the population of interest. The intervals we calculate will contain only the variability from the aggregate of the various tank farms and not the additional variability that will come from the transfer of the sludge from the tank farms to the yet undetermined MVST tanks. Again, what one may find in the MVST tanks can be quite different from what has been found in these tank farms. Even knowing which tanks will ultimately be transferred to which MVST will not reduce this uncertainty because we have only a point source sample, which was homogenized, to use to make any predictions. 


\subsection{AN OVERVIEW OF STATISTICAL INTERVALS}

Consider the problem of estimating the concentration of some chemical compound in sludge. Suppose further that 10 samples were taken from the sludge container. The arithmetic average of the concentrations obtained from the samples yield a value, say $10.3 \mathrm{mg} / \mathrm{kg}$. This value is called a point estimate of the average concentration found in the sludge analyzed. The following question comes to mind: Can we expect future observations to lie in the interval $10.3 \pm 5$ ? The size of the interval depends on the variability associated with the estimate, and this depends on the variability of the concentration values to be found in samples from the sludge. An appreciation of this variability is important in making decisions concerning the likely values of the concentration of the chemical compound and the possible effects this may have, say, in handling or treating the compound. If the uncertainty of our estimate is too great, as measured by the length of the interval, we may need to collect more data to improve our understanding and knowledge of the concentration of the chemical compound in the sludge.

There are three major types of statistical intervals:

1. confidence intervals,

2. tolerance intervals, and

3. prediction intervals.

These are different but are often confused with each other. The following definitions will hopefully remove any confusion.

A confidence interval is an interval that is formed to contain an unknown characteristic of the sample population. This unknown characteristic could be the mean or variance of the population of interest or a function of such parameters. Referring back to the concentration of the chemical compound, we might be interested in an interval, which we can claim with a specified degree of confidence, contains the mean concentration or the standard deviation of the concentration values for the chemical compound or the probability that the concentration of a randomly selected sample from the sludge population will exceed a stated threshold value, M.

A tolerance interval is an interval that contains a specified proportion of the sampled population with a given level of confidence. For example, we might wish to construct an interval to contain, with a specified degree of confidence, the concentration values of at least $90 \%$ of the population.

A prediction interval is an interval that will contain one or more future observations or some function of such future observations from a previously sampled population. For example, based on a past sample of concentration values for a specified chemical compound, we want to construct an interval to contain, with a specified degree of confidence, the concentration of all ten future samples or the average concentration of ten future samples.

Now that we have stated the definitions for the various types of intervals it is proper to discuss the purpose of the interval. Is the main purpose to describe the population from which the sample has been selected? Or is the purpose to predict the results of a future sample taken from the same population? Intervals that describe the sampled population are confidence intervals on the population mean, confidence intervals on the population standard deviation, or tolerance intervals for a population proportion. On the other hand, prediction intervals for a 
future mean, for a future standard deviation, or prediction intervals to include all of $\mathrm{n}$ future observations are concerned with predicting the results of a future sample.

In any of these cases, the sample we have taken is our only reference concerning the population of interest. How well the sampling is done will directly affect how well we can describe the population or predict what future samples may be like. The assumptions necessary to make valid conclusions were discussed earlier, but we emphasize again that poor data make poor conclusions, which can lead to poor decision making.

\subsection{DEFINITIONS AND EXAMPLES}

The following intervals will be given with examples on how to use them:

1. confidence interval for the population mean,

2. confidence interval for the probability of being greater than a specified value,

3. tolerance intervals to contain a population proportion, and

4. one-sided prediction bounds to contain all of $m$ future observations.

We emphasize one last time that these intervals are appropriate under given assumptions. In addition to the assumptions already given, we also assume for the four intervals that the sample was drawn from a normally distributed population. These same intervals for 2,3 , and 4 can be calculated if we assume the underlying distribution is lognormal, and finally, we examine the situation where we look at prediction intervals for the exponential distribution. The user of any of these techniques must take responsibility for checking any of the assumptions needed to use these methods for their purposes.

Because the four tank forms may have different distributions of analytes and different amounts of sludge mass (see Table 3.8), it may be prudent to use a weighted analysis to combine the data and obtain a weighted average and weighted standard deviation, say $\bar{x}_{w}$, and $s_{w}$, based on the weights derived from the sludge mass. It is these two statistics, $\bar{x}_{w}$, and $s_{w}$, that are used in the calculated intervals. The question then is how does one use the sludge mass and data from the tank forms to calculate the weighted mean and standard deviation to be used in calculating the intervals.

To simplify things, suppose that we are interested in combining the data from the BVEST and MVST forms only. To calculate the weights that observations from each form should be given, we simply use the proportion of sludge mass that each tank form contributes to the total. Using the data from Table 3.8, we come to the following conclusion:

$\begin{array}{rlr}\text { BVEST Sludge Mass } & =195,636 \mathrm{~kg} \\ \text { MVST Sludge Mass } & =579,613 \mathrm{~kg} \\ \text { Total } & =\quad \mathbf{7 7 5 , 2 4 9} \mathbf{k g}\end{array}$

Then the weight associated with each observation from BVEST is given by

$$
w_{1}=195,636 / 775,249=0.2524
$$


and for MVST is given by

$$
w_{2}=579,613 / 775,249=0.7476 .
$$

The formulas needed to calculate the two statistics we need for the intervals are

$$
\begin{gathered}
\overline{x_{w}}=\frac{\sum_{i=1}^{2} \sum_{j}^{n_{t}} w_{i} x_{i j}}{\sum_{i=1}^{2} \sum_{j=1}^{n_{i}} w_{i}}=\frac{w_{1} \sum_{j=1}^{n_{1}} x_{1 j}+w_{2} \sum_{j=1}^{n_{2}} x_{2 j}}{n_{1} w_{1}+n_{2} w_{2}} \\
s_{w}^{2}=\frac{\sum_{i=1}^{2} \sum_{j=1}^{n_{l}} w_{i}\left(x_{i j}-\bar{x}_{w}\right)^{2}}{n_{1}+n_{2}-1}=\frac{w_{1} \sum_{j=1}^{n_{1}}\left(x_{1 j}-\bar{x}_{w}\right)^{2}+w_{2} \sum_{j=1}^{n_{2}}\left(x_{2 j}-\bar{x}_{w}\right)^{2}}{n_{1}+n_{2}-1} .
\end{gathered}
$$

For example, consider the silver measurement from BVEST and MVST. Using the summary data, we find the following statistics for the silver analyte:

$$
\begin{array}{ll}
\text { BVEST: } & n_{1}=5, \bar{x}_{1}=17.33, s_{1}=21.27, \\
\text { MVST: } & n_{2}=8, \bar{x}_{2}=11.75, s_{2}=8.36
\end{array}
$$

By using the above information and the formula for the weighted average, it is easy to calculate the weighted average. Recall that $\mathrm{w}_{1}=.2523$ for BVEST and $\mathrm{w}_{2}=.7476$ for MVST so that

$$
\begin{aligned}
\bar{x}_{w} & =\frac{w_{1} \sum_{j=1}^{n_{1}} x_{1 j}+w_{2} \sum_{j=1}^{n_{2}} x_{2 j}}{n_{1} w_{1}+n_{2} w_{2}} . \\
& =\frac{w_{1} n_{1} \bar{x}_{1}+w_{2} n_{2} \bar{x}_{2}}{n_{1} w_{1}+n_{2} w_{2}} \\
& =\frac{0.2524(5)(17.33)+0.7476(8)(11.75)}{5(0.2524)+(.7476)(8)} \\
& =\frac{92.1449}{7.2428} \\
& =12.72
\end{aligned} .
$$


To calculate the weighted standard deviation, one must go to the original data values. It is easy to show that

$$
\begin{aligned}
& s_{w}^{2}=\frac{w_{1} \sum_{j=1}^{n_{1}}\left(x_{1 j}-\bar{x}_{w}\right)^{2}+w_{2} \sum_{j=1}^{n_{2}}\left(x_{2 j}-\bar{x}_{w}\right)^{2}}{n_{1}+n_{2}-1} \\
& =\frac{486.5548+372.8602}{12} \\
& =71.61792 \text {, } \\
& \text { so that } s_{w}=8.44 \text {. }
\end{aligned}
$$

\subsubsection{Confidence Interval for the Population Mean (Hahn and Meeker, pp. 54-55)}

A $100(1-\alpha) \%$ two-sided confidence interval to contain the population mean $\mu$ of a normal population is

$$
[\mu, \bar{\mu}]=\bar{x} \pm t_{(1-\alpha / 2, n-1)} s / \sqrt{n}
$$

where $\bar{x}$ is the sample mean; $\bar{x}=\sum_{i=1}^{n} x / n, n$ the number of observations in the sample, is the upper $100(1-\alpha / 2)$ percentile of the student $t$ distribution with $(n-1) t_{(1-\alpha / 2, n-1)}$ degrees of freedom, $s$ is the sample standard deviation;

$$
s=\sqrt{\frac{\sum_{l=1}^{n}\left(x_{i}-\bar{x}\right)^{2}}{(n-1)}} .
$$

To obtain an upper $100(1-\alpha) \%$ confidence use

$$
\bar{\mu}=\bar{x}+t_{(1-\alpha, n-1)} s / \sqrt{n} .
$$

We note that this method is dependent on the assumptions of normality and independent samples all taken from the same population. Intervals calculated above are for the mean of the population and will result in intervals of shortest length.

Example: Suppose we want to obtain a 95\% confidence interval for silver at BVEST. There are a total of 5 observations (namely, $2.03,3.30,3.30,28.00,50.00 \mathrm{mg} / \mathrm{kg}$ ) with $\bar{x}=17.33$ and $s=21.27$. Student's $t$ table (see Table 4.1, all Chap. 4 tables are located at the end of the chapter) we find $t_{(.975,4)}=2.776$ and $t_{(.95,4)}=2.132$. A two-sided $95 \%$ confidence interval for $\mu$ is given by

$$
\begin{aligned}
{[\underline{\mu}, \bar{\mu}] } & =17.33 \pm 2.776(21.27 / \sqrt{5}) \\
& =17.33 \pm 26.4060 \\
& =[-9.08,43.74] .
\end{aligned}
$$


Note than because a concentration cannot be negative, we would replace -9.08 with 0 . An upper $95 \%$ confidence bound for $\mu$ is

$$
\begin{aligned}
\bar{\mu} & =17.33+2.132(21.27 / \sqrt{5}) \\
& =17.33+20.28 \\
& =37.61
\end{aligned}
$$

\subsubsection{Confidence Interval for the Probability of Being less than a Specified Value}

(Hahn and Meeker, pp. 57-58)

A $100(1-\alpha) \%$ two-sided confidence interval to contain

$$
p_{L}=\operatorname{Pr}(Y \leq L),
$$

the probability that a normally distributed random variable $\mathrm{Y}$ is less than a specified lower limit, $L$ is

$$
\left[p_{L}, \bar{p}_{L}\right]=\left[h_{(1-\alpha / 2 ;-k, n)}, 1-h_{(1-\alpha / 2 ; k, n)}\right]
$$

where

$$
k=(\bar{x}-L) / s
$$

and the factors $h_{(1-\alpha ; k, n)}$ are given in Odeh and Owen ${ }^{27}$ (1980, Table 7) for all combinations of

$$
\begin{aligned}
& k=-3.0(0.20) 3.0 \\
& n=2(1) \quad 18,30,40,(20) 120,240,600,1000,, 1200
\end{aligned}
$$

and

$$
1-\alpha / 2=0.50,0.75,0.90,0.95,0.975,0.99,0.995
$$

Similarly, a $100(1-\alpha) \%$ two-sided confidence interval to contain $p_{G}=P(Y \geq L)=1-p_{L}$, the probability that a normally distributed random variable $\mathrm{Y}$ is greater than the upper limit $\mathrm{L}$, is given by

$$
\begin{aligned}
{\left[\underline{p}_{G}, \bar{p}_{G}\right] } & =\left[1-\bar{p}_{L}, 1-p_{L}\right] \\
& =\left[h_{(1-\alpha / 2 ; k n)}, 1-h_{(1-\alpha / 2 ;-k, n)}\right]
\end{aligned}
$$

\subsubsection{Tolerance Intervals to Contain a Specified Population Proportion \\ (Hahn and Meeker, pp. 58-60)}

A $100(1-\alpha) \%$ two-sided tolerance interval to contain at least a proportion, $p$, of a normal population is computed as:

$$
\left[\underline{T}_{p}, \bar{T}_{p}\right]=\bar{x} \pm g_{(1-\alpha ; p, n)} s
$$

Where $g_{(1-\varangle ; p, n)}$ is given in Odeh and Owen (1980, Table 3) for all combinations of 


$$
\begin{aligned}
p= & 0.75,0.90,0.95,0.975,0.99, \text { and } 0.995 \\
n= & 2(1) 100(2) 180(5) 300(10) 400(25) 650(50) 1000,1500 \\
& 2000,3000,5000,10000, \text { and } \infty .
\end{aligned}
$$

and

$$
1-\alpha=0.50,0.75,0.90,0.95,0.975,0.99 \text {, and } 0.995 \text {. }
$$

Tables 4.2 and 4.3 contain values of $g(1-\alpha ; p, n)$

$$
\begin{aligned}
\text { for } p & =0.90,0.95,0.99 \\
n & =4,5,6,7,8,9,10,12,15,20 \\
\text { and } 1-\alpha & =0.95,0.99 .
\end{aligned}
$$

A one-sided upper $100(1-\alpha) \%$ tolerance bound to exceed at least $100 p \%$ of the population is

$$
\bar{T}_{p}=\bar{x}+g_{(1-\alpha ; p, n)}^{\cdot} s,
$$

where $g_{(1-\alpha ; p, n)}^{\prime}$ is given in Odeh and Owen (1980, Table 1) for the same values of $p, n$, and $1-\alpha$ as for the two-sided factors. Table 4.4 contains values of $g_{(1-\alpha ; p, n)}^{\prime}$.

$$
\begin{gathered}
\text { for } n=2,3,4,5,6,7,8,9,10,11,12,15,20,35,60,120 \\
1-\alpha=0.95,0.99 \\
\text { and } p=0.90,0.96 \text {, and } 0.99
\end{gathered}
$$

Example: Using the silver data from BVEST, we have $\mathrm{n}=5$ observations with

$\bar{x}=17.33$ and $s=21.27$. It is desired to construct a $95 \%$ two-sided tolerance bound (i.e., $1-\alpha=0.95$ ) to contain $90 \%$ of the population values (i.e., $p=0.90$ ) and a one-sided $95 \%$ upper tolerance bound to exceed at least $90 \%$ of the population values.

We use $g_{(0.95 ; 0.90,5)}=4.291$ [Odeh and Owen (1980, Table 3.4.1) or Table 4.2] and $g_{(0.95 ; 0.90,5)}^{\prime}=3.407$ [Odeh and Owen $(1980$, Table 1.4.1) or Table 4.4]. A standard $95 \%$ two-sided tolerance interval is

$$
\begin{aligned}
{\left[T_{0.90}, \bar{T}_{0.90}\right] } & =17.33 \pm(4.291)(21.27) \\
& =[-73.94,108.60]
\end{aligned}
$$

Again, because we cannot have a negative concentration, we replace -73.94 by 0 . A $95 \%$ upper tolerance bound to exceed at least $90 \%$ of the population is

$$
\begin{aligned}
\bar{T}_{0.90} & =17.33+3.407(21.27) \\
& =89.80
\end{aligned}
$$

One might compare the above intervals to those based on the weighted values obtained by combining the MVEST and BVST values for silver. Recall that $\bar{x}_{w}=12.72$ and $s_{w}=8.44$, but now the sample size is $5+8=13$. Using Table 4.2 , we do not have an entry for a sample of size 13 , so we will use the smallest sample size corresponding to $n=12$. This will be more 
conservative than using $\mathrm{n}=15$ or some interpolating scheme. The corresponding entry for $n=12, p=0.90$ and $1-\alpha=.95$ is $g(.95,90,12)=2.67$. Thus, a standard $95 \%$ two-sided tolerance interval for the weighted data is

$$
\begin{aligned}
{\left[\underline{T}_{.90}, \bar{T}_{.90}\right] } & =12.72 \pm 2.678 .44) \\
& =[-9.81,35.25] .
\end{aligned}
$$

\subsubsection{One-sided and Two-sided Prediction Bounds to Contain All of M Future Observations (Hahn and Meeker, pp. 62-63)}

A $100(1-\alpha) \%$ two-sided prediction interval to contain the values of all of $m$ future randomly selected units from the previously sampled normal population is

$$
\left[\underline{y}_{m}, \bar{y}_{m}\right]=\bar{x}+r_{(1-\alpha ; m, n)} s
$$

where $r_{(1-\alpha ; m, n)}$ is tabulated in Hahn (1969) for all combinations of

$$
\begin{aligned}
& n=6(1) 21,25,31,41,61,121, \infty \\
& m=1(1) 12,15,20
\end{aligned}
$$

and

$$
1-\alpha=0.90,0.95,0.99 .
$$

In addition, Hahn and Meeker (1987, Table A.13) contains $r_{(1-\alpha ; m, n)}$ for

$$
\begin{aligned}
n & =4(1) 12,15,20,25,30,40,60,120 \\
m & =1(1) 10,12,16,20,40,60,80,100
\end{aligned}
$$

and

$$
1-\alpha=0.90,0.95 \text {, and } 0.99 \text {. }
$$

A conservative approximation for $r_{(1-\alpha ; m, n)}$ is given by

$$
r_{(1-\alpha, m, n)} \cong(1+1 / n)^{1 / 2} t_{(1-\alpha /(2 m) ; n-1)}
$$

The above approximation is based on a Bonferroni inequality and was suggested by Chew (1968). The approximation was investigated by Hahn (1969) and found to be satisfactory for most cases, except for combinations of small $n$, large $m$, and small $1-\alpha$. The expression is exact for $\mathrm{m}=1$ future observation. Tables 4.2 and 4.3 contain values of $m, n)$ for $1-\alpha=.95$ and $.99, n=4(1) 10,12,15,20$, and $m=1,2,5,1$ One-sided upper $100(1-\alpha) \%$ prediction bounds to exceed all of $\mathrm{m}$ future observations from a previously sampled normal population is

$$
\bar{y}_{m}=\bar{x}+r_{(1-\alpha ; m, n)}^{\prime} s
$$

where $r_{(1-\alpha ; m, n)}^{\prime}$ are tabulated in Hahn and Meeker (1987, Table A.14) for 


$$
\begin{aligned}
& n=4(1) 10,12,15,20,25,30,40,60,120 \\
& m=1(1) 10,12,16,20,40,60,80,100
\end{aligned}
$$

and

$$
1-\alpha=0.90,0.95 \text {, and } 0.99 \text {. }
$$

Again, a conservative approximation for $r_{(1-\alpha ; m, n)}^{\prime}$ is

$$
r_{(1-\alpha ; m, n)}^{\prime} \simeq(1+1 / n)^{1 / 2} t_{(1-\varangle / m, n-1)} .
$$

The expression was evaluated by Hahn (1970) with results similar to those for the approximation of the two-sided prediction interval. Table 4.5 contains values for $r_{(1-\alpha ; m, n)}^{\prime}$ for $1-\alpha=95.99, m=1,2,5,10,20$, and $n=4(1) 10,15,20$.

Example: Using the silver data from BVEST, we have $n=5$ observations with $\bar{x}=17.33$ and $s=21.27$. It is desired to form a $95 \%$ two-sided prediction interval to contain the future values of $\mathrm{m}=10$ future observations and an upper $95 \%$ one-sided prediction bound for $\mathrm{m}=10$ future observations. From Table 4.2, $\quad r_{(0.95 ; 10,5)}=5.229$ and from . Table 4.5, $\quad r_{(0.95 ; 10,5)}^{\prime}=4.418$.

A $95 \%$ two-sided prediction interval to contain all 10 future observations is given by

$$
\begin{aligned}
{\left[y_{10}, \bar{y}_{10}\right] } & =17.33 \pm 5.229(21.27) \\
& =[-93.91,128.57] .
\end{aligned}
$$

A one-sided upper $95 \%$ prediction bound to exceed all 10 future observations is given by

$$
\begin{aligned}
\bar{y}_{10} & =17.33+(4.418)(21.27) \\
& =111.34 .
\end{aligned}
$$

\subsubsection{Log Transformations}

In some situations, the data do not have a symmetrical distribution, and a transformation is necessary to use normal theory statistics. In the case where taking logarithms (basc e) of the data tend to make the distribution of the transformed data more symmetrical, we can still apply the methods given in Sects. 4.3.2 through 4.3.4 to obtain intervals or bounds on the transformed data and then apply the inverse transform to get back to the original data units. [nterested readers can see Hahn and Meeker ${ }^{29}$ (1991), page 73]. For example, in Sect. 4.3.3.we obtained a 95\% twosided tolerance bound to contain $90 \%$ of the population values. If we assume that the true distribution of the data is lognormal, then we log transform the data. The resulting mean and standard deviation for the silver data from BVEST (after taking logarithms) are

$$
\begin{aligned}
& \vec{x}=2.068 \\
& s^{\prime}=1.447
\end{aligned}
$$


Using Table 4.2, we find $g_{(0.95 ; 0.90,5)}=4.291$ and the two-sided tolerance interval on the transformed data is given by

$$
\begin{aligned}
{\left[\underline{T}_{0.90}^{\prime}, \bar{T}_{0.90}^{\prime}\right] } & =2.068 \pm 4.291(1.447) \\
& =[-4.141,8.277]
\end{aligned}
$$

The $95 \%$ two-sided tolerance bound to contain $90 \%$ of the population values of the untransformed data is given by

$$
\left[e^{I_{0.00}}, e^{\bar{T}_{0.00}}\right]=\left[e^{-4.141}, e^{8.277}\right]=[0.016,3932.380]
$$

\subsection{PREDICTION INTERVALS WHEN THE DATA IS EXPONENTIALLY DISTRIBUTED}

In Sect. 4.3.4 we discussed prediction intervals to contain all of $m$ future observations when the underlying distribution is normal. In this section we shall derive the equations necessary to do this for the exponential distribution. We assume that we are given a sample of size $n$ from this exponential population and we use this information to guide us in determining a bound that will contain all of $m$ future observations.

To begin, let us define the exponential distribution. The exponential distribution is characterized by a single parameter, $\theta$, and its density function is given by

$$
f(x ; \theta)=\frac{1}{\theta} e^{-x / \theta}, x>0, \theta>0 .
$$

Suppose that we observe $x_{1}, x_{2}, \ldots, x_{n}$ from this exponential distribution. It is easy to show that the minimum variance unbiased estimator of $\theta$ is given by

$$
\hat{\theta}=\sum_{i=1}^{n} \frac{x_{i}}{n}
$$

It is also easy to show that $2 n \hat{\theta} / \theta$ has a chi-squared distribution with $2 \mathrm{n}$ degrees of freedom (see Mann, Schafer, and Singpurwalla ${ }^{28}$, pages 164 and 165).

Now suppose we consider a future sample of size $m$ from this same population, say $y_{1}, y_{2}, \ldots$, $y_{m}$. The distribution of these future observations are also dependent on the unknown parameter $\theta$, but we can use our prior sample to remove the dependence by the following transformation. Consider the variables

$$
r_{i}=\frac{\left(y_{i} / \theta\right)}{(2 n \hat{\theta} / \theta)}=\frac{y_{i}}{2 \sum_{i=1}^{n} x_{i}} \quad i=1,2, \ldots, m
$$


The variables $r_{1}, r_{2}, \ldots, r_{m}$ are independent of $\theta$ because it disappears in the ratio. Thus we need to find the distribution of $r_{1}, r_{2}, \ldots, r_{m}$, and this will enable us to determine future $y$ values by using what are called pivotal statistics.

To begin with, we shall consider the conditional distribution of $r_{1}, r_{2}, \ldots, r_{m}$ given

$$
2 \sum_{i=1}^{n} x_{i} / \theta
$$

To simply the notation we shall let $\quad t=2 \sum_{i=1}^{n} x_{i} / \theta$

then we want the distribution of $r_{i}$ conditional on $u$ where

$$
r_{i}=\frac{y_{i} / \theta}{u} \quad i=1,2, \ldots, m
$$

Recall that we are conditioning on $u$ can be treated as a constant.

Because $\quad r_{i}=\frac{y_{i} / \theta}{u}$

then $y_{i}=u \theta r_{i}$, and it is easy to show that the conditional density of $r_{i}$ given $u$ is given by

$$
f\left(r_{i} \mid u\right)=u e^{-u r_{i}} \quad i=1,2, \ldots, m \text {. }
$$

Because the $y_{i}$ values are a random sample and therefore independent, it follows that the $r_{i}$ values are independent also, and we can write the joint density of $r_{1}, r_{2}, \ldots, r_{m}$ conditional on $u$ as the product of the marginals. Therefore

$$
f\left(r_{1}, r_{2}, \ldots, r_{m} \mid u\right)=u^{m} e^{-u \sum_{i=1}^{m} r_{i}}
$$

Recall that $\mathrm{u}$ is distributed as a chi-square random variable with $2 \mathrm{n}$ degrees of freedom so we may write the joint density of $r_{1}, r_{2}, \ldots, r_{m}$ and $u$ as

$$
\begin{aligned}
f\left(r_{1}, r_{2}, \ldots, r_{m}, u\right) & =f\left(r_{1}, r_{2}, \ldots, r_{m} \mid u\right) g(u) \\
& =u^{m} e^{-u \sum_{i=1}^{\infty} r_{1}} \frac{u^{n-1} e^{-w 2}}{2^{n} \Gamma(n)} \\
& =u^{m+n-1} \frac{e^{\frac{-u\left(1+2 \sum_{i=1}^{\infty} r_{1}\right)}{2}}}{2^{n} \Gamma(n)}
\end{aligned}
$$


Finally, we integrate out $\mathrm{u}$ to find the distribution on $r_{1}, r_{2}, \ldots, r_{m}$ which is given by

$$
f\left(r_{1}, r_{2}, \ldots, r_{m}\right)=\frac{\Gamma(m+n)}{\Gamma(n)} 2^{m}\left(1+2 \sum_{i=1}^{m} r_{i}\right)^{-(m+n)}
$$

Recall that we want to find the value for which each $y_{i}$ will be less than with a given probability. This corresponds to a value, call it $B$, for which all $r_{i}$ values will be less than with a specified probability. Because the density decreases as $r_{i}$ increases, it can be shown that the shortest interval that will contain a given probability is one whose left end point is zero. Thus, the shortest bounding interval is $[0, \mathrm{~B}]$ and we desire

$$
\int_{0}^{B} \int_{0}^{B} \ldots \int_{0}^{B} \frac{\Gamma(m+n)}{\Gamma(n)} 2^{m}\left(1+2 \sum_{i=1}^{m} r_{i}\right)^{-(m+n)} d r_{1} d r_{2} \ldots d r_{m}=\gamma .
$$

The value of $B$ is a function of $m, n$, and $\gamma$ so we shall denote this by $B[\gamma ; m, n]$.

For the case when $m=1$, we can solve the above integral equation analytically. The integral evaluates to

$$
1-\frac{1}{(1+2 B[\gamma ; 1, n])^{n}}=\gamma
$$

and hence

$$
B[\gamma ; 1, n]=\frac{1}{2}\left[\frac{1}{(1-\gamma)^{\frac{1}{n}}}-1\right]
$$

Because we have that

$$
r_{1}=\frac{y_{1} / \theta}{2 \sum_{i=1}^{n} x_{i} / \theta}=\frac{y_{1}}{2 \sum_{i=1}^{n} x_{i}}
$$

it follows that

$$
\operatorname{Pr}\left(r_{1}<B[\gamma ; 1, n]\right)=\gamma
$$

and by substitution for $r_{i}$ we have

$$
\operatorname{Pr}\left(\frac{y_{1}}{2 \sum_{i=1}^{n} x_{i}}<B[\gamma ; 1, n]\right)=\gamma
$$

or 


$$
\operatorname{Pr}\left(y_{1}<2 \sum_{i=1}^{n} x_{i} B[\gamma ; 1, n]\right)=\gamma
$$

and finally

$$
\operatorname{Pr}\left(y_{1}<\sum_{i=1}^{n} x_{i}\left[\frac{1}{(1-\gamma)^{\frac{1}{n}}}-1\right]\right)=\gamma
$$

As an example of the use of the above equation, suppose that the ten samples of total organic carbon (TOC) obtained from the OHF came from an exponential distribution. We found the average value of TOC to be 9898.0 , so that the sum of TOC is $10(9898.0)=98980$. Suppose we want a prediction interval for a single $(\mathrm{m}=1)$ future observation and we want to be $95 \%$ confident that any single future observation will be less than this bound. Because we want to be $95 \%$ confident then $\gamma=.95$, our previous sample size is $\mathrm{n}=10$, and our equation gives us

$$
\begin{aligned}
y_{1} & \leq \sum_{i=1}^{n} x_{i}\left[\frac{1 \cdot}{(1-.95)^{1 / 10}}-1\right] \\
& \leq 98980[1.349-1] \\
& \leq 34572 .
\end{aligned}
$$

We note that the maximum for TOC from the ten samples was 28,000 . Note the value $0.349=B[.95 ; 1,10]$, which can be found in Table 4.6. For values of $m \geq 2$, the integral equation must be used, and this equation is nontrivial and must be solved using computer programs. Table 4.6 contains the results of evaluating the integral equation for $\gamma=0.95, n=1$ (1) 10 , and $\mathrm{m}=1$ (1) 5 . 
Table 4.1. Selected percentiles of the student's $t$-distribution

\begin{tabular}{|c|c|c|c|c|c|}
\hline \multirow{2}{*}{$\begin{array}{l}\text { Degrees } \\
\text { of freedom }\end{array}$} & \multicolumn{5}{|c|}{$\mathbf{p}$} \\
\hline & 0.90 & 0.95 & 0.975 & 0.99 & 0.995 \\
\hline 1 & 3.078 & 6.314 & 12.706 & 31.821 & 63.657 \\
\hline 2 & 1.886 & 2.920 & 4.303 & 6.965 & 9.925 \\
\hline 3 & 1.638 & 2.353 & 3.182 & 4.541 & 5.841 \\
\hline 4 & 1.533 & 2.132 & 2.776 & 3.747 & 4.604 \\
\hline 5 & 1.476 & 2.015 & 2.571 & 3.365 & 4.032 \\
\hline 6 & 1.440 & 1.943 & 2.447 & 3.143 & 3.707 \\
\hline 7 & 1.415 & 1.895 & 2.365 & 2.998 & 3.499 \\
\hline 8 & 1.397 & 1.860 & 2.306 & 2.896 & 3.355 \\
\hline 9 & 1.383 & 1.833 & 2.262 & 2.821 & 3.250 \\
\hline 10 & 1.372 & 1.812 & 2.228 & 2.764 & 3.169 \\
\hline 11 & 1.363 & 1.796 & 2.201 & 2.718 & 3.106 \\
\hline 12 & 1.356 & 1.782 & 2.179 & 2.681 & 3.055 \\
\hline 13 & 1.350 & 1.771 & 2.160 & 2.650 & 3.012 \\
\hline 14 & 1.345 & 1.761 & 2.145 & 2.624 & 2.977 \\
\hline 15 & 1.341 & 1.753 & 2.131 & 2.602 & 2.947 \\
\hline 16 & 1.337 & 1.746 & 2.120 & 2.583 & 2.921 \\
\hline 17 & 1.333 & 1.740 & 2.110 & 2.567 & 2.898 \\
\hline 18 & 1.330 & 1.734 & 2.101 & 2.552 & 2.878 \\
\hline 19 & 1.328 & 1.729 & 2.093 & 2.539 & 2.861 \\
\hline 20 & 1.325 & 1.725 & 2.086 & 2.528 & 2.845 \\
\hline 21 & 1.323 & 1.721 & 2.080 & 2.518 & 2.831 \\
\hline 22 & 1.321 & 1.717 & 2.074 & 2.508 & 2.819 \\
\hline 23 & 1.319 & 1.714 & 2.069 & 2.500 & 2.807 \\
\hline 24 & 1.318 & 1.711 & 2.064 & 2.492 & 2.797 \\
\hline 25 & 1.316 & 1.708 & 2.060 & 2.485 & 2.787 \\
\hline 26 & 1.315 & 1.706 & 2.056 & 2.479 & 2.779 \\
\hline 27 & 1.314 & 1.703 & 2.052 & 2.473 & 2.771 \\
\hline 28 & 1.313 & 1.701 & 2.048 & 2.467 & 2.763 \\
\hline 29 & 1.311 & 1.699 & 2.045 & 2.462 & 2.756 \\
\hline$\infty$ & 1.282 & 1.645 & 1.960 & 2.326 & 2.576 \\
\hline
\end{tabular}


Table 4.2. The factor $g_{(0.95, p, n)}$ for calculating two-sided $95 \%$ tolerance intervals and the factor $\mathbf{r}_{(0.95, \mathrm{~m}, \mathrm{n})}$ for calculating two-sided $95 \%$ prediction intervals for $\mathrm{m}$ future observations

\begin{tabular}{|c|c|c|c|c|c|c|c|c|}
\hline \multirow{3}{*}{$\begin{array}{l}\text { Number } \\
\text { of given } \\
\text { observations } \\
\text { (n) }\end{array}$} & \multirow{2}{*}{\multicolumn{3}{|c|}{$\begin{array}{c}\mathbf{g}_{(0.95, p, n)} \text { for tolerance } \\
\text { intervals to contain at least } \\
100 \text { p of the distribution } \\
p\end{array}$}} & \multicolumn{5}{|c|}{$\begin{array}{c}\mathbf{r}_{(0.95, \mathrm{~m}, \mathrm{n})} \text { for simultaneous prediction } \\
\text { intervals to contain } \\
\text { all } \mathrm{m} \text { future observations }\end{array}$} \\
\hline & & & & \multicolumn{5}{|c|}{$\mathbf{m}$} \\
\hline & 0.90 & 0.95 & 0.99 & 1 & 2 & 5 & 10 & 20 \\
\hline 4 & 5.368 & 6.341 & 8.221 & 3.558 & 4.412 & 5.564 & 6.407 & 7.206 \\
\hline 5 & 4.291 & 5.077 & 6.598 & 3.041 & 3.697 & 4.577 & 5.229 & 5.853 \\
\hline 6 & 3.733 & 4.422 & 5.758 & 2.777 & 3.333 & 4.076 & 4.628 & 5.159 \\
\hline 7 & 3.390 & 4.020 & 5.241 & 2.616 & 3.114 & 3.774 & 4.265 & 4.749 \\
\hline 8 & 3.156 & 3.746 & 4.889 & 2.508 & 2.968 & 3.573 & 4.022 & 4.457 \\
\hline 9 & 2.986 & 3.546 & 4.633 & 2.431 & 2.863 & 3.429 & 3.848 & 4.256 \\
\hline 10 & 2.856 & 3.393 & 4.437 & 2.373 & 2.785 & 3.321 & 3.717 & 4.103 \\
\hline 12 & 2.670 & 3.175 & 4.156 & 2.290 & 2.680 & 3.170 & 3.530 & 3.890 \\
\hline 15 & 2.492 & 2.965 & 3.885 & 2.215 & 2.574 & 3.031 & 3.365 & 3.689 \\
\hline 20 & 2.319 & 2.760 & 3.621 & 2.145 & 2.480 & 2.902 & 3.208 & 3.503 \\
\hline
\end{tabular}

Table 4.3. The factor $g_{(0.95, \mathrm{p}, \mathrm{n})}$ for calculating two-sided $99 \%$ tolerance intervals and the factor $r_{(0,95, m, n)}$ for calculating two-sided $99 \%$ prediction intervals for $m$ future observations

\begin{tabular}{|c|c|c|c|c|c|c|c|c|}
\hline \multirow{3}{*}{$\begin{array}{c}\text { Number } \\
\text { of given } \\
\text { observations } \\
\text { (n) }\end{array}$} & \multirow{2}{*}{\multicolumn{3}{|c|}{ 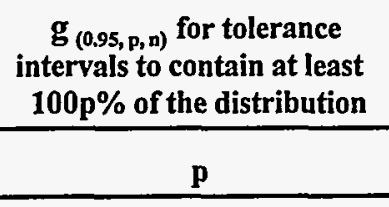 }} & \multicolumn{5}{|c|}{$\begin{array}{c}\mathbf{r}_{(0.95, \mathrm{~m}, \mathrm{n})} \text { for simultaneous prediction } \\
\text { intervals to contain } \\
\text { all } \mathbf{m} \text { future observations }\end{array}$} \\
\hline & & & & \multicolumn{5}{|c|}{$\mathbf{m}$} \\
\hline & 0.90 & 0.95 & 0.99 & 1 & 2 & 5 & 10 & 20 \\
\hline 4 & 9.416 & 11.118 & 14.405 & 6.530 & 7.942 & 9.884 & 11.325 & 12.698 \\
\hline 5 & 6.655 & 7.870 & 10.220 & 5.044 & 5.972 & 7.253 & 8.219 & 9.154 \\
\hline 6 & 5.383 & 6.373 & 8.292 & 4.355 & 5.071 & 6.055 & 6.803 & 7.535 \\
\hline 7 & 4.658 & 5.520 & 7.191 & 3.963 & 4.562 & 5.382 & 6.006 & 6.621 \\
\hline 8 & 4.189 & 4.968 & 6.479 & 3.712 & 4.238 & 4.953 & 5.499 & 6.038 \\
\hline 9 & 3.860 & 4.581 & 5.980 & 3.537 & 4.014 & 4.659 & 5.148 & 5.634 \\
\hline 10 & 3.617 & 4.294 & 5.610 & 3.408 & 3.850 & 4.442 & 4.892 & 5.339 \\
\hline 12 & 3.279 & 3.896 & 5.096 & 3.230 & 3.630 & 4.150 & 4.540 & 4.940 \\
\hline 15 & 2.967 & 3.529 & 4.621 & 3.074 & 3.426 & 3.888 & 4.234 & 4.578 \\
\hline 20 & 2.675 & 3.184 & 4.175 & 2.932 & 3.247 & 3.655 & 3.957 & 4.256 \\
\hline
\end{tabular}


Table 4.4. Factors $g^{\prime}{ }_{(1-\alpha ; p, n)}$ for calculating normal distribution one-sided $100(1-\alpha) \%$ tolerance bounds

\begin{tabular}{|c|c|c|c|c|c|c|}
\hline \multirow{3}{*}{$\mathbf{n}$} & \multicolumn{3}{|c|}{$.1-\alpha=0.95$} & \multicolumn{3}{|c|}{$1-\alpha=0.99$} \\
\hline & \multicolumn{3}{|c|}{$\mathbf{p}$} & \multicolumn{3}{|c|}{ p } \\
\hline & 0.90 & 0.95 & 0.99 & 0.90 & 0.95 & 0.99 \\
\hline 2 & 20.581 & 22.260 & 37.094 & 103.029 & 131.426 & 185.617 \\
\hline 3 & 6.155 & 7.656 & 10.553 & 13.995 & 17.370 & 23.896 \\
\hline 4 & 4.162 & 5.144 & 7.042 & $7.380^{\circ}$ & 9.083 & 12.387 \\
\hline 5 & 3.407 & 4.203 & 5.741 & 5.362 & 6.578 & 8.939 \\
\hline 6 & 3.006 & 3.708 & 5.062 & 4.411 & 5.406 & 7.335 \\
\hline 7 & 2.755 & 3.399 & 4.642 & 3.859 & 4.728 & 6.412 \\
\hline 8 & 2.582 & 3.187 & 4.354 & 3.497 & 4.285 & 5.812 \\
\hline 9 & 2.454 & 3.031 & 4.143 & 3.240 & 3.972 & 5.389 \\
\hline 10 & 2.355 & 2.911 & 3.981 & 3.048 & 3.738 & 5.074 \\
\hline 11 & 2.275 & 2.815 & 3.852 & 2.898 & .3 .556 & 4.829 \\
\hline 12 & 2.210 & 2.736 & 3.747 & 2.777 & 3.410 & 4.633 \\
\hline 15 & 2.068 & 2.566 & 3.520 & 2.521 & 3.102 & 4.222 \\
\hline 20 & 1.926 & 2.396 & 3.295 & 2.276 & 2.808 & 3.832 \\
\hline 35 & 1.732 & 2.167 & 2.995 & 1.957 & 2.430 & 3.334 \\
\hline 60 & 1.609 & 2.022 & 2.807 & 1.764 & 2.202 & 3.038 \\
\hline 120 & 1.503 & 1.899 & 2.649 & 1.604 & 2.015 & 2.797 \\
\hline
\end{tabular}


Table 4.5. Factors $r^{\prime}(1-\alpha ; m, n)$ for calculating normal distribution one-sided $100(1-\alpha) \%$ prediction bounds for $m$ future

observations using the results of a previous sample of $\mathbf{n}$ observations.

\begin{tabular}{|c|c|c|c|c|c|}
\hline \multirow[b]{2}{*}{$\mathbf{n}$} & \multicolumn{5}{|c|}{ m } \\
\hline & 1 & 2 & 5 & 10 & 20 \\
\hline & & & $1-\alpha=0.95$ & & \\
\hline 4 & 2.631 & 3.401 . & 4.472 & 5.285 & 6.063 \\
\hline 5 & 2.335 & 2.952 & 3.788 & 4.418 & 5.029 \\
\hline 6 & 2.177 & 2.715 & 3.433 & 3.971 & 4.495 \\
\hline 7 & 2.077 & 2.570 & 3.217 & 3.699 & 4.168 \\
\hline 8 & 2.010 & 2.471 & 3.071 & 3.516 & 3.948 \\
\hline 9 & 1.960 & 2.400 & 2.966 & 3.384 & 3.790 \\
\hline 10 & 1.923 & 2.346 & 2.887 & 3.284 & 3.670 \\
\hline 15 & 1.819 & 2.198 & 2.671 & 3.013 & 3.342 \\
\hline \multirow[t]{2}{*}{20} & 1.772 & 2.132 & 2.574 & 2.891 & 3.194 \\
\hline & & & $1-\alpha=0.99$ & & \\
\hline 4 & 5.077 & 6.305 & 8.070 & 9.434 & 10.764 \\
\hline 5 & 4.105 & 4.943 & 6.126 & 7.043 & 7.946 \\
\hline 6 & 3.635 & 4.298 & 5.221 & 5.935 & 6.643 \\
\hline 7 & 3.360 & 3.926 & 4.705 & 5.305 & 5.902 \\
\hline 8 & 3.180 & 3.685 & 4.372 & 4.900 & 5.425 \\
\hline 9 & 3.053 & 3.517 & 4.141 & 4.619 & 5.094 \\
\hline 10 & 2.959 & 3.393 & 3.972 & 4.412 & 4.851 \\
\hline 15 & 2.711 & 3.067 & 3.531 & 3.877 & 4.219 \\
\hline 20 & 2.602 & 2.927 & 3.342 & 3.649 & 3.950 \\
\hline
\end{tabular}


Table 4.6. Factors $B(.95 ; m, n)$ for calculating exponential distribution two-sided $95 \%$ prediction intervals for $m$ future observations using the results of a previous sample of $n$ observations

\begin{tabular}{|c|c|c|c|c|c|c|c|c|c|c|c|c|}
\hline \multirow[b]{2}{*}{$\mathbf{n}$} & \multicolumn{12}{|c|}{$\mathbf{m}$} \\
\hline & 1 & 2 & 3 & 4 & 5 & 6 & 7 & 8 & 9 & 10 & 15 & 20 \\
\hline 1 & 19.0 & 28.830 & 35.372 & 40.276 & 44.196 & 47.462 & 50.259 & 52.707 & 54.882 & 56.839 & 64.454 & 69.920 \\
\hline 2 & 3.472 & 4.833 & 5.725 & 6.395 & 6.931 & 7.379 & 7.763 & 8.101 & 8.401 & 8.671 & 9.728 & 10.491 \\
\hline 3 & 1.714 & 2.299 & 2.677 & 2.960 & 3.186 & 3.374 & 3.537 & 3.679 & 3.806 & 3.920 & 4.367 & 4.691 \\
\hline 4 & 1.115 & 1.465 & 1.688 & 1.855 & 1.987 & 2.098 & 2.193 & 2.277 & 2.351 & 2.418 & 2.681 & 2.871 \\
\hline 5 & 0.821 & 1.064 & 1.219 & 1.333 & 1.424 & 1.500 & 1.565 & 1.622 & 1.673 & 1.719 & 1.899 & 2.029 \\
\hline 6 & 0.648 & 0.833 & 0.949 & 1.035 & 1.103 & 1.160 & 1.208 & 1.251 & 1.289 & 1.323 & 1.457 & 1.555 \\
\hline 7 & .0 .534 & 0.682 & 0.775 & 0.843 & 0.897 & 0.942 & 0.980 & 1.014 & 1.044 & 1.071 & 1.177 & 1.254 \\
\hline 8 & 0.454 & 0.578 & 0.654 & 0.710 & 0.755 & 0.792 & 0.823 & 0.851 & 0.876 & 0.898 & 0.985 & 1.048 \\
\hline 9 & 0.395 & 0.500 & 0.565 & 0.613 & 0.651 & 0.682 & 0.709 & 0.732 & 0.753 & 0.772 & 0.845 & 0.898 \\
\hline 10 & 0.349 & 0.441 & 0.498 & 0.539 & 0.571 & 0.598 & 0.622 & 0.642 & 0.660 & 0.676 & 0.739 & 0.785 \\
\hline 11 & 0.313 & 0.394 & 0.444 & 0.480 & 0.509 & 0.533 & 0.553 & 0.571 & 0.587 & 0.601 & 0.657 & 0.697 \\
\hline 12 & 0.284 & 0.356 & 0.401 & 0.433 & 0.459 & 0.480 & 0.498 & 0.514 & 0.528 & 0.541 & 0.590 & 0.626 \\
\hline 13 & 0.259 & 0.325 & 0.365 & 0.395 & 0.418 & 0.437 & 0.453 & 0.467 & 0.480 & 0.491 & 0.536 & 0.568 \\
\hline 14 & 0.239 & 0.299 & 0.336 & 0.362 & 0.383 & 0.401 & 0.415 & 0.428 & 0.440 & 0.450 & 0.490 & 0.520 \\
\hline 15 & 0.221 & 0.277 & 0.310 & 0.335 & 0.354 & 0.370 & 0.383 & 0.395 & .0 .406 & 0.415 & 0.452 & 0.479 \\
\hline 16 & 0.206 & 0.257 & 0.288 & 0.311 & 0.329 & 0.343 & 0.356 & 0.367 & 0.377 & 0.385 & 0.419 & 0.444 \\
\hline 17 & 0.193 & 0.241 & 0.269 & 0.290 & 0.307 & 0.321 & 0.332 & 0.342 & 0.351 & 0.359 & 0.391 & 0.413 \\
\hline 18 & 0.181 & 0.226 & 0.253 & 0.272 & 0.288 & 0.301 & 0.311 & 0.321 & 0.329 & 0.337 & 0.366 & 0.387 \\
\hline 19 & 0.171 & 0.213 & 0.238 & 0.257 & 0.271 & 0.283 & 0.293 & 0.302 & 0.310 & 0.317 & 0.344 & 0.364 \\
\hline 20 & 0.162 & 0.211 & 0.225 & 0.242 & 0.256 & 0.267 & 0.277 & 0.285 & 0.292 & 0.299 & 0.325 & 0.343 \\
\hline
\end{tabular}




\section{REFERENCES}

1. F. T. Binford, S. D. Orfi, The Intermediate Level Waste System at the Oak Ridge National Laboratory Description and Safety Analysis, ORNL TM-6859, August, 1979.

2. J. R. DeVore, T. E. Herrick, K. E. Lott, Technology Study of Gunite Tank Sludge Mobilization at Oak Ridge National Laboratory, Oak Ridge Tennessee, ORNL/ER286, December, 1994.

3. Advanced Integrated Management Services, Inc., Site Characterization Summary Report for the Old Hydrofracture Facility, November 30, 1995 draft.

4. Lockheed Martin Energy Systems, Inc., Preliminary Engineering Report, Old Hydrofracture Facility Tanks Content Removal Project, April 3, 1996 draft.

5. Field Task Proposal, Cesium Removal Demonstration Project

6. Martin Marietta Energy Systems, Inc., Design Criteria for Melton Valley Storage Tanks - Capacity Increase, September 10, 1993.

7. F. J. Peretz, B. R. Clark, C. B. Scott, and J. B. Berry, Characterization of Low-Level Liquid Wastes at the Oak Ridge National Laboratory, ORNL/TM-10218, December 1986.

8. J. W. Autrey, D. A. Costanzo, W. H. Griest, L. L. Kaiser, J. M. Keller, C. E. Nix, B. A. Tomkins, Sampling and Analysis of the Inactive Waste Storage Tank Contents at ORNL, ORNL/ER-13, September 1990.

9. J. W. Autrey, J. M. Keller, W. H. Griest, J. L. Botts, R. L. Schenley, and M. A. Sipe, Sampling and Analysis of the Inactive Waste Tanks TH-2, WC-1, and WC-15, ORNL/ER-19 (February 1992).

10. M. B. Sears, J. L. Botts, R. N. Ceo, J. J. Ferrada, W. H. Griest, J. M.Keller, R. L. Schenley, Sampling and Analysis of Radioactive Liquid Wastes and Sludges in the Melton Valley and Evaporator Facility Storage Tanks at ORNL, ORNL/TM-11652, September, 1990.

11. Bechtel National, Inc., Results of Fall 1994 Sampling of Gunite and Associated Tanks at the Oak Ridge National Laboratory, Oak Ridge, Tennessee, ORNL/ER/Sub/87-99053/74, June 1995.

12. Bechtel National, Inc., Results of the 1995 Sampling of Gunite and Associated Tanks at Oak Ridge National Laboratory, ORNL/ER/Sub/87-99053/79, February, 1996.

13. C. W., Francis, S. W. Herbes, Chemical Characterization of Liquid and Sludge Contained in the Old Hydrofracture Tanks, Letter report to C. A. Bednarz, August, 1996.

14. J. M. Keller, J. M. Giaquinto, W. H. Griest, Characterization of Selected Waste Tanks 
from the Active LLLW System, ORNL/TM-13248, August, 1996.

15 M. B. Sears, Results of Sampling the Contents of the Liquid Low-Level Waste Evaporator Feed Tank W-22, ORNL/TM-13234 (in preparation).

16. USEPA, Test Methods for Evaluating Solid Waste, SW-846, 3rd ed., Office of Solid Waste and Emergency Response, Washington, D.C., November 1986.

17. Evaluation of Phase I and Phase II Sampling and Analysis Data for the Gunite and Associated Tanks at the Oak Ridge National Laboratory, Oak Ridge, Tennessee, ORNL/ER-365 (March 1996).

18. J. M. Giaquinto, A. A. Essling, and J. M. Keller, Comparison of SW-846 Method 3051 and Sw-846 Method 7471A for the Preparation of Solid Waste Samples for Mercury Determination, ORNL/TM-13236

19. A. M. Meeks and J. M. Keller, Separation Techniques for the Clean-up of Radioactive Mixed Waste for ICP-AES/ICP-MS Analysis, ORNL/TM-12329 (March 1993).

20. Radian Corporation, Remedial Investigation Report/Feasibility Study for the Gunite and Associated Tanks Operable Unit at Waste Area Grouping 1 at Oak Ridge National Laboratory, Oak Ridge Tennessee, November, 1993 Draft.

21. H. O. Weeren, Sluicing Operations at Gunite Waste Storage Tanks, ORNL/NFW84/42, September, 1984.

22. J. F. Walker, Jr., J. J. Perona, S. M. Robinson, In-Tank Evaporator Demonstrations During 1990/1991 at the ORNL Melton Valley Storage Tanks, ORNL/TM-12036, October, 1992.

23. V. L. Fowler, J. J. Perona, Evaporation Studies on Oak Ridge National Laboratory Low Level Liquid Waste, ORNL/TM-12243, March, 1993.

24. T. E. Kent, Cost Effectiveness of the In-tank Evaporator for Removal of Excess Water from the ORNL Melton Valley Storage Tanks.

25. A. J. Lucero, H. L. Jennings, D. C. VanEssen, V. C. Fowler, R. L. Cummins, B. S. Evans, J. D. Hewett, S. A. Richardson, D. R. McTaggart, W. R. Reed, R. J. Wood, T. E. Kent, Out-of-Tank Evaporator Demonstration Final Report, May 15, $1996 \mathrm{draft}$.

26. T. E. Kent, letter to C. B. Scott, "In Tank Evaporation Progress", March 7, 1995.

27. R.E. Odeh, and D.B. Owen, Tables for Normal Tolerance Limits, Sampling Plans, and Screening, Marcel Dekker, Inc., New York, 1980.

28 N.R. Mann, R.E. Schafer, and N.D. Singparwalla, Methods for Statistical Analysis of Reliability and Life Data, John Wiley and Sons, Inc., New York, 1976.

29. G. J. Hahn, and W. P. Meeker, Statistical Interviews, A Guide to Practicioners, John Wiley and Sons, Inc. New York, 1991. 
APPENDIX A

A HISTORY OF TANK WASTE AT ORNL 

From the beginning of Oak Ridge National Laboratory (ORNL) ${ }^{20}$, radioactive waste management required classification of the waste into categories dependent upon both the level and type (e.g., alpha or beta emitting) of radioactivity in the waste and the volume of waste. The category names and divisions between the categories have changed over time reflecting changes in the system of categorization. Despite this, the nature of the early categories are generally recognizable and can be related to current categories. Initially, liquid wastes were divided into three main categories: metal wastes, radiochemical wastes, and process wastes. A fourth category, referred to as warm waste, was also used during early operations.

Metal wastes, while radioactive, contained primarily uranium with small quantities of plutonium and/or thorium. These elements are all long-lived radionuclides and are a fissionable source material as well. Metal waste were generated and collected from a variety of facilities throughout the laboratory.

Radiochemical waste contained primarily fission product radionuclides that have significantly shorter half-lives than the metal waste radionuclides. Radiochemical liquid wastes were also referred to as "hot" chemical wastes and intermediate level wastes, and are currently referred to as liquid low-level waste (LLLW). Radiochemical waste was discharged from process vessels in laboratories and Building 3019 cells into hot drains or via hot sinks or glove boxes. They contained ${ }^{137} \mathrm{Cs}$ and ${ }^{90} \mathrm{Sr}$, which have relatively long half-lives, in addition to other radionuclides with short half-lives, various metals and small amounts of organics. The wastes usually originated as nitrate solutions, although some wastes were acidic chlorides or other corrosives. The acidic solutions were generally neutralized by the addition of sodium hydroxide before the wastes were sent to the Gunite tanks.

The process waste was considered to be nonradioactive or to have very low activity. Present guidance classifies process waste as containing total beta-gamma activity not to exceed $10,000 \mathrm{~Bq} / \mathrm{L}(0.27 \mu \mathrm{Ci} / \mathrm{L})$. Process waste is derived from cooling water, laboratory sinks other than hot sinks, and floor drains from facilities devoted to hot work.

A fourth category referred to as "warm waste" was in use during early operations. Warm waste was moderately radioactive and was an intermediate between process waste and radiochemical waste. Depending on the level of radioactivity present, "warm waste" was handled as either radiochemical waste or process waste.

\section{Gunite and Associated Tanks (GAAT) OPERATIONS}

The Gunite tanks, which were originally projected to have a one-year duration, were initially constructed to store all the radioactive liquid (radiochemical and metal) wastes generated by the X-10 site operations. However, before the Graphite Reactor first went critical on November 4,1943, expansion of the scope of work required that the period of operation be extended to three years. Due to expanding requirements for managing the radioactive waste liquids, the capacity of the tanks proved inadequate for 
permanent storage, and it became necessary to consider disposal of some portion of the -waste. Various approaches were used to manage the increasing volumes of waste, with the Gunite tanks remaining the central facility for most of ORNL's waste management activities into the 1970s.

The first waste management approach used in the 1940s was to separate the different waste streams as much as practical and to concentrate the radioactive components in the liquids via precipitation. The large Gunite tanks in the South Tank Farm were used for the precipitation process, with the smaller Gunite tanks in the North Tank Farm used either for the storage of metal waste or the collection of waste for characterization before transfer to the appropriate system. At that time the tanks in the South Tank Farm were operated in three pairs. The three tanks on the rorth side of the South Tank Farm (W-5, W-7, and W-9) received the waste stream and overflowed to the corresponding tanks on the south side (W-6, W-8, and W-10, respectively). Tanks W-5 and W-6 were used for the collection and treatment of the radiochemical waste stream, while Tanks W-7, W-8, W-9, and W-10 were used for the collection and treatment of the metal waste stream. The precipitation step concentrated most of the radionuclides in the precipitate (sludge) at the bottom of the tank and significantly reduced the level of activity in the remaining. liquid (supernatant). The sludge was stored in the bottom of the tanks until a process was developed to recover the uranium, plutonium, and/or thorium. The supernatant was discharged to a settling basin (Waste Holding Basin 3513, completed in July 1944) and then diluted with large volumes of process waste before discharge into White Oak Creek.

In 1945, precipitation was discontinued and Tanks W-5 and W-6 were used to collect and hold the radiochemical waste so that radionuclides with short half-lives could decay, which significantly reduced the total radioactivity of the waste. Tanks W- 5 and W- 6 held the radiochemical waste for about one month on average, after which it was discharged to the settling basin for dilution with process waste. Tanks W-7, W-8, W-9, and W-10 continued to be used to collect metal waste. However, the original piping for the transfer system was modified so that waste in any one tank in the South Tank Farm could be transferred to any other tank. Tank W-9 was used as the initial collection tank for metal waste; it was then transferred to either Tank W-7 or W-10 for precipitation. The supernatant from the precipitation process was transferred to the radiochemical waste system. At this time, Tank W-8 was only used for the temporary storage of metal waste.

Beginning in 1949, the radiochemical waste stream was treated by concentration using a pot-type evaporator. The evaporator allowed for the processing of larger volumes of wastes. In 1950, further ORNL expansion required additional modifications in the waste management system in order to handle the increased waste volumes and levels of radioactivity. Underground stainless steel tanks were installed near each building or area that was a source of radiochemical or metal waste. These tanks (W-1A, W-13, W-14, and W-15) installed in the North Tank Farm permitted better collection and segregation of the waste types, as well as sampling and measurement of waste volumes and rates of accumulation from each source. From 1952 to 1957, a metal recovery plant (building 3505 ) extracted approximately 130 tons of uranium from the accumulated metals waste in 
storage in the Gunite tanks. Residual waste from this process was incorporated into the radiochemical waste stream. Disposal of radiochemical waste in seepage pits began in 1952. The pot evaporator operation continued until 1954, when it's use was discontinued in favor of direct disposal of the waste in seepage pits. At this time, tanks W-5, W-6 and W-7 were used to hold the waste for the decay of the short half life radionuclides, while tanks W-8, W-9 and W-10 continued to be used for the precipitation and storage of metal waste.

In 1965, a new evaporator was constructed and placed in operation. Radiochemical waste was initially accumulated from the various collection tanks into tank W-5, which also continued to receive the supernatant from the precipitation of metal waste in tanks W-7 and $\mathrm{W}-10$. The radiochemical waste was transferred to the evaporator for concentration, and the concentrate was returned to tanks W-6 or W-8 for holding prior to disposal in the seepage pits. Disposal of liquid wastes continued in this manner until 1966 when routine use of the hydrofracture process was initiated.

Continuous improvements and modifications to the ORNL waste management system eventually eliminated the need for most of the older tanks. Tanks W-1, W-2, W-3, W-4, W-13, W-14, and W-15 in the North Tank Farm were removed from service in the late 1950 s or early $1960 \mathrm{~s}$. After the tanks were removed from service, the liquid waste was taken from the tanks while sludge and a small volume of residual liquid remained in the tanks. The large Gunite tanks in the South Tank Farm were removed from service in the late 1970s in favor of the Bethel Valley Evaporator Service Tanks (BVEST), evaporator, Melton Valley Storage Tanks (MVST) and New Hydrofracture Facility. Accumulated sludge precipitated from solution and residual solutions remained in the GAAT tanks until they were removed from the South Tank Farm tanks in 1982 and 1983 . However some liquid and sludge still remain. An estimated 1100 tons of sludge was removed from the GAAT and transferred to the New Hydrofracture Facility for disposal.

\section{DESCRIPTION OF 1982-83 GAAT SLUICING CAMPAIGN ${ }^{21}$}

During 1982-83, over a period of about 18 months, the six tanks in the South Tank Farm were sluiced, the sludge re-suspended, and the re-suspended slurry pumped to the Melton Valley Storage Tanks and the New Hydrofracture facility for disposal. Analyses of sludge samples showed great variability between tanks and between samples in a given tank. About half the sludge consisted of very small particles (less than $10 \mu \mathrm{m}$ ). The other half appeared to be agglomerates of the smaller particles. Laboratory tests demonstrated the feasibility of breaking the agglomerates in a grinder and suspending the fragments in a $2-1 / 2 \%$ bentonite suspension. Field tests demonstrated that a sluicer could be used for slurry re-suspension and that the re-suspended slurry could be pumped at concentrations up to $20 \%$ by weight. Strontium-90 was the major radionuclide.

The slurry was re-suspended in a series of batch operations. A 150,000-L (40,000-gal) batch of $2-1 / 2 \%$ bentonite and water was mixed and collected in a near-empty waste tank. This suspension was then pumped through a sluicer nozzle to impinge on and re-suspend the sludge in the tank being sluiced. The re-suspended sludge was pumped from the tank, 
through a grinder, and returned to the feed tank. This operation was continued until the slurry concentration approached 15 to $20 \mathrm{wt} \%$. At this point, the slurry was pumped to storage at the MVSTs, pending disposal by hydrofracture injection. The cycle was then -repeated until the sluiced tank was as empty as practicable.

The equipment required for the sluicing operation included the bentonite makeup system, the remotely controlled sluicer assembly, a grinder to break up oversized slurry particles, and two Moyno pumps for slurry transfer between tanks. An adjustable suction leg was provided for one of the pumps so that this leg could be extended as the sludge was removed from the tank. Because the structural strengths of the tank domes were unknown, all equipment that had to be mounted above a tank was supported on a platform that straddled the tank. The necessary penetrations into the tanks were made by a drilling rig mounted on the platform through a caisson cemented to the tank dome. The grinder and the two slurry pumps were installed in pits adjacent to the tanks. All slurry piping was contained within a larger pipe to limit the spread of contamination in the event of a leak. Most slurry lines were buried; those that were not were shielded to minimize radiation exposure.

About $90 \%$ of the sludge was re-suspended and transferred in 36 batches. A four-month facility shutdown occurred during the winter of 1982-1983 because the disposal well at the hydrofracture site was plugged. Sluicing operations were resumed in April 1983 and continued without serious difficulty until completion in January 1984.

The material remaining in the GAAT after the conclusion of the sluicing campaign is included in the inventory of material to be processed for the request for proposal, and the data from this material is what is included in this report.

\section{Old Hydrofracture Facility (OHF) OPERATIONS ${ }^{3}$}

Beginning in 1964, the liquid wastes from the radiochemical and supernatant from the metal waste precipitation streams were injected into a shale formation $1000 \mathrm{ft}$. below the ground surface in the Old Hydrofracture Facility. Using the hydrofracture process (described previously) a total of eighteen liquid waste injections were made at the OHF during its operational lifetime. The first seven injections were tests of the method and involved only waste blends with low levels of radioactivity. A total of about 2.3 million gal of grouted waste containing about 650,000 curies of radionuclides was disposed of in the subsequent injections until 1979, when New Hydrofracture Facility (building 7960) operations were initiated.

Liquids processed during OHF operations were not supposed to have solids for addition to the grout being injected, therefore, solids were never deliberately introduced into the $\mathrm{OHF}$ storage tanks. But during $\mathrm{OHF}$ operations it was noted that sludge was accumulating in the waste storage tanks at the hydrofracture site. This was evidenced by the loss of pump suction while an appreciable volume of waste remained in the tank. Stirring of the tank by. the air lift pumps and by recirculating the tank contents temporarily alleviated the problem but generally the loss of pump suction 
recurred. It is believed that small particles of insoluble materials were transferred to the hydrofracture tanks with the waste solution, settled out in the tanks, and probably agglomerated to form larger and less pumpable masses. Material currently in the tanks consists of deposits accumulated within the tanks during their operational life of serving as surge and feed tanks to the hydrofracture process (U.S. Department of Energy 1996). Since being shut down in 1980, the OHF system has been maintained in a safe storage mode.

\section{OPERATIONS IN THE BVEST's AND MVSTs $\mathrm{s}^{22,23}$}

The BVESTs were placed in service in 1979? and have received dilute LLLW and have stored evaporator concentrate. They were never a part of the sluicing operations in the GAAT system. Solids present in these tanks result from precipitation of materials in the waste when the evaporator concentrate is cooled, and from liquid transfers from the gunite tanks which had some solids incidental to the transfer. These latter transfers were discontinued completely in 1986?. The solids present have accumulated over the 17 year period of operations. No previous attempts have been made to remove these solids.

Originally, the MVSTs received sludges from the GAAT and were used as feed tanks for the New Hydrofracture Facility. During 1984, radioactivity was detected in monitoring wells surrounding the New Hydrofracture Facility, indicating possible migration of the radionuclides that had been injected into the shale formation. The injection operations were immediately shut down. Subsequent to this, the regulations controlling underground injection (Chap. 120046 of the rules of the Water Quality Board for the state of Tennessee, first issued May 22, 1985) would not allow the New Hydrofracture Facility to be permitted, leading to the abandonment of restart efforts. At the time of the migration detection, a batch of suspended GAAT sludge was in the MVSTs awaiting injection. This material was never injected underground and was allowed to precipitate in the MVST tanks. Additionally, materials generated by unplugging the hydrofracture well in 1982 were transferred to the MVSTs and never removed. Since late 1984, all LLLW concentrate generated at ORNL has been stored in the MVSTs and BVESTs.

The operational safety requirement for these tanks dictates that they be filled to no more than $95 \%$ of their capacity (and maintain at least 50,000 gal free volume), or 520,000 gal. An operational flexibility limit (OFL) of 470,000 gal for the subject tanks has been established by Waste Management personnel. Data indicated that as of January 1992, this OFL was being approached. To avoid shutdown of the ORNL LLLW system before the new MVST-Capacity Increase Project storage tanks will come on line, interim waste treatment options were implemented. Interim treatment options included source reduction, supernatant evaporation (in- tank and out-of-tank), and supernatant solidification in concrete. Since late fiscal year 1988, four solidification campaigns were conducted, processing some 200,000 gal of supernatants. Currently, there is no U.S. Department of Energy (DOE)-approved disposal method for this class of waste, although shipment to Nevada Test Site for disposal is being 
pursued.

\section{EVAPORATION AT THE ORNL MELTON VALLEY STORAGE TANKS}

Bench-scale tests at ORNL showed that $50-70 \%$ of the liquid in the MVST could be evaporated prior to solids precipitation, therefore one near-term strategy for management of the LLLW stored in the MVST was to sparge the tanks with air to evaporate the excess water from the tanks and to concentrate the stored LLLW to the point of near saturation. Operation of the in-tank-evaporation (ITE) process and an out-of-tank evaporation (OTE) process were chosen as the waste treatment option. The in-tank evaporation campaigns were performed in tanks W-24 to W-28 and W-31 and were conducted during 1990-94. An out-of-tank evaporation demonstration was completed in 1996. These programs are described in more detail below.

\section{IN-TANK EVAPORATION (ITE) ${ }^{22,24}$}

The transfer line from the concentrate storage tank at the evaporator to the MVST's is flushed with water after each transfer, and the flush water is collected in the MVST's also. As a result, the supernatant undergoes dilution can be concentrated by about 30 percent before solids precipitate from it. In-tank evaporation is a method for evaporating water from the supernatant without removing the supernatant from the MVST's. It was estimated that about $17,000 \mathrm{gal} / \mathrm{year}$ could be evaporated if $600 \mathrm{cfm}$ (100 cfm through each of 6 tanks) of air was supplied at a $-40^{\circ} \mathrm{F}$ dewpoint and the system was on-line 80 percent of the time. To facilitate supernatant solidification campaigns, two tanks remained quiescent and were not treated in this manner.

In ITE, an air sparge system is piped into each tank. Compressed air is metered into the tanks at a rate of $20 \mathrm{scfm}$ at $30 \mathrm{psig}$ per rotameter, which translates into $100 \mathrm{scfm}$ per tank. Each tank is also equipped with an air line providing sweep air that operates when the tanks are not being sparged, when the flow of sweep air may be reduced or eliminated. The air from both the spargers and the sweep exhausts through a flowmeter, mist eliminator and high-efficiency particulate air (HEPA) filters prior to exiting through a blower and a stack.

\section{OUT-OF-TANK EVAPORATION (OTE) $)^{22,23,25}$}

ITE is a relatively slow process and cannot keep up with the current LLLW generation rate nor would it suffice to increase MVST storage capacity in case of an emergency need. In order for ITE to process the expected future waste generation plus work off the present inventory in the MVSTs, measures were needed to increase the evaporation rate. This was done by installing a small external evaporator.

Evaporation studies were performed with MVST LLLW concentrate and with surrogates (nonradioactive) to determine the feasibility of a proposed out-of-tank-evaporation project. The volume of water evaporated in tests using surrogate and actual MVST supernatant ranged from 30 to $55 \%$ before precipitation of 
solids occurred. Vendor-site tests were also conducted with surrogate waste forms using a bench-scale single-stage, sub-atmospheric pressure, low- temperature evaporator. These tests were successful, and a $30 \%$ volume reduction was attained with no crystallization of solids, no foaming, and no fouling of the heat exchanger surfaces. Based on a study by Bechtel National, Inc.(completed in 1991), a single-stage, motor-driven vapor compression evaporator was suggested for the OTE process.

The OTE demonstration project was conducted to demonstrate the feasibility of using a skid mounted sub-atmospheric evaporator to process these wastes. Operation with radioactive waste began March, 1996 and was completed April, 1996. The system successfully processed approximately 22,000 gallons of MVST LLLW. Approximately 5,500 gallons of distillate were produced and sent to the Process Waste Treatment Plant while the remaining 16,500 gallons of concentrate were returned to the MVST tanks. Decontamination factors (DFs, defined as the ratio of contaminant concentrations in the distillate to that of the feed) achieved in the evaporator were on the order of $5 \times 10^{6}$, exceeding design requirements. Following completion of the Cesium Removal Demonstration project, the evaporator system is expected to be upgraded and routinely used at ORNL by WMRAD to process additional LLLW.

\section{WASTE COMPOSITION CHANGES DUE TO EVAPORATION ${ }^{23,26}$}

In December 1994, the MVST supernatants were sampled to assist in MVST treatability studies and waste management planning activities. The preliminary results ${ }^{10}$ from the analyses indicated that the supernatants were generally more concentrated, higher in cesium concentration, and have a lower $\mathrm{pH}$ than in previous sampling campaigns. The ITE process was started in June 1992 and was calculated to have successfully removed over 48,000 gal of free water. This has resulted in concentrating the supernatants and decreasing the $\mathrm{pH}$ by neutralization of free hydroxide by carbon dioxide in air. The increase in cesium concentration was caused both by concentrating the waste and by adding newly-generated LLLW which has a higher cesium content. (Radiochemical Engineering Development Center processing of Mark 42 targets has increased cesium concentration by one to two orders of magnitude.)The introduction of carbon dioxide by air sparging tends to lower the solution $\mathrm{pH}$, increasing the solubilities of the dissolved salts. Because the MVSTs were sparged with dry air (the ITE process), it could be expected that this occurred.

The increased nitrate and cesium concentrations of the MVST supernatant impact treatment disposal options. There is evidence that concentrations greater than $5 \mathrm{M}$ could lead to expansion, spalling, and cracking of the solidified forms caused by growth of large sodium nitrate crystals within the pore structure of the concrete. The Emergency Avoidance Solidification Campaign (EASC), Liquid Waste Solidification Project (LWSP) I, and LWSP II campaigns have been successfully performed with waste containing a maximum of $4.8 \mathrm{M}$ nitrate. Therefore, the supernatants from Tanks W-29 and W-30 were blended to reduce the nitrate concentration to $4.8 \mathrm{M}$ for LWSP III, performed in the spring of 1995??. In addition, a test program was implemented to 


\section{A-10}

determine, for the MVST supernatant, the highest nitrate concentration that can be solidified and still produce a physically stable product. This testing may indicate that a higher nitrate supernatant can be solidified safely, however until the test results are available, further LWSP campaigns will be designed to use combinations of tanks that result in nitrate and cesium concentrations within previous solidification concentration ranges. 
APPENDIX B

TANK SAMPLING DATA 


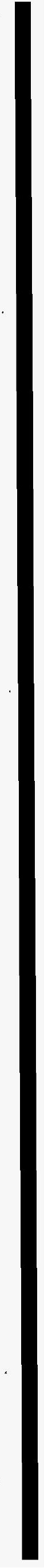




\section{TABLES B.1, B.2 AND B.3}

Measurement Data on Sludge Samples: 1985-1996 

B-5

Table B.1. Physical variable measurements on sludge samples from 1985 to 1996.

\begin{tabular}{|c|c|c|c|c|c|c|c|c|c|c|c|c|}
\hline Obs & Tank & Year & S_No & $\begin{array}{c}\text { Density } \\
(\mathrm{g} / \mathrm{ml})\end{array}$ & $\begin{array}{c}\mathrm{H}_{2} \mathrm{O} \\
\text { Fraction }\end{array}$ & $\mathrm{pH}$ & $\begin{array}{l}\text { TSOL } \\
(\mathrm{mg} / \mathrm{g})\end{array}$ & $\begin{array}{l}\text { DSOI } \\
\text { (mg/g) }\end{array}$ & $\begin{array}{l}\text { SSOL } \\
\text { (mg/g) }\end{array}$ & $\begin{array}{c}\text { TOC } \\
(\mathrm{mg} / \mathrm{kg})\end{array}$ & $\begin{array}{c}\mathrm{ICAR} \\
(\mathrm{mg} / \mathrm{kg})\end{array}$ & $\begin{array}{c}\mathrm{TCAR} \\
(\mathrm{mg} / \mathrm{kg})\end{array}$ \\
\hline 1 & พ03 & 1989 & S19 & & & & 300 & . & . & 3410 & & \\
\hline 2 & พ03 & 1994 & 212 & 1.07 & 0.576 & 10.5 & . & . & . & 530 & 2400 & 5100 \\
\hline 3 & พ03 & 1994 & 216 & 1.35 & 0.635 & 10.6 & . & . & . & 200 & 1700 & 1900 \\
\hline 4 & W03 & 1995 & 309 & . & 0.879 & . & . & . & . & 4240 & 1860 & 6100 \\
\hline 5 & พ03 & 1995 & 310 & . & 0.886 & . & & . & . & 4480 & 1110 & 5590 \\
\hline 6 & W04 & 1989 & S24 & . & • & . & 307 & . & . & 9190 & • & \\
\hline 7 & W04 & 1989 & H26 & . & & . & 349 & . & . & 9020 & . & \\
\hline 8 & WOA & 1994 & $217 \mathrm{H}$ & . & 0.711 & . & . & . & . & & & \\
\hline 9 & W04 & 1995 & 306 & . & 0.834 & . & . & . & . & 453 & 1990 & 2450 \\
\hline 10 & W04 & 1995 & 307 & 1.20 & 0.766 & . & & & . & 1130 & 1380 & 2510 \\
\hline 11 & พ05 & 1989 & S75 & . & & . & 348 & . & . & 4020 & & \\
\hline 12 & พ05 & 1994 & 230 & . & 0.720 & . & . & . & . & 700 & $1800^{\circ}$ & 2500 \\
\hline 13 & พ05 & 1995 & 314 & 1.26 & 0.683 & . & . & . & . & 847 & 1900 & 2740 \\
\hline 14 & พ05 & 1995 & 315 & 1.07 & 0.780 & . & & . & . & 627 & 1990 & 2620 \\
\hline 15 & พ06 & 1989 & S80 & & & & 406 & . & . & 9110 & & \\
\hline 16 & W06 & 1994 & 221 & 1.19 & 0.656 & 11.1 & . & . & . & 2400 & 3300 & 5600 \\
\hline 17 & พ06 & 1995 & 311 & 1.17 & 0.728 & . & . & . & . & 3310 & 3480 & 6790 \\
\hline 18 & พอ6 & 1995 & 312 & 1.46 & 0.625 & - & & . & . & 11700 & 5000 & 16600 \\
\hline 19 & พ07 & 1989 & S84 & . & . & . & 367 & . & . & 9030 & . & \\
\hline 20 & W07 & 1989 & H85 & & . & & 360 & . & . & 4010 & & \\
\hline 21 & พ07 & 1994 & 228 & 1.21 & 0.704 & 10.3 & . & . & . & 1300 & 4700 & 6100 \\
\hline 22 & Wo7 & 1994 & 229 & 1.23 & 0.679 & 10.2 & . & . & . & 1300 & 4700 & 6000 \\
\hline 23 & พ07 & 1995 & 303A-H & 1.18 & 0.587 & . & . & . & . & 866 & 4080 & 4950 \\
\hline 24 & พ07 & 1995 & 303B-H & 1.45 & 0.621 & . & . & . & . & 1520 & 4450 & 5960 \\
\hline 25 & พ07 & 1995 & 304 & 1.57 & 0.577 & . & . & . & . & 796 & 5040 & 5830 \\
\hline 26 & พ07 & 1995 & $301 \mathrm{H}$ & & 0.659 & . & . & . & . & & . & \\
\hline 27 & พ07 & 1995 & 302 & 1.47 & 0.747 & . & & . & . & 1740 & 4290 & 6030 \\
\hline 28 & พ08 & 1989 & S88 & & & $0^{\circ}$ & 558 & . & . & 11300 & & \\
\hline 29 & W08 & 1994 & 224 & 1.24 & 0.786 & 9.1 & . & . & . & 8400 & $7900^{\circ}$ & 16400 \\
\hline 30 & W08 & 1995 & 320 & 1.08 & 0.834 & . & . & . & . & 6420 & 6050 & 12500 \\
\hline 31 & พ08 & 1995 & 321 & 1.19 & 0.835 & . & & . & . & 5290 & 4240 & 9530 \\
\hline 32 & พ09 & 1989 & S92 & & & $\cdot$ & 944 & . & . & 13900 & & \\
\hline 33 & พอ9 & 1994 & 227 & 1.10 & 0.828 & 9.9 & . & . & . & 2900 & 1900 & 4800 \\
\hline 34 & พ09 & 1995 & 323 & 1.28 & 0.866 & . & . & . & . & 2930 & 1590 & 4520 \\
\hline 35 & W09 & 1995 & 324 & 1.25 & 0.867 & . & & . & . & 2120 & 2180 & 4300 \\
\hline 36 & W10 & 1989 & H12O & . & . & . & 845 & . & . & 14600 & . & \\
\hline 37 & W10 & 1989 & s96 & & & & 449 & . & . & 8180 & & \\
\hline 38 & W10 & 1994 & 226 & 1.13 & 0.728 & 10.6 & . & . & . & 4900 & 5100 & 10000 \\
\hline 39 & W10 & 1995 & 325 & 1.25 & 0.611 & . & . & . & . & 2640 & 3550 & 6180 \\
\hline 40 & W10 & 1995 & 326 & 1.23 & 0.771 & . & . & . & . & 4870 & 3430 & 8300 \\
\hline 41 & พ21 & 1985 & 0 & • & . & - & . & . & . & • & • & \\
\hline 42 & พ21 & 198 & 0 & . & . & - & . & . & . & & & \\
\hline 43 & ต21 & 1990 & พ21-S & 1.40 & & . & 511 & . & . & 6480 & 12000 & 18500 \\
\hline 44 & ท21 & 1996 & W21s-178 & 1.46 & 0.498 & . & . & . & . & 100 & 28000 & 28000 \\
\hline 45 & W22 & 198 & 0 & • & • & - & - & - & - & • & • & \\
\hline 46 & พ22 & 1985 & 0 & 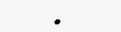 & • & - & & $\therefore$ & & & & \\
\hline 47 & พ22 & 1994 & พ22S-139 & 1.17 & 0.739 & . & 268 & 25.5 & 242 & 22100 & 10400 & 32500 \\
\hline 48 & พ123 & 1985 & 0 & . & . & . & . & • & • & . & & \\
\hline 49 & พ23 & 198 & 0 & 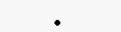 & . & . & & . & . & & & \\
\hline 50 & พ23 & 1990 & W23-S & 1.34 & & . & 544 & . & . & 4120 & 18100 & 22200 \\
\hline 51 & พ23 & 1996 & W23S-141 & 1.46 & 0.423 & . & . & . & . & 100 & 32000 & 32000 \\
\hline 52 & W24 & 198 & 0 & • & • & - & - & - & - & • & • & \\
\hline 53 & W24 & 1985 & 0 & . & . & . & ri & . & - & . & . & \\
\hline 54 & พ24 & 1985 & 0 & $\therefore$ & . & . & 454 & - & - & & & \\
\hline 55 & $W 24$ & 1989 & W24-S & 1.26 & . & . & 487 & . & . & 2940 & 6630 & 9570 \\
\hline 56 & W25 & 198 & 0 & • & - & - & • & - & - & • & • & \\
\hline 57 & W25 & 1985 & 0 & - & - & - & & - & - & - & - & \\
\hline 58 & W25 & 1985 & 0 & $\cdot$ & . & . & 580 & . & . & & $\cdot$ & \\
\hline 59 & พ25 & 1989 & พ25-S & 1.32 & . & . & 531 & - & . & 2330 & 3920 & 6250 \\
\hline 60 & W26 & 1985 & 0 & • & - & - & $\therefore$ & . & . & • & • & \\
\hline 61 & พ26 & 1985 & 0 & . & . & - & & . & . & - & - & \\
\hline 62 & พ26 & 1985 & 0 & . & . & . & 413 & . & . & & & \\
\hline 63 & พ26 6 & 1989 & พ26-S & 1.54 & . & . & 449 & . & . & 6220 & 12000 & 18200 \\
\hline 64 & W27 & 1985 & 0 & . & . & - & . & . & . & . & • & \\
\hline 65 & พ27 & 1985 & 0 & . & - & - & & - & - & - & - & \\
\hline 66 & W27 & 1985 & 0 & . & . & . & 408 & . & . & & & \\
\hline 67 & พ27 & 1989 & W27-K1-s & 1.26 & . & - & 386 & . & . & 2440 & 5250 & 7690 \\
\hline 68 & พ27 & 1989 & พ27-H1-H & 1.33 & . & . & 471 & . & . & 3830 & 12700 & 16500 \\
\hline
\end{tabular}


B-6

Table B.1 (continued)

\begin{tabular}{|c|c|c|c|c|c|c|c|c|c|c|c|c|}
\hline Obs & Tank & Year & S_No & $\begin{array}{c}\text { Density } \\
(\mathrm{g} / \mathrm{ml})\end{array}$ & $\begin{array}{l}\mathrm{H}_{2} \mathrm{O} \\
\text { Eraction }\end{array}$ & $\mathrm{pH}$ & $\begin{array}{l}\text { TSOL } \\
(\mathrm{mg} / \mathrm{g})\end{array}$ & $\begin{array}{l}\text { DSOI } \\
\text { (mg/g) }\end{array}$ & $\begin{array}{l}\text { SSOL } \\
(\mathrm{mg} / \mathrm{g})\end{array}$ & $\begin{array}{c}\text { TOC } \\
(\mathrm{mg} / \mathrm{kg})\end{array}$ & $\begin{array}{c}\text { ICAR } \\
(\mathrm{mg} / \mathrm{kg})\end{array}$ & $\begin{array}{c}\text { TCAR } \\
\text { (mg/kg) }\end{array}$ \\
\hline $\begin{array}{l}69 \\
70 \\
71 \\
72 \\
73 \\
74 \\
75 \\
76 \\
77 \\
78 \\
79 \\
80 \\
81 \\
82 \\
83 \\
84 \\
85 \\
86 \\
87 \\
88 \\
89 \\
90\end{array}$ & $\begin{array}{l}\text { W28 } \\
\text { W28 } \\
\text { w28 } \\
\text { W28 } \\
\text { W29 } \\
\text { W29 } \\
\text { W30 } \\
\text { W30 } \\
\text { W31 } \\
\text { W31 } \\
\text { W31 } \\
\text { W31 } \\
\text { T01 } \\
\text { T01 } \\
\text { T02 } \\
\text { T02 } \\
\text { T03 } \\
\text { T03 } \\
\text { T04 } \\
\text { T04 } \\
\text { T09 } \\
\text { T09 }\end{array}$ & $\begin{array}{l}1985 \\
1985 \\
1985 \\
1989 \\
1985 \\
1985 \\
1985 \\
1985 \\
1985 \\
1985 \\
1989 \\
1989 \\
1989 \\
1996 \\
1989 \\
1996 \\
1989 \\
1996 \\
1989 \\
1996 \\
1989 \\
1996\end{array}$ & $\begin{array}{l}0 \\
0 \\
0 \\
W 28-S \\
0 \\
0 \\
0 \\
0 \\
0 \\
0 \\
\text { W31-S } \\
\text { W31-H } \\
S 37 \\
0 \\
\text { S40 } \\
0 \\
\text { S43 } \\
0 \\
\text { S46 } \\
0 \\
\text { S48 } \\
0\end{array}$ & $\begin{array}{l}\dot{ } \\
1.49 \\
\dot{:} \\
\dot{0} \\
\dot{1.26} \\
\dot{1.33} \\
1.33 \\
1.39 \\
1.31 \\
1.23 \\
1.21 \\
1.16\end{array}$ & $\begin{array}{c}\dot{ } \\
\vdots \\
\vdots \\
\vdots \\
\vdots \\
0.683 \\
0.619 \\
0.604 \\
0.722 \\
0.702\end{array}$ & $\begin{array}{c}\dot{ } \\
\dot{0} \\
\dot{0} \\
\dot{0} \\
9.6 \\
9.6 \\
11.5 \\
10.4 \\
9.3\end{array}$ & $\begin{array}{r}. \\
450 \\
533 \\
42 \dot{8} \\
34 \dot{2} \\
34 \dot{4} \\
369 \\
964 \\
921 \\
32 \dot{4} \\
36 \dot{4} \\
25 \dot{3} \\
34 \dot{3} \\
.\end{array}$ & $\begin{array}{l}\dot{:} \\
\dot{.} \\
\dot{:} \\
\dot{.} \\
\dot{.} \\
\dot{.} \\
\dot{.} \\
\dot{.} \\
\dot{.} \\
\dot{.}\end{array}$ & 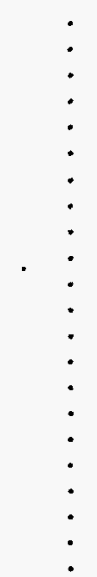 & $\begin{array}{r}\dot{ } \\
2500 \\
\dot{ } \\
\dot{ } \\
\dot{ } \\
\dot{ } \\
410 \\
8530 \\
18600 \\
4100 \\
28000 \\
13000 \\
9140 \\
4000 \\
4620 \\
9800 \\
7620 \\
100\end{array}$ & $\begin{array}{r}\dot{ } \\
3620 \\
\dot{ } \\
\dot{0} \\
\dot{ } \\
\dot{0} \\
1410 \\
21900 \\
8900 \\
16000 \\
12000 \\
5200 \\
16000\end{array}$ & 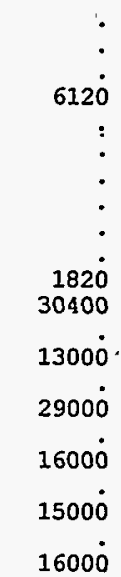 \\
\hline
\end{tabular}


Table B.2. Chemical variable measurements $(\mathrm{mg} / \mathrm{kg}$ ) on sludge samples from 1985 to 1996.

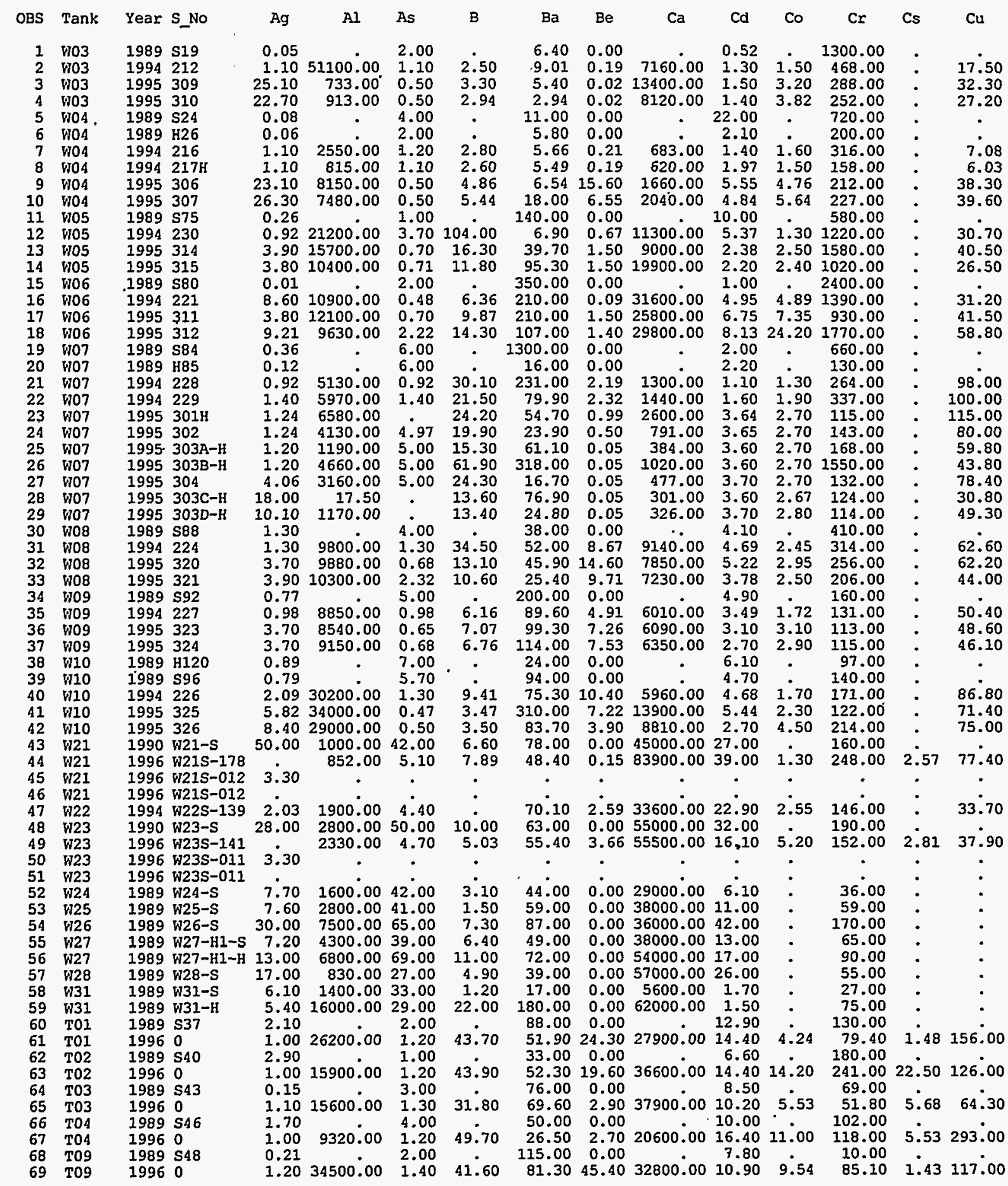


Table B.2 (continued)

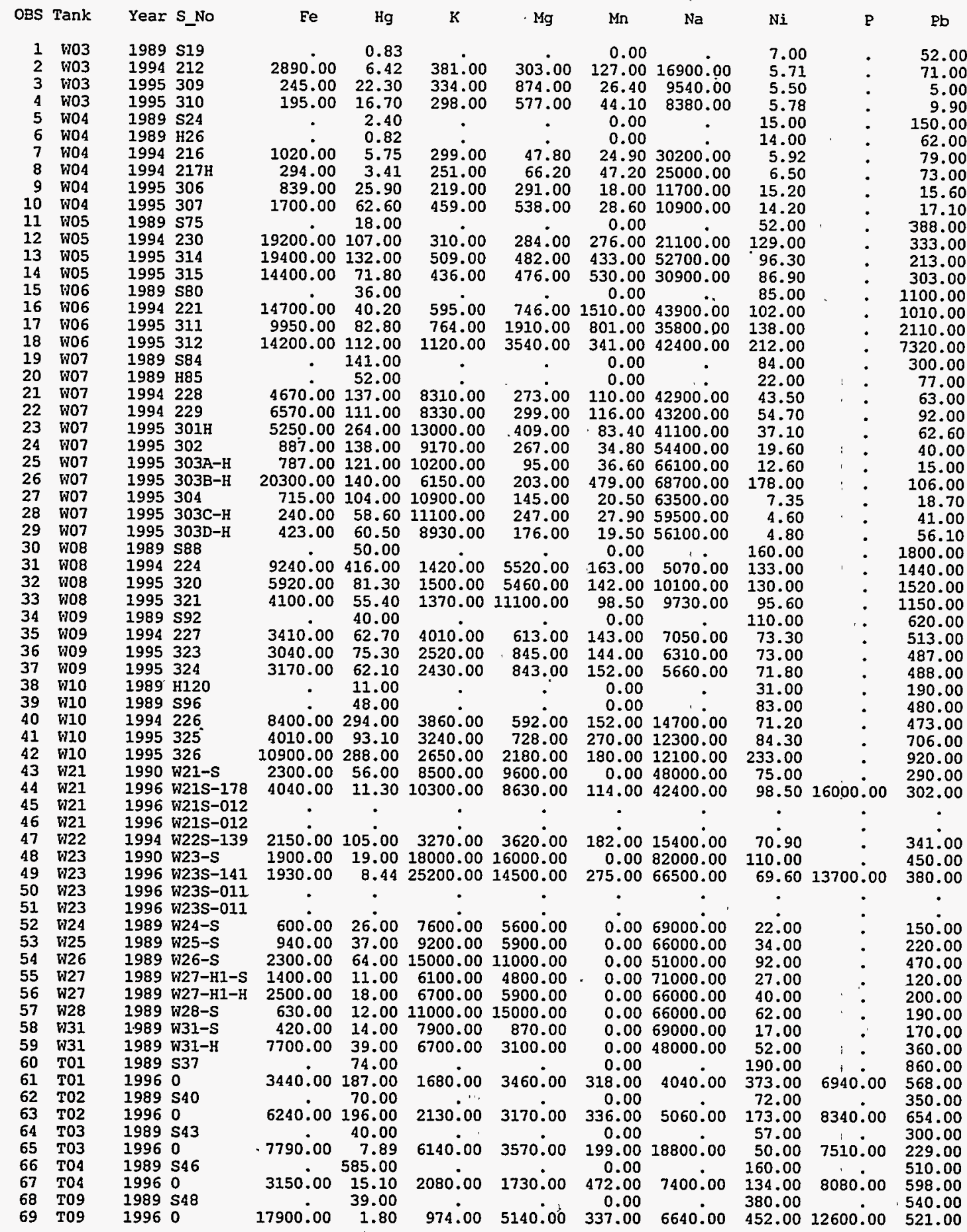


B-9

Table B.2 (continued)

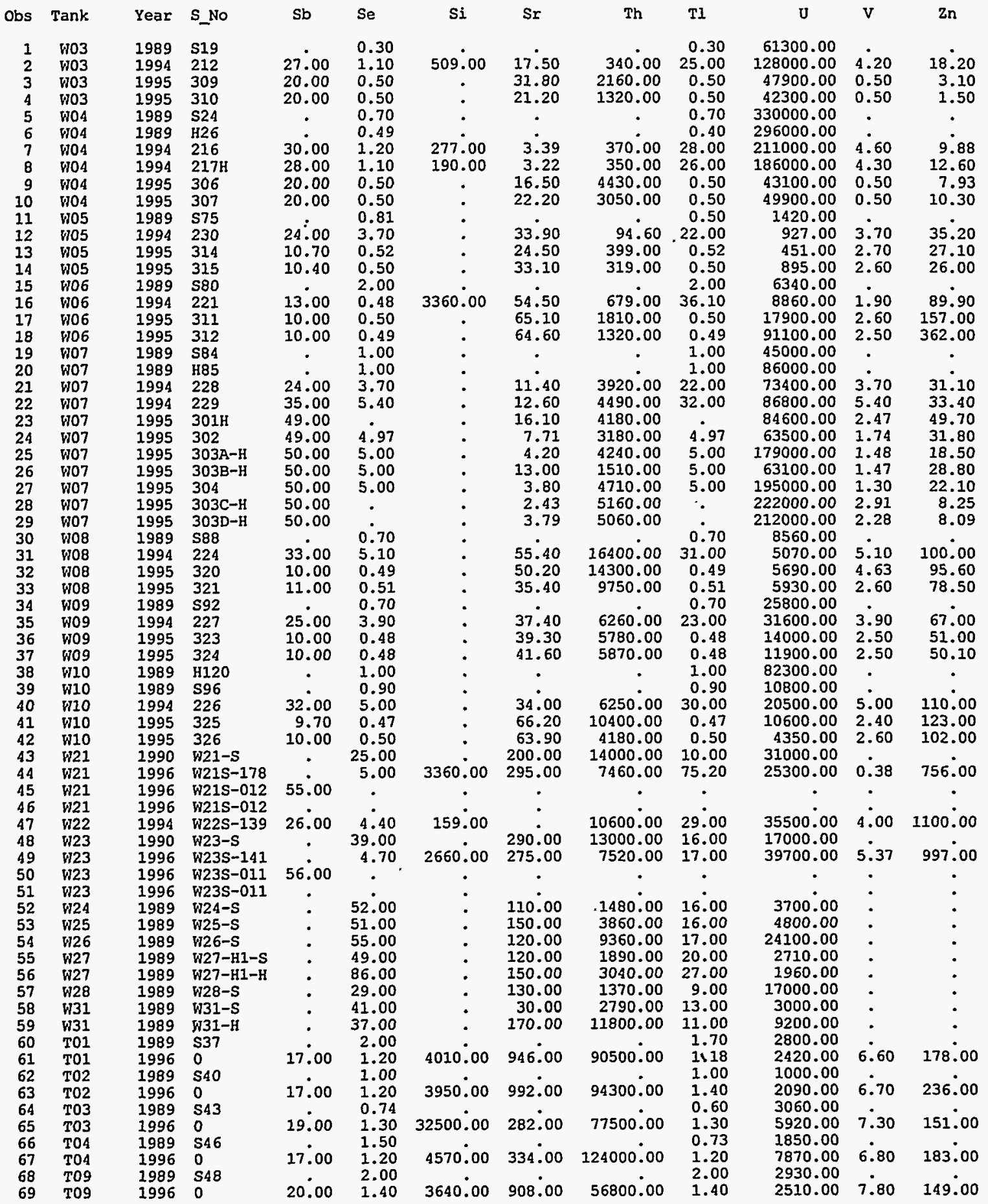




\section{B-10}

Table B.2 (continued)

\begin{tabular}{|c|c|c|c|c|c|c|c|c|c|c|c|}
\hline Obs & Tank & Year & S_No & Bromide & Chloride & Eluoride & Nitrate & Nitride & Phosphate & Sulfate & $\mathrm{HCN}$ \\
\hline $\begin{array}{l}1 \\
2 \\
3 \\
4\end{array}$ & $\begin{array}{l}\text { W03 } \\
\text { w03 } \\
\text { w03 } \\
\text { w03 }\end{array}$ & $\begin{array}{l}1989 \\
1994 \\
1995 \\
1995\end{array}$ & $\begin{array}{l}519 \\
212 \\
309 \\
310\end{array}$ & $\begin{array}{l}5.00 \\
6.00 \\
5.00\end{array}$ & $\begin{array}{l}5.00 \\
6.00 \\
5.00\end{array}$ & $\begin{array}{l}23.70 \\
20.90 \\
17.50\end{array}$ & $\begin{array}{l}87.00 \\
12.00 \\
10.00\end{array}$ & $\dot{\bullet} \cdot \dot{ }$ & $\begin{array}{l}3240.00 \\
1510.00 \\
1370.00\end{array}$ & $\begin{array}{l}318.00 \\
513.00 \\
539.00\end{array}$ & $\dot{\bullet}$ \\
\hline 5 & W04 & 1989 & S24 & . & . & 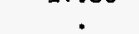 &. & . & . & $\begin{array}{c}.00 \\
.\end{array}$ & $\dot{0}$ \\
\hline 6 & Wo4 & 1989 & K26 & & - & & $\bullet$ & . & & & . \\
\hline 7 & WO4 & 1994 & 216 & 53.00 & 53.00 & 53.00 & 1370.00 & . & 3070.00 & 1910.00 & . \\
\hline 8 & พ04 & 1994 & $217 \mathrm{H}$ & . & 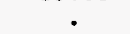 & 年 & . & . & (en & 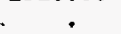 & . \\
\hline $\begin{array}{r}9 \\
10\end{array}$ & $\begin{array}{l}\text { W04 } \\
\text { W04 }\end{array}$ & $\begin{array}{l}1995 \\
1995\end{array}$ & $\begin{array}{l}306 \\
307\end{array}$ & $\begin{array}{l}5.00 \\
5.00\end{array}$ & $\begin{array}{l}5.00 \\
5.00\end{array}$ & $\begin{array}{l}22.60 \\
20.00\end{array}$ & $\begin{array}{l}1730.00 \\
1420.00\end{array}$ & $\dot{.}$ & $\begin{array}{l}434.00 \\
147.00\end{array}$ & $\begin{array}{l}2220.00 \\
1530.00\end{array}$ & : \\
\hline 11 & W05 & 1989 & s75 & . & . & . & . & . & . & - & . \\
\hline 12 & พ05 & 1994 & 230 & 48.00 & 48.00 & 1960.00 & 422.00 & . & 2678.00 & 250.00 & . \\
\hline 13 & W05 & 1995 & 314 & 34.00 & 34.00 & 1880.00 & 602.00 & . & 3090.00 & 308.00 & . \\
\hline 14 & พ05 & 1995 & 315 & 38.00 & 72.70 & 2080.00 & 639.00 & . & 3650.00 & 315.00 & - \\
\hline 15 & W06 & 1989 & 580 & $\therefore$ & $\circ 0^{\circ}$ & 119000 & $12300^{\circ}$ & - & $7900^{\circ}$ & $9400^{\circ}$ & - \\
\hline 16 & พ06 & 1994 & 221 & 64.00 & 64.00 & 11900.00 & 12300.00 & - & 7900.00 & 9400.00 & . \\
\hline $\begin{array}{l}17 \\
18\end{array}$ & W06 & $\begin{array}{l}1995 \\
1995\end{array}$ & 311 & .42 .00 & 167.00 & 4170.00 & 11600.00 & - & 6660.00 & 8510.00 & - \\
\hline $\begin{array}{l}18 \\
19\end{array}$ & $\begin{array}{l}\text { W06 } \\
\text { W07 }\end{array}$ & $\begin{array}{l}1995 \\
1989\end{array}$ & $\begin{array}{l}312 \\
584\end{array}$ & 40.00 & 144.00 & 1760.00 & .8570 .00 & - & 4430.00 & 5690.00 & - \\
\hline 20 & ต07 & 1989 & H85 & $\cdot$ & - & • & - & - & - & - & - \\
\hline 21 & W07 & 1994 & 228 & 88.00 & 2840.00 & 2320.00 & 38500.00 & $\dot{.}$ & 5320.00 & $8130^{\circ} .00$ & $\bullet$ \\
\hline 22 & W07 & 1994 & 229 & 111.00 & 2530.00 & 1870.00 & 32600.00 & $\dot{.}$ & 4750.00 & 7700.00 & $\dot{.}$ \\
\hline 23 & W07 & 1995 & $301 \mathrm{H}$ & 2360.00 & 101.00 & 2770.00 & 30000.00 & . & 3470.00 & 6540.00 & . \\
\hline 24 & พ07 & 1995 & 302 & 3280.00 & 106.00 & 2480.00 & 42000.00 & : & 4490.00 & 8720.00 & 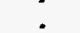 \\
\hline 25 & พ07 & 1995 & $303 A-H$ & 2820.00 & 118.00 & 1100.00 & 37300.00 & . & 4770.00 & 7700.00 & . \\
\hline 26 & พ07 & 1995 & $303 \mathrm{~B}-\mathrm{H}$ & 2930.00 & 102.00 & 3850.00 & 37700.00 & . & 5200.00 & 7990.00 & . \\
\hline 27 & W07 & 1995 & 304 & 2730.00 & 109.00 & 1720.00 & 36700.00 & . & 5190.00 & 7510.00 & . \\
\hline 28 & พ0? & 1995 & $303 \mathrm{C}-\mathrm{H}$ & . & . & . & . & . & . & • & . \\
\hline 29 & พ0i & 1995 & $303 \mathrm{D}-\mathrm{H}$ & . & - & . & . & - & . & - & . \\
\hline 30 & พ08 & 1989 & S88 & • & • & . & • & - & . & . & . \\
\hline 31 & ฤ08 & 1994 & 224 & 110.00 & 110.00 & 518.00 & 2500.00 & . & 1100.00 & 4300.00 & . \\
\hline 32 & พ08 & 1995 & 320 & 9.63 & 422.00 & 151.00 & 2690.00 & . & 191.00 & 3470.00 & . \\
\hline 33 & พ08 & 1995 & 321 & 9.04 & 423.00 & 130.00 & 2580.00 & . & 361.00 & 3280.00 & . \\
\hline 34 & พ09 & 1989 & s92 & . & • & - & $\cdot$ & . & $\cdot$ & $0^{*}$ & . \\
\hline 35 & พ09 & 1994 & 227 & 61.00 & 61.00 & 305.00 & 122.00 & - & 3660.00 & 622.00 & . \\
\hline $\begin{array}{l}36 \\
37\end{array}$ & $\begin{array}{l}\text { W09 } \\
\text { W09 }\end{array}$ & $\begin{array}{l}1995 \\
1995\end{array}$ & $\begin{array}{l}323 \\
324\end{array}$ & $\begin{array}{l}7.27 \\
7.43\end{array}$ & $\begin{array}{l}134.00 \\
141.00\end{array}$ & $\begin{array}{l}76.60 \\
83.80\end{array}$ & $\begin{array}{l}572.00 \\
613.00\end{array}$ & : & $\begin{array}{l}2990.00 \\
2230.00\end{array}$ & $\begin{array}{l}476.00 \\
511.00\end{array}$ & : \\
\hline 38 & W10 & 1989 & $\mathrm{H} 120$ & . & . & . & . & . & . & . & i. \\
\hline 39 & W10 & 1989 & 596 & . & . & . & . & - & . & . & . \\
\hline 40 & w10 & 1994 & 226 & 46.00 & 546.00 & 437.00 & 6270.00 & . & 460.00 & 2870.00 & $\dot{*}$ \\
\hline 41 & W10 & 1995 & 325 & 13.00 & 571.00 & 364.00 & 4440.00 & . & 291.00 & 1770.00 & . \\
\hline 42 & W10 & 1995 & 326 & 29.80 & 597.00 & 333.00 & 5760.00 & . & 242.00 & 1950.00 & . \\
\hline 43 & พ21 & 1990 & พ21-S & • & • & • & • & - & • & • & - \\
\hline 44 & พ21 & 1996 & w21s-178 & - & - & - & - & - & - & - & - \\
\hline 45 & พ21 & 1996 & พ21s-012 & • & • & • & • & - & • & • & . \\
\hline .46 & พ21 & 1996 & W21S-012 & 89.00 & 1120.00 & 157.00 & 166000.00 & . & 210.00 & 8030.00 & . \\
\hline 47 & W22 & 1994 & W22S-139 & . & . & . & . & - & . & . & $5: 40$ \\
\hline 48 & W23 & 1990 & W23-s & - & . & -' & - & - & . & . & . \\
\hline 49 & W23 & 1996 & W23s-141 & - & . & - & - & - & - & - & - \\
\hline 50 & พ23 & 1996 & พ23S-011 & • & $\cdot$ & • & $\cdot$ & - & • & $\cdot$ & - \\
\hline 51 & พ23 & 1996 & พ23S-011 & 470.00 & 3170.00 & 185.00 & 126000.00 & - & 200.00 & 3540.00 & . \\
\hline 52 & W24 & 1989 & W24-S & • & • & • & • & - & • & • & - \\
\hline 53 & พ25 & 1989 & พ25-S & - & . & - & - & - & - & - & - \\
\hline 54 & พ26 & 1989 & w26-s & . & . & - & - & . & . & . & . \\
\hline 55 & พ27 & 1989 & พ27-H1-S & - & - & - & . & - & - & - & - \\
\hline 56 & พ27 & 1989 & W27-H1-H & . & . & . & . 1 & . & . & - & . \\
\hline 57 & พ28 & 1989 & W28-S & - & . & . & . & . & . & - & - \\
\hline 58 & พ31 & 1989 & W31-s & . ' & - & - & - & - & - & . & - \\
\hline 59 & พ31 & 1989 & พ31-H & - & - & - & . & - & - & - & - \\
\hline 60 & T01 & $\begin{array}{l}1989 \\
1996\end{array}$ & 537 & 4.63 & 247.00 & 1176.00 & 52.60 & 629.00 & 18.50 & $339^{\circ} 00$ & • \\
\hline $\begin{array}{l}61 \\
62\end{array}$ & $\begin{array}{l}101 \\
\text { T02 }\end{array}$ & $\begin{array}{l}1996 \\
1989\end{array}$ & 540 & 4.03 & 241.00 & $1 / 6.00$ & 32.00 & 029.00 & & & $\dot{.}$ \\
\hline 63 & T02 & 1996 & 0 & 5.20 & 366.00 & 233.00 & 27.90 & 576.00 & 20.80 & $726: 00$ & . \\
\hline $\begin{array}{l}64 \\
65\end{array}$ & $\begin{array}{l}\text { T03 } \\
\text { T03 }\end{array}$ & $\begin{array}{l}1989 \\
1996\end{array}$ & $\begin{array}{l}543 \\
0\end{array}$ & 43.00 & 947.00 & 257.00 & $4250^{\circ} .00$ & 4670.00 & 174.00 & 2960.00 & : \\
\hline 66 & $\mathrm{TO4}$ & 1989 & 546 & . & $\bullet$ & $\bullet$ & $\cdot$ & • & $\bullet$ & $\bullet$ & . \\
\hline 67 & T04 & 1996 & 0 & 41.00 & 401.00 & 272.00 & 1470.00 & 1460.00 & 165.00 & 1210.00 & . \\
\hline 68 & T09 & 1989 & 548 & 70 & $3760^{\circ} .00$ & $140^{\circ} 00^{\circ}$ & $869^{\circ} 00$ & $210^{\circ} 00$ & $195^{\circ} 00$ & $016^{\circ}$ & - \\
\hline & T09 & 1996 & 0 & 70.00 & & 140.00 & 869.00 & 219.00 & 195.00 & 616.00 & - \\
\hline
\end{tabular}


Table B.3. Radiological variable measurements (bq/g) on sludge samples from 1985 to 1996.

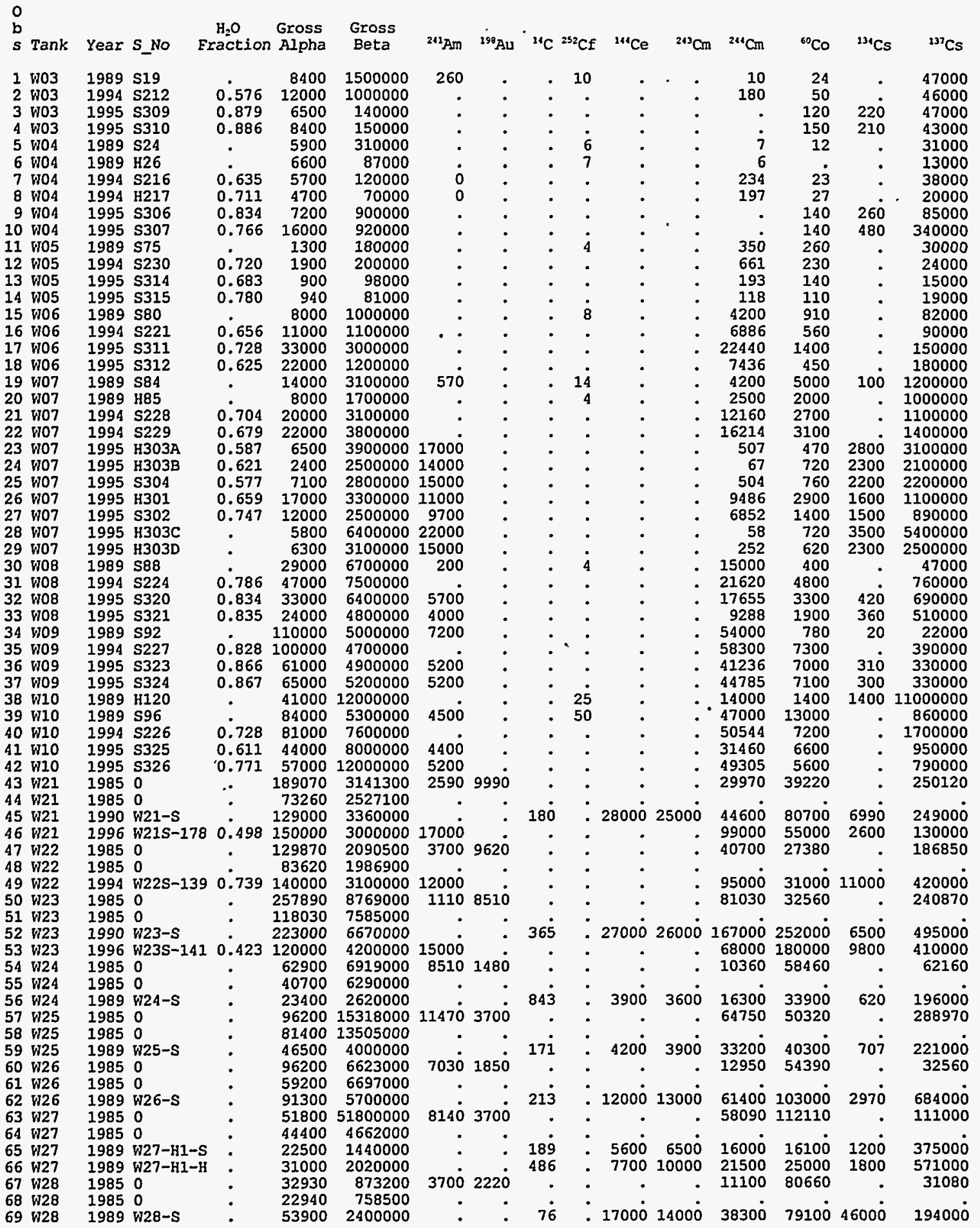


Table B.3 (continued)

b

s Tank Year S No

$\mathrm{H}_{2} \mathrm{O}$ Gross Gross

70 พ29 19850

71 พ29 19850

72 พ30 19850

73 พ30 19850

74 W31 19850

75 W31 19850

76 พ31 1989 พ31-s

77 พ31 1989 w31-H

$\begin{array}{llll}78 & \mathrm{~T} 01 & 1989 & \mathrm{~S} 37\end{array}$

79 T01 19960

80 T02 1989 S40

81 T02 19960

$\begin{array}{llll}82 & \text { T03 } & 1989 & 543\end{array}$

83 T03 19960

84 T04 1989546

85 TO4 19960

86 T09 1989 S48

87 T09 19960

\begin{tabular}{|c|c|c|c|}
\hline $\begin{array}{c}\mathrm{H}_{2} \mathrm{O} \\
\text { Eraction }\end{array}$ & $\begin{array}{l}\text { Gross } \\
\text { n Alpha }\end{array}$ & $\begin{array}{c}\text { Gross } \\
\text { Beta }\end{array}$ & ${ }^{2 t} \mathrm{Am}$ \\
\hline & 222000 & 1591000 & 17390 \\
\hline & 81400 & 1309800 & \\
\hline & 14060 & 1968400 & 2960 \\
\hline & 10730 & 1690900 & \\
\hline & 114700 & 14911000 & 12580 \\
\hline & 111000 & 15614000 & . \\
\hline & 23100 & 3180000 & "* \\
\hline & 85200 & 11700000 & . \\
\hline & 650000 & 59000000 & \\
\hline 0.683 & 460000 & 45000000 & 52000 \\
\hline & 250000 & 20000000 & \\
\hline & 530000 & 44000000 & 260 \\
\hline & 200000 & 25000000 & \\
\hline & 300000 & 23000000 & 150 \\
\hline & 370000 & $\begin{array}{l}36000000 \\
41000000\end{array}$ & $\begin{array}{l}8200 \\
8000\end{array}$ \\
\hline & 150000 & 16000000 & \\
\hline 0.702 & 350000 & 50000000 & 13000 \\
\hline
\end{tabular}

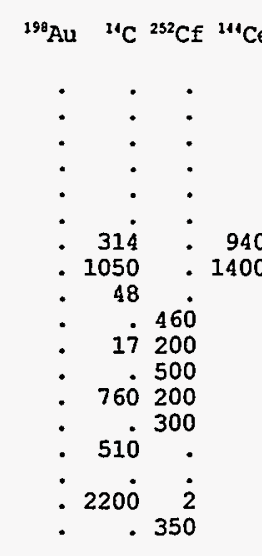
${ }^{243} \mathrm{Cm} \quad{ }^{241} \mathrm{Cm}$
- $3700^{\circ}$

${ }^{60} \mathrm{Co}$

${ }^{134} \mathrm{Cs} \quad{ }^{137} \mathrm{Cs}$

- 13209042920

61050

- 86950 45510

$17760^{\circ}$

$142080^{\circ}$

235000

564000

390000

$490 \quad 390000$

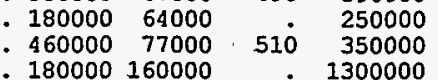

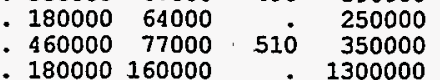

$\begin{array}{llll}180000 & 160000 & \\ 250000 & 100000 & 710 & 1300000 \\ 1600000\end{array}$

$\begin{array}{rrrr}250000 & 100000 & 710 \cdot 1600000 \\ 210000 & 60000 & . & 450000\end{array}$

$530000160000590 \quad 340000$

$97000 \quad 43000$

$\begin{array}{rrrr}97000 & 43000 & 400000 \\ 270000 & 49000 & 480 & 260000\end{array}$ 
Table B.3 (continued)

b

s Tan

$\begin{array}{ll}1 & \text { W03 } \\ 2 & \text { W03 } \\ 3 & \text { W03 }\end{array}$

4 W03

5 104

$\begin{array}{ll}7 & \text { WOA } \\ 8 & \text { WOA }\end{array}$

8 WOA
9 WOA

10 WOA

11 พ0

13 HOS

14 W05

15 พ06

16 พ06

17 WO

18 Wo

19 W07

20 พ07

21 107

22 ต07

23 WO7

24 WO

$25 \mathrm{W07}$

26 107

28 พ07

29 W07

30 พ08

31 108

32 W08

33 พ08

35 W09

36 พ09

37 HOS

38 W10

39 W10

$40 \mathrm{~W} 10$

41 W10

$42 W 10$

43 W21

45 W21
46 W21

$\begin{array}{ll}46 & W 21 \\ 47 & W 22\end{array}$

$\begin{array}{ll}47 & 122 \\ 48 & 122\end{array}$

49 W22

$50 \quad 123$

$51 \mathrm{~W} 23$

52 พ23

53 พ23

$54 \mathrm{~W} 24$

56 W24

57 W25

58 W25

59 พ25

60 ฟ26

61 พ26

62 พ26

63 W27

64 พ27

65 W27

67 พ28

$\begin{array}{ll}68 & \text { W28 } \\ 69 & \text { W28 }\end{array}$

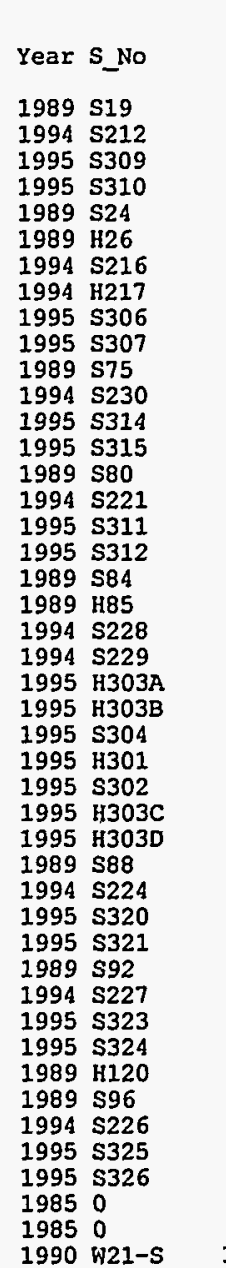

1990 พ21-S

19850

1994 W22S-139 $560000^{\circ} 250000^{\circ} 58000^{\circ}$

$19850 \quad 447700304140 \quad 94350$

19850

1990 W23-S $722000^{\circ} 514000^{\circ} 121000^{\circ}$

1996 W23S-141 1100000640000130000

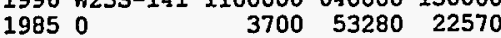

19850

1989 W24-S $\quad 62000^{\circ} 36000^{\circ} 10300^{\circ}$

$\begin{array}{lllll}19850 & 43290 & 39220 & 11840\end{array}$

19850

1989 W25-S

$8140 \dot{0} 5060 \dot{0} \quad 16300^{\circ}$

19850

$\begin{array}{lrrrr}1989 & \text { W26-S } & 492000 & 319000 & 75100 \\ 19850 & 37370 & 3700 & 6660\end{array}$

10ं

19850

1989 W27-H1-S $19900^{\circ} 12600^{\circ} 3400^{\circ}$

1989 W27-H1-H $24200 \quad 15100 \quad 3260$

19850

$11211065120 \quad 25530$

1989 W28-S $\quad 718000320000 \quad 97000^{\circ}$
${ }^{3 \mathrm{H}} \quad{ }^{95} \mathrm{Nb} \quad{ }^{237} \mathrm{~Np} \quad{ }^{241} \frac{\mathrm{Pu}}{\mathrm{AM}}{ }^{239} \frac{\mathrm{Pu}}{\mathrm{Pu}} \quad{ }^{238} \mathrm{Pu} \quad{ }^{239} \mathrm{Pu} \quad{ }^{210} \mathrm{Pu} \quad{ }^{211} \mathrm{Pu} \quad{ }^{212} \mathrm{Pu} \quad{ }^{211} \mathrm{Pu} \quad{ }^{106} \mathrm{Ru}$

- 2 - $\quad$ i 1703900

- $\quad \cdot \quad 408 \quad 4831 \quad 240 \quad 4400 \quad 280 \quad 1500$ o

$180 \quad 10 \dot{10} 19 \dot{2} 690 \dot{0}$

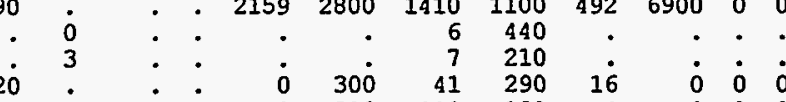

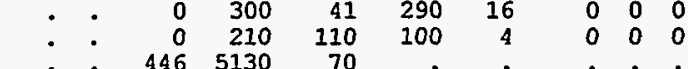

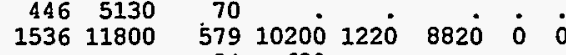

$\begin{array}{rrrrrrrr}54 \dot{0} & 49 \dot{8} & 160 & 370 & 5 \dot{2} & 71 \dot{0} & \dot{0} & \dot{0}\end{array}$

$228 \quad 340 \quad 40$

$\begin{array}{rrrr}253 & 470 & 30 & \\ 210 & 1800^{\circ}\end{array}$

$\begin{array}{rrr}5775 & 4900 & 600\end{array}$

$33447900 \quad 200$

- 11002400

- $5740 \quad 85 \dot{3} 1800$

$4400 \quad 1096 \quad 2300$

$\begin{array}{lll}194 & 570 & 666\end{array}$

$682 \quad 1300 \quad 500$

- 25672516

536599

- $13677^{\circ} 5300^{\circ} 2900^{\circ} 3200^{\circ}$

$\begin{array}{llllll}5300 & 4800 & 3500 & 760 & 8100 & i\end{array}$

- 848154004500300061059001 .

$$
\begin{array}{rrr}
8472 & 4600 \\
. & 22000 \quad 9200
\end{array}
$$

- $28200^{\circ} 8000^{\circ} 180006200120012000^{\circ} \dot{5} \dot{0}$

- $1372542009600 \quad 18006106600 \quad 2 \quad 0$

- 12545370076001700700770020

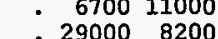

- $2300 \dot{4} 5000110004200110011000 \dot{3}$ 0

$\begin{array}{llllllll}8140 & 4400 & 9000 & 1400 & 550 & 6000 & 1 & 0\end{array}$ - $\begin{array}{llllllll}3876 & 5900 & 3400 & 3400 & 1200 & 7000 & 2 & 0\end{array}$

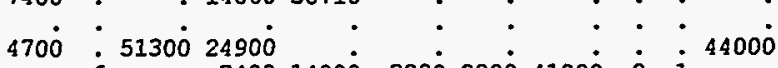

$\begin{array}{lllll}6 & 7400140003200280041000 \quad 2\end{array}$

1221

- $28000^{\circ} 790 \dot{0} 1600 \dot{0} 458 \dot{0} 34106630 \dot{0} \dot{3} \quad \dot{0}$

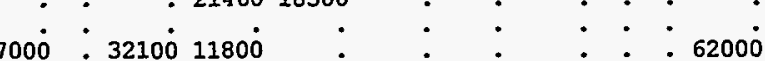

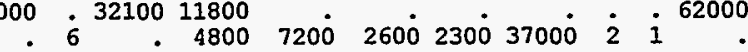

$560 \div 3740^{\circ} 1540^{\circ}$

$590^{\circ}-7350^{\circ} 2930^{\circ}$.

- $1480 \dot{0} 5110 \dot{0}$

. 74003330

$730^{\circ}: 4410^{\circ} 1040^{\circ}$

$1400 \div 67301860$

$2900^{\circ} \cdot 5280^{\circ} 1510^{\circ}$ 


\section{Table B.3 (continued)}

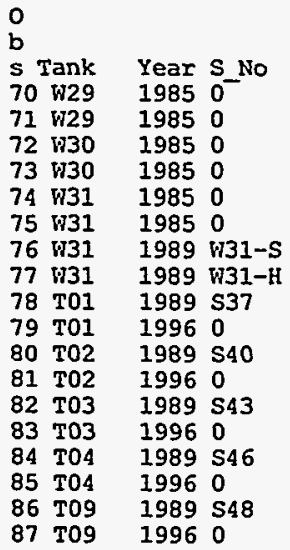

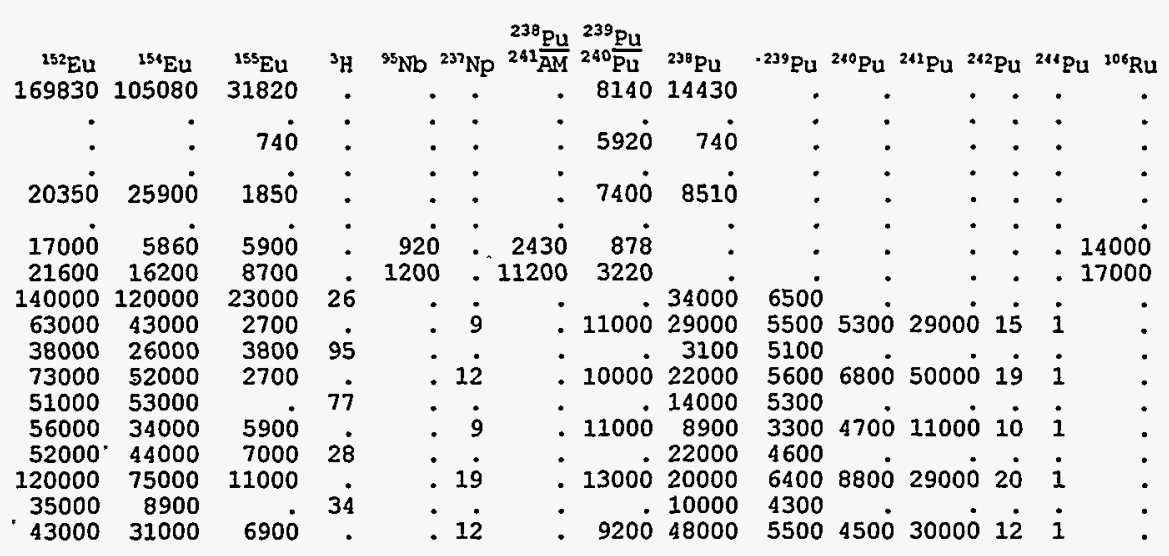




\section{B-15}

Table B.3 (continued)

\begin{tabular}{|c|c|c|c|c|c|c|c|c|c|c|c|c|c|}
\hline obs & Tank & Year & S_No & ${ }^{90} \mathrm{Sr}$ & ${ }^{99} \mathrm{TC}$ & ${ }^{232} \mathrm{Th}$ & ${ }^{233} \mathrm{U}$ & ${ }^{234} \mathrm{U}$ & ${ }^{235} \mathrm{U}$ & ${ }^{236} \mathrm{U}$ & ${ }^{238} \mathrm{U}$ & ${ }^{233} U /{ }^{234} U$ & ${ }^{95} \mathrm{Zr}$ \\
\hline 1 & พ03 & 1989 & S19 & 150000 & - & & 1100 & & & & 430 & - & - \\
\hline 2 & พ03 & 1994 & S212 & 580000 & - & 1 & 671 & 1534 & 65 & 2 & 1576 & - & - \\
\hline 3 & พ03 & 1995 & S309 & 39000 & . & 9 & & 2197 & & $\therefore$ & 683 & - & - \\
\hline 4 & w03 & 1995 & s310 & 19000 & . & 5 & 1183 & 478 & 21 & 3 & 521 & - & - \\
\hline 5 & W04 & 1989 & S24 & 89000 & - & . & 2000 & • & • & . & 2300 & - & - \\
\hline 6 & พ04 & 1989 & H26 & 21000 & . & . & 2700 & & & . & 3000 & - & - \\
\hline 7 & W04 & 1994 & S216 & 39000 & . & 2 & 0 & 2720 & 107 & 6 & 2598 & - & . \\
\hline 8 & W04 & 1994 & H217 & 19000 & . & 1 & 0 & 2524 & 94 & 0 & 2290 & . & - \\
\hline 9 & พ04 & 1995 & S306 & 260000 & . & 18 & $\dot{0}$ & 929 & & : & 497 & - & - \\
\hline 10 & W04 & 1995 & S307 & 170000 & . & 12 & 0 & 677 & 25 & 4 & 614 & . & - \\
\hline 13 & W05 & 1989 & S75 & 29000 & . & & 46 & $\therefore$ & & . & & . & - \\
\hline 12 & W05 & 1994 & S230 & 79000 & . & 0 & 30 & 9 & 0 & 0 & 11 & . & - \\
\hline 13 & W05 & 1995 & S314 & 24000 & . & 2 & . & - & - & . & • & - & - \\
\hline 14 & W05 & 1995 & S315 & 16000 & • & 1 & & - & • & - & - & - & - \\
\hline 15 & พ06 & 1989 & S80 & 360000 & . & $\cdot$ & 270 & & & - & & - & - \\
\hline 16 & พ06 & 1994 & S221 & 190000 & . & 3 & 0 & 140 & 5 & 0 & 109 & - & - \\
\hline 17 & ต06 & 1995 & S311 & 950000 & . & 7 & - & • & - & - & • & - & - \\
\hline 18 & W06 & 1995 & s312 & 400000 & - & 5 & $\therefore$ & - & - & - & • & - & - \\
\hline & พ07 & 1989 & S84 & 810000 & . & . & 540 & - & - & • & & • & - \\
\hline & พ07 & 1989 & H85 & 310000 & . & & 1700 & & & & 1600 & - & - \\
\hline 2 & W07 & 1994 & S228 & 790000 & • & 16 & 257 & 930 & 37 & 1 & 904 & - & - \\
\hline 22 & พ07 & 1994 & s229 & 870000 & . & 18 & 273 & 1099 & 44 & 1 & 1069 & - & - \\
\hline 2 & พ07 & 1995 & H303A & 110000 & . & 17 & 0 & 2429 & 91 & 4 & 2204 & - & . \\
\hline 2 & W07 & 1995 & H303B & 18000 & . & 6 & 0 & 856 & 32 & 0 & 777 & . & - \\
\hline 25 & พ07 & 1995 & S304 & 140000 & . & 19 & . & 2407 & • & . & 1960 & . & - \\
\hline 2 & พ07 & 1995 & H301 & 950000 & . & 17 & . & 1462 & - & . & 969 & - & - \\
\hline 2 & พ07 & 1995 & S302 & 680000 & . & 13 & . & 1092 & . & . & 756 & . & - \\
\hline 28 & พ07 & 1995 & H303C & 18000 & . & 21 & - & 2291 & - & . & 2471 & - & - \\
\hline 2 & พ07 & 1995 & H303D & 100000 & . & 21 & & 2463 & . & . & 2350 & . & - \\
\hline 3 & พ08 & 1989 & S88 & 2800000 & . & . & 1600 & & & & & . & - \\
\hline 3 & W08 & 1994 & S224 & 2900000 & . & 67 & 762 & 62 & 2 & 0 & 62 & - & - \\
\hline 3 & พ08 & 1995 & S320 & 2200000 & . & 58 & 736 & 76 & 3 & 1 & 70 & - & - \\
\hline & พ08 & 1995 & S321 & 1800000 & . & 40 & 558 & 76 & 3 & 0 & 73 & . & 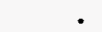 \\
\hline 3 & พอ9 & 1989 & s92 & 2200000 & . & . & 3100 & & & & & . & - \\
\hline 3 & พ09 & 1994 & S227 & 1700000 & . & 25 & 663 & 286 & 15 & 2 & 389 & & - \\
\hline & W09 & 1995 . & \$323 & 1700000 & . & 24 & 793 & 162 & 6 & 1 & 173 & 1220 & \\
\hline & พ09 & 1995 & 5324 & 1800000 & . & 24 & 774 & 135 & 5 & 1 & 147 & 1365 & \\
\hline 38 & W10 & 1989 & H12O & 1200 & . & • & 2100 & . & . & . & 1300 & • & \\
\hline & W10 & 198 & S96 & 8600000 & . & & 50 & & : & - & & - & \\
\hline & w10 & 1994 & S226 & 2400000 & . & 25 & 731 & 236 & 9 & 2 & 253 & & \\
\hline 4 & W10 & 1995 & S325 & 3000000 & - & 42 & 1323 & 115 & 4 & 1 & 131 & 1320 & - \\
\hline 4 & W10 & 1995 & S326 & 4700000 & . & 17 & 392 & 51 & 2 & 0 & 54 & 342 & \\
\hline 43 & W21 & 1985 & 0 & & . & . & 1850 & . & . & - & • & • & 98420 \\
\hline 44 & W21 & 1985 & 0 & 606800 & - & - & & - & - & - & - & - & \\
\hline 45 & W2I & 1990 & W21-S & 783000 & & & 8130 & & : & - & & - & 39000 \\
\hline 46 & พ21 & 1996 & W21s-178 & 440000 & 810 & 30 & 9718 & 570 & 4 & 6 & 314 & - & \\
\hline 47 & W22 & 1985 & 0 & & • & • & 2146 & • & . & . & • & - & 108040 \\
\hline 48 & W22 & 1985 & 0 & 377400 & & & & 105 & 6 & & & - & - \\
\hline 49 & W22 & 1994 & W22S-139 & 620000 & 170 & 43 & 5553 & 145 & 6 & 4 & 440 & - & 125800 \\
\hline 5 & W23 & 1985 & 0 & & & • & 4810 & - & - & - & - & - & 125800 . \\
\hline & $\begin{array}{l}\text { W23 } \\
\text { W23 }\end{array}$ & $\begin{array}{l}1985 \\
1990\end{array}$ & $\begin{array}{l}0 \\
\text { พ23-s }\end{array}$ & $\begin{array}{l}2726900 \\
2330000\end{array}$ & $:$ & : & $11800^{\circ}$ & - & - & $\cdot$ & : & : & $45000^{\circ}$ \\
\hline & W23 & 1996 & W23S-141 & 580000 & $380^{\circ}$ & $3 i$ & 19408 & 900 & 6 & 10 & 492 & . & \\
\hline & W24 & 1985 & 0 & & . & - & 925 & • & - & • & • & - & 23680 \\
\hline & พ24 & & 0 & 2812000 & . & . & & - & - & - & - & - & \\
\hline & W24 & 1989 & พ24-S & 1150000 & - & . & 515 & - & . & - & - & - & $\begin{array}{l}2800 \\
3700\end{array}$ \\
\hline & W25 & $\begin{array}{l}1985 \\
1985\end{array}$ & $\begin{array}{l}0 \\
0\end{array}$ & ร00000ํ. & - & • & 2701 & - & • & $\cdot$ & $\cdot$ & • & 3700 \\
\hline & $\begin{array}{l}\text { W25 } \\
\text { W25 }\end{array}$ & $\begin{array}{l}1985 \\
1989\end{array}$ & พ25-s & $\begin{array}{l}5994000 \\
1730000\end{array}$ & $\dot{0}$ & $\dot{0}$ & 837 & $\dot{.}$ & $\dot{0}$ & : & : & $:$ & 4600 \\
\hline 6 & พ26 & 1985 & 0 & & . & . & 2220 & . & . & . & . & . & 3700 \\
\hline & พ26 & 1985 & 0 & 2971100 & - & - & & - & - & - & - & - & \\
\hline & พ26 & 1989 & W26-S & 1840000 & - & - & 6660 & - & - & - & - & - & $\begin{array}{r}130000 \\
3700\end{array}$ \\
\hline 6 & พ27 & & 0 & & • & - & 1591 & - & - & - & - & - & \\
\hline 6 & พ27 & 1985 & 0 & 1961000 & - & - & & - & - & - & - & - & \\
\hline & W27 & 1989 & W27-H1-s & 421000 & - & - & 518 & - & - & - & - & - & 1700 \\
\hline & W27 & 1989 & W27-H1-H & 615000 & • & - & 620 & - & - & - & - & - & $\begin{array}{r}2600 \\
34040\end{array}$ \\
\hline & W28 & 1985 & 0 & & - & - & 1739 & - & • & - & - & - & 34040 \\
\hline & W28 & & 0 & 210900 & - & - & & - & - & - & - & - & \\
\hline & พ28 & 1989 & พ28-S & 606000 & . & - & 3560 & - & - & - & - & - & 4000 \\
\hline
\end{tabular}


B-16

Table B.3 (continued)

\begin{tabular}{|c|c|c|c|c|c|c|c|c|c|c|c|c|c|}
\hline Obs & Tank & Year & S_No & ${ }^{90} \mathrm{Sr}$ & ${ }^{99} \mathrm{Tc}$ & ${ }^{232} \mathrm{Th}$ & ${ }^{233} \mathrm{U}$ & ${ }^{23} 4 \mathrm{U}$ & ${ }^{235} \mathrm{U}$ & ${ }^{236} \mathrm{U}$ & ${ }^{238} \mathbf{U}$ & ${ }^{233} \mathrm{U} /{ }^{234} \mathrm{U}$ & ${ }^{95} \mathrm{Zr}$ \\
\hline 70 & 629 & 1985 & 0 & & $\bullet$ & - & 2738 & - & - & - & - & $\because$ & 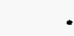 \\
\hline 71 & พ29 & 1985 & 0 & 455100 & - & - & & - & - & - & - & - & . \\
\hline 72 & \$30 & 1985 & 0 & & - & - & 444 & - & $\therefore$ & - & - & - & - \\
\hline 73 & W30 & 1985 & 0 & 740000 & - & - & & - & - & - & - & - & - \\
\hline 74 & พ31 & 1985 & 0 & & • & - & 2257 & - & - & - & - & - & - \\
\hline 75 & \$31 & 1985 & 0 & 7437000 & • & - & & . & . & - & . & . & \\
\hline 76 & W31 & 1989 & W31-S & 1430000 & - & . & 508 & - & - & - & - & . & 4700 \\
\hline 77 & พ31 & 1989 & พ31-H & 5170000 & - & . & 2050 & - & - & . & - & - & 6600 \\
\hline 78 & T01 & 1989 & S37 & 32000000 & - & - & & & $\bullet$ & • & • & - & \\
\hline 79 & T01 & 1996 & 0 & 20000000 & 13 & 370 & 7900 & 110 & 1 & 1 & 30 . & - & - \\
\hline 80 & T02 & 1989 & S40 & 12000000 & $\therefore$ & . & 8300 & $\therefore$ & : & : & $\therefore$ & - & - \\
\hline 81 & T02 & 1996 & 0 & 18000000 & 47 & 380 & 7800 & 95 & 1 & 1 & 26 & - & $\bullet$ \\
\hline 82 & T03 & 1989 & $\$ 43$ & 8100000 & $\dot{0}$ & & 8300 & & 0 & : & $\therefore$ & - & $\bullet$ \\
\hline 83 & T03 & 1996 & 0 & 8500000 & 33 & 320 & 15000 & 130 & 2 & 1 & 73 & - & \\
\hline 84 & T04 & 1989 & 546 & 22000000 & - & & 7100 & & - & : & $\therefore$ & - & $\bullet$ \\
\hline 85 & T04 & 1996 & 0 & 16000000 & 28 & 500 & 24000 & 180 & 2 & 2 & 97 & - & \\
\hline 86 & T09 & 1989 & S48. & 14000000 & $\dot{0}$ & $\dot{0}$ & 4400 & $\therefore$ & : & ; & $\therefore$ & • & \\
\hline 87 & T09 & 1996 & 0 & 20000000 & 140 & 230 & 6400 & 57 & 1 & 1 & 31 & - & \\
\hline
\end{tabular}


TABLES B.4, B.5 AND B.6

Measurement Data on Liquid Samples: 1985-1996 


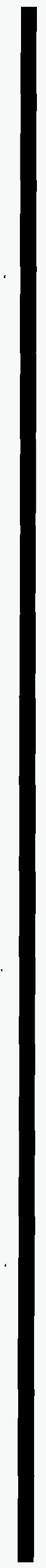


B-19

Table B.4. Physical variable measurements on liquid samples from 1985 to 1996.

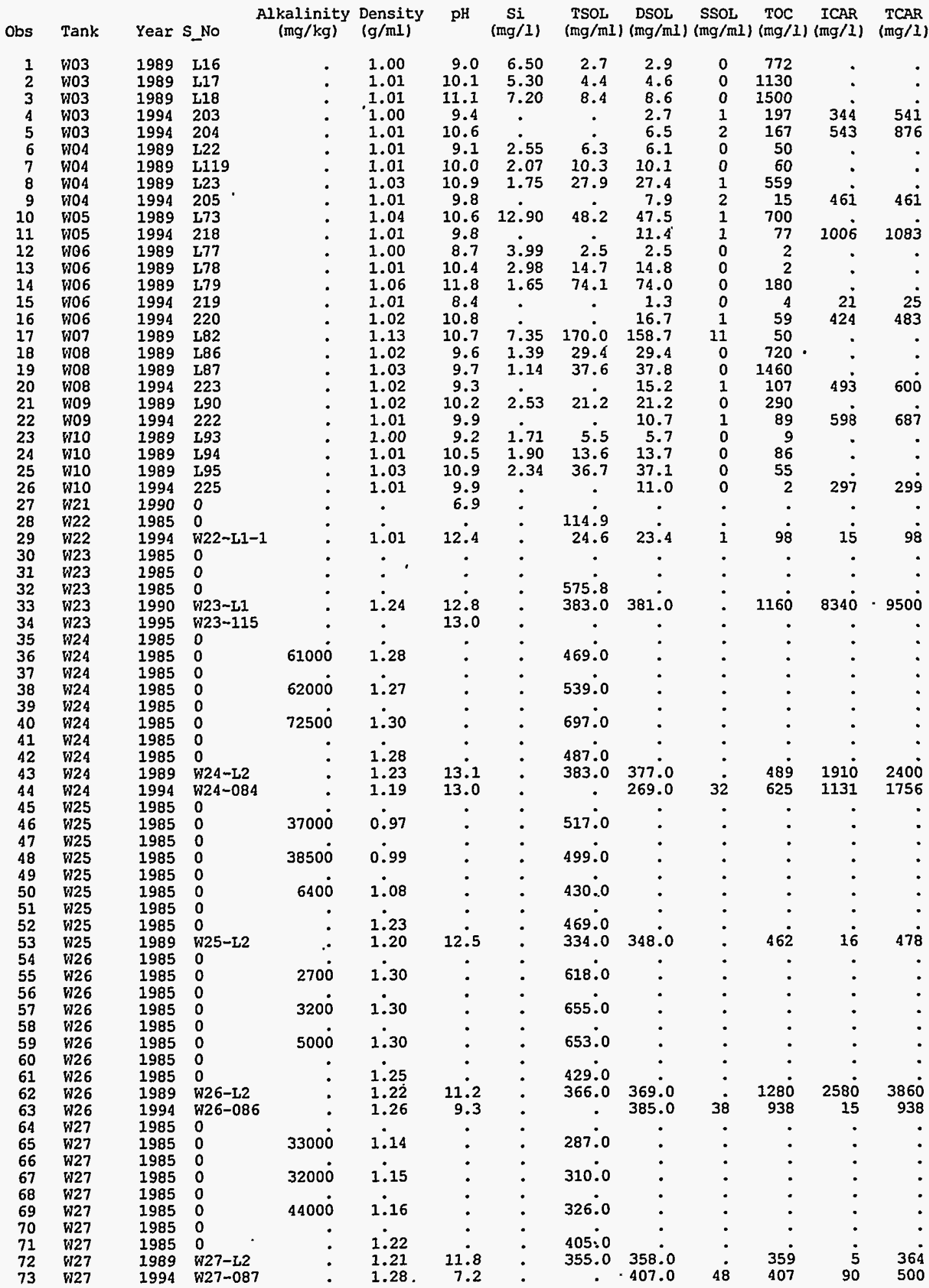


Table B.4 (continued)

\begin{tabular}{|c|c|c|c|c|c|c|c|c|c|c|c|c|c|}
\hline Obs & Tank & Year & S_No & $\begin{array}{c}\text { Alkalinity } \\
(\mathrm{mg} / \mathrm{l})\end{array}$ & $\begin{array}{l}\text { Density } \\
(\mathrm{g} / \mathrm{ml})\end{array}$ & $\mathrm{pH}$ & $\underset{(m g / 1)}{s i}$ & $\begin{array}{l}\text { TSOL } \\
(\mathrm{mg} / \mathrm{ml})\end{array}$ & $\begin{array}{l}\text { DSOL } \\
\text { (mg/ml) }\end{array}$ & $\underset{(\mathrm{mg} / \mathrm{ml})}{\mathrm{SSOL}}$ & $\begin{array}{l}\text { TOC } \\
(\mathrm{mg} / 1)\end{array}$ & $\begin{array}{l}\text { ICAR } \\
\text { (mg/1) }\end{array}$ & $\begin{array}{l}\text { TCAR } \\
\text { (mg/1 }\end{array}$ \\
\hline $\begin{array}{l}74 \\
75\end{array}$ & W28 & 1985 & 0 & & & - & - & & • & • & • & • & \\
\hline $\begin{array}{l}75 \\
76\end{array}$ & 1928 & 1985 & 0 & 2000 & 1.24 & - & • & 434.0 & • & - & - & • & \\
\hline $\begin{array}{l}76 \\
77\end{array}$ & $\begin{array}{l}\text { W28 } \\
\text { w28 }\end{array}$ & 1985 & 0 & $2000^{\circ}$ & 1.25 & - & - & $30^{\circ}$ & - & - & - & - & \\
\hline 78 & $\begin{array}{l}\text { ค28 } \\
\text { w28 }\end{array}$ & $\begin{array}{l}1985 \\
1985\end{array}$ & $\begin{array}{l}0 \\
0\end{array}$ & & $\times 1.20$ & : & $\dot{.}$ & 438.0 & - & - & - & - & \\
\hline 79 & พ28 & 1985 & 0 & 51500 & 1.27 & . & : & 490.0 & . & : & $\dot{.}$ & $\dot{0}$ & \\
\hline 80 & W28 & 985 & 0 & & & - & . & & . & . & . & : & \\
\hline 81 & W28 & 1985 & 0 & . & 1.33 & $0^{\circ}$ & - & 597.0 & & . & . & . & \\
\hline 82 & พ28 & 1985 & 0 & - & 1.09 & 12.1 & . & • & 570.0 & . & . & . & \\
\hline 83 & W28 & 1985 & 0 & . & 1.27 & & . & & 490.0 & $\therefore$ & & & \\
\hline 84 & W28 & 1989 & ต28 $-\mathrm{L} 2$ & . & 1.29 & 9.1 & . & 478.0 & 485.0 & 16 & 574 & 7 & \\
\hline 85 & 1928 & 1994 & W28-088 & - & 1.33 & 7.2 & • & • & 524.0 & 46 & 735 & 44 & 77 \\
\hline 86 & Y29 & 1985 & 0 & . & $\therefore 27$ & • & - & & • & • & - & - & \\
\hline 87 & พ29 & 985 & 0 & . & 1.27 & & - & 442.0 & & - & - & - & \\
\hline 88 & พ29 & 1985 & 0 & - & 1.22 & 13.5 & . & • & 400.0 & . & . & . & \\
\hline 89 & W29 & 1985 & 0 & . & 1.24 & & . & . & 390.0 & . & . & . & \\
\hline 90 & W29 & 988 & 1 & . & 1.24 & 13.6 & . & . & • & . & . & . & \\
\hline 91 & พ29 & 1988 & 2 & . & 1.24 & 13.6 & - & - & - & - & - & . & \\
\hline 92 & W29 & 1988 & 3 & . & 1.24 & 13.6 & . & - & - & - & - & . & \\
\hline 93 & พ29 & 1988 & 1 & . & 1.24 & 13.6 & - & . & - & - & - & - & \\
\hline 94 & พ29 & 1988 & 2 & . & 1.24 & 13.6 & . & - & - & - & - & - & \\
\hline 95 & W29 & 1988 & 2D & - & 1.26 & 13.6 & - & - & . & • & . & . & \\
\hline 96 & W29 & 1988 & 3 & . & 1.24 & 13.6 & . & $\cdot \cdot$ & . & . & . & . & \\
\hline 97 & W29 & & 1 & . & 1.25 & 13.6 & . & . & . & . & . & . & \\
\hline 98 & W29 & 988 & 2 & . & 1.25 & 13.6 & • & - & - & • & - & . & \\
\hline 99 & พ29 & 1988 & 3 & . & 1.25 & 13.6 & . & & & . & 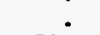 & & \\
\hline 100 & พ29 & 1989 & W29-II & . & 1.23 & 12.7 & • & 377.0 & 375.0 & . & 507 & 478 & 985 \\
\hline & พ29 & 1989 & W29-I2 & . & 1.23 & 12.8 & . & 379.0 & 376.0 & . & 563 & 477 & 1040 \\
\hline 02 & W29 & 1989 & W29-I4 & . & 1.23 & 12.7 & . & 382.0 & 375.0 & - & 377 & 456 & \\
\hline 103 & พ30 & 1985 & 0 & . & & • & . & & • & . & • & • & \\
\hline & W30 & & 0 & . & 1.26 & & . & 492.0 & & • & • & - & \\
\hline & W30 & 1985 & 0 & . & 1.23 & 13.7 & . & . & 390.0 & . & . & . & \\
\hline 106 & พ30 & 1985 & 0 & . & 1.23 & & . & . & 370.0 & . & . & . & \\
\hline 107 & w30 & 1988 & 1 & . & 1.24 & 13.9 & . & • & . & . & . & . & \\
\hline & พ30 & 1988 & 2 & . & 1.24 & 13.9 & - & . & - & • & - & . & \\
\hline 109 & พ30 & 1988 & 2D & . & 1.24 & 13.9 & . & . & . & . & . & . & \\
\hline 10 & w30 & & 3 & . & 1.24 & 13.9 & . & • & . & . & . & & \\
\hline & พ30 & & 1 & . & 1.24 & 13.9 & . & . & . & . & . & . & \\
\hline 112 & พ30 & 1988 & 2 & - & 1.24 & 13.9 & - & . & . & . & . & . & \\
\hline 13 & พ30 & 1988 & 3 & . & 1.24 & 13.9 & . & . & . & . & . & . & \\
\hline & พ3 & & 1 & 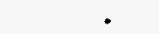 & 1.24 & 13. & . & & . & . & . & . & \\
\hline 1 & w30 & 1988 & 2 & . & 1.24 & 13.9 & . & . & . & . & . & . & \\
\hline 116 & พ30 & & 3 & . & 1.24 & 13. & : & & & . & & & \\
\hline & พ30 & 198 & พ30-L1 & . & 1.22 & 12.8 & . & 396.0 & 371.0 & . & 203 & 602 & 80 \\
\hline 11 & พ30 & 1989 & W30-L2 & . & 1.22 & 12.9 & . & 391.0 & 377.0 & . & 99 & 596 & 69 \\
\hline 119 & พ30 & 198 & W30-L4 & . & 1.2 & 12. & . & 374.0 & & . & 199 & 600 & \\
\hline & & & 0 & . & & 12.5 & . & & & . & . & & \\
\hline 12 & พ31 & & 0 & . & 1.18 & & • & & 340.0 & • & & & \\
\hline 122 & W31 & 1989 & W31-โ2 & . & 1.21 & 11.7 & - & 349.0 & 351.0 & 8 & 445 & 19 & 464 \\
\hline 123 & พ31 & & W31-089 & . & 1.26 & 11.9 & 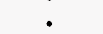 & & 391.0 & 38 & 741 & 489 & 123 \\
\hline 12 & TO & & L35 & . & 1. & 9.7 & 9.34 & 7.2 & 6.4 & 1 & 836 & & \\
\hline 125 & T0 & 1989 & L36 & . & 1 & 9.7 & 6.81 & 6.9 & 6. & 0 & 790 & 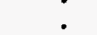 & \\
\hline 126 & T01 & & 0 & - & 1.0 & 9. & & 8.6 & 8.4 & 0 & 478 & 572 & 1050 \\
\hline 127 & T02 & & L38 & - & 1.01 & 9.9 & 5.07 & 12.5 & 11. & 1 & 1120 & & \\
\hline 128 & T02 & 198 & L112 & . & 1.01 & 9.9 & 6.81 & 12.1 & 11. & 1 & 1100 & . & \\
\hline 129 & T02 & & L39 & . & 1.8 & 9.9 & 6.97 & 11.6 & 10. & 1 & 1310 & & \\
\hline 130 & T02 & 19. & 0 & - & 1.02 & 9.5 & & 13.7 & 13.5 & 0 & 820 & 1060 & 1880 \\
\hline 131 & T03 & & L42 & . & 1.04 & 12.7 & 77.10 & 53.4 & 51.9 & 2 & 12600 & & \\
\hline 132 & T03 & & 0 & - & 1.0 & 11.6 & & 56.5 & 54.2 & 1 & 2130 & 800 & 2930 \\
\hline 133 & T04 & & L111 & . & 1.02 & 11.7 & 1.96 & 23.9 & 23.6 & $\overline{0}$ & 460 & & \\
\hline 134 & T04 & & L44 & • & 1.0 & 11.7 & 1.96 & 26.3 & 23. & 3 & 460 & . & \\
\hline 135 & T04 & 198 & L45 & . & 1.02 & 11.7 & 1.45 & 23.4 & 23.7 & 0 & 473 & & \\
\hline 136 & T04 & & 0 & : & 1.02 & 10.4 & . & 17.5 & 17.2 & 0 & 550 & 392 & 942 \\
\hline 137 & T09 & & L47 & - & 1.0 & 9.1 & 9.76 & 42.2 & 41.5 & 1 & 850 & & \\
\hline $13 \varepsilon$ & T09 & 1996 & 0 & . & 1.02 & 9.1 & . & 16.1 & 15.9 & 0 & 62 & 413 & 475 \\
\hline
\end{tabular}


Table B.5. Chemical variable measurements $(\mathrm{mg} / \mathrm{kg})$ on liquid samples from 1985 to 1996.

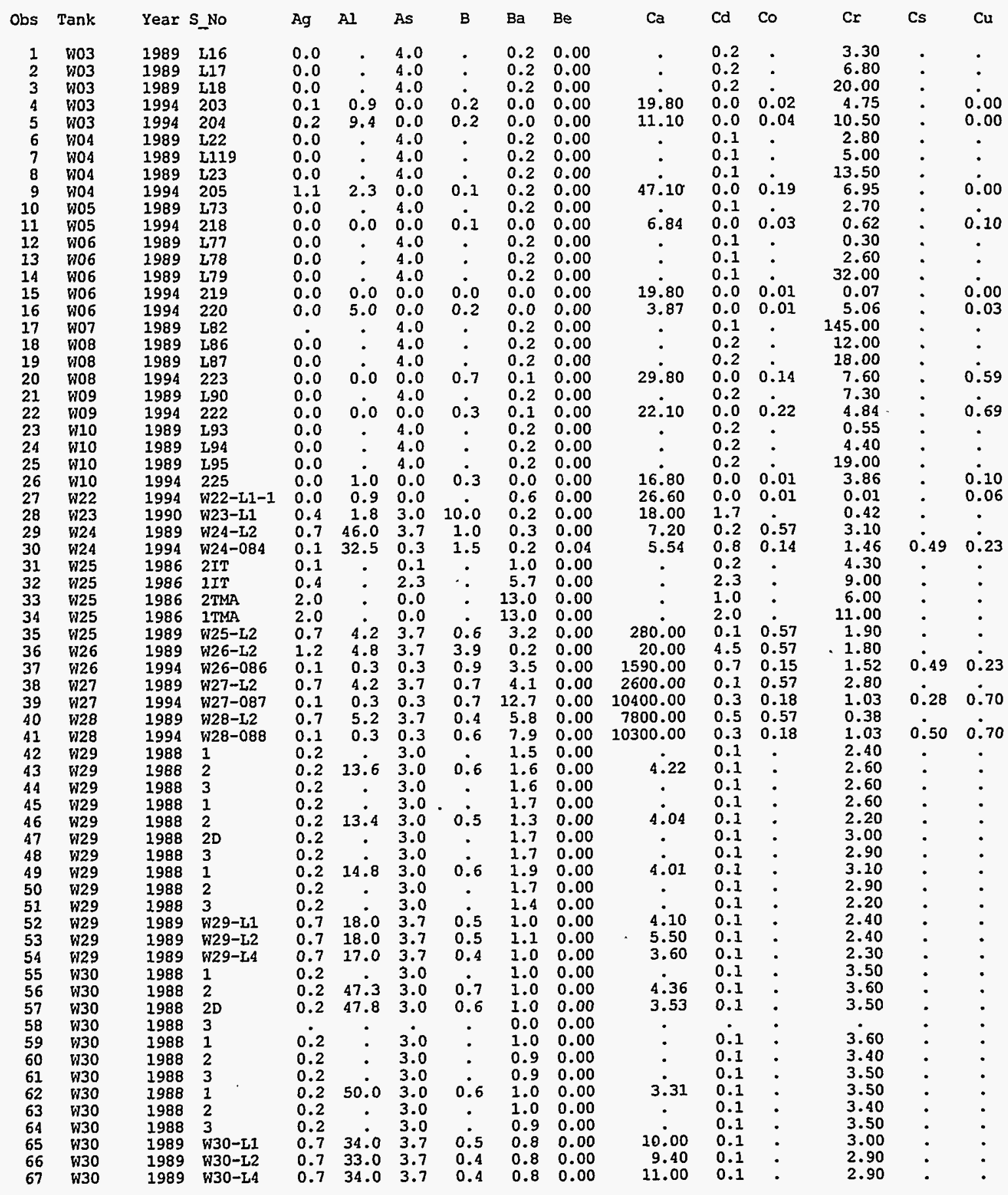


Table B.5 (continued)

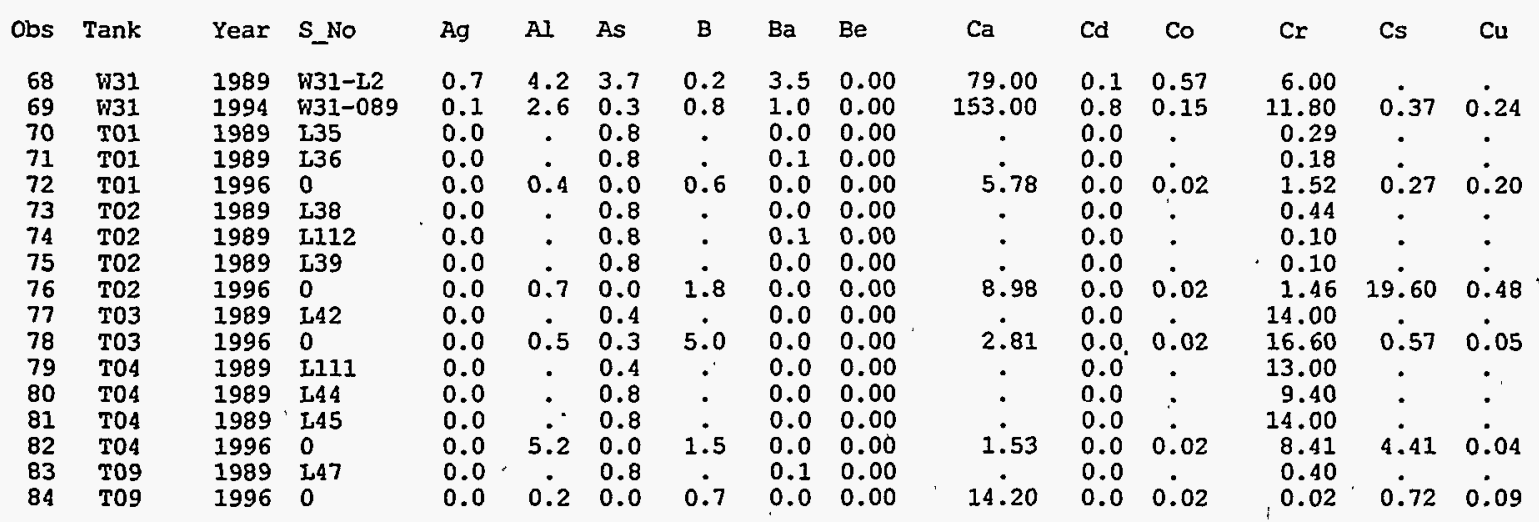


Table B.5 (continued)

\begin{tabular}{|c|c|c|c|c|c|c|c|c|c|c|c|c|}
\hline Obs & Tank & Year & S_No & $\mathrm{Fe}$ & $\mathrm{Hg}$ & K & Mg & Mn & $\mathrm{Na}$ & $\mathrm{Ni}$ & P & $\mathrm{Pb}$ \\
\hline 1 & พ03 & 1989 & L16 & . & 0.01 & . & . & 0.00 & . & 1.00 & . & 2.00 \\
\hline 2 & W03 & 1989 & L17 & . & 0.01 & . & . & 0.00 & . & 1.00 & . & 2.00 \\
\hline 3 & พ03 & 1989 & L18 & $\cdot$ & 0.02 & $0^{\circ}$ & $\cdot$ & 0.00 & $\dot{0}$ & 1.00 & . & 2.00 \\
\hline 4 & W03 & 1994 & 203 & 0.13 & 0.01 & 18.7 & 3.60 & 0.02 & 1050 & 0.06 & . & 0.01 \\
\hline 5 & ท03 & 1994 & 204 & 0.33 & 0.03 & 20.8 & 0.79 & 0.03 & 2360 & 0.10 & . & 0.01 \\
\hline 6 & พ04 & 1989 & L22 & . & 0.01 & . & . & 0.00 & . & 1.00 & . & 2.00 \\
\hline 7 & W04 & 1989 & L119 & . & 0.01 & . & . & 0.00 & . & 1.00 & . & 2.00 \\
\hline 8 & W04 & 1989 & $\mathrm{~L} 23$ & . & 0.01 & & . & 0.00 & & 1.00 & . & 2.00 \\
\hline 9 & WO4 & 1994 & 205 & 0.45 & 0.00 & 21.3 & 0.02 & 0.17 & 2200 & 0.23 & . & 0.06 \\
\hline 10 & W05 & 1989 & L73 & . & 0.41 & & . & 0.00 & & 1.00 & . & 2.00 \\
\hline 21 & W05 & 1994 & 218 & 0.04 & 0.03 & 76.3 & 1.98 & 0.01 & 4250 & 0.11 & : & 0.43 \\
\hline 12 & พ06 & 1989 & L77 & . & 0.01 & . & . & 0.00 & . & 1.00 & . & 2.00 \\
\hline 13 & พ06 & 1989 & L78 & . & 0.01 & . & . & 0.00 & . & 1.00 & . & 2.00 \\
\hline 14 & พือ6 & 1989 & 279 & $\cdot$ & 0.07 & & $0^{\circ}$ & 0.00 & . & 1.50 & . & 2.00 \\
\hline 15 & W06 & 1994 & 219 & 0.05 & 0.00 & 22.3 & 2.06 & 0.00 & 361 & 0.01 & . & 0.43 \\
\hline 16 & W06 & 1994 & 220 & 0.00 & 0.02 & 151.0 & 0.61 & 0.00 & 6440 & 0.15 & . & 0.43 \\
\hline 17 & พ07 & 1989 & L82 & . & 11.00 & 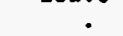 & . & 0.00 & . & 1.00 & . & 2.00 \\
\hline 18 & พัด & 1989 & L86 & . & 0.09 & . & . & 0.00 & . & 1.00 & . & 2.00 \\
\hline 19 & W0B & 1989 & L87 & . & 0.17 & $0^{\circ}$ & $\cdot$ & 0.00 & & 1.00 & . & 2.00 \\
\hline 20 & W08 & 1994 & 223 & 0.14 & 0.33 & 627.0 & 5.39 & 0.08 & 4370 & 0.27 & . & 0.47 \\
\hline 21 & พ09 & 1989 & L90 & & 0.06 & & & 0.00 & & 1.00 & . & 2.00 \\
\hline 22 & W09 & 1994 & 222 & 0.31 & 0.16 & 896.0 & 3.97 & 0.16 & 2640 & 0.29 & . & 1.03 \\
\hline 23 & W10 & 1989 & L93 & . & 0.01 & . & • & 0.00 & . & 1.00 & . & 2.20 \\
\hline 24 & w10 & 1989 & L94 & . & 0.05 & . & . & 0.00 & . & 1.00 & . & 2.00 \\
\hline 25 & b1o & 1989 & L95 & . & 0.37 & & 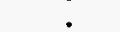 & 0.00 & & 1.00 & . & 2.00 \\
\hline 26 & W10 & 1994 & 225 & 0.03 & 0.12 & 819.0 & 2.81 & 0.01 & 2800 & 0.06 & . & 0.43 \\
\hline 27 & พ22 & 1994 & W22-L1-1 & 0.08 & 0.03 & 40.9 & 0.03 & 0.00 & 5190 & 0.14 & . & 0.43 \\
\hline 28 & W23 & 1990 & W23-L1 & 0.70 & 0.07 & 78000.0 & 3.40 & 0.00 & 82000 & 3.00 & . & 2.70 \\
\hline 29 & W24 & 1989 & W24-L2 & 2.60 & 0.05 & 11000.0 & 1.30 & 0.00 & 100000 & 0.38 & . & 6.70 \\
\hline 30 & W24 & 1994 & W24-084 & 0.04 & 0.05 & 20600.0 & 0.34 & 0.01 & 74800 & 0.83 & . & 2.00 \\
\hline 31 & W25 & 1986 & $2 \mathrm{IT}$ & . & 0.21 & . & . & 0.00 & . & . & . & 5.50 \\
\hline 32 & W25 & 1986 & $1 \mathrm{IT}$ & . & 0.50 & . & . & 0.00 & . & . & . & 11.0 \\
\hline 33 & ห25 & 1986 & $2 \mathrm{TMA}$ & . & 0.26 & . & . & 0.00 & . & . & . & 8.00 \\
\hline 34 & พ25 & 1986 & $1 \mathrm{TMA}$ & & 1.60 & & & 0.00 & & & . & 11.0 \\
\hline 35 & W25 & 1989 & W25-L2 & 2.60 & 0.05 & 17000.0 & 1.30 & 0.00 & 78000 & 0.45 & . & 2.10 \\
\hline 36 & H26 & 1989 & W26-L2 & 2.60 & 0.08 & 51000.0 & 3.50 & 0.00 & 68000 & 8.20 & . & 3.20 \\
\hline 37 & H26 & 1994 & W26-086 & 0.04 & 0.09 & 40900.0 & 145.00 & 0.01 & 79900 & 6.99 & . & 2.20 \\
\hline 38 & พ27 & 1989 & W27-L2 & 2.60 & 0.05 & 8500.0 & 1.30 & 0.00 & 90000 & 0.38 & . & 2.10 \\
\hline 39 & W27 & 1994 & W27-087 & 0.04 & 0.64 & 21500.0 & 1090.00 & 0.29 & 95100 & 3.18 & . & 2.20 \\
\hline 40 & W28 & 1989 & พ28-L2 & 2.60 & 0.14 & 26000,0 & 1600.00 & 0.00 & 96000 & 1.40 & : & 2.10 \\
\hline 41 & ज128 & 1994 & W28-088 & 0.04 & 0.14 & 30100,0 & 1870.00 & 0.03 & 110000 & 2.84 & : & 2.20 \\
\hline 42 & พ29 & 1988 & 1 &. & 0.60 & & & 0.00 & & . & - & . \\
\hline 43 & W29 & 1988 & $\overline{2}$ & . & 0.60 & 11100.0 & 0.02 & 0.00 & 103000 & . & . & . \\
\hline 44 & W29 & 1988 & 3 & . & 0.60 & 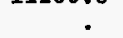 & - & 0.00 & . & . & - & . \\
\hline 45 & พ29 & 1988 & 1 & . & 0.60 & $\sigma^{\circ}$ & . & 0.00 & & - & . & . \\
\hline 46 & H29 & 1988 & 2 & . & 0.60 & 9720.0 & 0.01 & 0.00 & $103000^{\circ}$ & . & . & . \\
\hline 47 & W29 & 1988 & 2D & . & 0.60 & ? &. & 0.00 & . & . & : & . \\
\hline 48 & พ29 & 1988 & 3 & . & 0.60 & & 1. & 0.00 & & . & . & . \\
\hline 49 & พ29 & 1988 & 1 & . & 0.60 & 10500.0 & 0.02 & 0.00 & 104000 & . & . & . \\
\hline 50 & พ29 & 1988 & 2 & . & 0.60 & . & . & 0.00 & . & . & . & . \\
\hline 51 & พ129 & 1988 & 3 & . & 0.60 & & $\because$ & 0.00 & & & . & $\cdot$ \\
\hline 52 & W29 & 1989 & พ29-L1 & 2.60 & 0.09 & 10000.0 & 1.30 & 0.00 & 110000 & 0.38 & - & 2.10 \\
\hline 53 & พ29 & 1989 & W29-L2 & 2.60 & 0.08 & 10000.0 & 1.30 & 0.00 & 110000 & 0.38 & - & 2.10 \\
\hline 54 & พ 29 & 1989 & W29-L4 & 2.60 & 0.09 & 10000.0 & 1.30 & 0.00 & 110000 & 0.38 & . & 2.30 \\
\hline 55 & พ30 & 1988 & 1 & . & 0.60 & & $\cdot$ & 0.00 & & • & • & - \\
\hline 56 & W30 & 1988 & 2 & . & 0.60 & 7890.0 & 0.01 & 0.00 & 111000 & . & . & . \\
\hline 57 & พ30 & 1988 & $2 \mathrm{D}$ & . & 0.60 & 8440.0 & 0.01 & 0.00 & 104000 & . & . & . \\
\hline 58 & พ30 & 1988 & 3 & : & 0.00 & . & . & 0.00 & . & . & . & . \\
\hline 59 & W30 & 1988 & $i$ & . & 0.60 & . & . & 0.00 & . & - & - & . \\
\hline 60 & พ30 & 1988 & 2 & : & 0.60 & . & . & 0.00 & . & . & - & . \\
\hline 61 & พ30 & 1988 & 3 & . & 0.60 & & & 0.00 & & . & . & . \\
\hline 62 & W30 & 1988 & 1 & . & 0.60 & 8820.0 & 0.01 & 0.00 & 111000 & . & . & . \\
\hline 63 & W30 & 1988 & 2 & . & 0.60 & . & . & 0.00 & 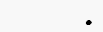 & . & . & . \\
\hline 64 & 130 & 1988 & 3 & . & 0.60 & & • & $0.00^{\circ}$ & & . & . & . \\
\hline 65 & พ30 & 1989 & พ30-L1 & 2.60 & 0.10 & 9200.0 & 1.30 & 0.00 & 100000 & 0.38 & . & 3.00 \\
\hline 66 & w30 & 1989 & W30-L2 & 2.60 & 0.10 & 9300.0 & 1.30 & 0.00 & 100000 & 0.38 & • & 2.90 \\
\hline 67 & พ30 & 1989 & พ30-L4 & 2.60 & 0.10 & 9400.0 & 1.30 & 0.00 & 110000 & 0.38 & . & 2.30 \\
\hline
\end{tabular}


Table B.5 (continued)

\begin{tabular}{|c|c|c|c|c|c|c|c|c|c|c|c|c|}
\hline Obs & Tank & Year & S_No & $\mathrm{Fe}$ & $\mathrm{Hg}$ & $K$ & $\mathrm{Mg}$ & Mn & $\mathrm{Na}$ & $\mathrm{Ni}$ & $\mathbf{P}$ & $\mathrm{Pb}$ \\
\hline $\begin{array}{l}68 \\
69 \\
70 \\
71 \\
72 \\
73 \\
74 \\
75 \\
76 \\
77 \\
78 \\
79 \\
80 \\
81 \\
82 \\
83 \\
84\end{array}$ & $\begin{array}{l}\text { W31 } \\
\text { W31 } \\
\text { T01 } \\
\text { T01 } \\
\text { T01 } \\
\text { T02 } \\
\text { T02 } \\
\text { T02 } \\
\text { T02 } \\
\text { T03 } \\
\text { T03 } \\
\text { T04 } \\
\text { T04 } \\
\text { T04 } \\
\text { T04 } \\
\text { T09 } \\
\text { T09 }\end{array}$ & $\begin{array}{l}1989 \\
1994 \\
1989 \\
1989 \\
1996 \\
1989 \\
1989 \\
1989 \\
1996 \\
1989 \\
1996 \\
1989 \\
1989 \\
1989 \\
1996 \\
1989 \\
1996\end{array}$ & $\begin{array}{l}\text { W31-L2 } \\
\text { W31-089 } \\
\text { I35 } \\
\text { L36 } \\
0 \\
I 38 \\
\text { III2 } \\
\text { I39 } \\
0 \\
\text { L42 } \\
0 \\
\text { I111 } \\
\text { I44 } \\
\text { I45 } \\
0 \\
\text { I44 } \\
0\end{array}$ & $\begin{array}{c}2.60 \\
0.09 \\
\vdots \\
0.01 \\
\vdots \\
0.08 \\
0.02 \\
\vdots \\
0.01 \\
0.01\end{array}$ & $\begin{array}{r}0.15 \\
0.71 \\
0.06 \\
0.07 \\
0.54 \\
0.10 \\
0.10 \\
0.15 \\
0.27 \\
5.70 \\
12.80 \\
7.90 \\
1.10 \\
2.70 \\
1.98 \\
3.40 \\
0.90\end{array}$ & $\begin{array}{c}9500.0 \\
16500.0 \\
\dot{0} \\
847.0 \\
\dot{0} \\
1380.0 \\
3420.0 \\
\dot{0} \\
1320.0 \\
695.0\end{array}$ & $\begin{array}{c}1.30 \\
0.37 \\
\vdots \\
1.11 \\
\vdots \\
4.86 \\
0.03 \\
\vdots \\
0.07 \\
2.97\end{array}$ & $\begin{array}{l}0.00 \\
0.01 \\
0.00 \\
0.00 \\
0.00 \\
0.00 \\
0.00 \\
0.00 \\
0.00 \\
0.00 \\
0.00 \\
0.00 \\
0.00 \\
0.00 \\
0.00 \\
0.00 \\
0.00\end{array}$ & $\begin{array}{r}94000 \\
99200 \\
\dot{0} \\
2210 \\
\dot{0} \\
3590^{\circ} \\
1480 \dot{0} \\
\dot{ } \\
4550 \\
4830\end{array}$ & $\begin{array}{l}0.38 \\
0.95 \\
0.20 \\
0.20 \\
0.04 \\
0.20 \\
0.20 \\
0.20 \\
0.04 \\
0.10 \\
0.07 \\
0.10 \\
0.20 \\
0.20 \\
0.04 \\
0.20 \\
0.04\end{array}$ & $\begin{array}{c}\dot{\vdots} \\
48.6 \\
\dot{0} \\
33.4 \\
129.0 \\
\dot{0} \\
30.1 \\
25.6\end{array}$ & $\begin{array}{l}2.10 \\
2.20 \\
1.00 \\
1.00 \\
0.01 \\
1.00 \\
1.00 \\
1.00 \\
0.02 \\
0.50 \\
0.01 \\
0.50 \\
1.00 \\
1.00 \\
0.01 \\
1.00 \\
0.01\end{array}$ \\
\hline
\end{tabular}


Table B.5 (continued)

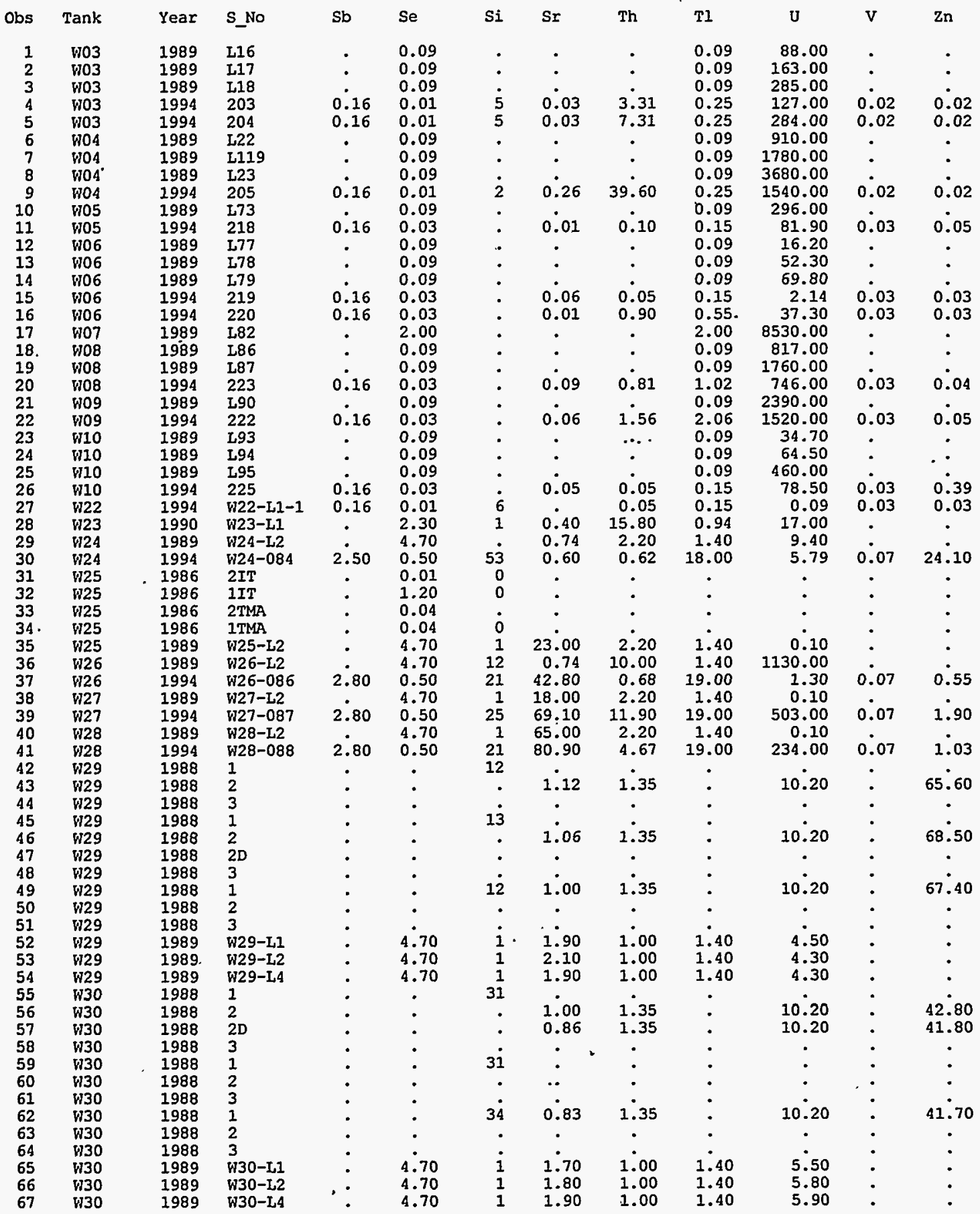


Table B.5 (continued)

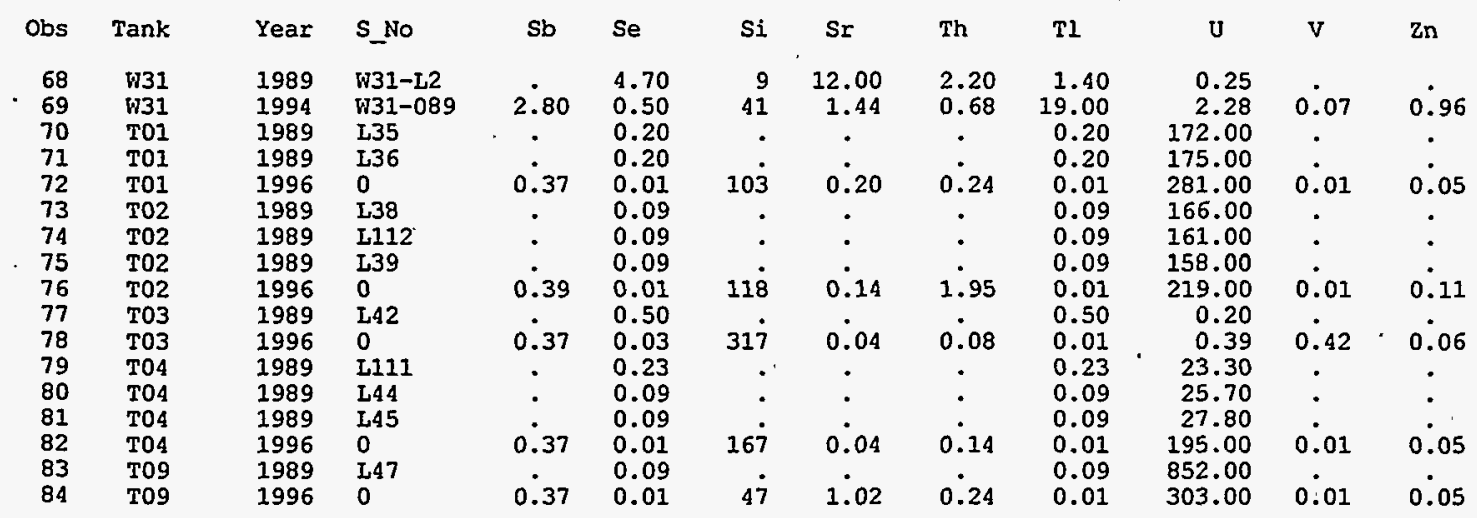


Table B.5 (continued)

\begin{tabular}{|c|c|c|c|c|c|c|c|c|c|c|c|c|c|c|}
\hline Obs & Tank & Year & E S_No & $\begin{array}{l}\text { Bicar- } \\
\text { bonate }\end{array}$ & $\begin{array}{l}\text { Brom- C } \\
\text { ide a }\end{array}$ & $\begin{array}{l}\text { Carbon- } \\
\text { ate }\end{array}$ & $\begin{array}{l}\text { Chlor- } \\
\text { ride }\end{array}$ & $\begin{array}{l}\text { Fluo- } \\
\text { ride }\end{array}$ & $\begin{array}{l}\text { Hydro- } \\
\text { xide }\end{array}$ & $\begin{array}{l}\text { Nitr- } \\
\text { ate }\end{array}$ & $\begin{array}{l}\text { Nitr- } \\
\text { ite }\end{array}$ & $\begin{array}{l}\text { Phosp- } \\
\text { hate }\end{array}$ & $\begin{array}{l}\text { Sulf- } \\
\text { ate }\end{array}$ & HC \\
\hline 1 & พ03 & 1989 & L16 & • & . & - & - & - & . & - & . & • & & \\
\hline 2 & พ03 & 989 & L17 & . & . & . & . & . & - & • & - & - & - & \\
\hline 3 & W03 & 1989 & L18 & & & 6000 & 72 & 0.5 & $1700^{\circ}$ & 1 & - & 458 & $33 \dot{0}$ & \\
\hline 4 & w03 & 1994 & $\begin{array}{l}203 \\
204\end{array}$ & $\begin{array}{l}6100 \\
6100\end{array}$ & $\begin{array}{l}0.5 \\
0.5\end{array}$ & $\begin{array}{l}6000 \\
6000\end{array}$ & $\begin{array}{l}1.2 \\
9.5\end{array}$ & $\begin{array}{l}0.5 \\
0.5\end{array}$ & 1700 & $\frac{1}{2}$ & : & $\begin{array}{l}458 \\
674\end{array}$ & $\begin{array}{l}335 \\
529\end{array}$ & \\
\hline $\begin{array}{l}5 \\
6\end{array}$ & พ04 & 989 & L22 & . & . & . & . & • & • & . & . & • & 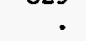 & \\
\hline 7 & W04 & 989 & L119 & - & - & - & - & - & - & - & - & . & . & \\
\hline 8 & W04 & 989 & L23 & & 0.5 & & 28.1 & 12.9 & $1700^{\circ}$ & 1580 & - & $\dot{3}$ & 823 & \\
\hline 9 & W04 & 994 & 205 & 6100 & 0.5 & 6000 & & 12.9 & 1700 & 1580 & • & 38 & 823 & \\
\hline $\begin{array}{l}10 \\
11\end{array}$ & $\begin{array}{l}\text { W05 } \\
\text { W05 }\end{array}$ & $\begin{array}{l}1989 \\
1994\end{array}$ & $\begin{array}{l}\text { L73 } \\
218\end{array}$ & $6100^{\circ}$ & 10.0 & $6000^{\circ}$ & 83.0 & 458.0 & $1700^{\circ}$ & 916 & : & $2270^{\circ}$ & 252 & \\
\hline 12 & พ06 & 1989 & L77 & . & . & • & . & . & . & • & . & • & 202 & \\
\hline 13 & W06 & 1989 & L78 & - & . & - & - & - & - & - & - & - & - & \\
\hline 14 & W06 & 1989 & L79 & & & & & & & $\therefore$ & - & $\therefore$ & - & \\
\hline 15 & W06 & 1994 & 219 & 6100 & 2.5 & 6000 & 20.0 & $\begin{array}{r}49.0 \\
99\end{array}$ & 1700 & $\begin{array}{r}703 \\
6260\end{array}$ & • & 15 & 51 & \\
\hline 16 & $\begin{array}{l}\text { W06 } \\
\text { w07 }\end{array}$ & $\begin{array}{l}1994 \\
1989\end{array}$ & $\begin{array}{l}220 \\
\mathrm{~L} 82\end{array}$ & 6100 & 5.0 & 6000. & 151.0 & 808.0 & 1700. & 6260 & • & 963 & 1610 & \\
\hline 18 & พ08 & 1989 & L86 & . & . & . & : & : & $\dot{.}$ & : & : & $\dot{.}$ & : & $\dot{0}$ \\
\hline 19 & W08 & 1989 & L87 & & $0^{\circ}$ & & & & & & . & $0^{\circ}$ & 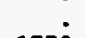 & \\
\hline 20 & W08 & 1994 & 223 & 6100 & 10.0 & 6000 & 322.0 & 61.0 & 1700 & 2497 & - & 82 & 1770 & \\
\hline 2. & w09 & 1989 & $\begin{array}{l}L 90 \\
222\end{array}$ & $6100^{\circ}$ & 5.0 & 6000 & 133.0 & $55^{\circ} .0$ & $1700^{\circ}$ & 868 & & 1310 & 407 & \\
\hline 22 & $\begin{array}{l}\text { W09 } \\
\text { W10 }\end{array}$ & $\begin{array}{l}1994 \\
1989\end{array}$ & $\begin{array}{l}222 \\
\mathrm{~L} 93\end{array}$ & 0100 & 0.0 & . & . & . & 160 & $\begin{array}{r}868 \\
.\end{array}$ & : & 1310 & 401 & \\
\hline $\begin{array}{l}23 \\
24\end{array}$ & W10 & $\begin{array}{l}1989 \\
1989\end{array}$ & $\begin{array}{l}\text { L93 } \\
\text { L94 }\end{array}$ & . & . & . & . & . & . & : & : & $\dot{.}$ & : & \\
\hline 25 & W10 & 1989 & L95 & & & & & & & * & $\cdot$ & ${ }^{\circ}$ & • & \\
\hline 26 & W10 & 1994 & 225 & 6100 & 10.0 & 6000 & 306.0 & 140.0 & 1700 & 4140 & . & 40 & 408 & \\
\hline 27 & W22 & 1994 & W22-I1-1 & 6100 & 195.0 & 6000 & 355.0 & 86.0 & 500 & 12700 & - & 10 & 119 & .01 \\
\hline 28 & W23 & 1990 & W23-I1 & $\sin$ & • & 40000 & 3600.0 & 1000.0 & 2600 & 200000 & - & 5000 & 7800 & \\
\hline 29 & W24 & 1989 & W24-L2 & 600 & & 9000 & 2600.0 & 500.0 & 4900 & 260000 & . & 5000 & 5000 & \\
\hline 30 & W24 & 1994 & พ24-084 & 6100 & 11.0 & 6000 & 4380.0 & 1080.0 & 1700 & 197000 & - & 11 & 1720 & .10 \\
\hline 31 & W25 & 1986 & $2 I T$ & • & • & • & • & • & & • & - & - & • & \\
\hline 3 & W25 & 1986 & 1 IT & - & - & - & - & - & - & - & - & - & - & \\
\hline 32 & พ125 & 986 & 2TMA & . & - & - & - & - & - & - & - & - & - & \\
\hline & พ25 & 1986 & 1TMA & & : & $60 \dot{0}$ & $2500^{\circ} .0$ & 500.0 & $1000^{\circ}$ & $260000^{\circ}$ & $:$ & $5000^{\circ}$ & $5000^{\circ}$ & \\
\hline $\begin{array}{l}35 \\
36\end{array}$ & $\begin{array}{l}\text { W25 } \\
\text { พ26 }\end{array}$ & $\begin{array}{l}1989 \\
1989\end{array}$ & $\begin{array}{l}\text { W25-L2 } \\
\text { W26-L2 }\end{array}$ & $\begin{array}{r}600 \\
1000\end{array}$ & & 12000 & 3500.0 & 500.0 & 200 & 204000 & 5 & 5000 & 5000 & \\
\hline 37 & พ26 & 1994 & พ26-086 & 6100 & 690.0 & 6000 & 4800.0 & 1040.0 & 1700 & 299000 & . & 10 & 2940 & .03 \\
\hline 38 & w27 & 1989 & W27-L2 & 600 & & 600 & 2500.0 & 500.0 & 200 & 280000 & & 5000 & 5000 & \\
\hline 39 & พ27 & 1994 & พ27-087 & 6100 & 343.0 & 6000 & 3800.0 & 975.0 & 1700 & 342000 & . & 10 & 1570 & .03 \\
\hline 40 & W28 & 1989 & W28-L2 & 600 & & 600 & 4800.0 & 500.0 & 200 & 370000 & & 5000 & 5000 & \\
\hline & & & ต28-088 & 6100 & 395.0 & 6000 & 5950.0 & .1070 .0 & 1700 & 425000 & & 10 & 1750 & .01 \\
\hline 42 & พ29 & 1988 & 1 & & • & 8400 & • & . & & & & . & • & • \\
\hline 43 & พ29 & & & • & - & 8400 & - & - & 4080 & 1000 & & - & - & \\
\hline 44 & W29 & & & . & . & 8400 & . & - & 4080 & 290000 & & - & & \\
\hline 45 & W29 & 988 & 1 & . & . & & . & . & & & & . & & \\
\hline 46 & W29 & & 2 & - & - & 8400 & - & - & 4250 & & & - & & \\
\hline 47 & W29 & & 2D & - & . & 84 & . & - & 4250 & 90000 & & - & & \\
\hline 48 & W29 & & 3 & . & . & & - & . & 39 & & & - & & \\
\hline 49 & W29 & 1988 & 1 & - & - & 90 & . & . & 4080 & & & - & & \\
\hline 50 & W29 & & & . & . & 8400 & - & - & 4080 & 000 & & & • & \\
\hline 51 & W29 & & 3 & & . & 8400 & & & 4080 & & & & & \\
\hline 52 & W29 & 1989 & พ29-L1 & 600 & . & 2600 & 2900.0 & 500.0 & 1100 & & & 5000 & 5000 & \\
\hline 53 & W29 & & พ29-I2 & 600 & - & 2400 & $2800.0^{\circ}$ & 500.0 & 1200 & & & 5000 & 5000 & \\
\hline 54 & W29 & & W29-L4 & 600 & . & & 2900.0 & 500.0 & 1300 & 280000 & & 5000 & 5000 & \\
\hline 55 & พ30 & 1988 & 1 & 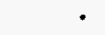 & - & 8400 & • & • & & & & & - & \\
\hline 56 & W30 & & & • & - & 7800 & - & - & 8160 & & & - & & - \\
\hline 57 & W30 & & 2D & - & - & & - & - & 8160 & 290000 & & & & \\
\hline 58 & w30 & & 3 & $\cdot$ & - & & . & - & 850 & & & - & & \\
\hline 59 & w30 & 198 & 1 & - & • & 8400 & - & - & 8330 & 000 & & - & & : \\
\hline 60 & W30 & & 2 & - & 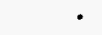 & & - & - & 8330 & & & & & \\
\hline 61 & W30 & 1988 & 3 & & - & 7800 & • & • & $\begin{array}{l}8500 \\
8160\end{array}$ & $\begin{array}{l}280000 \\
280000\end{array}$ & & : & : & . \\
\hline $\begin{array}{l}62 \\
63\end{array}$ & $\begin{array}{l}\text { W30 } \\
\text { W30 }\end{array}$ & $\begin{array}{l}1988 \\
1988\end{array}$ & $\frac{1}{2}$ & : & : & $\begin{array}{l}8400 \\
7800\end{array}$ & : & : & $\begin{array}{l}8160 \\
8330\end{array}$ & 280000 & & : & $\bullet$ & : \\
\hline 64 & W30 & 1988 & 3 & & . & 7800 & & & 8330 & 280 & & . & & \\
\hline 6 & w30 & 198 & พ30-L1 & 600 & . & 3200 & 2800.0 & 500.0 & 2200 & 270000 & & 5000 & 5000 & \\
\hline & $\begin{array}{l}\text { W30 } \\
\text { W30 }\end{array}$ & & $\begin{array}{l}\text { W30-L2 } \\
\text { W30-L4 }\end{array}$ & $\begin{array}{l}600 \\
600\end{array}$ & - & 3100 & 2900.0 & 500.0 & 2200 & 270000 & & 5000 & 5000 & \\
\hline
\end{tabular}




\section{B-28}

Table B.5(continued)

\begin{tabular}{|c|c|c|c|c|c|c|c|c|c|c|c|c|c|}
\hline Obs & Tank & Year S_No & $\begin{array}{l}\text { Bicar- } \\
\text { bonate }\end{array}$ & $\begin{array}{l}\text { Brom- } \\
\text { ide }\end{array}$ & $\begin{array}{l}\text { Carbon- } \\
\text { ate }\end{array}$ & $\begin{array}{l}\text { Chlor- } \\
\text { ride }\end{array}$ & $\begin{array}{l}\text { Fluo- } \\
\text { ride }\end{array}$ & $\begin{array}{l}\text { Hydro- } \\
\text { xide }\end{array}$ & $\begin{array}{l}\text { Nitr- } \\
\text { ate }\end{array}$ & $\begin{array}{l}\text { Nitr- } \\
\text { ite }\end{array}$ & $\begin{array}{l}\text { Phosp- } \\
\text { hate }\end{array}$ & $\begin{array}{l}\text { Sulf- } \\
\text { ate }\end{array}$ & $-\mathrm{HCN}$ \\
\hline $\begin{array}{l}68 \\
69\end{array}$ & $\begin{array}{l}\text { W31 } \\
\text { W31 }\end{array}$ & $\begin{array}{ll}1989 & W 31-L 2 \\
1994 & W 31-089\end{array}$ & $\begin{array}{r}600 \\
6100\end{array}$ & 425.0 & $\begin{array}{r}600 \\
6000\end{array}$ & $\begin{array}{l}2600.0 \\
4370.0\end{array}$ & $\begin{array}{r}500.0 \\
1050.0\end{array}$ & $\begin{array}{r}200 \\
1700\end{array}$ & $\begin{array}{l}280000 \\
311000\end{array}$ & : & $\begin{array}{r}5000 \\
10\end{array}$ & $\begin{array}{l}5000 \\
1670\end{array}$ & .22 \\
\hline 70 & T01 & 1989 L35 & • & - & • & • & • & • & • & • & • & • & - \\
\hline 71 & T01 & 1989 L36 & & . & • & & - & - & . & . & . & . & . \\
\hline 72 & T01 & 19960 & . & 5.0 & . & 464.0 & 37.5 & - & 141 & 948 & 20 & 557 & . \\
\hline 73 & T02 & 1989 L38 & . & - & . & . & . & . & . & . & . & . & . \\
\hline 74 & T02 & 1989 L112 & - & * & - & - & - & - & . & . & - & - & . \\
\hline 75 & T02 & 1989 L39 & - & & - & & . & - & . & . & . & . & . \\
\hline 76 & T02 & 19960 & - & 10.4 & . & 737.0 & 53.4 & - & 95 & 975 & 20 & 1380 & - \\
\hline 77 & T03 & 1989 L42 & - & $\cdot$ & - & $\cdot$ & $\cdot$ & - & . & & • & & - \\
\hline 78 & T03 & 19960 & - & 25.5 & - & 1630.0 & 283.0 & - & 7140 & 6300 & 20 & 4890 & - \\
\hline 79 & T04 & 1989 L111 & - & • & - & . & • & - & • & . & - & • & - \\
\hline 80 & T04 & $1989 L 44$ & - & - & - & - & - & - & - & - & - & - & - \\
\hline 81 & TOA & 1989 L45 & . & & - & & • & - & & & . & & . \\
\hline 82 & T04 & 19960 & - & 11.8 & 8 & 650.0 & 59.2 & - & 3010 & 1680 & 20 & 1580 & - \\
\hline $\begin{array}{l}83 \\
84\end{array}$ & $\begin{array}{l}\text { T09 } \\
\text { T09 }\end{array}$ & $\begin{array}{ll}1989 & L 47 \\
1996 & 0\end{array}$ & : & 50.9 & : & 5490.0 & 19.5 & : & $2100^{\circ}$ & 8 & $2 \dot{0}$ & 821 & : \\
\hline
\end{tabular}


Table B.6. Radiological variable measurements (bq/g) on liquid samples from 1985 to 1996.

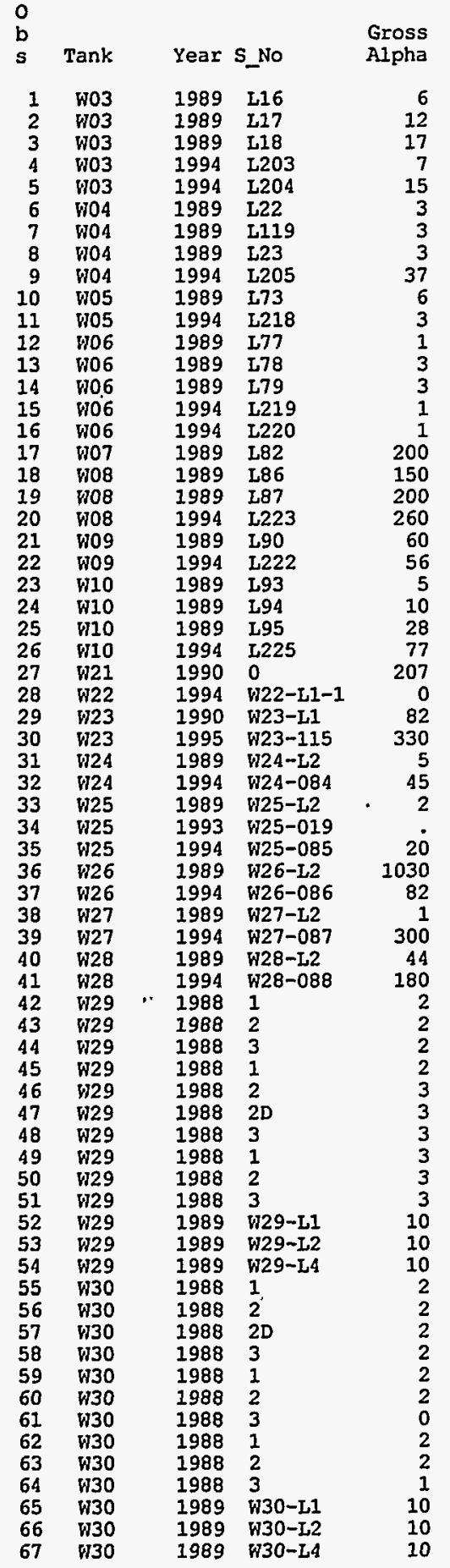

$$
\begin{aligned}
& \text { Gross } \\
& { }^{211} \mathrm{Am} \quad{ }^{11} \mathrm{C} \quad{ }^{141} \mathrm{Ce} \quad{ }^{252} \mathrm{Cf} \quad{ }^{211} \mathrm{Cm} \quad{ }^{60} \mathrm{Co} \quad{ }^{136} \mathrm{Cs} \quad{ }^{137} \mathrm{Cs} \\
& 490 \\
& \begin{array}{r}
490 \\
1200
\end{array} \\
& 560 \\
& \begin{array}{r}
960 \\
1600
\end{array} \\
& 2600 \\
& 2200 \\
& 1700 \\
& 4200 \\
& \begin{array}{l}
1400 \\
2800
\end{array} \\
& 6000 \\
& 19000 \\
& 8900 \\
& \begin{array}{r}
7630 \\
560000
\end{array} \\
& 240000 \\
& 280000 \\
& 190000 \\
& 71000 \\
& 31000 \\
& 78000 \\
& 190000 \\
& 226000 \\
& 150000 \\
& 462000 \\
& 2000000 \\
& 230000 \\
& \begin{array}{r}
1300000 \\
392000
\end{array} \\
& \begin{array}{r}
392000 \\
1400000
\end{array} \\
& 2200000 \\
& 1700000 \\
& 330000 \\
& \begin{array}{l}
330000 \\
530000
\end{array} \\
& 980000
\end{aligned}
$$

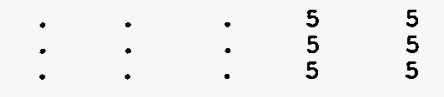

$$
\begin{aligned}
& \begin{array}{rlr}
10 & & 580 \\
0 & : & 840 \\
0 & : & 1300 \\
0 & : & 470 \\
0 & : & 820 \\
10 & : & 890 \\
10 & . & 1400 \\
13 & . & 2100 \\
0 & : & 1100 \\
160 & . & 5500 \\
9 & . & 1100 \\
13 & \text {. } & 1600 \\
28 & \text {. } & 5600
\end{array} \\
& 20000 \\
& 1000 \\
& \begin{array}{r}
6200 \\
640000
\end{array} \\
& \begin{array}{l}
640000 \\
340000
\end{array} \\
& 400000 \\
& 160000 \\
& 63000 \\
& 26000 \\
& 31000 \\
& 83000 \\
& 240000 \\
& 74000 \\
& 228000 \\
& \begin{array}{l}
100000 \\
436000
\end{array} \\
& 1500000 \\
& \begin{array}{rrr}
1800 & 52000 & 1500000 \\
329 & 1340 & 221000
\end{array} \\
& \begin{array}{rrr}
320 & 71000 & 1100000 \\
1880 & 3770 & 327000
\end{array} \\
& 32 \dot{9} 130 \dot{0} \\
& 310^{\circ} 82000^{2} \quad 1200000^{\circ} \\
& 12200 \quad 13100 \quad 2070000 \\
& 2700 \quad 36000 \quad 1400000 \\
& \begin{array}{rrr}
309 & 1610 & 216000 \\
2000 & 1400 & 330000
\end{array} \\
& \begin{array}{rrr}
2000 & 1400 & 330000 \\
8720 & 10600 & 566000
\end{array} \\
& 4900 \quad 4200 \quad 620000 \\
& \begin{array}{lll}
1258 & 8066 & 240870
\end{array} \\
& \begin{array}{lll}
1110 & 7141 & 240130
\end{array} \\
& \begin{array}{lll}
1036 & 7067 & 230140
\end{array} \\
& 925 \quad 7067 \quad 234025 \\
& \begin{array}{lll}
1184 & 6697 & 226070
\end{array} \\
& \begin{array}{rll}
777 & 6734 & 219040
\end{array} \\
& 1221 \quad 7252 \quad 238095 \\
& 1184 \quad 6993 \quad 234950 \\
& \begin{array}{lll}
1258 & 6845 & 237910
\end{array} \\
& \begin{array}{lll}
925 & 7474 & 239020
\end{array}
\end{aligned}
$$

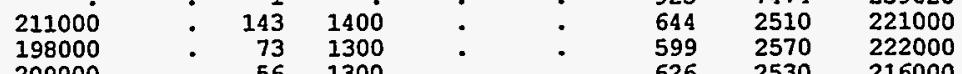

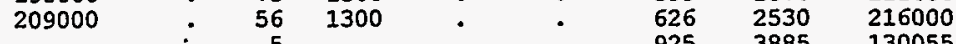

$$
\begin{aligned}
& \begin{array}{lll}
925 & 3885 & 130055 \\
814 & -4107 & 132090
\end{array} \\
& \begin{array}{lll}
814 & 4107 & 132090 \\
666 & 4144 & 130980
\end{array} \\
& \begin{array}{lll}
666 & 4144 & 130980 \\
777 & 4107 & 126910
\end{array} \\
& 851 \quad 4107 \quad 130980 \\
& 851 \quad 3922 \quad 130055 \\
& \begin{array}{lll}
629 & 4033 & 123025
\end{array} \\
& 962 \quad 4255 \quad 132090 \\
& \begin{array}{lll}
962 & 4255 & 132090 \\
814 & 4107 & 128020
\end{array} \\
& \begin{array}{lll}
814 & 4107 & 128020 \\
888 & 3663 & 123025
\end{array} \\
& 493 \quad 2050 \quad 186000
\end{aligned}
$$


B-30

Table B.6 (continued)

\begin{tabular}{|c|c|c|c|c|c|c|c|c|c|c|c|c|}
\hline Tank & Year & S_No & $\begin{array}{l}\text { Gross } \\
\text { Alpha }\end{array}$ & $\begin{array}{r}\text { Gross } \\
\text { Beta }\end{array}$ & ${ }^{2} \cdot{ }^{1} \mathrm{Am}$ & ${ }^{21} \mathrm{C}$ & ${ }^{14} \mathrm{Ce}$ & ${ }^{252} \mathrm{Cf}$ & ${ }^{24} \mathrm{Cm}$ & ${ }^{60} \mathrm{Co}$ & ${ }^{134} \mathrm{Cs}$ & ${ }^{137} \mathrm{Cs}$ \\
\hline พ31 & 1989 & W31-L2 & 1 & 358000 & & 112 & 780 & - & . & 323 & 5010 & 229000 \\
\hline พ31 & 1994 & พ31-089 & 29 & 600000 & 1900 & & 800 & : & : & 350 & 16000 & 480000 \\
\hline T01 & 1989 & L35 & 190 & 81000 & . & . & . & . & . & 50 & . & 74000 \\
\hline T01 & 1989 & L36 & 210 & 78000 & $\cdot$ & : & $\because$ & . & . & 50 & & 75000 \\
\hline T01 & 1996 & 0 & 340 & 86000 & . & & . & . & . & 21 & 49 & 64000 \\
\hline $\mathrm{T} 02$ & 1989 & L38 & 200 & 140000 & . & 480 & . & . & . & 75 & . & 140000 \\
\hline T02 & 1989 & LI12 & 210 & 140000 & . & 360 & . & . & . & 75 & . & 140000 \\
\hline T02 & 1989 & L39 & 200 & 140000 & . & 230 & . & . & . & 75 & & 140000 \\
\hline $\mathrm{T02}$ & 1996 & 0 & 300 & 150000 & . & 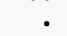 & . & . & . & 67 & 67 & 120000 \\
\hline T03 & 1989 & L42 & 2 & 280000 & . & . & . & . & . & 360 & & 270000 \\
\hline $\mathrm{T} 03$ & 1996 & 0 & 3 & 230000 & . & . & . & . & . & 120 & 82 & 190000 \\
\hline T04 & 1989 & L111 & 38 & 310000 & . & . & . & . & : & 52 & 2 & 300000 \\
\hline T04 & 1989 & $\mathrm{~L} 44$ & 36 & 280000 & . & . & . & . & . & 64 & . & 300000 \\
\hline T04 & 1989 & $\mathrm{~L} 45$ & 49 & 310000 & . & . & . & . & . & 52 & . & 300000 \\
\hline T04 & 1996 & 0 & 270 & 220000 & . & $\cdot$ & . & . & . & 17 & 81 & 180000 \\
\hline T09 & 1989 & L47 & 700 & 340000 & - & . & . & . & . & 0 & & 290000 \\
\hline T09 & 1996 & 0 & 500 & 120000 & . & & . & . & . & 28 & 59 & 92000 \\
\hline
\end{tabular}


Table B.6 (continued)

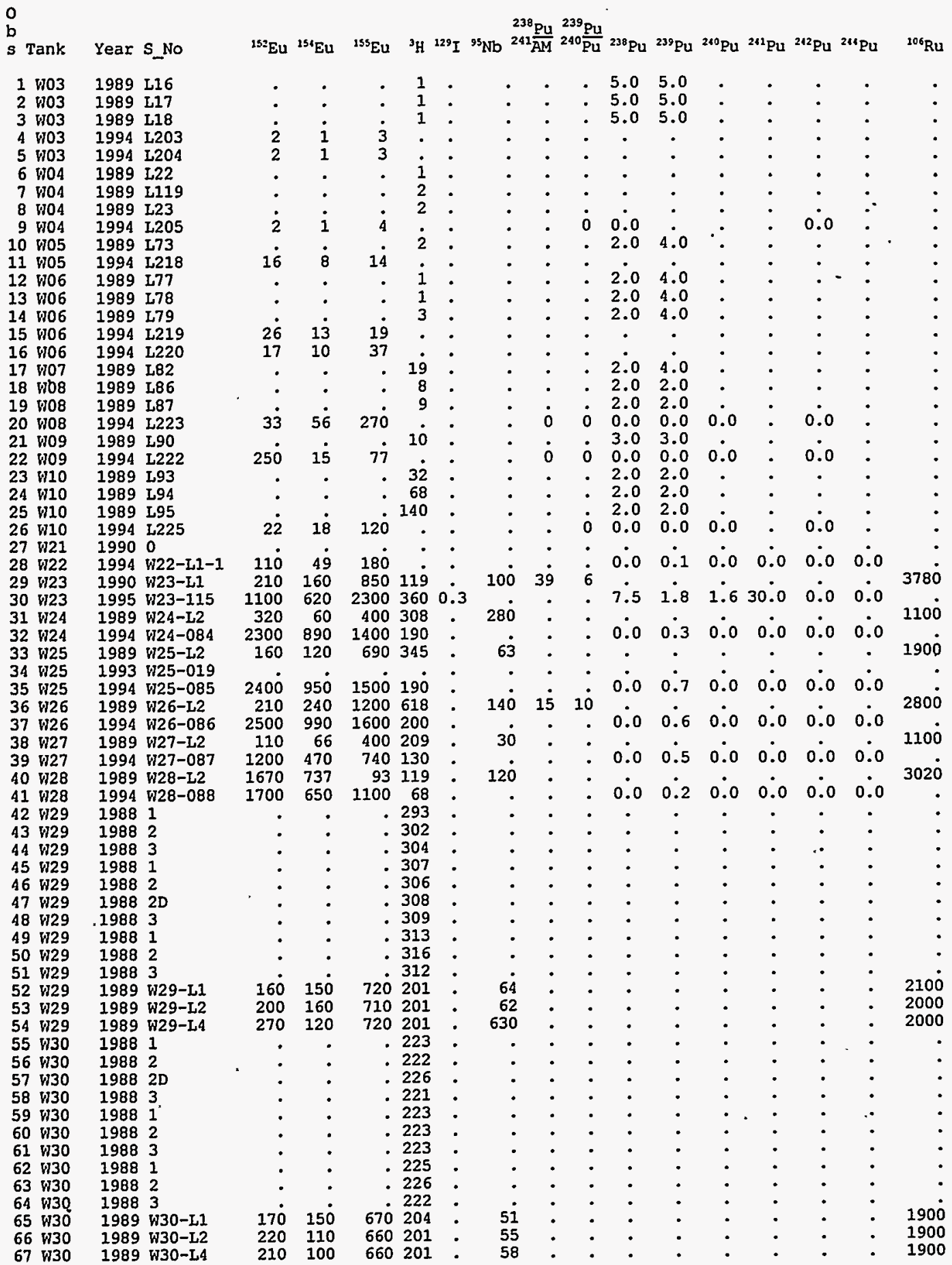


Table B.6 (continued)

0

b Tank

68 พ31

$70 \mathrm{~T} 01$

$71 \mathrm{T01}$

72 T01

73 T02

74 T02

$75 \mathrm{~T} 02$

76 T02

$77 \mathrm{T03}$

78 T03

79 T04

$80 \mathrm{T04}$

$81 \mathrm{TO4}$

82 T04

83 T09

84 T09
Year S_No

1989 พ31-L2 1994 พ31-089 1989 L35 1989 L36 19960

1989 L38

1989 L112

1989 L39

19960

1989 L42

19960

1989 L111

1989 L44

1989 L45

19960

1989 L47

19960

\begin{tabular}{|c|c|c|c|c|c|c|c|c|c|c|c|c|c|c|}
\hline${ }^{152} \mathrm{Eu}$ & ${ }^{158} \mathrm{Eu}$ & ${ }^{155} \mathrm{Eu}$ & ${ }^{3} \mathrm{H}$ & ${ }^{29} I$ & ${ }_{95}^{5} \mathrm{Nb}$ & ${ }_{241}^{238} \frac{\mathrm{Pu}}{\mathrm{AM}}$ & ${ }_{240}^{239} \frac{\mathrm{Pu}}{\mathrm{Pu}}$ & ${ }^{23 \theta} \mathrm{Pu}$ & ${ }^{239} \mathrm{Pu}$ & ${ }^{240} \mathrm{Pu}$ & ${ }^{261} \mathrm{Pu}$ & ${ }^{242} \mathrm{Pu}$ & ${ }^{2 \prime \prime P u}$ & ${ }^{106} \mathrm{Ru}$ \\
\hline $\begin{array}{r}93 \\
1500\end{array}$ & $\begin{array}{r}67 \\
580\end{array}$ & $\begin{array}{l}420 \\
900\end{array}$ & $\begin{array}{l}156 \\
100\end{array}$ & - & $\begin{array}{r}33 \\
.\end{array}$ & : & • & 0.0 & 0.1 & 0.0 & 0.0 & 0.0 & 0.0 & 1100 \\
\hline . & 急 & . & 71 & . & . & $\therefore$ & . & . & . & 0.0 & . & . & . & . \\
\hline & & & 71 & . & . & $\therefore$ & . & • & . & . & . & . & . & . \\
\hline 35 & 31 & 140 & • & . & . & . & 0 & 1.9 & . & . & . & . & . & . \\
\hline - & - & . . & 210 & • & . & . & - & . & . & - & - & • & - & - \\
\hline . & . & & 210 & . & . & . & . & - & . & . & . & - & . & . \\
\hline & • & & 210 & . & • & . & . & . & . & . & : & . & . & • \\
\hline 39 & 31 & 190 & & . & • & . & 2 & 3.3 & . & . & . & . & . & . \\
\hline & • & & -170 & . & . & . & - & - & . & . & - & . & . & • \\
\hline 35 & 50 & 240 & & . & . & . & - & . & - & . & . & . & . & . \\
\hline • & • & & 110 & . & . & : & - & - & - & - & - & . & - & • \\
\hline . & . & & 110 & . & - & . & - & . & . & . & . & . & . & . \\
\hline$\dot{0}$ & $\therefore$ & & 110 & - & - & . & . & $\therefore$ & - & - & - & - & - & . \\
\hline 35 & 44 & 240 & & - & - & - & 2 & 3.7 & • & - & - & - & - & . \\
\hline$\dot{1 I}$ & $3 \dot{5}$ & $17 \dot{0}$ & 160 & : & : & : & $\dot{0}$ & 0.9 & $\dot{.}$ & $:$ & $:$ & : & $:$ & : \\
\hline
\end{tabular}




\begin{tabular}{|c|c|c|c|c|c|c|c|c|c|c|c|c|c|}
\hline$\varepsilon 6$ & • & • & * & $\cdot$ & • & $\cdot$ & 0.0 & $\bullet$ & 0S59 & $\checkmark T-0 \varepsilon M$ & $686 \mathrm{I}$ & $0 \varepsilon \|$ & $\angle 9$ \\
\hline OTL & : & : & : & : & • & $\cdot$ & 0.0 & : & 0829 & $Z T-0 \varepsilon M$ & $686 \mathrm{I}$ & $O E M$ & 99 \\
\hline S6 & $\dot{\bullet}$ & • & • & : & : & : & 0.0 & $\dot{ }$ & OEL9 & IT-0EM & $686 \tau$ & $0 \varepsilon M$ & 99 \\
\hline$\dot{*}$ & $\dot{\bullet}$ & $\dot{0}$ & $\bullet$ & $\bullet$ & 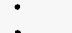 & : & & • & $\varepsilon \varepsilon 0 \emptyset$ & $\varepsilon$ & $886 \tau$ & OEM & 89 \\
\hline • & . & $\dot{\bullet}$ & : & $\dot{0}$ & : & $\dot{ }$ & • & $\cdot$ & $656 \varepsilon$ & $z$ & $886 \mathrm{I}$ & OEM & $\varepsilon 9$ \\
\hline : & • & . & . & & : & $:$ & $z \cdot 0$ & - & $\varepsilon \varepsilon, 0$ & $\tau$ & $886 \tau$ & OEM & 29 \\
\hline$\dot{\bullet}$ & - & - & - & & . & : & • & $\cdot$ & $656 \varepsilon$ & $\varepsilon$ & $886 \tau$ & $0 \varepsilon \|$ & โ9 \\
\hline : & - & - & • & . & . & $\dot{0}$ & • & $\bullet$ & SSZV & $z$ & $886 I$ & $0 \varepsilon \Lambda$ & 09 \\
\hline$\dot{.}$ & - & - & - & & - & $\dot{.}$ & 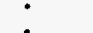 & $\dot{.}$ & $\angle 9 \varepsilon \varepsilon$ & $\tau$ & $886 \mathrm{I}$ & $0 \varepsilon M$ & 65 \\
\hline • & • & * & - & - & • & $\dot{.}$ & $\dot{70}$ & $\bullet$ & Ib৮E & $\varepsilon$ & $886 \tau$ & OEM & 89 \\
\hline : & • & - & • & - & - & : & $z \cdot 0$ & $\dot{0}$ & ZSSE & $a z$ & $886 \mathrm{~T}$ & OEM & $\angle S$ \\
\hline - & • & $\cdot$ & - & - & • & $\dot{\bullet}$ & $2 * 0$ & $\because$ & $276 \varepsilon$ & $z$ & $886 \tau$ & $O E M$ & 9S \\
\hline $00 \tau$ & : & $\cdot$ & • & • & - & - & 0 & 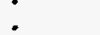 & 9Z9E & $\tau$ & $886 \mathrm{I}$ & $0 E M$ & S9 \\
\hline 0 II & : & $\dot{*}$ & • & $\cdot$ & • & - & $\begin{array}{l}0.0 \\
0.0\end{array}$ & . & $080 L$ & $67-6 Z M$ & $686 \tau$ & 624 & $b G$ \\
\hline$\varepsilon 6$ & $\dot{.}$ & $\dot{.}$ & 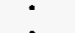 & $\cdot$ & - & - & $\begin{array}{l}0.0 \\
0.0\end{array}$ & - & $\begin{array}{l}080 L \\
0869\end{array}$ & $\begin{array}{l}27-62 M \\
\tau T-62 M\end{array}$ & $\begin{array}{l}686 \mathrm{~T} \\
686 \mathrm{~T}\end{array}$ & $\begin{array}{l}62 M \\
62 M\end{array}$ & $\begin{array}{l}E S \\
Z C\end{array}$ \\
\hline : & : & $\cdot$ & $\cdot$ & $\cdot$ & - & • & $\because$ & • & $\begin{array}{l}0869 \\
\text { ૬૬टb }\end{array}$ & $\varepsilon$ & $886 \tau$ & $\begin{array}{l}6 C M \\
62 M\end{array}$ & $\begin{array}{l}25 \\
\text { IS }\end{array}$ \\
\hline$\dot{.}$ & : & $\bullet$ & $\cdot$ & $\cdot$ & $\bullet$ & $\bullet$ & $\cdot$ & $\cdot$ & $8 \tau 26$ & $z$ & $886 \tau$ & 6211 & OS \\
\hline$\dot{\bullet}$ & - & $\cdot$ & $\cdot$ & $\bullet$ & $\bullet$ & • & $z \cdot 0$ & $\cdot$ & GโSB & $\tau$ & $886 \mathrm{~T}$ & $62 M$ & 60 \\
\hline • & - & $\dot{.}$ & • & $\cdot$ & 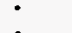 & - & • & $\cdot$ & $\varepsilon L L F$ & $\varepsilon$ & $886 \mathrm{I}$ & $62 M$ & 86 \\
\hline • & $\cdot$ & $\dot{.}$ & • & • & $\dot{0}$ & • & $\bullet$ & $\cdot$ & 0โ86 & $\alpha z$ & $886 \mathrm{I}$ & $6 Z M$ & $L B$ \\
\hline$\dot{.}$ & • & : & $\dot{0}$ & $\dot{.}$ & : & $\cdot$ & $z^{*} 0$ & $\cdot$ & LIZS & $z$ & $886 \tau$ & $62 M$ & 96 \\
\hline : & $\cdot$ & & $\dot{0}$ & $\dot{.}$ & • & - & • & • & $9 \varepsilon L b$ & $\tau$ & $886 \tau$ & $6 Z M$ & S\& \\
\hline : & - & : & $\dot{0}$ & • & • & • & • & $\cdot$ & LIZS & $\varepsilon$ & $886 \tau$ & 624 & $B$ \\
\hline$\dot{*}$ & - & & $\dot{.}$ & $\dot{.}$ & • & $\bullet$ & $z \cdot 0$ & $\bullet$ & S29b & $Z$ & $886 t$ & $62 M$ & $\varepsilon 6$ \\
\hline • & $\varepsilon$ & 0.0 & $\dot{0}$ & $\dot{ }$ & $\cdot$ & $\cdot$ & $\cdot$ & $\cdot$ & $\angle 786$ & I & $886 \tau$ & $62 M$ & 26 \\
\hline$\dot{0 z z}$ & : & & 0.0 & 0.0 & 86 & $\dot{.}$ & 0.0 & 005 & 0000ZI & $880-82 M$ & $866 I$ & $82 M$ & Ib \\
\hline $02 z$ & 9 & 0.0 & $\tau \cdot 0$ & 0.0 & $\tau \tau z$ & : & $0^{\circ} 0$ & & $0002 Z \tau$ & ZT-8ZM & $686 \tau$ & $8 Z 14$ & 06 \\
\hline Zs & : & 0 & 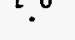 &. & the & $\dot{-}$ & 0.0 & 092 & 00099 & $\angle 80-\angle Z M$ & $666 \tau$ & $\angle Z M$ & $6 \varepsilon$ \\
\hline & 0 & 0.0 & 0.0 & 0.0 & $\tau$ & $\cdot$ & $\begin{array}{l}0.0 \\
0.0\end{array}$ & $\dot{0}$ & 00EZS & $Z T-L Z M$ & $686 \tau$ & $\operatorname{LZM}$ & $8 E$ \\
\hline 0.22 & OT & 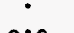 & & • & 026 & $9 \varepsilon$ & $\begin{array}{l}0.0 \\
0.0\end{array}$ & $006 \mathrm{I}$ & $\begin{array}{l}000 L \tau \\
\text { IGZ }\end{array}$ & $\begin{array}{r}980-9 Z M \\
Z T-9 Z M\end{array}$ & $\begin{array}{l}666 \tau \\
686 \tau\end{array}$ & $\begin{array}{l}92 M \\
9 Z M\end{array}$ & $\begin{array}{l}l \varepsilon \\
g \varepsilon\end{array}$ \\
\hline$\dot{*}$ & ? & 0.0 & 0.0 & 0.0 & t & $:$ & 0.0 & $O Z L$ & $00 \tau \tau$ & $580-s Z M$ & $866 \tau$ & $S Z M$ & sE \\
\hline $0 Z \tau$ & - & • & - & - & - & $\dot{.}$ & 0.0 & 02 & • & $6 \mathrm{T0}-5 Z M$ & $\varepsilon 66 \tau$ & SZM & $\nabla \varepsilon$ \\
\hline & 0 & 0.0 & 0.0 & 0.0 & $z$ & $\dot{\bullet}$ & 0.0 & • & $0076 \tau$ & ZT-SZM & $686 I$ & $S 2 M$ & $\varepsilon \varepsilon$ \\
\hline 005 & $\bullet$ & & & & : & $\dot{0}$ & $\begin{array}{l}0.0 \\
0.0\end{array}$ & 099 & $\begin{array}{l}059 \\
988\end{array}$ & $\begin{array}{r}b 80-b Z M \\
Z T-b Z M\end{array}$ & $\begin{array}{l}566 \tau \\
686 \tau\end{array}$ & $\begin{array}{l}B Z M \\
B Z M\end{array}$ & ZE \\
\hline & ? & 0.0 & 0.0 & 0.0 & 0 & $\cdot$ & $\cdot$ & OOOEI & 00TS & SII-EZM & S66I & $\varepsilon Z M$ & OE \\
\hline OOI & $\dot{0}$ & ${ }^{*}$ & $\dot{0}$ & $\bullet$ & 9 & $\checkmark$ & $\tau \cdot 0$ & & $9 \varepsilon b$ & โT-ยZM & $066 \tau$ & $E Z M$ & 62 \\
\hline - & 0 & 0.0 & 0.0 & 0.0 & ? & $\dot{.}$ & $0 \%$ & $\varepsilon$ & $006 \varepsilon$ & $\tau-\tau \tau-\tau Z M$ & $666 \tau$ & $2 Z M$ & 82 \\
\hline - & $\tau$ & 0.0 & 0.0 & 0.0 & 9 & - & 0.0 & $\dot{0}$ & $\begin{array}{l}\text { 000TS } \\
08 L\end{array}$ & $\begin{array}{r}0 \\
\text { szzI }\end{array}$ & $\begin{array}{l}066 \tau \\
666 \tau\end{array}$ & $\begin{array}{l}\text { TZM } \\
\text { OTM }\end{array}$ & $\begin{array}{l}L Z \\
9 z\end{array}$ \\
\hline . & $\varepsilon$ & & & $\bullet$ & $L$ & $\cdot$ & 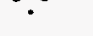 & - & $0 \tau z$ & 567 & $686 \tau$ & oTM & - 92 \\
\hline$\bullet$ & $\tau$ & $\cdot$ & • & $\cdot$ & 2 & $\cdot$ & • & $\cdot$ & $09 L$ & 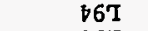 & $686 I$ & OIM & $\$ 2$ \\
\hline • & 2 & $\cdot$ & • & • & $z$ & • & $\bullet$ & - & $00 Z T$ & $\varepsilon 67$ & $686 \tau$ & oIM & $\varepsilon z$ \\
\hline • & $6 \mathrm{I}$ & 0.0 & $L \cdot 0$ & 0.0 & 0 & 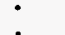 & 0.0 & : & 002 & 2227 & $\$ 66 I$ & $60 M$ & $z z$ \\
\hline " & $\dot{-}$ & $\dot{0}$ & $\therefore$ & $\therefore$ & $\varepsilon$ & $\dot{.}$ & & : & $O L \varepsilon$ & 067 & $686 \tau$ & $60 M$ & $\tau Z$ \\
\hline : & 6 & 0.0 & 0 & 0.0 & В0T & : & 0.0 & : & 067 & EZZT & $766 \tau$ & $80 M$ & 02 \\
\hline 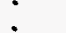 & $\dot{.}$ & : & : & : & $z$ & $\dot{\bullet}$ & $\bullet$ & * & 095 & $\angle 87$ & $686 \mathrm{I}$ & $80 \mathrm{M}$ & $6 I$ \\
\hline 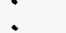 & . & . & $\dot{.}$ & : & $?$ & : & $\dot{.}$ & $\dot{ }$ & 099 & 987 & $686 \tau$ & $80 \mathrm{M}$ & $8 \tau$ \\
\hline 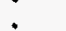 & $T$ & $\therefore$ & 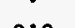 & $\therefore$ & 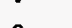 & $\dot{0}$ & 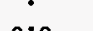 & $\dot{0}$ & 009 & 281 & $686 I$ & $\angle O M$ & $L I$ \\
\hline . & $\begin{array}{l}\tau \\
0\end{array}$ & 0.0 & 0.0 & $0^{\circ} 0$ & 0 & : & 0.0 & : & OST & 0ZZT & $866 \tau$ & $90 M$ & $9 \tau$ \\
\hline - & $?$ & 0.0 & 0.0 & 0.0 & $?$ & $\dot{0}$ & $0 \% 0$ & : & $\begin{array}{l}008 \varepsilon \\
06 \mathrm{~T}\end{array}$ & 6IZT & $666 \mathrm{I}$ & $90 \mathrm{~A}$ & GI \\
\hline • & • & • & • & • & - & - & • & . & $\begin{array}{l}06 \mathrm{I} \\
8 L\end{array}$ & $\begin{array}{l}6 L T \\
8 L T\end{array}$ & $686 \mathrm{I}$ & 904 & 6I \\
\hline • & • & • & • & • & • & • & • & - & $\begin{array}{l}8 L \\
0 \tau \varepsilon\end{array}$ & $\begin{array}{l}8 L T \\
L L T\end{array}$ & $\begin{array}{l}686 \tau \\
686 \tau\end{array}$ & $\begin{array}{l}9014 \\
904\end{array}$ & $\begin{array}{l}\varepsilon \tau \\
\text { ZT }\end{array}$ \\
\hline • & $\mathrm{T}$ & $0 \% 0$ & 0.0 & 0.0 & 0 & $\bullet$ & 0.0 & $\bullet$ & $b$ & $8 \mathrm{IZT}$ & b66 I & SOM & โโ \\
\hline " & : & $\because$ & 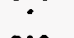 & $\because$ & : & • & 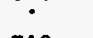 & • & 6 & $E L T$ & $686 \tau$ & SOH & OT \\
\hline - & $6 \mathrm{~T}$ & $\tau \cdot 0$ & 8.0 & $8.8 T$ & $I$ & • & $\tau \cdot 0$ & : & $00 z$ & SO27 & $.666 \tau$ & BOM & 6 \\
\hline - & $\cdot$ & $\cdot$ & & & • & • & & • & 062 & $\varepsilon Z T$ & $686 \tau$ & DOH & 8 \\
\hline • & - & • & - & • & $\bullet$ & • & $\bullet$ & $\bullet$ & $\cdot$ & 6III & $686 \tau$ & $\triangle O M$ & $L$ \\
\hline • & • & $\bullet$ & - & $\cdot$ & $\cdot$ & • & • & $\dot{.}$ & $\dot{ }$ & ZZT & $686 \mathrm{~T}$ & bOM & 9 \\
\hline$\dot{.}$ & $\begin{array}{l}z \\
z\end{array}$ & 0.0 & $\tau \cdot 0$ & $\begin{array}{l}9^{\circ} \varepsilon \\
L^{\circ} \cdot L\end{array}$ & ${ }_{D}^{0 I}$ & $\dot{0}$ & $\begin{array}{l}0.0 \\
0.0\end{array}$ & & $\begin{array}{l}\varepsilon \\
\varepsilon\end{array}$ & $\begin{array}{l}\text { BOZT } \\
\text { EOZT }\end{array}$ & $\begin{array}{l}B 66 \tau \\
B 66 \tau\end{array}$ & $\begin{array}{l}\text { EOH } \\
\text { EOM }\end{array}$ & $\begin{array}{l}\mathbf{S} \\
\mathbf{b}\end{array}$ \\
\hline . & ? & 0 & $I 00$ & $L I$ & $\begin{array}{l}b \\
s\end{array}$ & - & 0 & - & $\begin{array}{l}\varepsilon \\
06\end{array}$ & $\begin{array}{r}\text { EUCI } \\
81 T\end{array}$ & $686 \mathrm{~L}$ & EOM & $\varepsilon$ \\
\hline • & $\cdot$ & • & • & • & $\mathbf{S}$ & $\cdot$ & • & $\cdot$ & 89 & LIT & $686 \mathrm{I}$ & EOM & $z$ \\
\hline • & • & • & • & $\cdot$ & $\mathbf{S}$ & • & $\cdot$ & • & OB & $9 โ 7$ & $686 \tau$ & $\varepsilon O M$ & $\tau$ \\
\hline$I Z_{56}$ & $\mathbf{\Omega}_{\theta \varepsilon z}$ & $\mathbf{\Omega}_{g k z}$ & $\mathbf{\Omega}_{\mathbf{s t z}}$ & $\Omega_{\text {rcz }}$ & $\mathrm{n}_{\mathfrak{t} \mathfrak{z} z}$ & $\mathrm{n}_{z c z}$ & Чذ $\beth_{z \varepsilon z}$ & $2 \mathbb{L}_{66}$ & $I S_{06}$ & $\mathrm{ON}^{-} \mathrm{S}$ & בeәג & Yued & sqo \\
\hline
\end{tabular}


B-34

Table B.6 (continued)

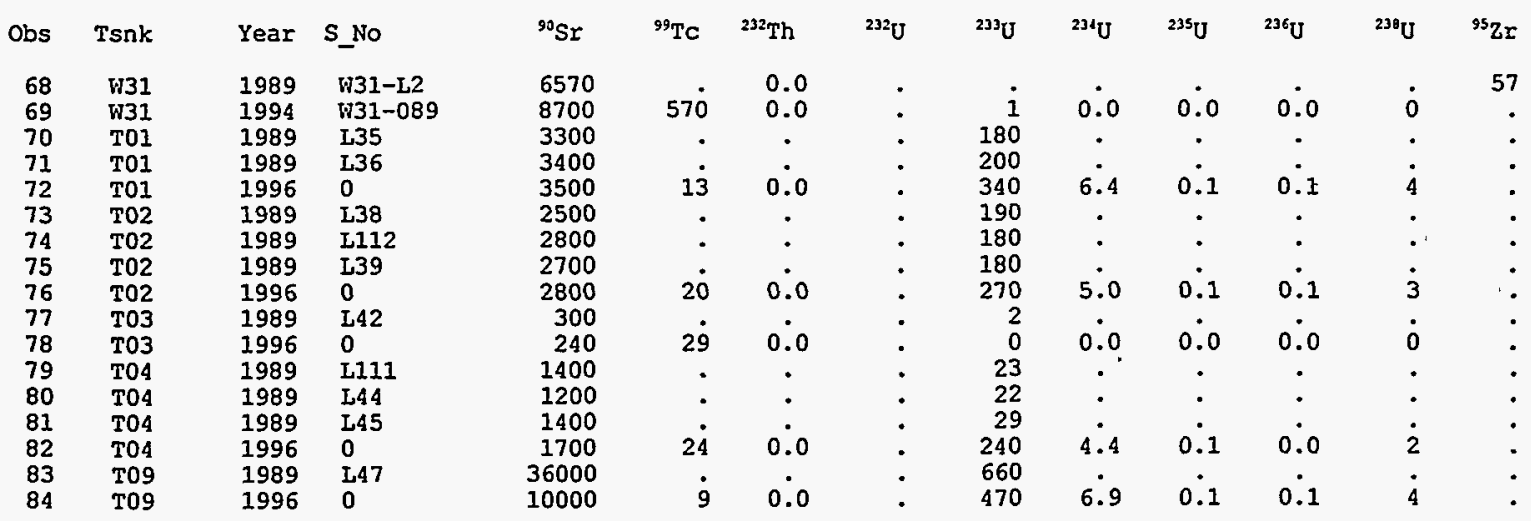


TABLES B.7, B.8, B.9, B.10, B.11, AND B.12

Organic Analysis 

Table B.7. Sludge organic concentrations $(\mu \mathrm{g} / \mathrm{kg})$ reported in Sears' report [10].

\begin{tabular}{|c|c|c|c|c|}
\hline \multirow{2}{*}{$\begin{array}{l}\text { Semi-Volatile } \\
\text { Compounds }\end{array}$} & \multicolumn{4}{|c|}{ Tanks } \\
\hline & W24 & W25 & W31-1 & W31-2 \\
\hline Di-n-butylphthalate & 9800 & 4000 & 19000 & 2000 \\
\hline Bis-(2-ethylhexyl)phthalate & 17000 & 2400 & 1300 & 1800 \\
\hline Di-n-octylphthalate & 18000 & 15000 & & \\
\hline Naphthalene & & 460 & & 440 \\
\hline Phenanthrene & & 480 & & 520 \\
\hline Unknown & 187830 & 145900 & 143200 & 149700 \\
\hline Unknown hydrocarbon & 22260 & 110100 & 48200 & 175700 \\
\hline Unknown Phthalate & 69300 & 55400 & & \\
\hline Diethylbenzene & & 9900 & & \\
\hline Dimethylbenzene & & & & 5500 \\
\hline Tributyl Phosphate & & & 1900 & 120000 \\
\hline
\end{tabular}




\section{B-38}

Table B.8. Sludge organic concentrations $(\mu \mathrm{g} / \mathrm{kg})$ reported in Autrey's report [9].

\begin{tabular}{|c|c|c|c|c|c|c|c|c|c|c|c|c|}
\hline \multirow{2}{*}{$\begin{array}{l}\text { Semi-Volatile } \\
\text { Compounds }\end{array}$} & \multicolumn{12}{|c|}{ Tanks } \\
\hline & T02 & T04 & W03 & W04-1 & W04-2 & W06 & W07-1 & W07-2 & W08 & W09 & W10-1 & W10-2 \\
\hline Di-n-butylphthalate & 4600 & 3400 & 47 & 1400 & 2100 & 210 & 2200 & 300 & 630 & 760 & 770 & 2600 \\
\hline Diethylphthlate & 2800 & 2400 & & 49 & 33 & 150 & 510 & 200 & 430 & 450 & & \\
\hline Bis(2-ethylhexyl)phthalate & 24000 & & 23 & 5700 & 11000 & 31000 & & 57000 & & 160000 & & 130000 \\
\hline Napthalene & 2300 & & & & & & & & 2600 & 370 & 270 & \\
\hline Di-n-octylphthalate & & & & 160 & 51 & & & & & & & \\
\hline Fluoroanthene & & & & 110 & 220 & 340 & & 260 & 740 & 1100 & 8000 & 1800 \\
\hline Phenanthrene & & & 12 & 130 & 170 & 680 & & & 1300 & 1300 & 5100 & 1700 \\
\hline Pyrene & & & & & 170 & 350 & & & 850 & 850 & 8100 & 1400 \\
\hline Chrysene & & & 4 & & 69 & & & & & & & 760 \\
\hline 2-Methylnaphalene & & & & & & & & & 1300 & & & \\
\hline Benzo(a)pyrene & & & & & & & & & & & 1900 & \\
\hline Benzo(b)fluoroanthene & & & & & & & & & & & 2200 & \\
\hline Benzo(g,h,i)perylene & & & & & & & & & . & & 870 & \\
\hline Benzo(a)anthrecene & & & & & & & & & & & & 660 \\
\hline
\end{tabular}




\section{B-39}

Table B.9 Sludge Arochlor concentrations $(\mu \mathrm{g} / \mathrm{kg}$ ) reported for GAAT tanks. The symbol " $<$ " indicates' the measurement is less than the value [17].

\begin{tabular}{|ccccccccccc|}
\hline $\begin{array}{c}\text { Arochlor } \\
\mathrm{s}\end{array}$ & W03 & W04 & W05 & W06 & W07-1 & W07-2 & W08 & W09 & W010 \\
\hline \hline 1016 & $<120$ & $<120$ & $<1200$ & $<248$ & $<120$ & $<112$ & $<2400$ & $<5860$ & $<8560$ \\
1221 & $<120$ & $<120$ & $<1200$ & $<248$ & $<120$ & $<112$ & $<2400$ & $<5860$ & $<8560$ \\
1232 & $<120$ & $<120$ & $<1200$ & $<248$ & $<120$ & $<112$ & $<2400$ & $<5860$ & $<8560$ \\
1242 & $<120$ & $<120$ & $<1200$ & $<248$ & $<120$ & $<112$ & $<2400$ & $<5860$ & $<8560$ \\
1248 & 9 & 12 & $<1200$ & $<248$ & $<120$ & $<112$ & $<2400$ & $<5860$ & $<8560$ \\
1254 & 3 & 33 & 145 & 290 & 82 & 111 & 120 & 88 & 28257 \\
1260 & $<240$ & 43 & 60 & 110 & $<240$ & 14 & $<4800$ & 11360 & 6336 \\
\hline
\end{tabular}


Table'B.10. Sludge ogranic concentrations $(\mathrm{mg} / \mathrm{kg}$ ) reported in GAAT Phase 2 report and Keller's report [17,14]. The same concentration values were reported for all tanks with a few noted exceptions.

\begin{tabular}{|c|c|c|c|}
\hline Tanks & $\begin{array}{l}\text { Concentration for } \\
\text { All Tanks }\end{array}$ & Organic Compounds & Exceptions \\
\hline $\begin{array}{l}\text { W06-1 } \\
\text { W06-2 } \\
\text { W07-1 } \\
\text { W07-2 } \\
\text { W08-1 } \\
\text { W08-2 } \\
\text { W09-1 } \\
\text { W09-2 } \\
\text { W10-1 } \\
\text { W10-2 } \\
\text { W21 } \\
\text { W23 }\end{array}$ & $\begin{array}{c}\text { NHVOA } \\
10\end{array}$ & $\begin{array}{c}\text { 1,1,1-Trichloroethane, 1,1,2,2-Tetrachloroethane, } \\
\text { 1,1,2-Trichloroethane, 1,1,2- } \\
\text { Trichlorotrifluoroethane, } \\
\text { 1,1-Dichloroethylene, 1,2-Dichloroethane, } \\
\text { 1,4-Dichlorobenzene, 2-Nitropropane, Benzene, } \\
\text { Bromoform, Carbon Disulfide, Carbon } \\
\text { Tetrachloride, } \\
\text { Chlorobenzene, Chloroform, Cyclohexane, } \\
\text { Ethylbenzene, Methylene Chloride, } \\
\text { Ortho-Dichlorobenzene, Tetrachloroethylene, } \\
\text { Toluene, Trichloroethylene, } \\
\text { Trichlorofluoromethane, Vinyl Chloride, Xylene }\end{array}$ & $\begin{array}{c}\text { W06-1 }=1.4 \text { for TCE } \\
\text { W06-2 }=4.0 \text { for TCE } \\
\text { TCE }=\text { Trichloroethylene } \\
\text { W09-2 }=1.4 \text { for } 1,1-\mathrm{DCE} \\
\text { W10-1 }=2.1 \text { for } 1,1-\mathrm{DCE} \\
\text { W10-2 }=1.7 \text { for } 1,1-\mathrm{DCE} \\
\text { DCE }=\text { Dichloroethylene } \\
\text { W10-2 }=1.1 \text { for } \\
\text { Tetrachloroethylene }\end{array}$ \\
\hline
\end{tabular}


Table B.11. Sludge semi-volatile organic concentrations $(\mathrm{mg} / \mathrm{kg})$ reported in GAAT Phase 2 report and Keller's report [17,14].

\begin{tabular}{|c|c|c|c|c|c|c|c|c|c|c|c|c|c|}
\hline \multirow{2}{*}{$\begin{array}{l}\text { Semi-Volitile } \\
\text { Compound }\end{array}$} & \multicolumn{13}{|c|}{ Tanks } \\
\hline & W06-1 & W06-2 & W07-1 & W07-2 & W07-3 & W08-1 & W08-2 & W09-1 & W09-2 & W10-1 & W10-2 & W21 & W23 \\
\hline 2-4-Dinitrotoluene & 0.9 & 0.9 & 0.6 & 0.6 & 0.6 & 0.9 & 0.9 & 0.9 & 0.9 & 0.9 & 0.9 & 0.6 & 0.6 \\
\hline 2,4-Dinitrophenol & & & & & & & & & & & & 10.0 & 10.0 \\
\hline 2-Methylphenol & 15.0 & 15.0 & 10.0 & 10.0 & 10.0 & 15.0 & 15.0 & 15.0 & 15.0 & 15.0 & 15.0 & 10.0 & 10.0 \\
\hline 4-Methylphenol & 15.0 & 15.0 & 10.0 & 10.0 & 10.0 & 15.0 & 15.0 & 15.0 & 15.0 & 15.0 & 15.0 & 10.0 & 10.0 \\
\hline Hexachlorobenzene & 0.9 & 0.9 & 0.6 & 16.0 & 0.6 & 0.9 & 0.9 & 0.9 & 0.9 & 0.9 & 0.9 & 0.6 & 0.6 \\
\hline Hexachloroethane & 15.0 & 15.0 & 10.0 & 0.6 & 10.0 & 15.0 & 15.0 & 15.0 & 15.0 & 15.0 & 15.0 & 10.0 & 10.0 \\
\hline Nitrobenzene & 15.0 & 15.0 & 10.0 & 10.0 & 10.0 & 15.0 & 15.0 & 15.0 & 15.0 & 15.0 & 15.0 & 10.0 & 10.0 \\
\hline Pentachlorophenol & 15.0 & 15.0 & 10.0 & 10.0 & 10.0 & 15.0 & 15.0 & 15.0 & 15.0 & 15.0 & 15.0 & 10.0 & 10.0 \\
\hline Di-n-butylphthalate & & & 6.2 & 10.0 & 8.4 & & & & & & & i & \\
\hline Unknown-1 & & & 3.4 & 2.0 & 1.1 & & & & & & & & \\
\hline Unknown-2 & & & 1.1 & 3.3 & 3.4 & & & & & & & & \\
\hline Unknown-3 & & & 1.0 & 3.5 & 1.6 & & & & & & & & \\
\hline Unknown-4 & & & & & 1.1 & & & & & & & & \\
\hline
\end{tabular}


Table B.12. Tenatively identified volatile and semi-volatile concentrations $(\mathrm{mg} / \mathrm{kg})$ reported in Keller's report [14]. Arochlor concentrations (mg/kg) are included.

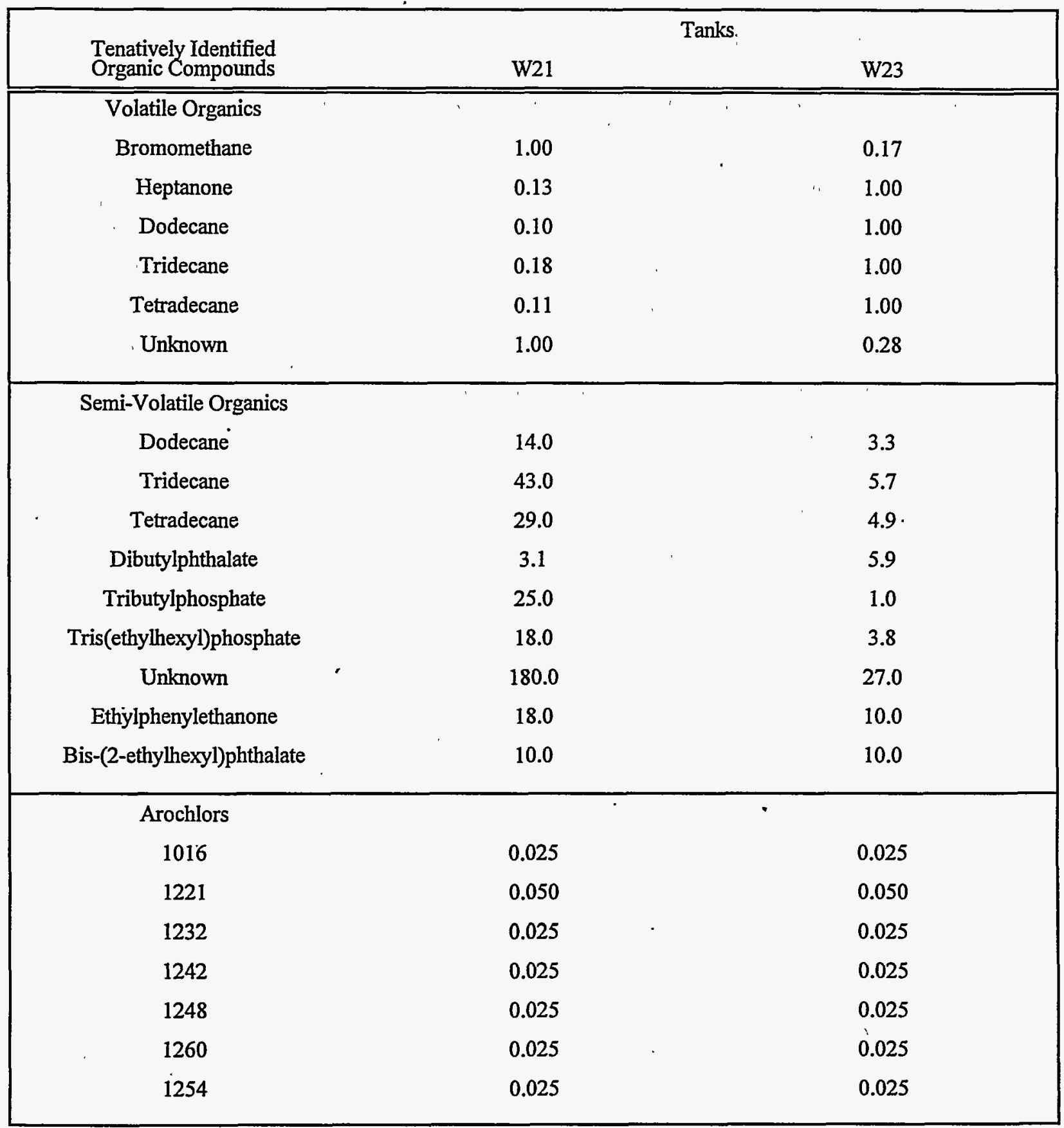


Table B.13. Liquid organic concentrations ( $\mu \mathrm{g} / \mathrm{l})$ reported in Sears' report $[10]$.

\begin{tabular}{|c|c|c|c|c|c|c|c|c|c|}
\hline \multirow{2}{*}{$\begin{array}{l}\text { Organic } \\
\text { Compounds }\end{array}$} & \multicolumn{9}{|c|}{ Tanks } \\
\hline & W24 & W25 & W29-1 & W29-2 & W29-3 & W30-1 & W30-2 & W30-3 & W31 \\
\hline \multicolumn{10}{|l|}{ Volatile Organics } \\
\hline Methylene Chloride & 30 & 37 & 7 & 10 & 7 & 17 & 6 & 10 & 30 \\
\hline Acetone & 12 & 12 & 27 & 15 & 11 & 11 & 16 & 18 & 18 \\
\hline Toluene & & & 9 & 6 & 6 & 7 & 18 & 19 & \\
\hline \multicolumn{10}{|l|}{$\underline{\text { Semi-Volatile Organics }}$} \\
\hline Benzoic Acid & 40 & 2500 & 3500 & 3000 & 2300 & 1300 & 2300 & 1400 & 2400 \\
\hline Diethylphthalate & & 63 & & & & & & & \\
\hline Di-n-octylphthalate & & & 250 & 430 & 69 & & 290 & & \\
\hline 2-Nitrophenol & & & & & & & & 1400 & \\
\hline \multicolumn{10}{|l|}{$\begin{array}{l}\text { Tenative ID } \\
\text { Compounds }\end{array}$} \\
\hline \multicolumn{10}{|l|}{$\underline{\text { Volatile Organics }}$} \\
\hline Trichlorotrifluoromethane & 36 & & 29 & & & 31 & & 20 & 6 \\
\hline Unknown & & 6 & 13 & & & 7 & & 5 & \\
\hline \multicolumn{10}{|l|}{ Semi-Volatile Organics } \\
\hline Unknown & 6066 & 34280 & 17030 & 19810 & 11940 & 6188 & 7603 & 5449 & 38480 \\
\hline Unknown Phenol & & & & & & & 420 & & \\
\hline Dibromonitrophenol & & & & & & & & & 2400 \\
\hline 2,4-Dibromo-4-nitrophenol & & & 1800 & 2000 & 1600 & & 600 & & \\
\hline
\end{tabular}

Table B.14. Liquid organic concentrations $(\mu \mathrm{g} / \mathrm{l})$ measured by direct aqueous injection gas chromatograph reported in Autrey's report [8,9].

\begin{tabular}{|cccccccc|}
\hline $\begin{array}{c}\text { Organic } \\
\text { Compounds }\end{array}$ & T4/L-044 & T4/L-045 & T4/L-111 & W3/L-016 & W3/L-017 & W3/L-018 & W4/L-023 \\
\hline \hline Acetone & 7000 & 8000 & 7000 & & & 7000 & \\
Ethyl Alcohol & 37000 & 37000 & 37000 & & & & \\
I-Propyl Alcohol & 3000 & 3000 & 3000 & & & & \\
Methyl Alcohol & 46000 & 27000 & 42000 & 38000 & 40000 & 20000 \\
n-Butyl Alcohol & 3000 & 6000 & 3000 & & & 7000 & \\
2-Butanone & & & & & 5000 & \\
4-Methyl-2-Pentanone & & & & & & 7000 \\
\hline
\end{tabular}




\section{B-44}

Table B.14 (continued)

\begin{tabular}{|c|c|c|c|c|c|c|c|}
\hline \multirow{2}{*}{$\begin{array}{c}\text { Organic } \\
\text { Compounds }\end{array}$} & \multicolumn{7}{|c|}{ Tanks/Samples } \\
\hline & W6/L-079 & W7/L-082 & W8/L-086 & W8/L-087 & W10/L-093 & W10/L-094 & W10/L-095 \\
\hline Acetone & & & 1000 & 3000 & & & 3000 \\
\hline Ethyl Alcohol & & & & & & & 1000 \\
\hline I-Propyl Alcohol & 3000 & & & & & & \\
\hline Methyl Alcohol & & 14000 & & 1000 & 27000 & 37000 & $41000^{\circ}$ \\
\hline n-Butyl Alcohol & & & & 2000 & & & 1000 \\
\hline 2-Butanone & & & & 1000 & & & 1000 \\
\hline 4-Methyl-2-Pentanone & & & & & - & & \\
\hline
\end{tabular}


Table B.15. Liquid organic concentrations $(\mu \mathrm{g} / \mathrm{l})$ measured by gas, chromatographlmass spectrometry reported in Autrey's report [8,9].

\begin{tabular}{|c|c|c|c|c|c|c|c|c|c|c|c|c|}
\hline \multirow[b]{2}{*}{$\begin{array}{c}\text { Organic } \\
\text { Compounds }\end{array}$} & \multirow[b]{2}{*}{$\underset{\mathrm{L}-038 \mathrm{~A}}{\mathrm{~T} 2}$} & \multirow[b]{2}{*}{$\begin{array}{c}\mathrm{T} 2 \\
\mathrm{~L}-039 \mathrm{~A}\end{array}$} & \multirow[b]{2}{*}{$\begin{array}{c}\mathrm{T} 2 \\
\mathrm{~L}-112 \mathrm{~A}\end{array}$} & \multirow[b]{2}{*}{$\begin{array}{c}\text { T4 } \\
\mathrm{L}-044 \mathrm{~A}\end{array}$} & \multirow[b]{2}{*}{$\begin{array}{c}\mathrm{T} 4 \\
\mathrm{~L}-045 \mathrm{~A}\end{array}$} & \multicolumn{2}{|c|}{ Tanks/Samples } & \multirow[b]{2}{*}{$\begin{array}{c}\text { W3 } \\
\text { L-17A }\end{array}$} & \multirow[b]{2}{*}{$\begin{array}{c}\text { W3 } \\
\text { L-18A }\end{array}$} & \multirow[b]{2}{*}{$\begin{array}{c}\text { W4 } \\
\mathrm{L}-022 \mathrm{~A}\end{array}$} & \multirow[b]{2}{*}{$\begin{array}{c}\text { W4 } \\
\text { L-23A }\end{array}$} & \multirow[b]{2}{*}{$\begin{array}{c}\text { W4 } \\
\text { L-119A }\end{array}$} \\
\hline & & & & & & $\stackrel{\mathrm{T} 4}{\mathrm{~L}-111 \mathrm{~A}}$ & $\begin{array}{c}\text { W3 } \\
\text { L- } \\
16 \mathrm{~A}\end{array}$ & & & & & \\
\hline Acetone & 20 & 22 & 17 & 400 & 220 & 72 & 2 & 26 & 5 & & 55 & \\
\hline Benzene & 3 & & & 7 & 10 & 7 & & & 4 & & 3 & 2 \\
\hline Bromodichloromethane & & & & 7 & & & & & & & & \\
\hline Chloroform & 340 & 370 & 310 & 170 & 160 & 120 & & 1 & & & & \\
\hline Ethylbenzene & & & & 20 & 20 & 5 & & & & & & \\
\hline Methylene Chloride & 1000 & 820 & 860 & 12 & 14 & 12 & 4 & 4 & 3 & 10 & 10 & 10 \\
\hline Toluene & 12 & 7 & 8 & 78 & 98 & 60 & 5 & 14 & 37 & 13 & 14 & 46 \\
\hline 4-Methyl-2-Pentanone & & & & 11 & 10 & & & & 18 & & 1102 & 3 \\
\hline Trichloroethene & & & & & 3 & & 11 & 14 & 11 & & 49 & 14 \\
\hline Xylene & & & & & 170 & 36 & & & & & & \\
\hline 2-Hexanone & & & & & 20 & & & & & & & \\
\hline Tetrachloroethene & & & & & & & 6 & 8 & & & & \\
\hline \multicolumn{13}{|l|}{ Carbon Tetrachloride } \\
\hline Chlorobenzene & & & & & 4 & & & & 8 & & & \\
\hline 1,2-Dichloroethene & & & & & & & & & & & & \\
\hline 2-Butanone & & & & & & & & & & & & \\
\hline
\end{tabular}




\section{B-46}

Table B.15 (continued)

\begin{tabular}{|c|c|c|c|c|c|c|c|c|c|c|c|}
\hline \multirow[b]{2}{*}{$\begin{array}{l}\text { Organic } \\
\text { Compounds }\end{array}$} & \multirow[b]{2}{*}{$\begin{array}{c}\text { W6 } \\
\text { L-077 }\end{array}$} & \multirow[b]{2}{*}{$\begin{array}{c}\text { W6 } \\
\text { L-078 }\end{array}$} & \multirow[b]{2}{*}{$\begin{array}{c}\text { W6 } \\
\text { L-079A }\end{array}$} & \multirow[b]{2}{*}{$\begin{array}{c}\text { W7 } \\
\mathrm{L}-082 \mathrm{~A}\end{array}$} & \multicolumn{3}{|c|}{ - Tanks/Samples } & \multirow[b]{2}{*}{$\begin{array}{c}\text { W9 } \\
\text { L-090A }\end{array}$} & \multirow[b]{2}{*}{$\begin{array}{c}\text { W10 } \\
\mathrm{L}-094 \mathrm{~A}\end{array}$} & \multirow[b]{2}{*}{$\begin{array}{c}\text { W10 } \\
\text { L-094B }\end{array}$} & \multirow[b]{2}{*}{$\begin{array}{c}\text { W10 } \\
\text { L- } \\
095 \mathrm{~A}\end{array}$} \\
\hline & & & & & $\begin{array}{c}\text { W7 } \\
\text { L-082B }\end{array}$ & $\begin{array}{c}\text { W8 } \\
\text { L-086A }\end{array}$ & $\begin{array}{c}\text { W8 } \\
\text { L-087A }\end{array}$ & & & & \\
\hline Acetone & 67 & 44 & 111 & 26 & 31 & 64 & 45 & 70 & & & 97 \\
\hline Benzene & & 2 & 10 & & & 3 & 6 & 2 & 6 & 38 & 22 \\
\hline \multicolumn{12}{|l|}{ Bromodichloromethane } \\
\hline Chloroform & 5 & 9 & 3 & 3 & 3 & & $\cdot$ & 44 & . & & 16 \\
\hline \multicolumn{12}{|l|}{ Ethylbenzene } \\
\hline Methylene Chloride & 9 & 8 & 7 & 7 & 4 & 12 & 7 & 13 & 13 & 19 & 12 \\
\hline Toluene & 6 & 10 & 10 & 14 & 9 & 3 & 4 & 9 & 12 & & 26 \\
\hline 4-Methyl-2-Pentanone & & 9 & 91 & 7 & 7 & 15 & & 11 & & & 23 \\
\hline Trichloroethene & 13 & 24 & 82 & & & & & 5 & 27 & & 81 \\
\hline \multicolumn{12}{|l|}{ Xylene } \\
\hline 2-Hexanone & & & 9 & & & 41 & & & & & \\
\hline Tetrachloroethene & 47 & 158 & 507 & 24 & 39 & & & 4 & 21 & & 48 \\
\hline Carbon Tetrachloride & 4 & & & 1088 & 1021 & & & & & & \\
\hline Chlorobenzene & & & & & & & & 5 & & & 5 \\
\hline 1,2-Dichloroethene & & & & & & & & & 11 & & 31 \\
\hline 2-Butanone & & & 75 & & & & & & & & \\
\hline
\end{tabular}




\section{B-47}

Table B.16. Liquid semi-volatile organic concentrations $(\mu \mathrm{g} / 1)$ reported in Autrey's report $[8,9]$.

\begin{tabular}{|c|c|c|c|c|c|c|c|c|c|}
\hline $\begin{array}{c}\text { Semi-Volatile } \\
\text { Compounds }\end{array}$ & $\begin{array}{c}\text { T2 } \\
\text { L-038 }\end{array}$ & $\begin{array}{c}\mathrm{T} 2 \\
\mathrm{~L}-039\end{array}$ & $\begin{array}{c}\mathrm{T} 2 \\
\mathrm{~L}-112\end{array}$ & $\begin{array}{c}\text { T3 } \\
\text { L-016 }\end{array}$ & $\begin{array}{c}\text { W3 } \\
\mathrm{L}-017\end{array}$ & $\begin{array}{c}\text { W3 } \\
\text { L-018 }\end{array}$ & $\begin{array}{c}\text { W4 } \\
\mathrm{L}-022\end{array}$ & $\begin{array}{c}\mathrm{W} 4 \\
\mathrm{~L}-023\end{array}$ & $\begin{array}{c}\text { W4 } \\
\text { L-119 }\end{array}$ \\
\hline Di-n-Butylphthalate & & & 24 & 60 & 48 & 230 & 11 & & \\
\hline Bis(2-ethylhexyl)phthalate & 200 & 300 & 280 & & & & & & \\
\hline 2-Nitrophenol & 170 & 200 & 180 & & & 53 & & & \\
\hline 2,4-Dichlorophenol & 100 & 140 & & & . & & & & \\
\hline 2,4,5-Trichlorophenol & 99 & 110 & 120 & & & & & & \\
\hline Napthalene & & & & & & & & 160 & 35 \\
\hline Di-n-octylphthalate & & & & 49 & 80 & & & & \\
\hline Fluoroanthene & & & & & & 56 & & & \\
\hline Phenanthrene & . & & & & & 33 & & & \\
\hline Pyrene & & & & & & 60 & & & \\
\hline Benzoic Acid & & & & & & & & & \\
\hline
\end{tabular}

Table B.16 (continued)

\begin{tabular}{|c|c|c|c|c|c|c|}
\hline \multirow[b]{2}{*}{$\begin{array}{l}\text { Semi-Volatile } \\
\text { Compounds }\end{array}$} & \multicolumn{6}{|c|}{ Tanks/Samples } \\
\hline & $\begin{array}{c}\text { W6 } \\
\text { L-079 }\end{array}$ & $\begin{array}{c}\text { W7 } \\
\text { L-082A }\end{array}$ & $\begin{array}{c}\text { W8 } \\
\text { L-087 }\end{array}$ & $\begin{array}{c}\text { W9 } \\
\text { L-090 }\end{array}$ & $\begin{array}{l}\text { W10 } \\
\text { L-094 }\end{array}$ & $\begin{array}{l}\text { W10 } \\
\text { L-095 }\end{array}$ \\
\hline Di-n-Butylphthalate & & & 17 & 20 & & \\
\hline Bis(2-ethylhexyl)phthalate & & & & & & \\
\hline 2-Nitrophenol & & & & & & \\
\hline 2,4-Dichlorophenol & & & & & & \\
\hline 2,4,5-Trichlorophenol & & & & & & \\
\hline Napthalene & & & 28 & & & 20 \\
\hline Di-n-octylphthalate & & & & & & \\
\hline Fluoroanthene & & & & & & \\
\hline Phenanthrene & & & & & & \\
\hline Pyrene & & & & & & \\
\hline Benzoic Acid & 290 & 1900 & & & 400 & 2900 \\
\hline
\end{tabular}


Table B.17. Liquid ogranic concentrations (mg/l) reported in GAAT Phase 2 report and Keller's report $[17,14]$. The same concentration values were reported for all tanks.

\begin{tabular}{|c|c|c|}
\hline Tanks & $\begin{array}{l}\text { Concentration for } \\
\text { All Tanks }\end{array}$ & Organic Compounds \\
\hline \multirow{2}{*}{$\begin{array}{c}\text { W6 } \\
\text { W8-1 } \\
\text { W8-2 } \\
\text { W9 } \\
\text { W10 }\end{array}$} & VOA & 1,1,1-Trichloroethane, 1,1,2,2-Tetrachloroethane, \\
\hline & $5,00 \mathrm{E}-03$ & $\begin{array}{c}\text { 1,1,2-1 richloroethane, 1,1,2-1,ichorotrifuoroetnane, } \\
\text { 1,-Dichloroethylene, 1,2-Dichloroethane, } \\
\text { 1,4-Dichlorobenzene, 2-Nitropropane, Benzene, } \\
\text { Bromoform, Carbon Disulfide, Carbon. Tetrachloride, } \\
\text { Chlorobenzene, Chloroform, Cyclohexane, } \\
\text { Ethylbenzene, Methylene Chloride, } \\
\text { Ortho-Dichlorobenzene, Tetrachloroethylene, } \\
\text { Toluene, Trichloroethylene, } \\
\text { Trichlorofluoromethane, Vinyl Chloride, Xylene }\end{array}$ \\
\hline
\end{tabular}


QUALITATIVE DESCRIPTIONS OF SAMPLES TAKEN IN THE VARIOUS SAMPLING CAMPAIGNS 


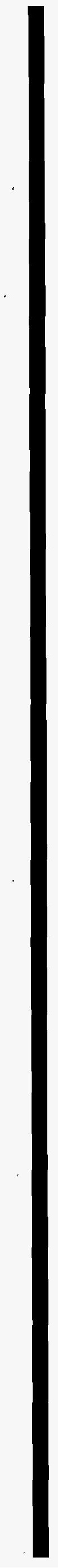




\section{MVST TANKS}

Description and volume estimates of sludges in the Melton Valley Storage Tanks from the Peretz Report ${ }^{7}$.

Estimated

Tank Sludge Description

Radiation Level

Volume

W-24

Approximately $1.5 \mathrm{ft}$ of a soft, fluid sludge.

$200 \mathrm{mR} / \mathrm{hr}$ at $6^{\prime \prime}$

W-25

About $4 \mathrm{ft}$ of sludge similar to that in W-24,

About $1 \mathrm{R} / \mathrm{hr}$

3,600 but containing at $1 \mathrm{ft}$. noticeable amounts of sand (possibly from hydrofracture slotting.) Higher radiation levels than W-24.

W-26

About $2.5 \mathrm{ft}$ of soft sludge containing more sand than found in W-25. Radiation levels similar to W-24.

W-27 A hard, crusty layer about 3 in. thick was found $2.5 \mathrm{ft}$ from the bottom of the tank. Sludge under the crust was similar to that in W-24; a somewhat thicker consistency may have been due to the crust breaking off into the sample.

W-28 About 8 in. of sludge similar to that found in W-24.

$200 \mathrm{mR} / \mathrm{hr}$ at $6^{\prime \prime} \quad 7,500$

not reported

7,500

W-29

About $1.5 \mathrm{ft}$ of soft sludge a little thicker than in W-24 but with similar radiation levels

W-30

(same as W-29)

$200 \mathrm{mR} / \mathrm{hr}$ at $6 " \quad \cdot 3,600$

W-31 About $3 \mathrm{ft}$. of extremely thick sludge. The sampler rod had to be hammered through the sludge to reach the tank bottom. The sludge was not at all fluid, and was much "hotter" than the other tanks.

not reported

1,100

$200 \mathrm{mR} / \mathrm{hr}$ at $6^{\prime \prime} \quad 3,600$

$4 \mathrm{R} / \mathrm{hr}$ at $4 \mathrm{in.} \quad 9,800$

Notes: It is generally believed that there is more sludge on the discharge side of the tanks than on the suction side, relative to the depth at the center. The tank contents were not circulated during sampling, but the aerators were left on. A liquid sample was not taken from W-31 because the contents consisted mainly of sludge. 


\section{MVST TANKS}

Description and volume estimates of sludges in the Melton Valley Storage Tanks from the Sears Report ${ }^{10}$.

Tanks W-29 and W-30 were modified to serve as feed tanks to the EASC system. The tank penetrations were used for the pump module suction legs. Samples of the aqueous supernatant were collected from these tanks using the pump module (Isolock) sampler. It is not possible to gain access through the penetrations to sample the tanks by the methods described in above. No sludge samples were taken from tanks W-29 and W-30 and no checks were made for an organic layer.

In the first sampling effort of tank W-27, a soft-sludge sample was collected at the supernatant-sludge interface (sample W27-S1). When the effort was made to sample the next layer of sludge, a very hard layer that felt like concrete was encountered about $38 \mathrm{in}$. above the tank bottom. This layer was hard enough to bend the stainless steel closure plate on the sampler and, thus, no sample was collected. A sample.of the upper soft sludge layer (W27-S2) was collected later in the second sampling effort. This core overlaps the solids phase of sample W27-S1. The auger bit sampler was used to cut through the hard layer. It was estimated that the hard layer was about $1-\mathrm{ft}$ thick. The sampler was then pushed through an underlying soft sludge layer (no cutting force needed) to the bottom of the tank. Upon examination of the sampler (W27-H1) at the analytical laboratory, it was found that the hard sludge had plugged the lower part of the sampler (i.e. the cutting bit end between the blades and immediately above the gate valve). The barrel section of the sampler contained soft sludge from the upper layer. At the analytical laboratory, the soft sludge was poured into one jar (W27-H1-S) and the hard sludge was scraped with a spatula into a second jar (W27-H1-H). A sample of the soft sludge that lies under the hard sludge was not obtained.

\begin{tabular}{|c|c|c|c|c|c|}
\hline Tank & $\begin{array}{l}\text { Liquid: } \\
\text { radiation } \\
\text { Levels }^{\mathrm{a}} \\
(\mathrm{R} / \mathrm{h})\end{array}$ & $\begin{array}{l}\text { Orgar } \\
\text { layer }\end{array}$ & Number/type & $\begin{array}{l}\text { Sludge samples } \\
\text { Radiation } \\
\text { levels } \\
(\mathrm{R} / \mathrm{h})\end{array}$ & Comments \\
\hline$W-21$ & 0.3 & No & $2 /$ soft sludge & $1.0-1.5$ & $\begin{array}{l}\text { Sonicated sludge: consistency of } \\
\text { prepared mustard;medium yellow with } \\
\text { dark flecks }\end{array}$ \\
\hline $\mathrm{W}-23$ & 0.12 & No & $3 /$ soft sludge & $1.0-2.5$ & $\begin{array}{l}\text { Top sample (W23-S1): smooth } \\
\text { brownish-yellow paste; } 2.5 \mathrm{R} / \mathrm{h} \text {. } \\
\text { Sonicated sludge: consistency of } \\
\text { prepared mustard; medium brown with } \\
\text { dark fleck }\end{array}$ \\
\hline
\end{tabular}


Valley and Evaporator Facility Storage Tanks ORNL/TM-11653.

c: $\quad \mathrm{NA}=$ not applicable because of no access to tanks W-29 and W-30 for sampling.

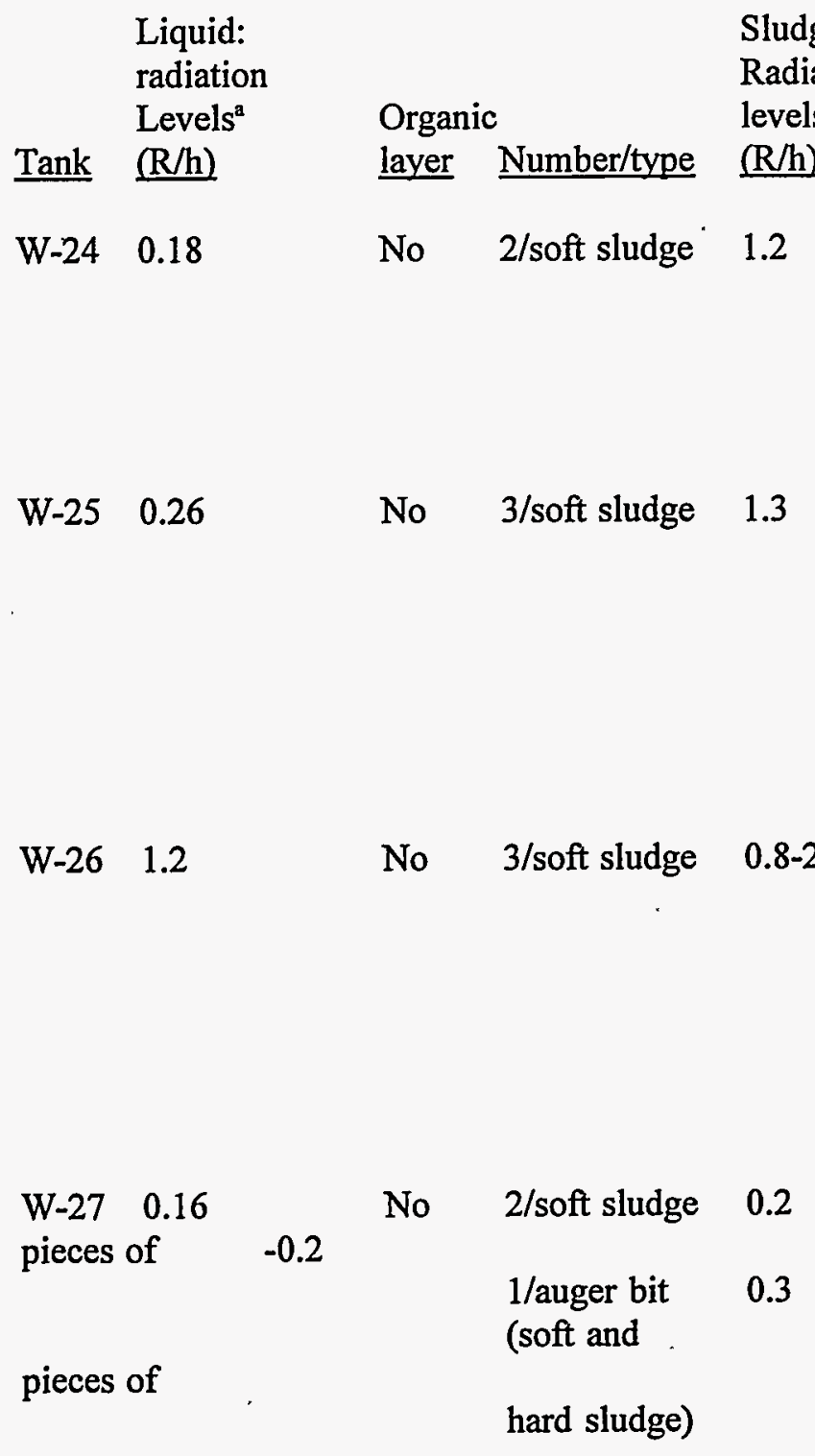

Sludge samples

Radiation

levels

Comments

Could probably pump with a peristaltic pump except for the thin layer of mud on bottom Sonicated sludge: light yellow tan; very fine particles with a few coarser particles

Thicker sludge than in tank W-24. Could probably pump with a peristaltic pump except for the thin layer of mud on bottom. Sonicated sludge: light tan; very fine particles with a few coarser particles.

Top sample (W26-S1): highest radiation level Bottom sampler (W26-S3): highest viscosity of the tank samples studied by $\mathrm{Ceo}$ and Shor ${ }^{\mathrm{b}}$ Sonicated sludge: dense and plastic with the consistency Of peanut butter; gritty particles

Sample W27-S2: appearance of small concrete in a softer sludge

Soft sludge in auger-bit sampler:

(a) Un-sonicated: appearance of small

concrete in a softer sludge

(b) Sonicated sludge (W27-H1-S): gray and gritty; consistency of cooked oatmeal

Hard sludge:

(a) Felt like hitting concrete during sampling; on first attempt to collect sample W27-S2 bent closure plate of soft sludge sampler when hit hard layer (b) Consistency like a hard mud; no free liquid; appearance of concrete pieces mixed with mud or clay; too stiff to sonicate General: soft sludge over hard layer; 
had to cut hard layer with auger-bit sampler; estimated I $\mathrm{ft}$ thick; below hard layer about 2-fl thick layer of soft sludge; hard sludge plugged sampler; no sample of underlying soft layer

a: $\quad$ Field survey.

b: $\quad$ R. N. Ceo and J. T. Shor Physical Characterization of Radioactive Sludges in Selected Melton Valley and Evaporator Facility Storage Tanks ORNL/TM-11653.

c: $\quad \mathrm{NA}=$ not applicable because of no access to tanks W-29 and W-30 for sampling.

Liquid: radiation Levels $^{\mathrm{a}}$

Tank $(\mathrm{R} / \mathrm{h})$

W-28 0.480

to the

sample

$W-29 \quad 0.1$

W-30 $\quad 0.11$

W-31 0.18

watery

particles
Sludge samples

Radiation

levels

Organic

$\underline{\mathrm{R} / \mathrm{h})}$

1.2

1/soft sludge

took second

for more

material

with a

\section{Comments}

Fluid (weight of handle carried sampler bottom of the tank)

Sludge (W28-S1): deep yellow; seems homogeneous

Sonicated sludge: very finely divided few dark flakes

NA

NA

NA NA NA

$1.5-2.2$

$2 /$ soft sludge

Sonicated soft sludge: medium tan sludge; fine and very fine

separated during centrifugation

1/hard sludge 2.8
Hard sludge:appearance of clay or mud with a little grit 
a: $\quad$ Field survey.

b: R. N. Ceo and J. T. Shor Physical Characterization of Radioactive Sludges in Selected Melton Valley and Evaporator Facility Storage Tanks ORNL/TM-11653.

c: $\quad \mathrm{NA}=$ not applicable because of no access to tanks W-29 and W-30 for sampling. 


\section{OHF Tanks}

The OHF Chemical Characterization Report Description of sludges in the Melton Valley Storage Tanks ${ }^{4}$.

The sludge in tank T-9 appeared neutral grayish in color with a greenish tint in the supernatant. The sludge appeared to be soft, thick mud. A sludge column of 10.5 in. was obtained. This measurement correlates fairly well with field log notes generated by LGWOD personnel during 1988 sampling ( 9 in. was documented). The sludge read $50 \mathrm{R} / \mathrm{h}$ (through the plastic bag) after it was removed, but this was mostly from a deposit on the outside of the sample tube. The sample read $6 \mathrm{R} / \mathrm{h}$ through the metal can in the sample carrier.

The sludge in tank T-4 appeared brownish-grey in color with a greenish tint in the supernatant. The sludge appeared to be soft, thin mud. A sludge column of $14 \mathrm{in}$. was obtained. This measurement correlates fairly well with field log notes generated by LGWOD personnel during 1988 sampling (12 in. was documented). The sludge read $30 \mathrm{R} / \mathrm{h}$ (through the plastic bag) after it was removed. The sample read $5 \mathrm{R} / \mathrm{h}$ through the metal can in the sample carrier. The background at the top of the hole was $110 \mathrm{mR} / \mathrm{h}$ at the hole.

The sludge in tank T-3 appeared brownish in color with a greenish tint in the supernatant. The sludge appeared to be soft, thin mud. A sludge column of 10 in. was obtained. This measurement does not correlate very well with field log notes generated by LGWOD personnel during 1988 sampling (16 in. was documented). The sludge read $15 \mathrm{R} / \mathrm{h}$ (through the plastic bag) after it was removed. The sample read $1.5 \mathrm{R} / \mathrm{h}$ through the metal can in the sample carrier.

The sludge in tank T-2 appeared tan to brownish in color with a greenish tint in the supernatant. The sludge appeared to be soft, thin mud. A sludge column of 6 in. was obtained. This measurement does not correlate very well with field log notes generated by LGWOD personnel during 1988 sampling (12 in. was documented). The sludge read $35 \mathrm{R} / \mathrm{h}$ (through the plastic bag) after is was removed. The sample read $100 \mathrm{mR} / \mathrm{h}$ through the metal can in the sample carrier.

The sludge in tank T-1 from both samples appeared tan to brownish in color with a greenish tint in the supernatant. Both samples looked like soft, thin mud. A sludge column of 8 in. was obtained. This measurement correlates fairly well with field $\log$ notes generated by LGWOD personnel during 1988 sampling ( 9 in. was documented). Radiation readings showed $18 \mathrm{R} / \mathrm{h}$ and $20 \mathrm{R} / \mathrm{h}$ at contact for the first and second samples, respectively. Through the can, the readings were $0.7 \mathrm{R} / \mathrm{h}$ and $2.5 \mathrm{R} / \mathrm{h}$ for the first and second samples, respectively. 


\section{GAAT Tanks}

The following observations were obtained when the field sampling was completed and the Phase I sampling team debriefed ${ }^{11}$ :

- What is known as "hard sludge" is more accurately described as "dense sludge." The sampler had good tactile feedback from the sampling tool and could feel a gradual thickening of the sludge, but no distinct hardpan was evident. The feel of the sample tool on the concrete tank bottom was very distinct. The laboratory technicians who emptied the tubes reinforced this observation.

- The sludge generally rinsed clean from the outside of the sampling tool with a gentle stream of water, although some small clayey pieces adhered to the sample tube.

- Except for tanks W-5 and W-10, all of the sludges appeared to have similar textures. The only variations are colors.

- Tank W-10 contains "trash" including cotton string, pieces of plastic, and concrete chips up to the size of a dime that prevented the sampler from closing on the first two tries.

- Tank W-5 contains almost no sludge, and the sample team was able to see what they thought was the concrete bottom of the tank at the west port. The team scraped the sample tube along the bottom at the west port and retrieved a small amount of "sludge" that consisted mostly of small white flakes (thought to be concrete chips).

A discrepancy exists between the sludge probe reading and the depth of sludge retrieved from tank W-6. In four instances, the probe read approximately 2 in. but 7- to 8-in. cores were recovered. In all other tanks, the probe depth correlated with the recovered core height. Liquids from the tanks tend to be pale yellow, but those from W-3 and W-4 are bright yellow.

During Phase II the tank characterization system was used to characterize tanks W-3, W-4, $\mathrm{W}-5, \mathrm{~W}-6, \mathrm{~W}-8, \mathrm{~W}-9$, and $\mathrm{W}-10$. The samples retrieved were a variety of colors and consistencies. The grab sample from tank W-3 was a yellow soupy liquid with small flakes. The W-7 tube sample had three distinct layers: an orange, pasty layer; a brown, gravelly, sandy layer; and a yellow, silty layer. The grab sample from W-10 was a mixture of brown, gravelly, silty liquid sludge. The W-5 grab sample contained hard orange chunks that were large enough to be separated out. 


\section{INTERNAL DISTRIBUTION}

1. D. Anderson

2. R. D. Bailey

3. J. S. Baldwin

4-5. C. K. Bayne

6. E. C. Beahm

7. J. Beauchamp

8. C. A. Bednarz

9. J. M. Begovich

10. D. E. Benker

11. J. E. Bigelow

12. D. A. Bostick

13. R. W. Brandenburg

14. D. E. Brashears

15. J. Chapman

16. D. E. Coffey

17. T. B. Conley

18. A. G. Croff

19. N. Dailey

20. D. Daugherty

21-22. S. M. DePaoli

23-24. J. R. DeVore

25. D. K. Downing

26. B. Z. Egan

27. M. Evans

28. J. E. Francis

29. J. R. Forgy

30. T. M. Gilliam

31. W. Griest

32. O. W. Hale

33. R. Hagenauer

34. L. Holder

35. T. D. Hylton

36. M. A. Johnson

37. R. T. Jubin

38-39. J. M. Keller

40. C. M. Kendrick

41. T. E. Kent

42. F. Kornegay

43. G. R. Larson

44. D. D. Lee

45. M. R. Leuze

46. A. J. Lucero

47. J. J. Maddox

48. C. A. Manrod

49. R. Martin

50. R. C. Mason

51. A. J. Mattus

52. B. C. McClelland
53. C. P. McGinnis

54. L. E. McNeese

55. A. Meeks

56. G. T. Mei

57-59. T. H. Monk

60. J. W. Moore

61. T. W. Morris

62. T. E. Myrick

63. L. Nguyen

64. C. E. Oliver

65. C. D. Parks

66. S. M. Robinson

67. T. O. Rogers

68. S. T. Rudell

69. J. Saffell

70. T. F. Scanlan

71. R. E. Schreiber

72. F. J. Schultz

73. C. B. Scott

74. D. H. Smith

75. J. L. Snyder

76. R. D. Spence

77. J. L. Stellern

78. R. C. Stewart

79. J. R. Stokely

80. P. A. Taylor

81. J. R. Trabalka

82. D. Van Hoesen

83. J. F. Walker, Jr.

84. J. S. Watson

85. T. D. Welch

86. R. M. Wham

87. J. Williams

88. J. H. Wilson

89. B. V. Wojtowicz

90. C. Wynn

91. L. Yong

92-93. Central Research Library

94. Document Reference Section

95-96. Laboratory Records Department

97-98. WMRAC Document Management Center

99. Laboratory Records, ORNL

100. ORNL Patent Section

101. ER Document Management Center-RC 


\section{EXTERNAL DISTRIBUTION}

102. J. B. Berry, Lockheed Martin Hanford, 2440 Stevens Center, P. O. Box 1500, Richland, WA 99352-1505

103. Scott Boeke, U.S. Department of Energy, 3 Main, Oak Ridge, TN 37830

104. H. Boston, Lockheed Martin Hanford, 2440 Stevens Center, P. O. Box 1500, Richland, WA 99352-1505

105. P. W. Gibbons, Westinghouse Hanford Company, P. O. Box 1970, Richland, WA 99352

106. Sherry Gibson, U.S. Department of Energy, 3 Main, Oak Ridge, TN 37830

107. J. H. Lee, Sandia National Laboratories, P. O. Box 5800, Albuquerque, NM 87185

108. C. S. Mims, U.S. Department of Energy, 3 Main, Oak Ridge, TN 37830

109. Jacquie Noble-Dial, U.S. Department of Energy, 3 Main, Oak Ridge, TN 37830

110. Elizabeth Phillips, U.S. Department of Energy, 3 Main, Oak Ridge, TN 37830

.111. J. M. Plodinec, Westinghouse Savannah River Co., P.O. Box 616, Aiken, SC 29802

112. Gary Riner, U.S. Department of Energy, 3 Main, Oak Ridge, TN 37830

113. M. Roddye, U.S. Department of Energy, Federal Building, EW92, Oak Ridge, TN 37830

114. R. W. Root, Jr, Pacific Northwest National Laboratory, P. O. Box 999, Richland, WA 99352

115. T. L. Stewart, Pacific Northwest National Laboratory, P. O. Box 999, Richland, WA 99352

116. John Sweeney,U.S. Department of Energy, 3 Main, Oak Ridge, TN 37830

117. W. T. Thompson, Lockheed Martin Hanford, 2440 Stevens Center, P. O. Box 1500, Richland, WA 99352-1505

118-119. Office of Scientific and Technical Information, P. O. Box 62, Oak Ridge, TN 37830 